\title{
Conceptual Design Report \\ for a Direct Hydrogen Proton Exchange Membrane Fuel Cell for Transportation Application
}

5 September 1995

RECENED

HOV 141995

OSTI

Contract DE-AC02-94CE50390

Document Control Number 6004707

(DOE/CE/50390-9)

\author{
Prepared By: \\ Pentastar Electronics, Inc. \\ 110 Wynn Drive \\ P. O. Box 1929 \\ Huntsville, AL 35807-0929
}

Prepared For:

U.S Department of Energy

Chicago Operations Office

9800 South Cass Avenue

Argonne, IL 60439 


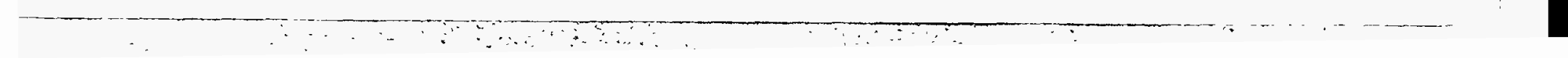




\section{TABLE OF CONTENTS}

Page

EXECUTIVE SUMMARY

1.0 VEHICLE CONSIDERATIONS ........................................................................ 1-1

1.1 Vehicle Determination .............................................................................. 1-1

1.2 Powertrain Size and Operational Requirements ........................................ 1-23

2.0 VEHICLE PERFORMANCE REQUIREMENTS .......................................................

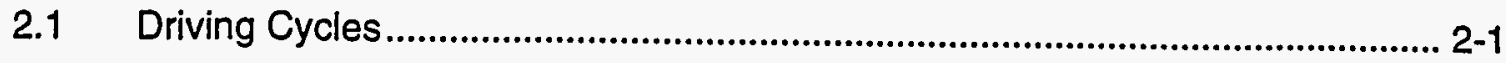

2.2 Vehicle Configuration .................................................................................. 2-4

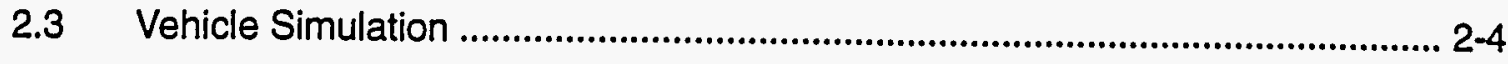

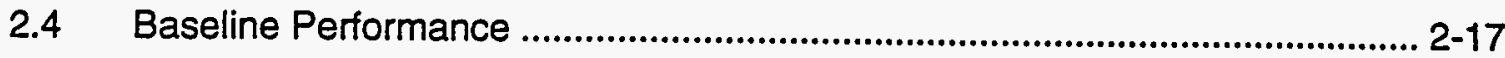

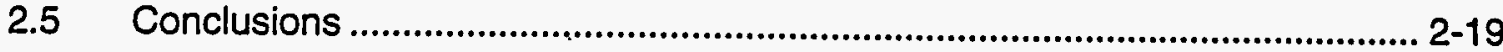

3.0 PEM FUEL CELL SUBSYSTEM .................................................................... $3-1$

3.1 Vehicular PEM Fuel Cells ............................................................................ 3-1

3.2 PEM Fuel Cell Conceptual Design .............................................................. 3-2

3.3 Fuel Cell Subsystem Conceptual Design ........................................................ 3-5

3.4 Performance Characteristics ..................................................................... 3-8

3.5 Gas Management Subsystem Description .................................................... 3-18

4.0 HYDROGEN STORAGE SUBSYSTEM REQUIREMENTS ....................................... 4-1

4.1 Hydrogen Storage On Board Vehicles ........................................................ 4-1

4.2 Gaseous Hydrogen Storage System Concept ................................................ 4-3

4.3 Liquid Hydrogen Storage System Concept .................................................... 4-15

4.4 Dewar Size Estimates ............................................................................... 4-17

5.0 LOAD LEVELING UNIT SUBSYSTEM ........................................................... 5-1

5.1 Load Leveling Unit Concept ....................................................................... 5-1

5.2 LLU Subsystem Description ....................................................................... 5-3

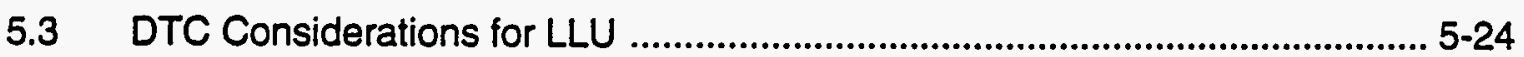

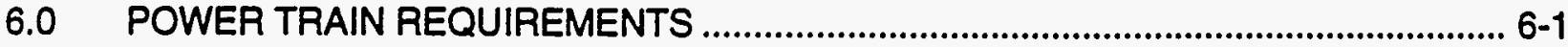

6.1 Motor Operating Characteristics .................................................................. 6-1

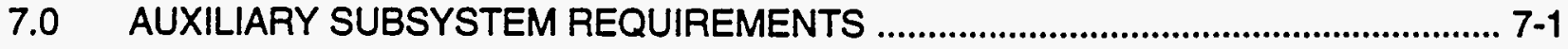

7.1 Heating/Cooling Subsystem Design ............................................................. 7-1

7.2 Regenerative Braking Subsystem .............................................................. 7-2

7.3 Electrical Power Steering (EPS) Subsystem ............................................. 7-2 
TABLE OF CONTENTS (Continued)

Page

8.0 ACRONYM LIST AND DEFINITIONS

8-1

APPENDIX A. Chopper/Regulator Design ……..................................................................

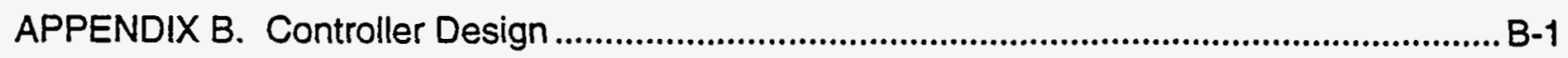

APPENDIX C. Gas Management Controller ………................................................................. C-1

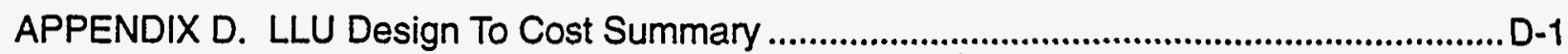

APPENDIX E. Simulation Modeling Data ...................................................................... E-1

APPENDIX F. Hydrogen Storage Designs ....................................................................... F-1 


\section{LIST OF ILLUSTRATIONS}

Figure

Page

DPHV Vehicle Configuration 3

DPHV Electrical Configuration 6

Vehicle Parameters for Goal 3 1-1

1-2 Propulsion and Vehicle Improvements Needed for $80 \mathrm{MPG}$ $1-2$

1-3 Fuel Cell Pathway to 80 MPG $1-2$

Subcompact Packaging Design $1-7$

Minivan Packaging Design $1-9$

1-7 PNGV LH Mid-Size Sedan Packaging Design

2-1 Alternative Acceleration Profiles ............................................................................. 2-2

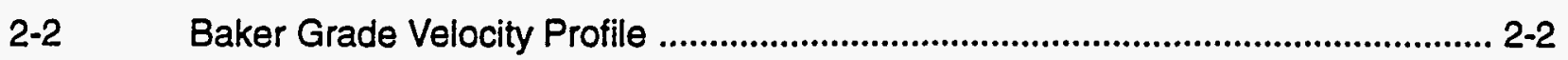

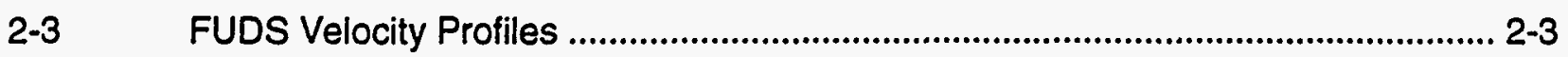

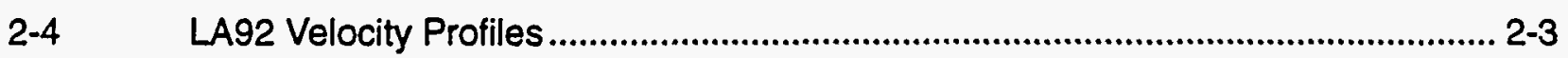

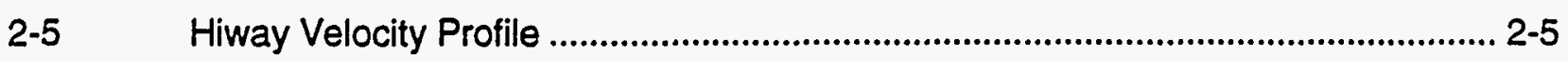

3-1 Basic Operation of the Vehicular PEM Fuel Cell .................................................... 3-3

3-2 Optimal PEM Fuel Cell Subsystem Configuration ....................................................... 3-6

3-3 AlliedSignal Automotive PEM Fuel Cell Power Plant Concept .................................. 3-6

3-4 PEM Fuel Cell Subsystem Cooling Scheme ............................................................ 3-7

3-5 Overall Water Balance for the FCS Subsystem at 2 Atmospheres ........................ 3-10

3-6 Comparison of Model Prediction with Experimental Polarization Curve

3-7 Rated Power and off-Design Stack Voltages for $50 \mathrm{~kW}$

Fuel Cell Stack 


\section{LIST OF ILLUSTRATIONS (Continued)}

Figure

Page

3-8 Stack and Subsystem Efficiency for $50 \mathrm{~kW}$ FCS

Hydrogen Usage Rate (50-kW Stack)

3-10 Hydrogen Consumption per Unit Power (50 kW Fuel Cell Stack)

3-11 Effect of Turbocompressor Design on Subsystem Efficiency 3-16

3-12 Fuel Cell Subsystem Transient Response 20-50 kW Load Change (50 kW Stack) 3-17

3-13 Optimal PEM FCS Configuration ................................................................... 3-18

4-1 Gaseous Hydrogen Storage System Schematic .................................................. 4-4

4-2 Hydrogen Density as a Function of Pressure and Temperature ............................. 4-6

4-3 Best-Fit Gaseous Hydrogen Installation Layout ................................................... 4-7

4-4 Tank Refuel Adiabatic Temperature Response .................................................. 4-9

4-5 Refuel Temperature Response with Heat Transfer .............................................. 4-11

4-6 Hydrogen Tank Refueling Temperature Rise .................................................... 4-12

4-7 Refueling Tank Temperature Rise Without Turbine ........................................... 4-13

4-8 Potential Refueling Schemes for Pressurized Gas

Storage Systems

Proposed Liquid Refueling Scheme

4-10 Liquid Hydrogen Installation Layout (1-Tank) ................................................. 4-19

5-1 LLU Component Configuration ........................................................................ 5-2

5-2 Vehicle Operational Effects on LLU Operation ................................................... 5-4

5-3 DPHV Battery Configuration for Cell and Stack Monitoring ..................................5-11

5-4 Typical Battery Temperature Sensing Circuitry ................................................. 5-12

5-5 Bolder Spiral-Wound Battery Technology .................................................... 5-13

5-6 Electrosource "Horizon" Battery Features ...................................................... 5-14

5-7 Chopper/Regulator Configuration ............................................................... 5-16

5-8 Current Control Circuit................................................................................ 5-17

5-9 Simplified Boost Current Circuit ................................................................. 5-18

5-10 Simplified Buck Current Circuit................................................................... 5-19

5-11 MC68332 Block Diagram .................................................................... 5-22

7-1 HVAC Refrigerant Circuit Diagram ............................................................ 7-1

7-2 Regenerative Braking Subsystem Configuration .............................................. 7-3

7-3 Electric Power Steering Subsystem ................................................................. 7-4 


\title{
LIST OF TABLES
}

Table

Page

3-2 Mass and Volume Projections for $50 \mathrm{~kW}$ PEM Fuel Cell Stack

\section{DISCLAIMER}

\begin{abstract}
This report was prepared as an account of work sponsored by an agency of the United States Government. Neither the United States Government nor any agency thereof, nor any of their employees, makes any warranty, express or implied, or assumes any legal liability or responsibility for the accuracy, completeness, or usefulness of any information, apparatus, product, or process disclosed, or represents that its use would not infringe privately owned rights. Reference herein to any specific commercial product, process, or service by trade name, trademark, manufacturer, or otherwise does not necessarily constitute or imply its endorsement, recommendation, or favoring by the United States Government or any agency thereof. The views and opinions of authors expressed herein do not necessarily state or reflect those of the United States Government or any agency thereof.
\end{abstract}





\section{Executive Summary}

This report presents the conceptual design for a Direct-Hydrogen-Fueled Proton Exchange Membrane (PEM) Fuel Cell System for transportation applications. The design is based on the initial selection of the Chrysler LH sedan as the target vehicle with a $50 \mathrm{~kW}$ (gross) PEM Fuel Cell Stack (FCS) as the primary power source, a battery-powered Load Leveling Unit (LLU) for surge power requirements, an on-board hydrogen storage subsystem containing high pressure gaseous storage, a Gas Management Subsystem (GMS) to manage the hydrogen and air supplies for the FCS, and electronic controllers to control the electrical system. The design process has been dedicated to the use of Design-to-Cost (DTC) principles.

The Direct Hydrogen-Powered PEM Fuel Cell Stack Hybrid Vehicle (DPHV) system is designed to operate on the Federal Urban Driving Schedule (FUDS) and Hiway Cycles. These cycles have been used to evaluate the vehicle performance with regard to range and hydrogen usage. The PEM FCS, the hydrogen storage and the gas management subsystems will be developed by AlliedSignal Aerospace Engineering. The lead acid batteries used to supply surge power will be selected as test data and availability dictate.

The major constraints for the DPHV vehicle are vehicle and battery weight, transparency of the power system and drive train to the user, equivalence of fuel and life cycle costs to conventional vehicles, and vehicle range. The energy and power requirements are derived by the capability of the DPHV system to achieve an acceleration from 0 to $60 \mathrm{MPH}$ within 12 seconds, and the capability to achieve and maintain a speed of $55 \mathrm{MPH}$ on a grade of seven percent.

The size of the vehicle was selected as a six passenger payload capability and the need for cargo storage for those passengers. The vehicle test weight (curbside weight plus test payload) is 3330 pounds, representing a design task 10 percent lower than that of the current Chrysier LH sedan.

The conceptual design for the DPHV vehicle is shown in Figure 1. This design shows the Hydrogen Storage Subsystem (HSS) being located beneath the trunk and separated by the rear suspension with three 5000 psia tanks being used to provide 12 pounds of usable hydrogen (lower pressure limit is fixed by the outlet Hydrogen Low Pressure Control Valve). A detailed description of the HSS is given in section 4. The FCS is located in the space currently containing the transmission for the conventional Internal Combustion Engine power train. The GMS hardware is mainly located in the front of the vehicle in the engine compartment. A detailed description of the FCS Subsystem and GMS is given in section 3 .

Batteries have been chosen as the supplemental energy supply for the LLU Subsystem. Load Leveling Batteries which provide surge power support to supplement the FCS Subsystem are located under the vehicle front seats. The controller units (motor and power) are located under the hood in the engine compartment. A detailed description of the LLU, selection of the LLU energy source, and the power controller designs is given in section 5 . 


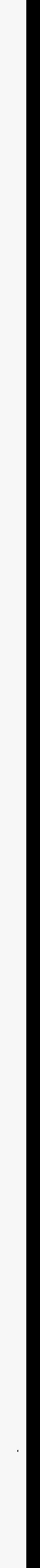




\section{DIRECT HYDROGEN PEM FUEL CELL VEHICLE}

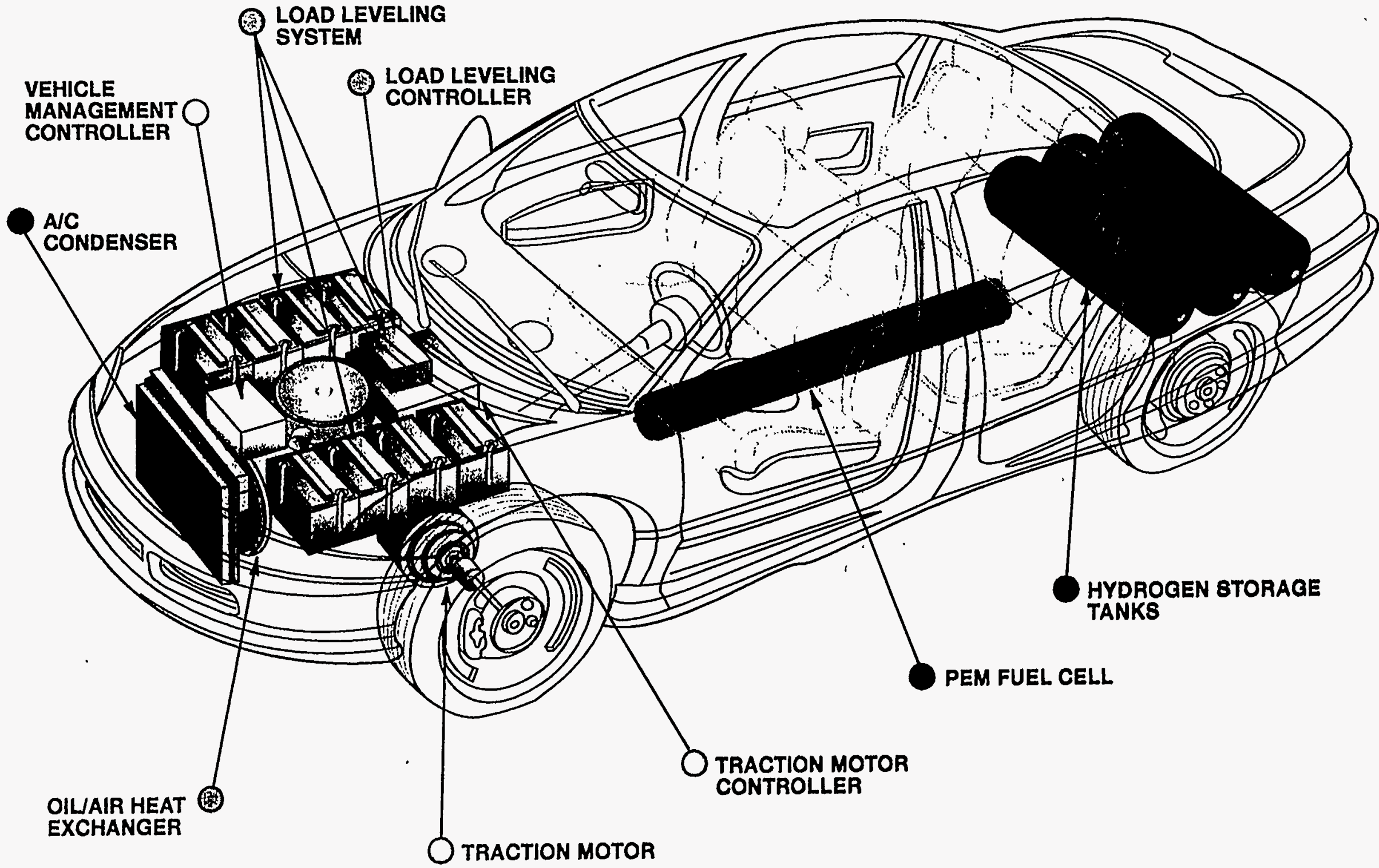

Figure 1. DPHV Vehicle Configuration 

The conceptual DPHV system is based on a $50 \mathrm{~kW}$-rated PEM Fuel Cell Stack with a net, usable power of $40 \mathrm{~kW}$. The PEM fuel cell will consist of five $10 \mathrm{~kW}$ modules. Although materials have been selected for the membrane, bipolar plates and the electrode assemblies for the prototype PEM fuel céll continue to be researched and developed as an ongoing cost sharing effort. The lead acid battery-powered LLU subsystem has a specific energy content greater than $30 \mathrm{Wh} /$ $\mathrm{kg}$ and a specific power density less than $0.2 \mathrm{~kW} / \mathrm{kg}$. The motor tentatively selected for use as the power train drive source is the Westinghouse 3 phase AC motor. The DC input power bus to this motor's controller will have a nominal voltage of 320 VDC. A chopper/regulator circuit will control the output of the FCS to provide the primary power to the power train. The LLU subsystem will be connected directly to the DC power bus. Regenerative braking will be used to provide extended range of operation for the vehicle. The electrical configuration for the system is shown in Figure 2.

Preliminary simulation results for the DPHV system show that the peak power required to accelerate the vehicle to $60 \mathrm{MPH}$ within 12 seconds requires values between 65 and $100 \mathrm{~kW}$ depending on the manner in which the peak speed is attained. The steady-state system power required to sustain the vehicle speed at $55 \mathrm{MPH}$ on a seven percent grade is $40 \mathrm{~kW}$.

Preliminary simulation of the FUDS and Hiway cycles indicates a hydrogen use (mileage) of 67.6 miles per gallon (gasoline equivalent) for no regenerative braking and 73.2 miles per gallon for regenerative braking. These values correspond to ranges of 321 and 348 miles, respectively. The use of the FCS Subsystem and the GMS will be optimized as the system design is finalized in order to achieve the goal of a 380 mile range. Table 1 provides the design goals for the DPHV system. These goals have been developed to conform to the Partnership for a New Generation of Vehicles (PNGV) goals wherever possible.

Table 1. DPHV Vehicle Design Goals

\section{Parameter}

Vehicle Test Weight

Wheel Radius

Frontal Area

Drag Coefficient (Cd)

Rolling Resistance Coefficient (Cr)

Vehicle Range

Time to Accelerate to $60 \mathrm{MPH}$

Peak Power to Achieve Acceleration Goal

Steady-State Power for Baker Grade Achievement

FCS Peak Power (Deliverable)

FCS Nominal Operating Temperature

HSS Pressure

Hydrogen Storage Capacity

LLU Power Source

LLU Peak Power

Nominal DC Battery Voltage

LLU Energy Density

Chopper/Regulator Input Voltage

Chopper/Regulat or Output Voltage
Units

Pounds

Feet

Feet2

***

\$**

Miles

Seconds

kW

kW

kW

${ }^{\circ} \mathrm{C}$

Pounds/Inch2

Pounds

***

kW

VDC

$W h / k g$

VDC

VDC
Value

3330

1.07

23.5

0.250

.0064

380

12

76.3

40

40

85

5000

12.6

Batteries

60

320

41

200-400

240-320 
DPHV SYSTEM DIAGRAM

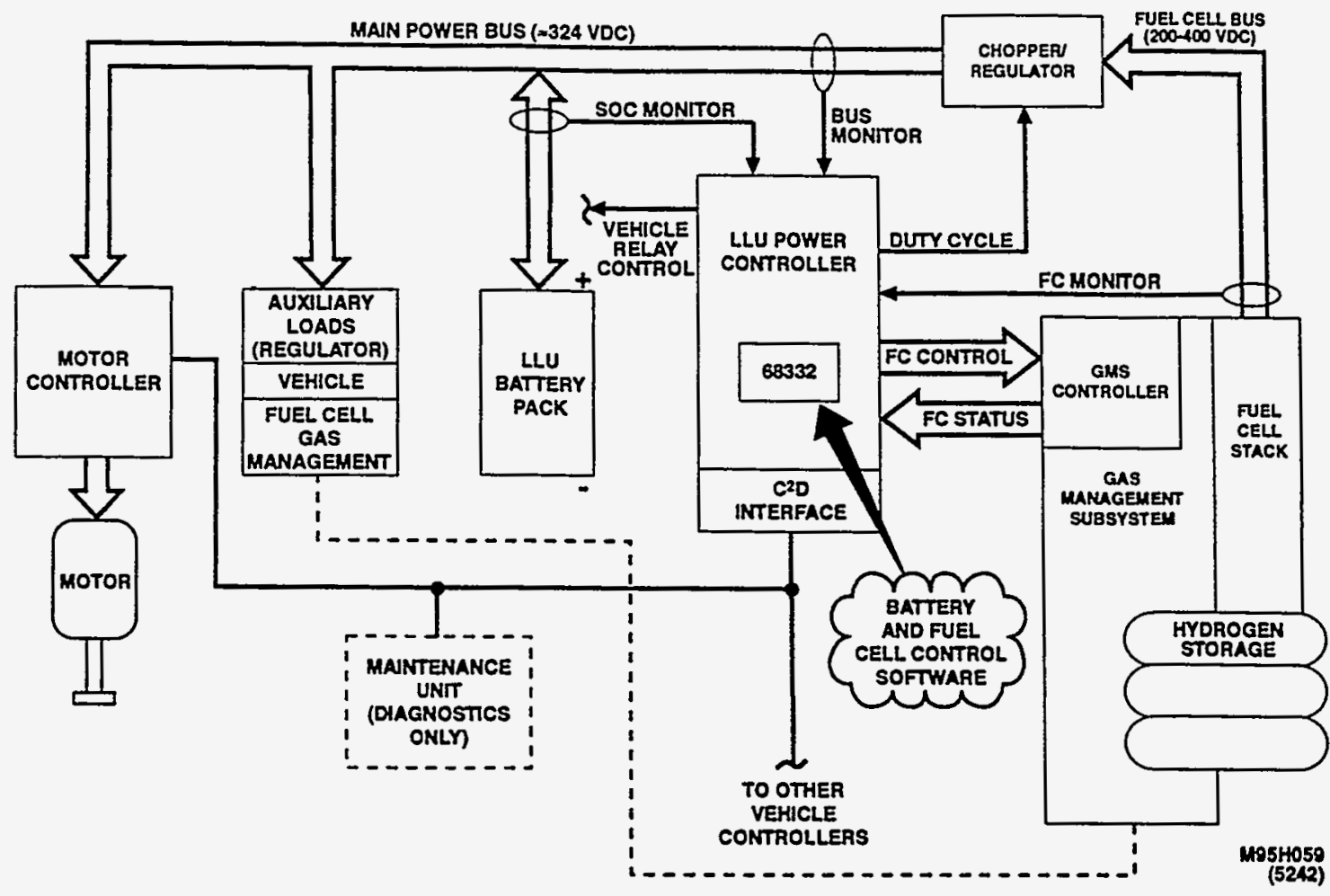

Figure 2. DPHV Electrical Configuration

Table 2 provides the weight allocation which has been assigned to the DPHV system. Column 2 of this table provides the system design goals while column 3 provides the current weight of the subsystem defined in column 1.

Table 2. DPHV Weight Allocation

Subsystem

Chassis/Body

Fuel Cell Stack

Hydrogen Storage

Gas Management

Load Leveling

Power Train

Total Weight

\section{Design Goal (Ibs)}

2290

110

230

55

205

290

3180
Current Weight (lbs)

2550

110

230

55

314

290

3549 


\section{SECTION 1 \\ VEHICLE CONSIDERATIONS}

\subsection{Vehicle Determination}

\subsubsection{Introduction}

As part of this design study, four vehicle classes (subcompact sedan, midsize sedan [LH], minivan and full-size pickup truck) were considered before one was chosen. An assumption was made in this study that all of the vehicles, except the $\mathrm{LH}$, had 1995 model specifications. The $\mathrm{LH}$, by virtue of being chosen for the Partnership for a New Generation of Vehicles (PNGV), was considered in terms of both a 1995 model, for prototype (mule) purposes, and in terms of an 80 mpg PNGV LH vehicle. The performance objectives of PNGV are shown in Figure 1-1.

- Six-passenger vehicle (similar to Taurus, Lumina, or Concorde).

- Current Taurus: $26.5 \mathrm{mpg}$, therefore mpg goal is about $80 \mathrm{mpg}$ combined city/ highway (unadjusted Federal test procedure).

- Performance of 0 to 60 MPH in 12 seconds.

- Operating metro-highway range of 380 miles on the 1994 Federal Drive Cycle. Operating life of 100,000 miles.

- Equivalent:

- Performance, ride, handling, noise, vibration, etc.

- Customer features: interior volume, luggage space, climate control, entertainment packages.

Figure 1-1. Vehicle Parameters for Goal 3

In order to arrive at an $80 \mathrm{mpg}$ LH sedan, the improvements shown in Figure 1-2, path 1, were modified using 85 percent efficient energy storage, a motor/ controller efficiency of 85 percent, and fuel cell efficiency of 50 percent (figures are averaged over the combined city and highway driving cycles).

Based on Figure 1-3, it is assumed that the fuel economy improvement in using such a combination will be (67/27) or 2.5 times that of the conventional Internal Combustion Engine (ICE) version. For example, since an LH currently provides approximately $30 \mathrm{mpg}$ (Environmental Protection Agency [EPA]-adjusted, or labeled), the fuel economy figure used in Table $1-1$ is $75 \mathrm{mpg}$ 


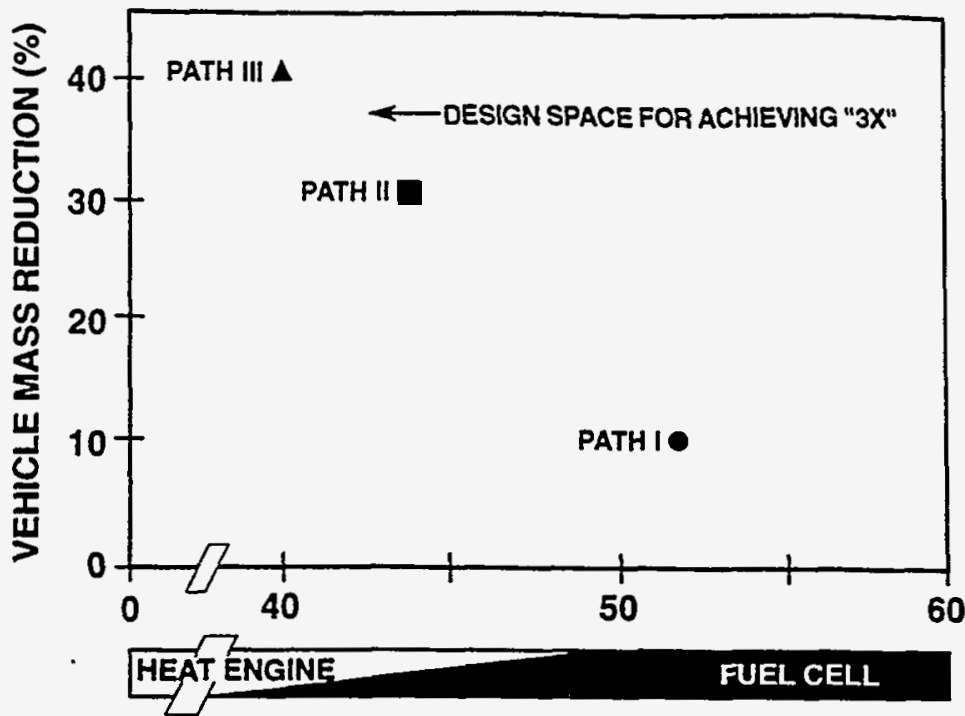

POWER SOURCE THERMAL EFFICIENCY - \%

\begin{tabular}{|l|}
\hline EXI \\
\hline $51 \%$ THERMAL EFFICIENCY \\
$10 \%$ MASS REDUCTION \\
$50 \%$ REGENERATIVE BRAKING \\
$90 \%$ EFFCIENT ENERGY STORAGE \\
$76.5 \%$ EFFCIENT ORIVELINE \\
$20 \%$ LOWER DRAG \\
$20 \%$ LOWER ROLUNG RESISTANCE \\
$30 \%$ LOWER ACCESSORIES LOADS \\
\hline
\end{tabular}

\begin{tabular}{|c|}
\hline 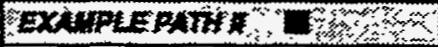 \\
\hline $\begin{array}{l}44 \% \text { THERMAL EFFICIENCY } \\
30 \% \text { MASS REDUCTION } \\
60 \% \text { REGENERATIVE BRAKING }\end{array}$ \\
\hline $\begin{array}{l}90 \% \text { EFFICIENT ENERGY STORAGE } \\
76.5 \% \text { EFFCIENT DAIVELINE } \\
20 \% \text { LOWER ORAG } \\
20 \% \text { LOWER ROLLNG RESISTANCE } \\
30 \% \text { LOWER ACCESSORIES LOADS }\end{array}$ \\
\hline
\end{tabular}

4

40\% THERMAL EFFICIENCY

$40 \%$ MASS REDUCTION

$70 \%$ REGENERATIVE BRAKING

$90 \%$ EFFICIENT ENERGY STORAGE

76.5\% EFFICIENT DRIVELINE

$20 \%$ LOH

20\% LOWEA ROLUNG RESISTANCE $30 \%$ LOWEA ACCESSORIES LOADS

Figure 1-2. Propulsion and Vehicle Improvements Needed for 80 MPG (Adapted from PNGV)

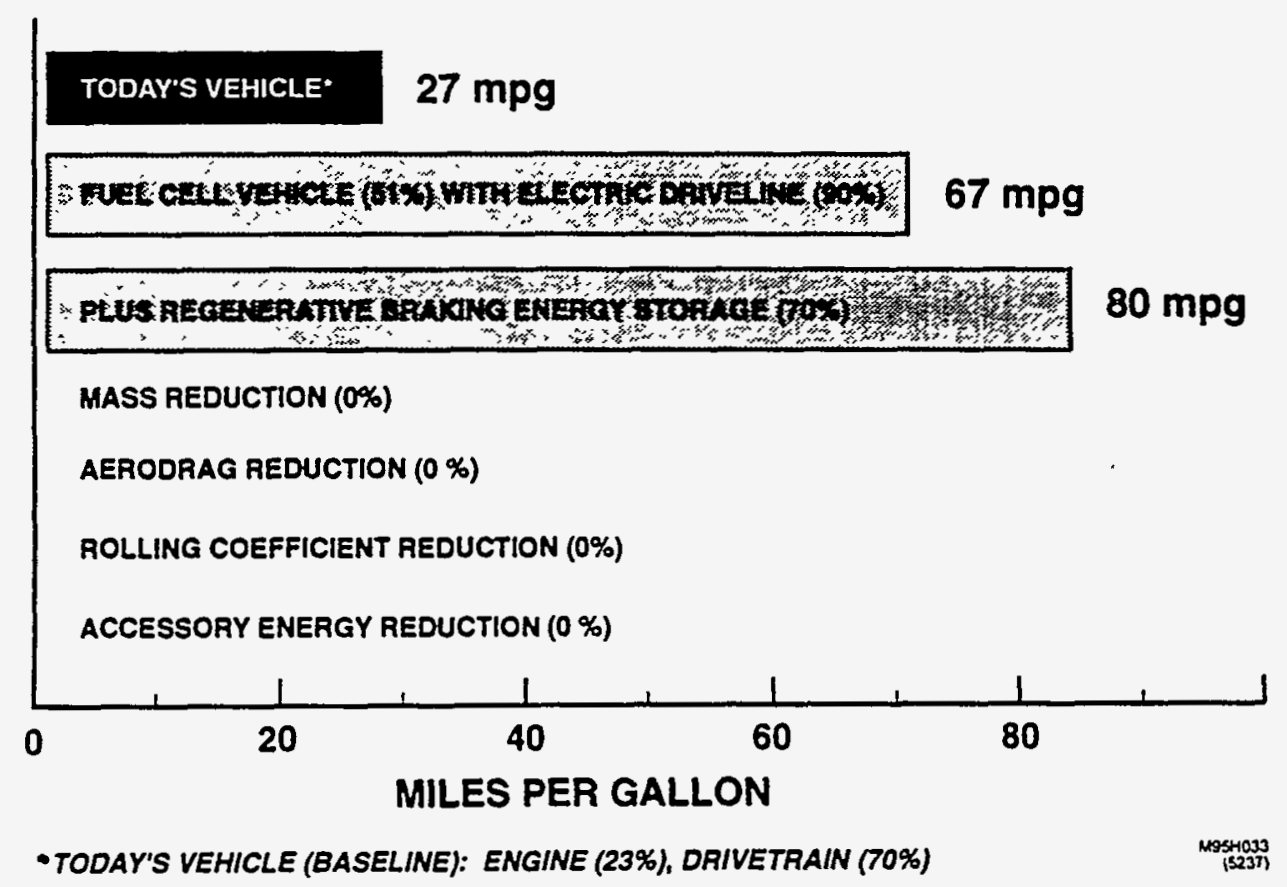

Figure 1-3. Fuel Cell Pathway to 80 MPG (Adapted from PNGV) 
$(30 \times 2.5)$. As mentioned before, the sole exception to this $2.5 X$ rule is the PNGV vehicle which is meant to provide $3 X$.

\subsubsection{Vehicle Selection Process}

The four factors discussed below were considered in making the vehicle selection.

- Vehicle Power Requirements - The following equation was used to determine steadystate power requirements:

$$
P=0^{\star} 5^{\star} p^{\star} C_{d}{ }^{*} A^{*} v^{3}+m^{\star} g^{*} C_{r}^{*} \cos ()^{\star} v+m^{\star} g^{*} \sin ()^{\star} v
$$

where

$$
\begin{aligned}
p & =\text { density of air at } 300^{\circ} \mathrm{K}=1.293 \mathrm{~kg} / \mathrm{m}^{3} \\
& =\text { angle of grade } \mathrm{v}=\text { vehicle velocity, in m/s } \\
g & =\text { acceleration due to gravity, in } \mathrm{m} / \mathrm{s}^{2} \\
C_{d} & =\text { drag coefficient; } C_{r}=\text { rolling resistance coefficient } \\
P & =\text { Power. }
\end{aligned}
$$

Table 1-1 explains the other symbols and shows the specifications used for each vehicle. In every case, an energy storage (or peak power) device is required to make up the extra power needed to provide a 12 second, 0-60 MPH, acceleration.

Power from the fuel cell is also needed to operate the hotel loads (e.g Heating/Nentilation/Air Conditioning [HVAC], power steering, headlights, etc.). For example, the power steering and headlight functions must be capable of being operated when the fuel cell is providing peak continuous power and the combination consumes around $2 \mathrm{~kW}$; operation of HVAC, potentially capable of an even bigger power drain, is not typically required under these performance test conditions. If the HVAC is operating then hill climbing capability will be compromised slightly. However, in all other situations normal performance can still be obtained even with the HVAC on.

- Vehicle Range Requirements - Each of the four vehicle classes currently has a different range based on available packaging space for the fuel tank and vehicle's fuel economy. However, it was decided that since the range of these vehicles is somewhat arbitrary a reasonable comparison can still be made if it is assumed that each vehicle needs to provide approximately 380 miles range. This is in accordance with the PNGV goals for the LH. 
Table 1-1. Vehicular Performance Requirements

\begin{tabular}{|c|c|c|c|c|c|}
\hline & $\begin{array}{c}1995 \\
\text { Subcompact } \\
\text { Sedan }\end{array}$ & $\begin{array}{l}1995 \text { Midsize } \\
\text { Sedan (LH) } \\
\text { for } \\
\text { Prototype } \\
\text { Use }\end{array}$ & $\begin{array}{l}\text { PNGV Midsize } \\
\text { Sedan }\end{array}$ & $\begin{array}{l}1995 \\
\text { Minivan } \\
\text { (AS) }\end{array}$ & $\begin{array}{l}1995 \\
\text { Fullsize } \\
\text { Pickup } \\
\text { Truck } \\
\text { (BR) }\end{array}$ \\
\hline $\begin{array}{l}\text { Aerodynamic Drag } \\
\text { Coefficient } 1, \mathrm{C}_{d}\end{array}$ & 0.33 & 0.35 & 0.25 & 0.40 & 0.48 \\
\hline Frontal Area, $A, m^{2}\left(\mathrm{ft}^{2}\right)$ & $\begin{array}{c}1.92 \\
(20.6) \\
\end{array}$ & $\begin{array}{c}2.20 \\
(23.5) \\
\end{array}$ & $\begin{array}{l}2.20 \\
(23.5)\end{array}$ & $\begin{array}{l}2.63 \\
(28.3)\end{array}$ & $\begin{array}{c}5.952 \\
(64)\end{array}$ \\
\hline $\begin{array}{l}\text { Rolling Resistance } \\
\text { Coefficient } 1, C_{r}\end{array}$ & 0.0070 & 0.0076 & 0.0064 & 0.0091 & 0.0148 \\
\hline $\begin{array}{l}\text { Vehicle Performance Test } \\
\text { Weight } 1, \mathrm{~m}, \mathrm{~kg}(\mathrm{lb})\end{array}$ & $\begin{array}{r}1250 \\
(2745) \\
\end{array}$ & $\begin{array}{c}1770 \\
(3892) \\
\end{array}$ & $\begin{array}{c}1510 \\
(3330) \\
\end{array}$ & $\begin{array}{c}2030 \\
(4475) \\
\end{array}$ & $\begin{array}{c}5580 \\
(12500) \\
\end{array}$ \\
\hline Fuel Cell Power ${ }^{3}, \mathrm{~kW}(\mathrm{HP})$ & $\begin{array}{c}40 \\
(53) \\
\end{array}$ & $\begin{array}{c}50 \\
(67) \\
\end{array}$ & $\begin{array}{c}40 \\
(53) \\
\end{array}$ & $\begin{array}{c}60 \\
(80)\end{array}$ & $\begin{array}{c}130 \\
(174) \\
\end{array}$ \\
\hline $\begin{array}{l}\text { Fuel Economy } 4 \text {, EPA- } \\
\text { Adjusted, or Label Figure, } \\
\text { mpg Gasoline Equivalent }\end{array}$ & 75 & 54 & $\begin{array}{c}66 \\
\text { (80 mpg based } \\
\text { on CAFE credit) }\end{array}$ & 50 & 37 \\
\hline Range Requirement, Miles & 380 & 380 & 380 & 380 & 380 \\
\hline $\begin{array}{l}\text { Hydrogen Internal Storage } \\
\text { Volume5, liter ( } \mathrm{ft} 3 \text {, gallons) }\end{array}$ & $\begin{array}{c}225 \\
(7.9,60)\end{array}$ & $\begin{array}{c}310 \\
(10.9,80)\end{array}$ & $\begin{array}{c}260 \\
(9.1,70)\end{array}$ & $\begin{array}{c}330 \\
(11.8,87)\end{array}$ & $\begin{array}{c}450 \\
(16,118)\end{array}$ \\
\hline $\begin{array}{l}1995 \text { vehicle curb weight+300 lb } \\
\text { Figure } 1-2 \\
\text { trailer included } \\
\text { net power } \\
\text { assuming } 2.5 \text { times ICE vehicle's } \\
\text { unadjusted for ambient temperat }\end{array}$ & $x^{-1}+x^{2}$ & 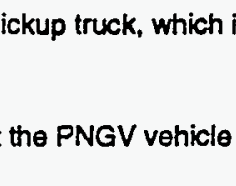 & & & \\
\hline
\end{tabular}

Labeled fuel economy figures, rather than EPA-tested figures, are used in determining the fuel's energy storage requirements. For example, the LH sedans achieve approximately 26-27 mpg on the EPA combined City/Highway Cycle (hence $3 X$ is $80 \mathrm{mpg}$ ) and yet the EPA-adjusted figure is $21-22 \mathrm{mpg}$. When combined with the gasoline tank volume (or hydrogen storage tank volume if gallons gasoline equivalent is used) this adjusted fuel economy figure provides an approximate indication of the vehicle's range.

However, in the case of compressed gas storage, the actual range given ambient refueling conditions will be approximately $3 / 4$ times the nominal range which is that predicted from the energy content of the fuel tank and the fuel economy; this discrepancy between actual and nominal range is explained in Section 4 . In other words, if conventional pressurized five minute refueling takes place, then the vehicle's range would be reduced to approximately 285 miles for all of the vehicles. Nominal ranges of 380 miles will be used in Section 1.1.3.

- Vehicle Cost - Cost is vitally important but the sensitivity to increased cost due to advanced technology is clearly different when comparing the demographics of sub- 
compact owners versus luxury car owners. For this reason, new technology is often introduced into the high end of the market first before the effects of mass production allow the same technology (e.g. ABS, fuel injection, etc.) to flow down to the subcompact car segment.

- Vehicle Mission - Attention was given to how the implications of fuel cell and hydrogen storage cost, weight and volume (dictated by factors 1,2 and 3) might affect the vehicle's mission and how it would interact with the demographics of the vehicle's customers to ensure that the product could reasonably be marketed.

As an extreme example, minivan customers take safety and interior cabin space more seriously than do sports car owners while hauling capability is of paramount important to pickup truck owners. For cars, a certain threshold trunk space has to be met, but this is subjective since a small trunk might be acceptable in certain situations (e.g. convertibles).

\subsubsection{Conclusion}

- Subcompact Sedan - The subcompact car, by virtue of its low cost, is not designed to have the same utility or performance as other vehicles and so in this sense it is not so demanding an application. For example, it is the lightest and most fuel efficient vehicle in the fleet and therefore requires the smallest fuel cell system and the smallest volume of hydrogen storage given the assumption that all vehicles, except the midsize LH sedans, need to provide 350 miles range. However, this reduction in fuel tank volume does not compensate for the fact that much less packaging space is available compared with the other vehicles. A packaging study, shown in Figure 1-4, reveals that two tanks of approximately equal length, mounted down the tunnel, may be the optimum use of available space and results in $2.7 \mathrm{ft}$ of hydrogen storage which translates into a range of approximately only 120 miles or three times less than required. For purposes of clarity, only the tanks are shown and not the supporting hardware. Another consideration is that the initial cost of a fuel cell hybrid vehicle is very likely to be higher than for a conventional vehicle and the likely consumers for such a vehicle must be both willing and able to pay extra to make an environmental statement. This tends to rule out an economical subcompact car at this time.

- Minivan - With regard to minivans, recent surveys confirm that interior volume is their most important attribute so that any reduction caused by a need for hydrogen storage is a critical problem. Figure 1-5 shows the arrangement of the four tanks used in Chrysler's 120 mile range CNG-powered minivan. Since, for a given pressure and volume hydrogen stores approximately three-four times less energy than natural gas, the same four tanks storing hydrogen at 5,000 psia will provide the fuel cell-powered minivan with approximately the same nominal range which is one-third the range required. (For the same safety factor, 5,000 psia hydrogen requires slightly thicker tank walls than 3,000 psia natural gas so the range may be impaired even more.) More 


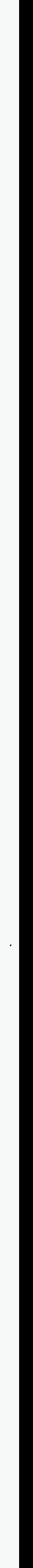




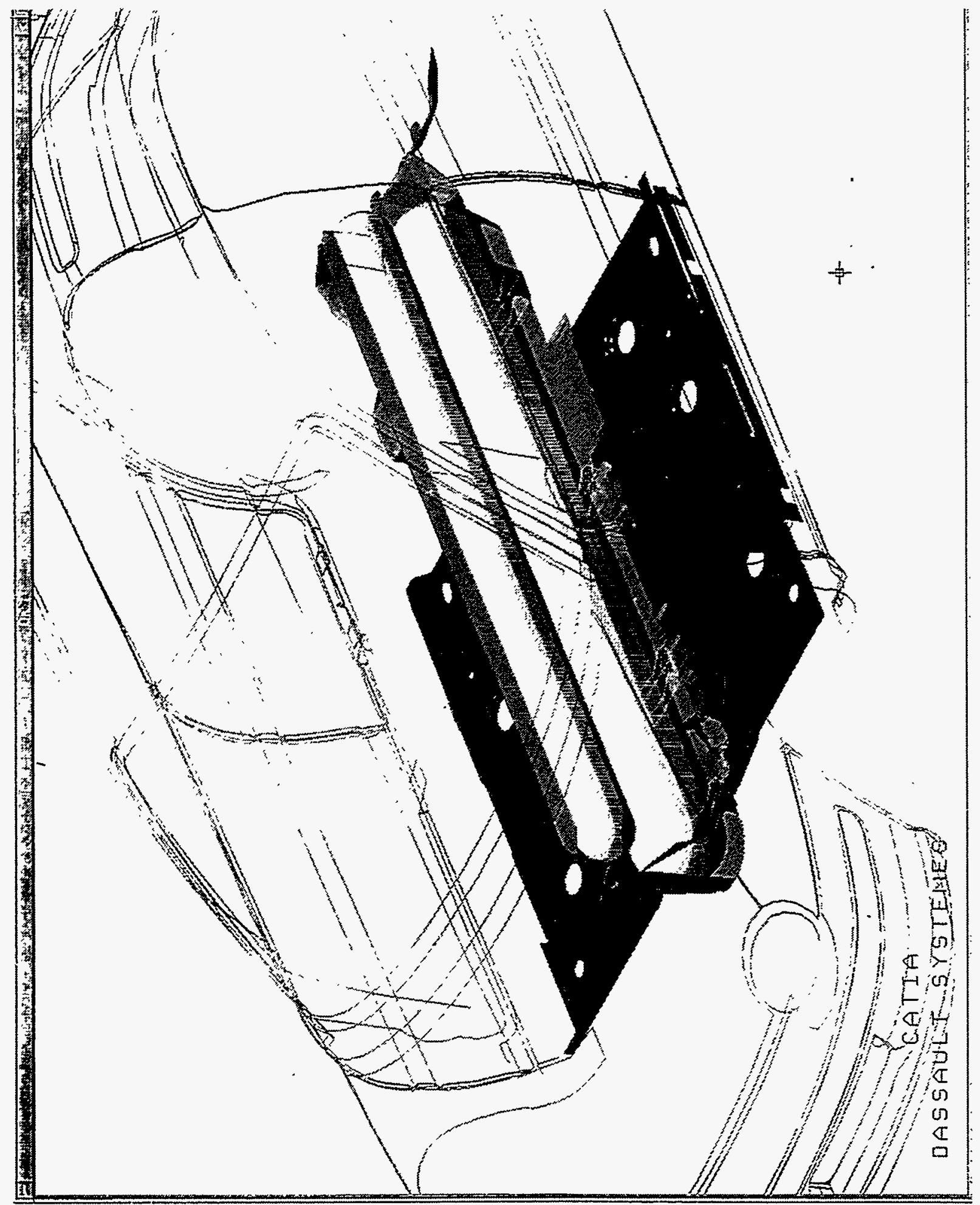

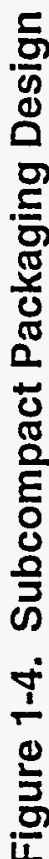





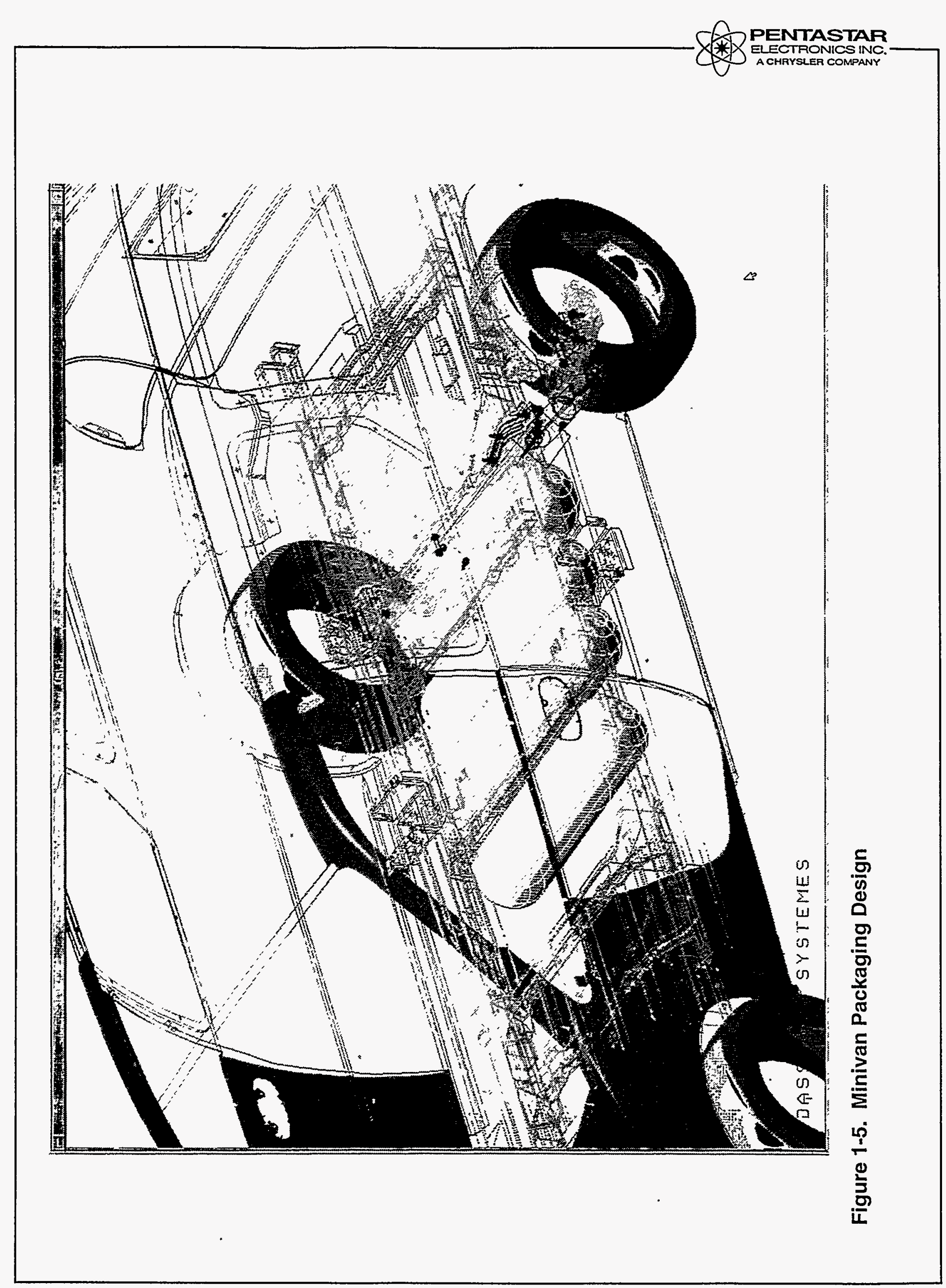




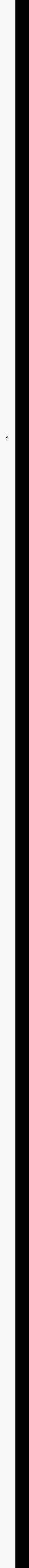


tanks can be added, of course, but the tank cost will be much too expensive and interior cabin space and payload will be compromised. Clearly, the need for 380 miles range imposes severe penalties for a hydrogen-powered minivan. Another factor which must be considered is safety which is particularly important in this category. The public's perception of hydrogen as a dangerous fuel may be more of an issue for this vehicle than for other vehicle segments. Finally, the need for a larger fuel cell and hydrogen storage tank will add more cost than for the midsize sedan and yet minivan customers may be even less willing to pay a premium.

- Full-size Pickup Truck - The pickup truck appears to be the least sensible choice for a hydrogen fuel cell powered vehicle because its specific mission requires high power requirements. Steady cruising at high speeds or up long grades create a special situation for a pickup truck since these vehicles are meant to be capable of carrying heavy payloads and towing trailers. The fuel cell power requirements will, therefore, be much higher than for other vehicles, even the minivan, and this will reduce payload capability and substantially increase vehicle cost. The volume occupied by the hydrogen storage tanks will also be higher than for the other vehicles because the vehicle is less fuel efficient and yet an equal or better range is demanded. Figure 1-6 shows a 3,000 psia CNG tank occupying part of the full-size pickup truck's bed and it is predicted that a 5,000 psia hydrogen fuel cell powered version might provide a range of up to 250 miles if the required fuel cell efficiency target is met.

- Midsize Sedan - The agreement between the automakers and the Federal Government PNGV is a major reason for the current interest in fuel cells for automotive applications. The midsize sedan may have been chosen as the Goal 3 (3X) vehicle because it represents the heart of a potential fuel cell vehicle market in that the demographics of vehicle ownership parallels closely the majority of the population that is both willing and able to adopt advanced technology. This has important consequences for the fuel cell and hydrogen storage tanks. From a technical challenge standpoint, the midsize sedan does not place the same burden on a powertrain as a truck and space is less critical than in a minivan so that the viability of both the fuel cell and the hydrogen storage is enhanced. Figures 1-7, 1-8, and 1-9 show a packaging study for a PNGV LH which will provide a nominal 380 mile range in an $80 \mathrm{mpg}$ vehicle - more information concerning this design is contained in Section 4. A liquid hydrogen version was also studied, and is shown in Figure 1-10.

Figure 1-11 illustrates the midsize sedan conceptual design with the three hydrogen storage tanks in the rear, the fuel cell stack in the tunnel and the ancillaries, motorl controller, and battery under the hood.

In summary, the midsize sedan appears to represent the optimum vehicle in terms of fuel cell and hydrogen storage tank cost, weight and volume and customer acceptance. 


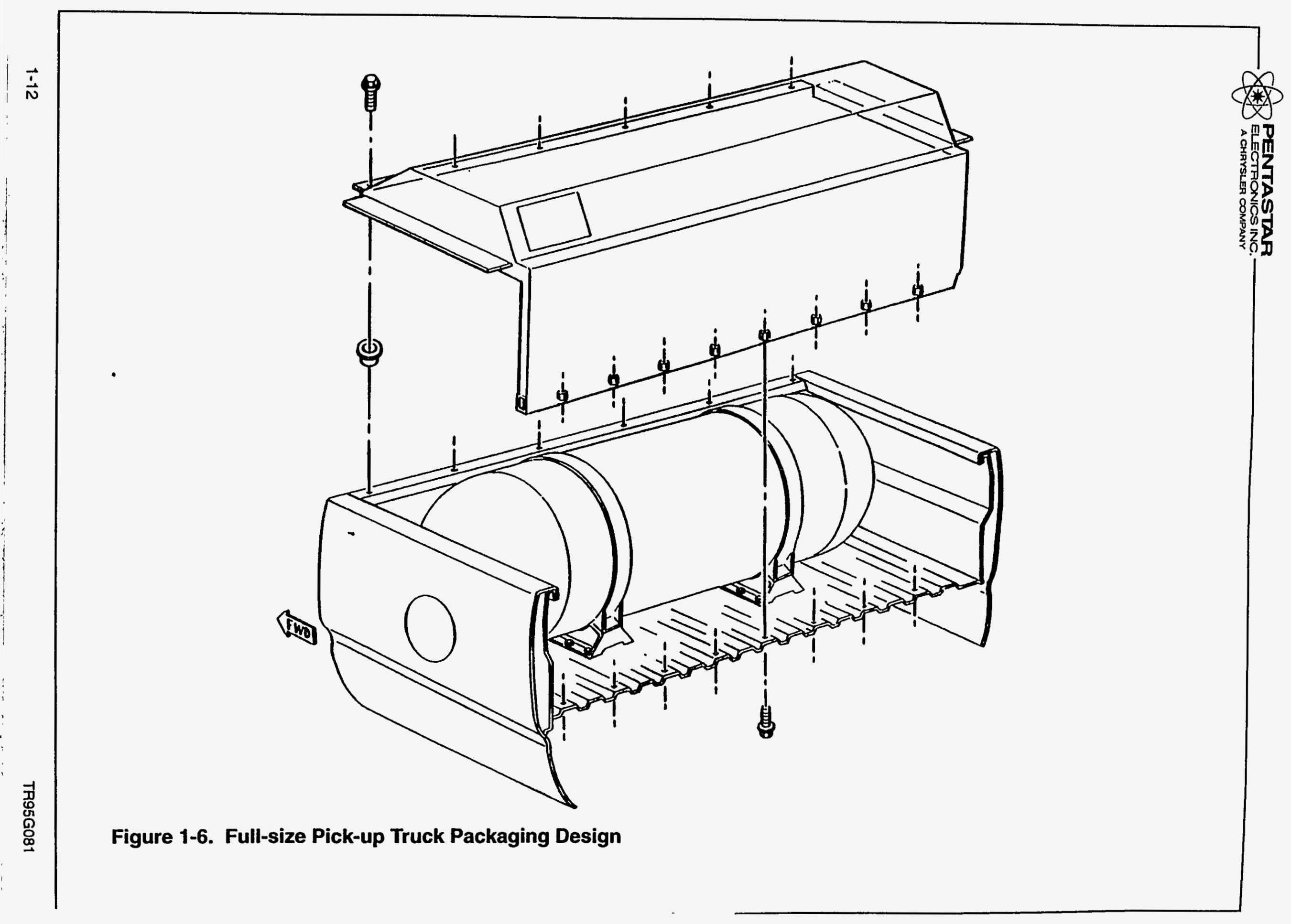




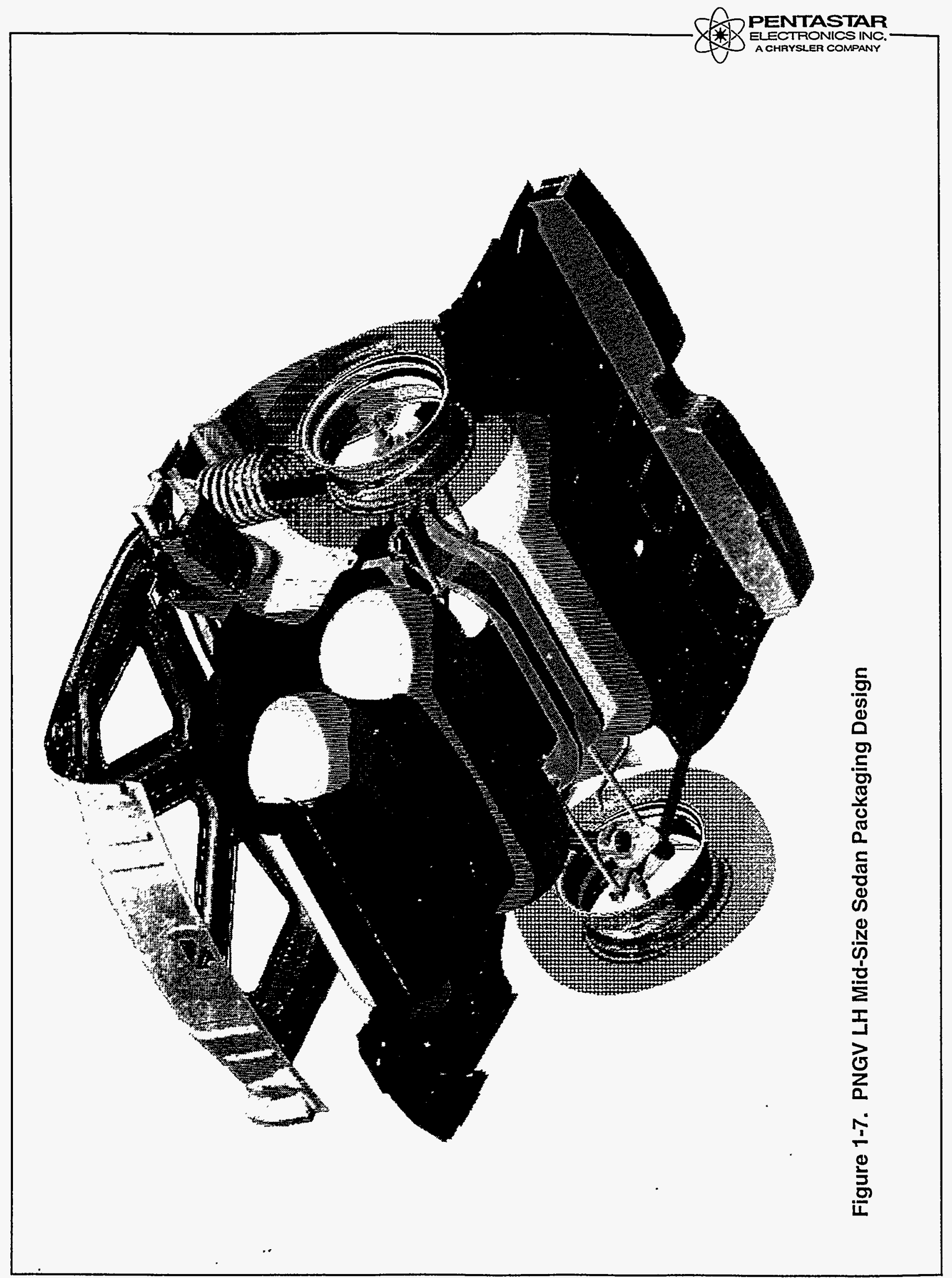





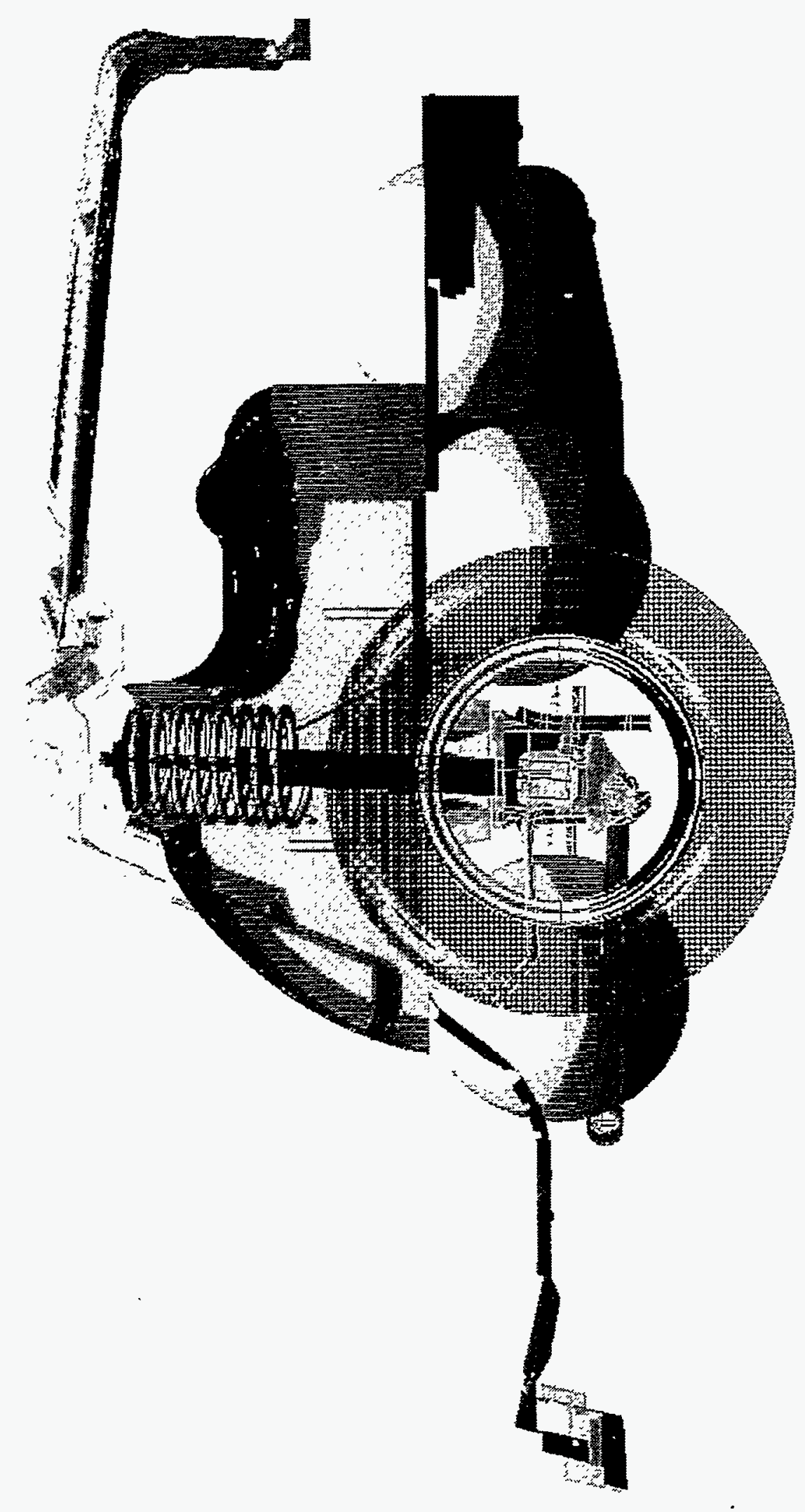

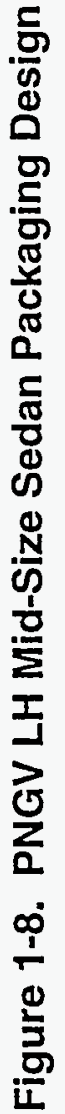





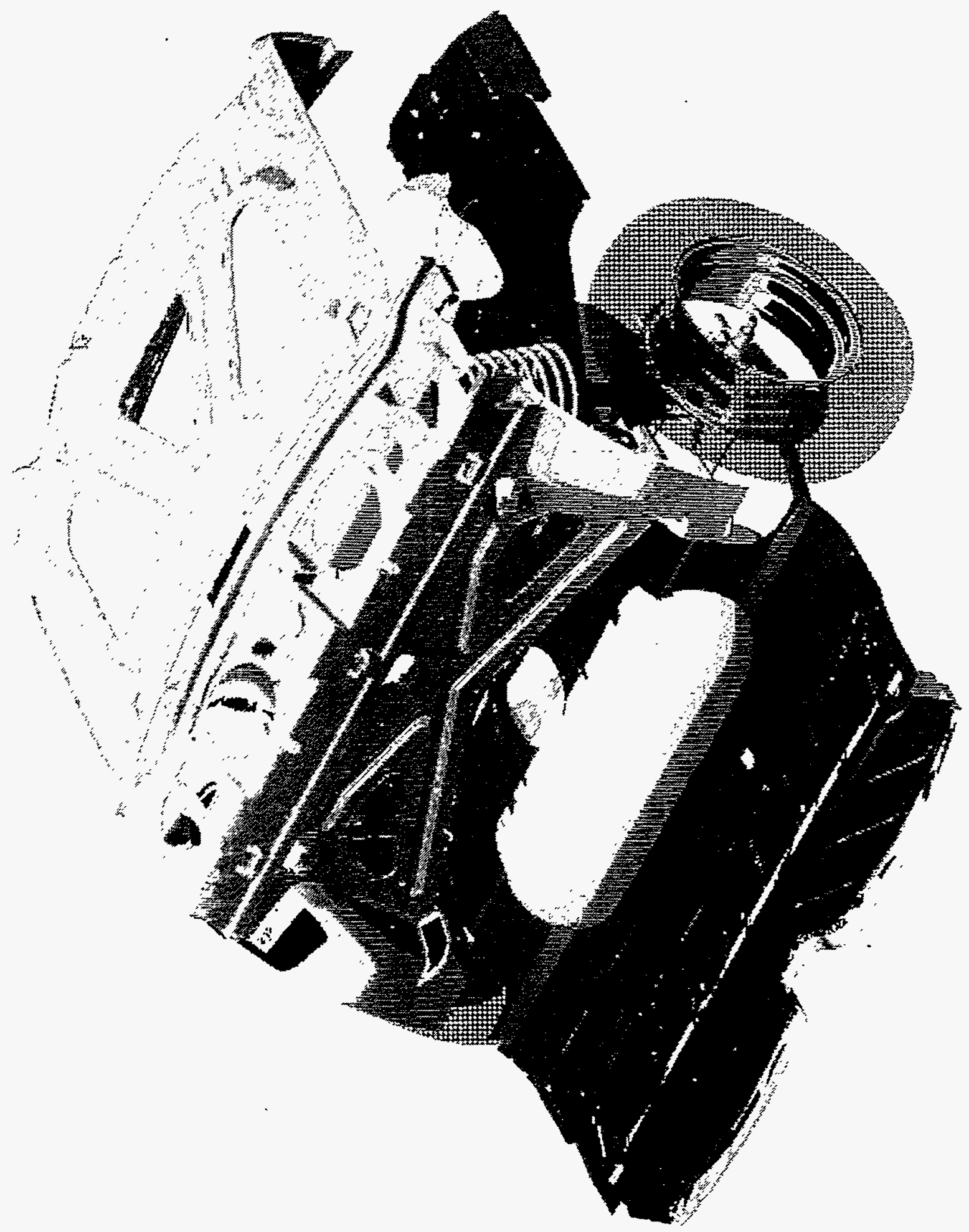

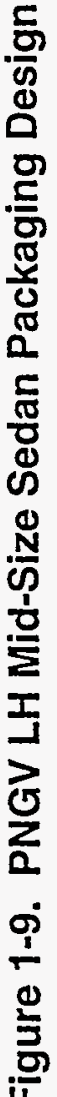




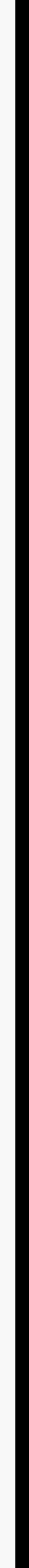




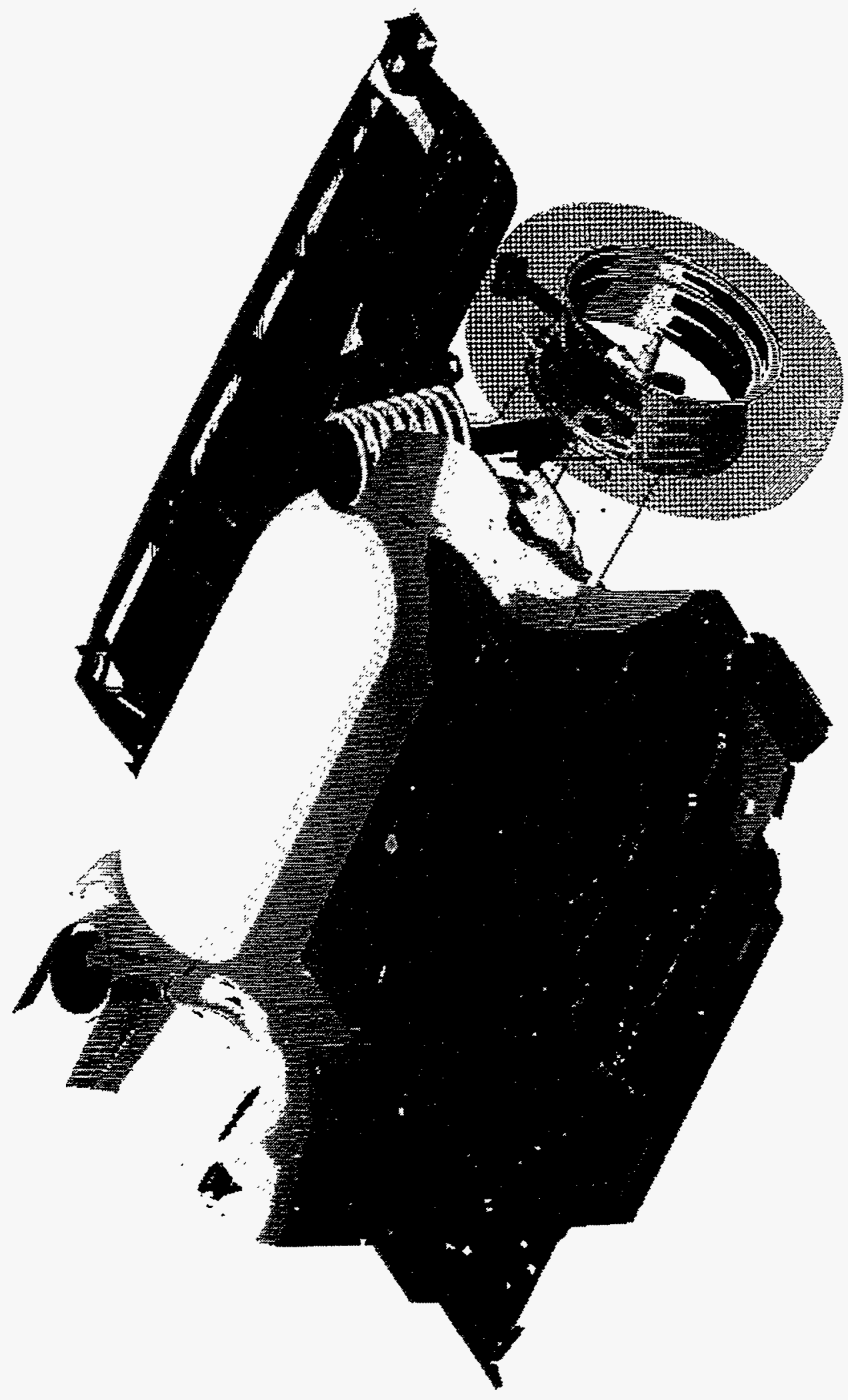

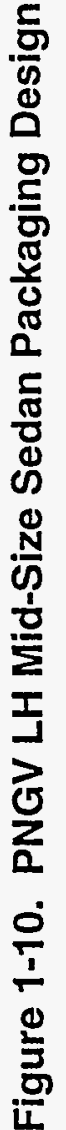





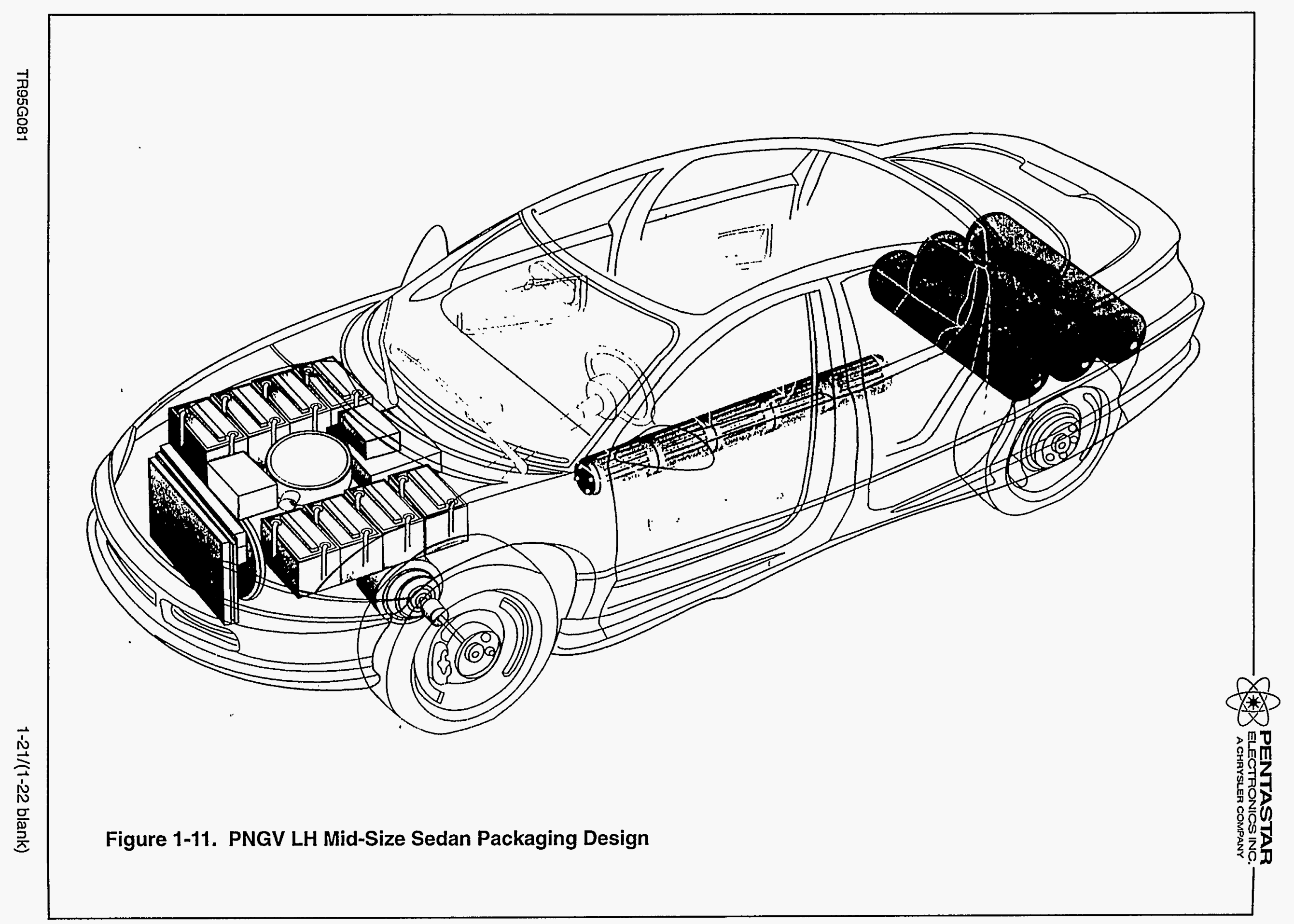




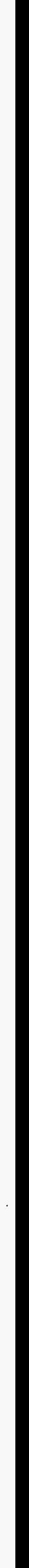




\subsection{Powertrain Size and Operational Requirements}

\subsubsection{Hybridization}

Analyses to date have shown that hybridization is required for a fuel cell vehicle to meet cost, weight, efficiency, and performance goals. It is very important to consider more than just the fuel cell's polarization curve when trying to analyze the optimum system for maximizing vehicle fuel economy when designing systems for hybrid fuel cell vehicles; factors such as regenerative braking, fuel cell part load efficiency, and fuel cell shutdown capability must also be considered in the design process. Cost and weight are also factors to consider on a systems level since the level of improvement that can be made in competing technologies, such as batteries, is unknown. Tradeoff analyses are an ongoing process and will continue as new and better information becomes available.

Following is a discussion of the three major areas considered in the design of a hybrid system:

- Regenerative Braking - Since the vehicle mass of the fuel cell vehicle is relatively high (because it is assumed that the efficiency is so high that only a small mass reduction is necessary to meet $80 \mathrm{mpg}$ PNGV goals) the effect of regenerative braking is marked. The dedicated fuel cell propulsion systems lacks regenerative braking, which can be the equivalent of 5-10 percent absolute efficiency, pointing out the difference between a 50 percent efficient fuel cell and a $40-45$ percent efficient one. Such a difference is highly significant.

- Fuel Cell Part Load Efficiency - Most driving is done under very light load (for example, $10 \mathrm{~kW}$ corresponds to approximately $60 \mathrm{MPH}$ cruising with a typical air conditioning load) and Figure 1-12 (taken from Figure 3-10) shows how the projected efficiency of a $40 \mathrm{~kW}$ fuel cell system's performance falls drastically below $4 \mathrm{~kW}$ (10 percent of rated load) due to the behavior of less-than-ideal air compressors. This leads to the conclusion that a $90 \mathrm{~kW}$ fuel cell system will probably operate less efficiently under 10 percent of rated load than a $40 \mathrm{~kW}$ fuel cell operating under the same driving conditions (i.e. between 10 and 25 percent rated load). When the vehicle demands 20-40 $\mathrm{kW}$ from the fuel cell system then the $90 \mathrm{~kW}$ version may be slightly more efficient than the $40 \mathrm{~kW}$ but the amount of time spent under these conditions is relatively small (steep hill climbing and fast cruising). Moreover, during periods of very light load ( $<4 \mathrm{~kW}$ ) the $40 \mathrm{~kW}$ fuel cell can recharge the battery. For example, if only $1-2 \mathrm{~kW}$ is required for propulsion or for hotel loads, the hybridized fuel cell can generate $5 \mathrm{~kW}$ and use the surplus power to regenerate the battery's charge. Despite the 60-65 percent turnaround efficiency of this approach it may still be more efficient than operating the fuel cell at 1-2 kW, as Figure 1-13 shows. The $90 \mathrm{~kW}$ fuel cell, on the other hand, has to provide the 1-2 kW since there will be no energy storage device. Improvements in air compressor technology and, to a lesser extent, the fuel cell stack may change this argument in the future. 


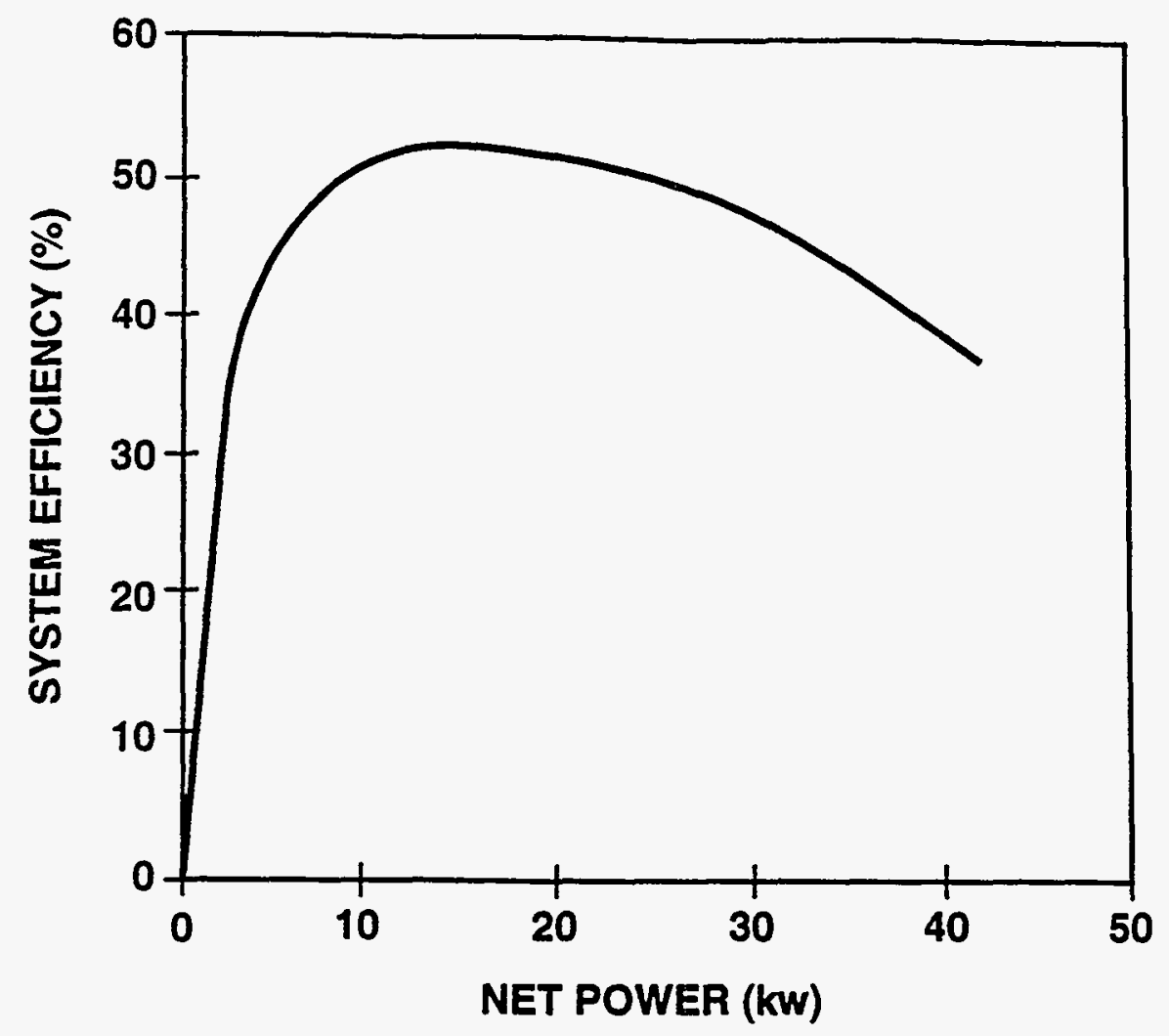

Figure 1-12. System Efficiency

- Fuel Cell Shutoff Capability - The ability to turn the fuel cell off while the vehicle is decelerating and idling may increase the efficiency of the fuel cell significantly during the EPA combined city/highway cycle, discussed in Section 2.1.

Figure 1-14 shows that the vehicle does not require motive power for nearly 60 percent of the urban drive cycle. (The highway mode is not so critical in this respect but this cycle is also where the ICE is relatively competitive on an efficiency basis.)

Another energy conversion device, the compression-ignition engine, has already demonstrated this idle-off capability in production versions and if fuel cells cannot meet the same requirement then the relative efficiency advantage of the fuel cell will be lowered to the point where it may not be competitive. A dedicated fuel cell will have to be kept on all the time since fast response is demanded while starting from a stoplight, for example. In this environment, a cooled-down fuel cell may be sluggish and, therefore, dangerous. However, if the fuel cell is hybridized the battery can cope with the fast takeoffs and allow the fuel cell the option of being turned off when the car is decelerating or idling. 


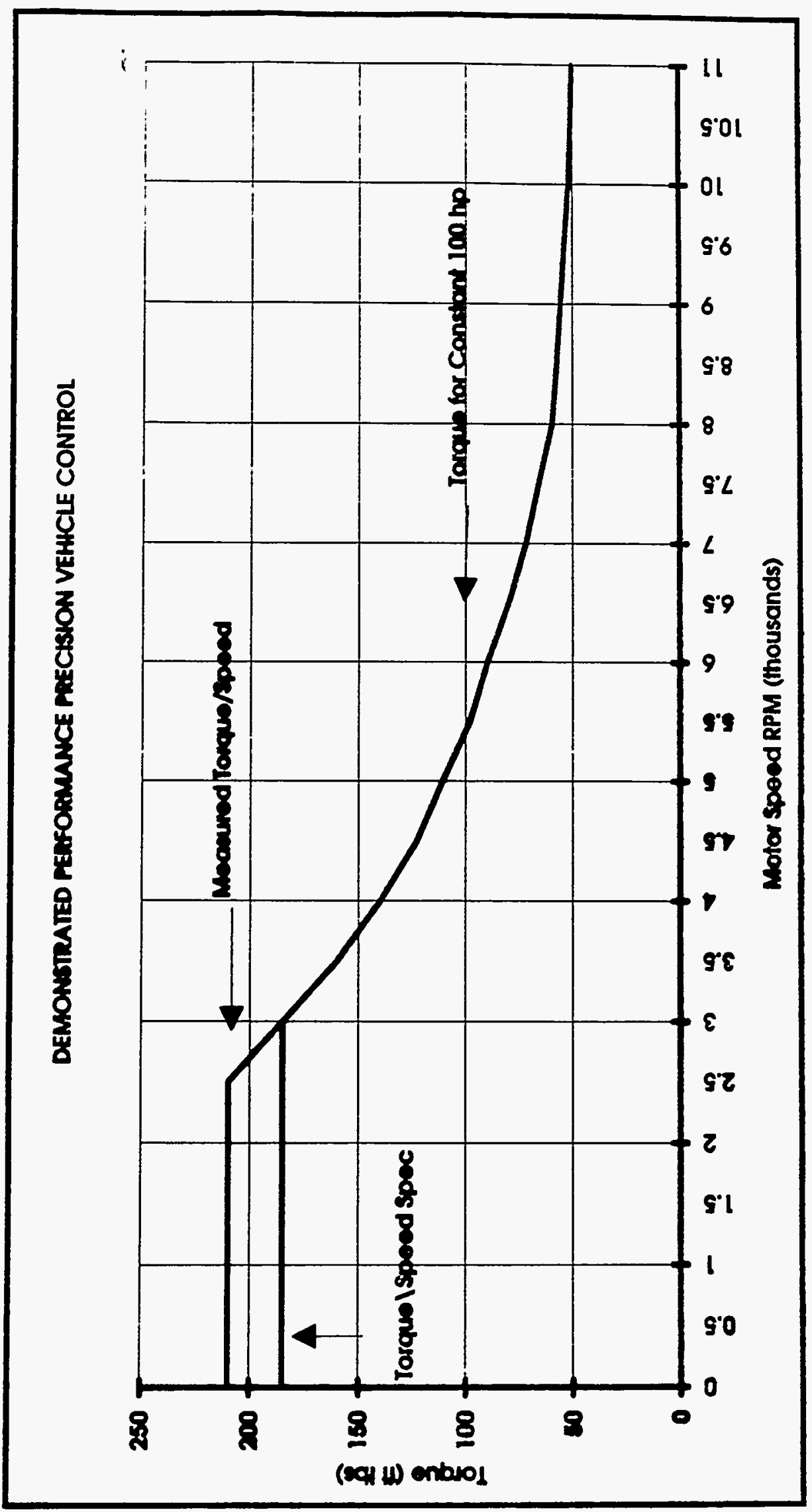

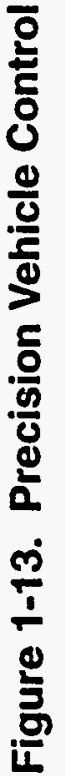




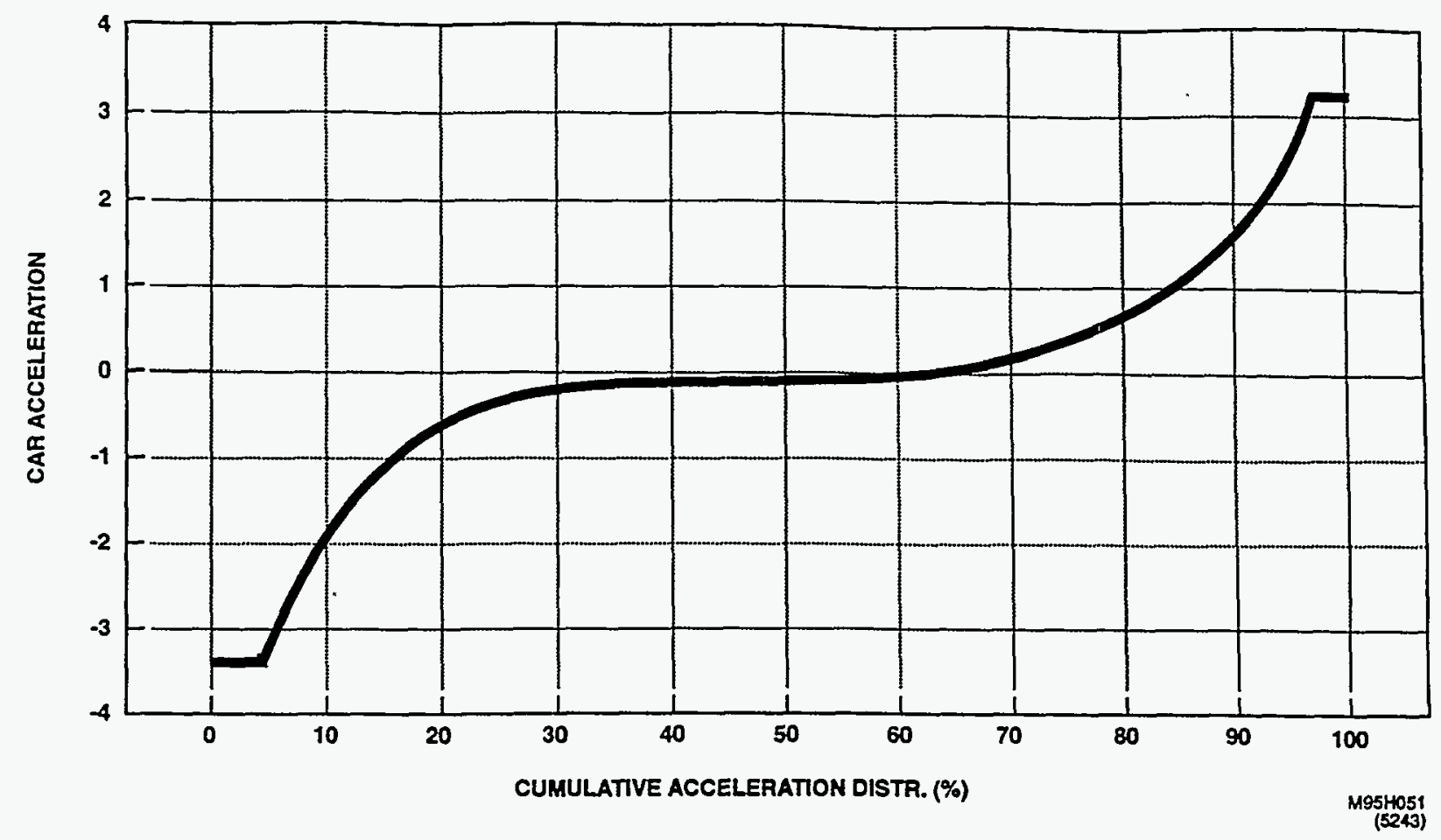

Figure 1-14. Acceleration Histogram (EPA City Driving Cycle)

The need for the powertrain to be operational at key-on is currently a restriction on fuel cells since they might not produce adequate power immediately and will not deliver power at all if the ambient temperature is sufficiently cold. If the fuel cell is not hybridized, the "solutions" to this dilemma may involve burning some hydrogen to heat the fuel cell but this would generate emissions. Alternatively, the fuel cell can be kept warm by feeding hydrogen transiently into it while the car is parked. The generated electricity, however, is wasted since there are no on-board batteries. Any approach will clearly reduce real-world fuel economy since hydrogen is consumed without the vehicle travelling anywhere. If the fuel cell is heated up by an external heating element, fuel must still be consumed somewhere to maintain the fuel cell in a state of operator readiness. Moreover, an external heating element will only work if an electrical supply is at hand so that airport parking may still be a problem. The EPA fuel economy tests do not consider these scenarios but they are important, nonetheless.

\subsubsection{Fuel Cell Power Sizing}

The following two factors were considered in the study to establish fuel cell power sizing.

- Hill Climbing Capability - The fuel cell is sized to give comparable hill-climbing performance with today's $\mathrm{LH}$ while the batteries take care of the supplemental power required for acceleration. The alternative approach of sizing the fuel cell for highway 
cruising and using enough batteries to allow the worst grades to be climbed was not used. The latter approach does allow a downsizing of the fuel cell as a favorable tradeoff for a larger battery in terms of weight, size, and cost and it will also create shallower discharges during startup and acceleration which might extend battery life.

However, it was not chosen because the control issues and drivability/ litigation concerns associated with ensuring that the vehicle never abruptly decelerates during hill climbing, due to the battery power failing, makes the latter approach more risky. Ensuring that the fuel cell will propel the vehicle up any grade so long as fuel is in the tank will also make the vehicle drive more like a conventional car.

- Vehicle Selection - A PNGV LH rather than a $1995 \mathrm{LH}$, was used since the fuel cell vehicle is being designed with PNGV in mind. This factor, as Table 1-1 shows, suggested that a $40 \mathrm{~kW}$ fuel cell system (all power figures quoted refer to net power, not gross) should be adequate to provide a PNGV LH with acceptable performance.

Since the fuel cell will consist of five $10 \mathrm{~kW}$ modules, the peak net power may actually be closer to $44 \mathrm{~kW}$ than $40 \mathrm{~kW}$ and thus will provide a useful margin of safety.

\subsubsection{Electric Motor and Battery Sizing}

The $1995 \mathrm{LH}$, fitted with the 3.3 liter $150 \mathrm{HP}(112 \mathrm{~kW})$ engine, obtains a $0.60 \mathrm{mph}$ time in around 11.1 seconds so that if the PL is 10 percent lighter and more aerodynamic the total power requirements of a conventional LH should be at least 10 percent less, or $100 \mathrm{~kW}$.

However, when determining the required balance between the $40 \mathrm{~kW}$ fuel cell system and the power required to accelerate the vehicle $0-60 \mathrm{mph}$ in 12 seconds, it is very important to consider low-end torque since this also dictates how rapidly an acceleration can occur. Provided there is adequate cooling, certain electric motors (constant torque up to half speed followed by constant power as shown in Figure 1-13) can outperform a conventional mechanical drive system so that an electric powertrain conservatively might only need to deliver $75 \mathrm{~kW}$ to obtain a 0-60 MPH time comparable with a conventional $100 \mathrm{~kW}$ powertrain. Since the drive train is an average of 85 percent efficient during this period, the maximum power output from the electric powertrain has to be approximately $80 \mathrm{~kW}$.

Since it must be assumed, under extreme cold conditions, that the fuel cell might be incapable of supplying power to the vehicle for the first several minutes, maintenance of the performance requirements under these conditions would dictate that the battery be sized for $80 \mathrm{~kW}$. Thus, during typical driving conditions when the fuel cell is operational, the combined power of the battery and fuel cell would be greater than necessary.

In order to be able to accept regenerative braking at all times and yet be able to deliver pulse power for accelerations when required means that the battery State of Charge (SOC) should fluctuate within a narrow band (e.g. 60-90 percent SOC). This means that the battery may need to 
be sized for $3 \mathrm{kWh}$ so that approximately $2 \mathrm{kWh}$, which should be sufficient for startup power and energy requirements, is usable. Worst case startup 0-60 MPH in 12 second accelerations require $0.5 \mathrm{kWh}$. Since further cruising at $60 \mathrm{MPH}$ for two minutes consumes an additional $0.5 \mathrm{kWh}, \mathrm{a}$ usable energy storage of $2 \mathrm{kWh}$ should be sufficient. Note that when the fuel cell can be kept viably in a state of near user readiness, by preventing it from freezing during very cold ambient conditions, less energy storage may be necessary since the cruising power requirements might be met by the fuel cell producing half its rated power after 15 seconds.

In the near term the batteries that can be used will have specific amp-hour capabilities such as $10 \mathrm{Ah}$, so that the difference between, say, a $6 \mathrm{kWh}$ and a $3 \mathrm{kWh}$ battery pack will be a marginal improvement in performance under extreme conditions. This will probably result in an unacceptable tradeoff in terms of doubling the cost, weight, and volume. When all performance requirements are balance against the cost, vehicle weight and system efficiency, the optimum specifications for a LLU should be a $60 \mathrm{~kW}, 3 \mathrm{kWh}$, and $320 \mathrm{VDC}$ system.

\subsubsection{Conclusion}

Hybridization is imperative if the fuel-cell powered vehicle is going to meet cost, weight, and efficiency targets. It will also be essential if the vehicle's drivability and utility is to approximate that of a conventional vehicle in terms of startup and transient response. Table 1-1 provides the vehicle design requirements for each of the vehicles considered in the vehicle selection procedure.

Highly efficient, compact, and inexpensive insulation may be found to mitigate complications caused by cooling in the PEM FCS, but several other problems (e.g. regenerative braking, weight penalty, low power load inefficiency) still remain. There will have to be unforeseen major advances in fuel cells in order for the concept of a dedicated fuel cell to make sense for light-duty vehicle applications. 


\section{SECTION 2 \\ VEHICLE PERFORMANCE REQUIREMENTS}

This section provides a discussion of the analyses which have been performed to determine the response of the Direct Hydrogen Fueled Proton Exchange Membrane Fuel Cell System for a Hybrid Vehicle (DPHV) conceptual vehicle to various driving conditions and vehicle requirements.

\subsection{Driving Cycles}

The various driving cycles which determine the vehicle performance include the acceleration to $60 \mathrm{MPH}$ within 12 seconds, the Baker Grade (vehicle attaining a speed of 55 MPH on a seven percent grade), the Federal Urban Driving Schedule (FUDS) and the HIWAY cycle. The impact of each of these driving cycles on vehicle performance is discussed below.

\subsubsection{Acceleration Cycle}

The definition of the 0 to $60 \mathrm{MPH}$ acceleration within 12 seconds determines the peak power capability requirement for the DPHV system. The manner in which this acceleration is achieved should reflect the vehicle power train response capabilities. Thus the motor and motor controller must have performance characteristics which allow the achievement of the required acceleration with the minimum expenditure of power.

Figure 2-1 provides four different acceleration scenarios which have been analyzed for the DPHV system. The curve labelled as Accel1 corresponds to a two speed transmission acceleration, Accel corresponds to the $60 \mathrm{MPH}$ cycle used in the first analysis using the SIMPLEV simulation code, and Accel2 corresponds to a constant acceleration cycle $\left(7.33 \mathrm{ft} / \mathrm{sec}^{2}\right)$. The curve labelled as AccelL corresponds to the acceleration profile used for modelling the Partnership for a New Generation of Vehicles (PNGV) performance characteristics.

\subsubsection{Baker Grade Cycle}

The Baker Grade cycle provides a scenario in which the vehicle achieves a speed of 55 MPH on a seven percent grade. The vehicle speed and power versus time for this cycle is shown in Figure 2-2. It should be noted that $55 \mathrm{MPH}$ speed is achieved for this cycle in 34 seconds. This is an arbitrary time allocation since the requirement does not specify the time in which the requirement must be met.

\subsubsection{FUDS/LA92 Cycles}

The FUDS cycle, shown in Figure 2-3, represents a nominal driving sequence in a city environment. This cycle has also been modified to represent driving conditions in a city with freeway access represented by the LA92 cycle, shown in Figure 2-4. 


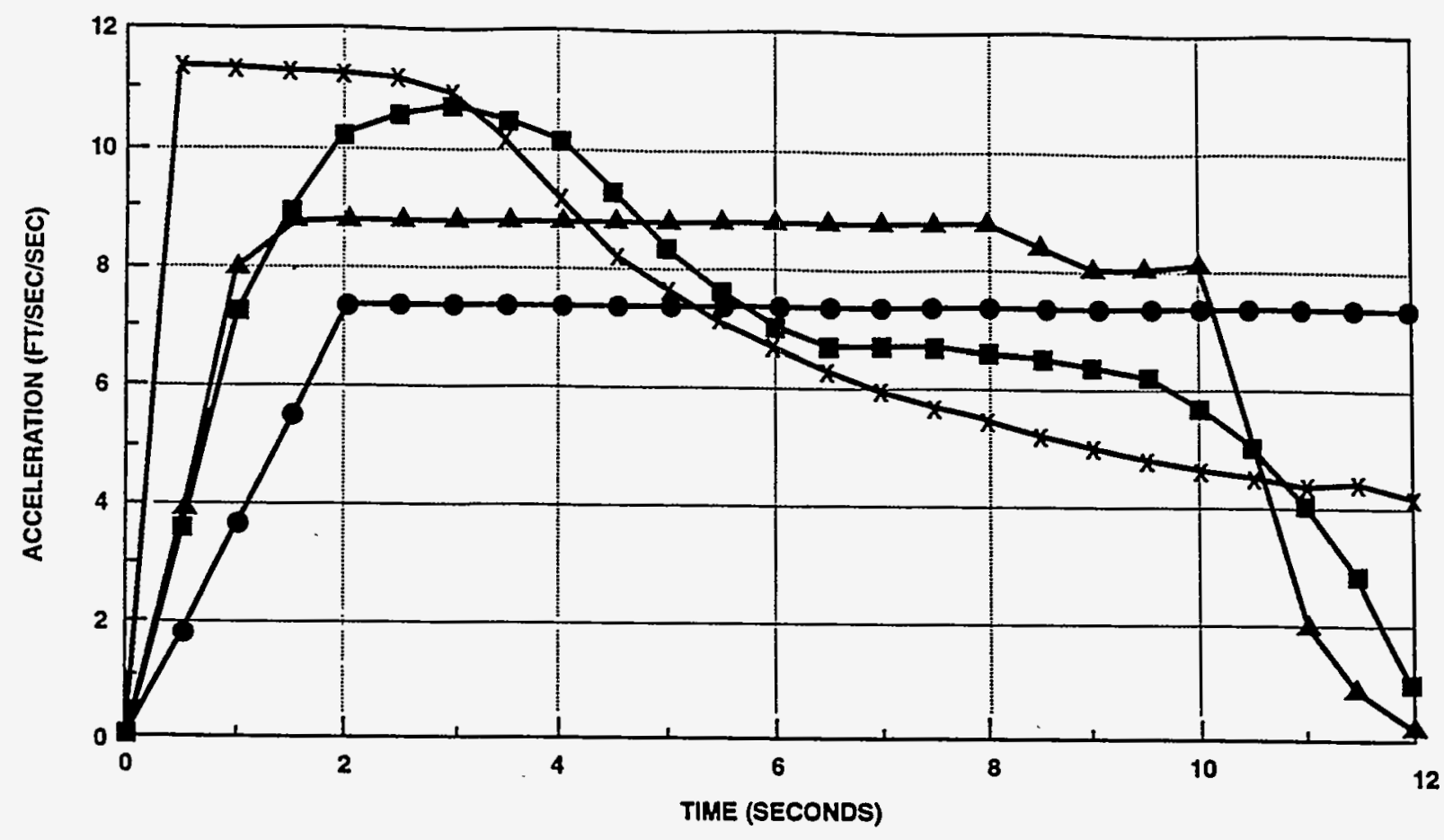

LEGEND:

Accel1 $\rightarrow$ Accol $\rightarrow$ Accol2 - Accoll $\rightarrow-$

Figure 2-1. Alternative Acceleration Profiles

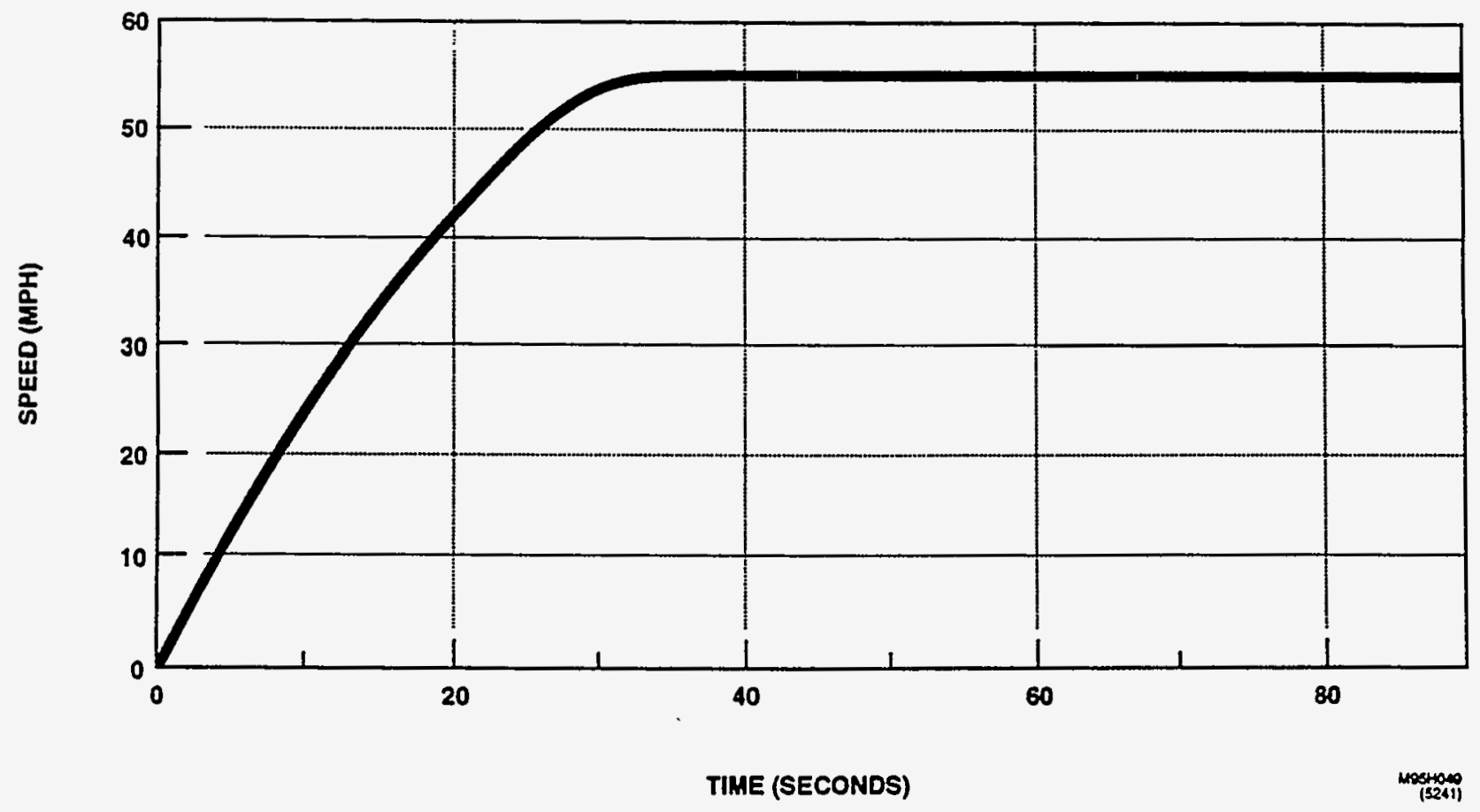

Figure 2-2. Baker Grade Velocity Profile 


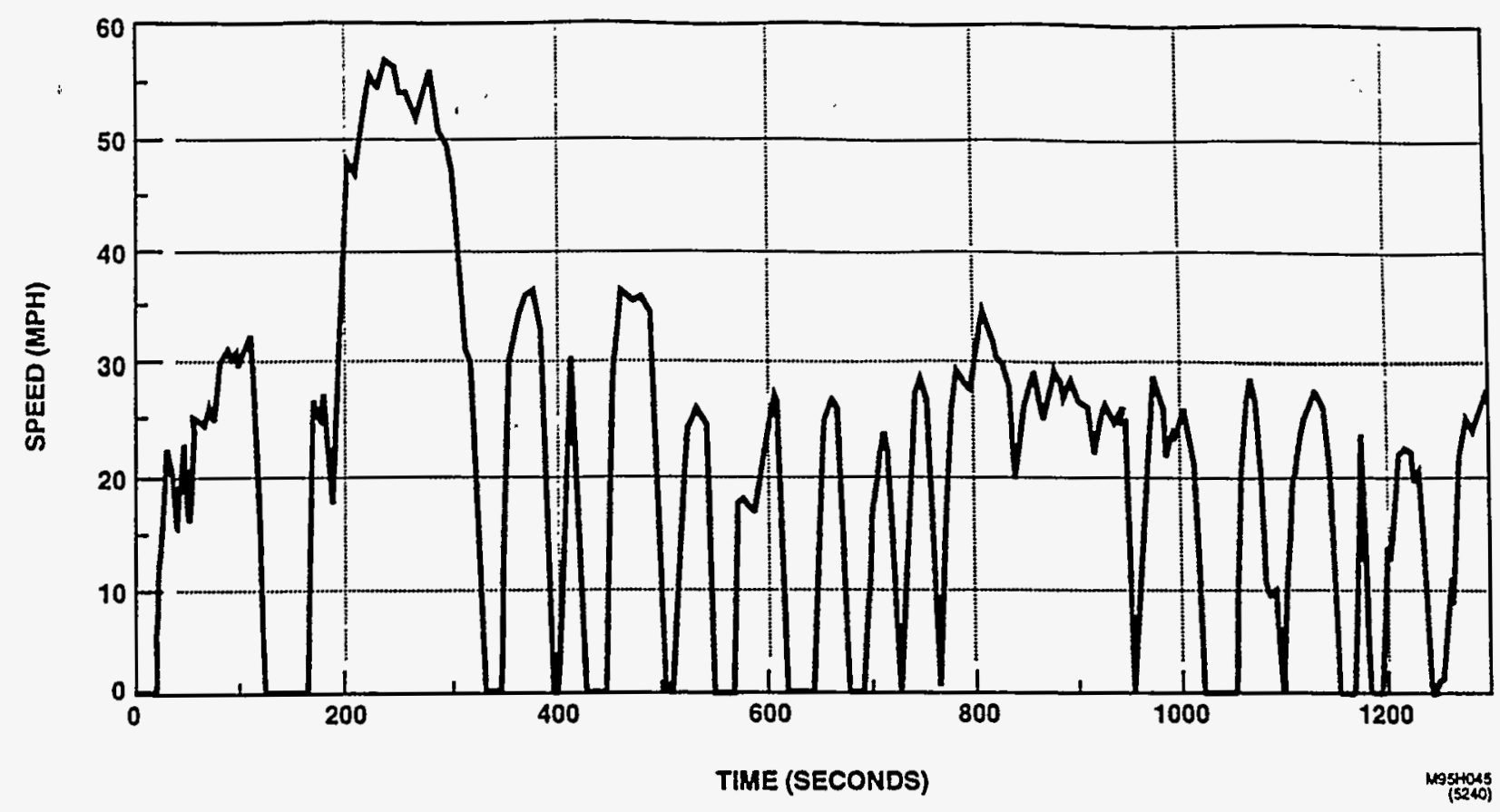

Figure 2-3. FUDS Velocity Profile

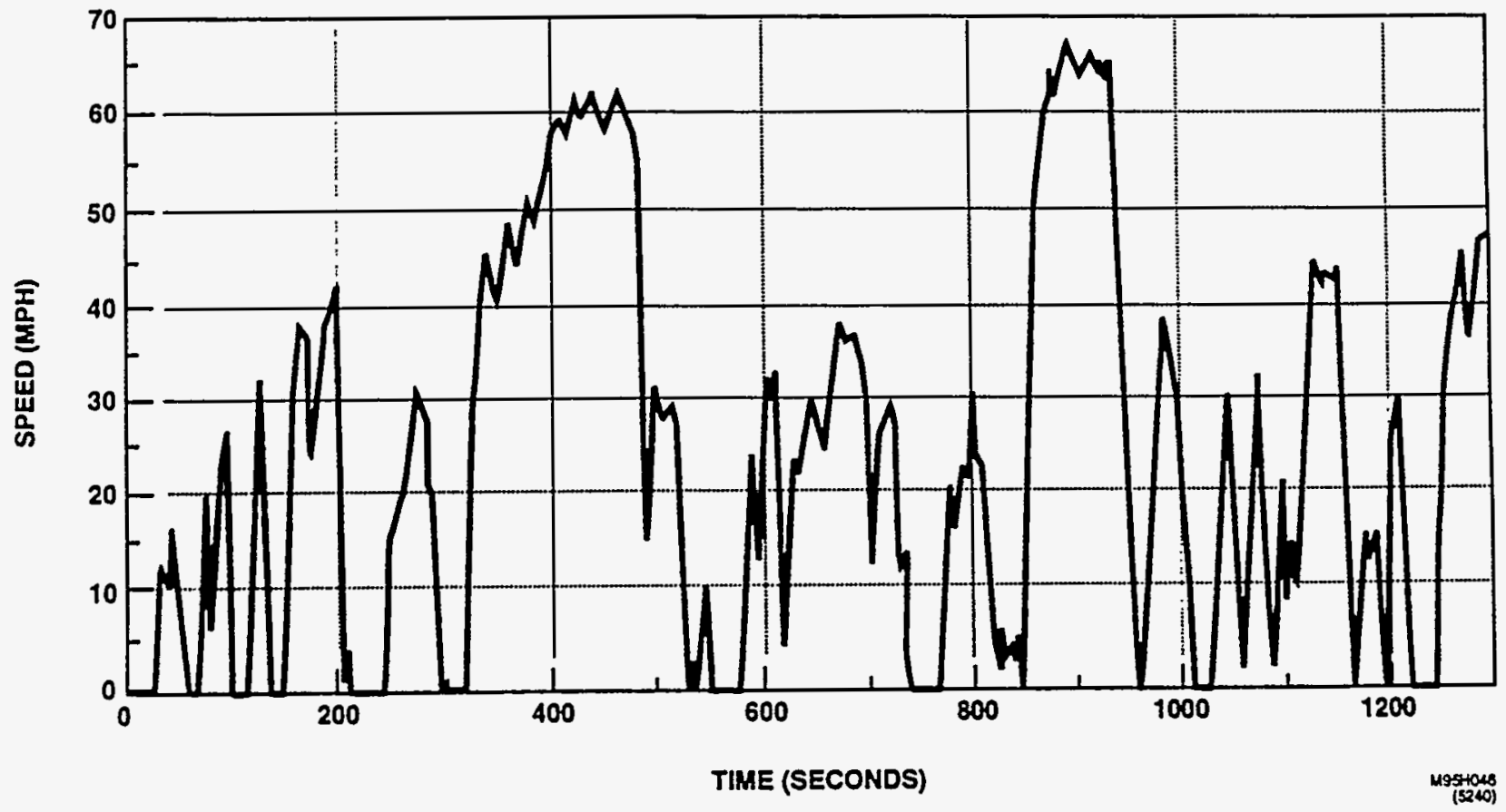

Figure 2-4. LA92 Velocity Profile 


\subsubsection{HIWAY Cycle}

The HIWAY cycle represents a driving environment in which the vehicle travels on freeways with no impediments. This driving cycle requires much less stopping and starting than the FUDS or LA92 driving cycles. Figure $2-5$ provides the velocity profile for the HIWAY cycle.

\subsection{Vehicle Configuration}

As noted in Section 1, the Chrysler LH Sedan has been selected as the target vehicle for the DPHV system. Figure 2 in the Executive Summary section shows the electrical configuration for the DPHV system. The basic system uses the Hydrogen-Powered Fuel Cell Stack (FCS) to provide for steady-state power with a battery-powered Load Leveling Unit (LLU) providing for surge power requirements.

\subsubsection{Vehicle Physical Characteristics}

Upon selection of the PL Sedan as the DPHV vehicle, Chrysler Liberty provided a set of vehicle characteristics, as shown in Table 2-1, to assist the analysis of system requirements. Additional vehicle definition has been provided by Liberty with the selection of the Westinghouse AC 3-phase motor and the identification of the transaxle member with a gear ratio of 9.34 . The initial motor efficiency has been assumed to be 85 percent (less than the stretch goal of 90 percent for the PNGV program). The test weight for the vehicle is 10 percent less than the current Chrysler LH Sedan. The vehicle test weight includes a payload of 350 pounds.

Table 2-1. LH Sedan Test Vehicle Parameters

$\begin{array}{lcc}\quad \text { Parameter } & \text { Units } & \text { Value } \\ \text { Vehicle Test Weight } & \text { Pounds } & 3330 \\ \text { Wheel Radius } & \text { Feet } & 1.07 \\ \text { Frontal Area } & \text { Feet2 } & 23.5 \\ \text { Drag Coefficient (Cd) } & * * * & 0.250 \\ \text { Rolling Resistance Coefficient (Cr) } & * * * & .0064\end{array}$

\subsection{Vehicle Simulation}

The simulation of the DPHV system has been performed using three different techniques. The first technique involved modeling the vehicle using the SIMPLEV simulation code. The second technique involved analysis of the vehicle via analytic techniques while the third method involved the application of the modified Chrysler TEVan simulation code. Each of these techniques are described on the following pages.

\subsubsection{SIMPLEV, Version 3.1, Modeling}

The SIMPLEV simulation code (Version 3.1) has been used to periorm several parametric studies of the vehicle performance under each of the cycles noted in Section 2.1. A vehicle file 


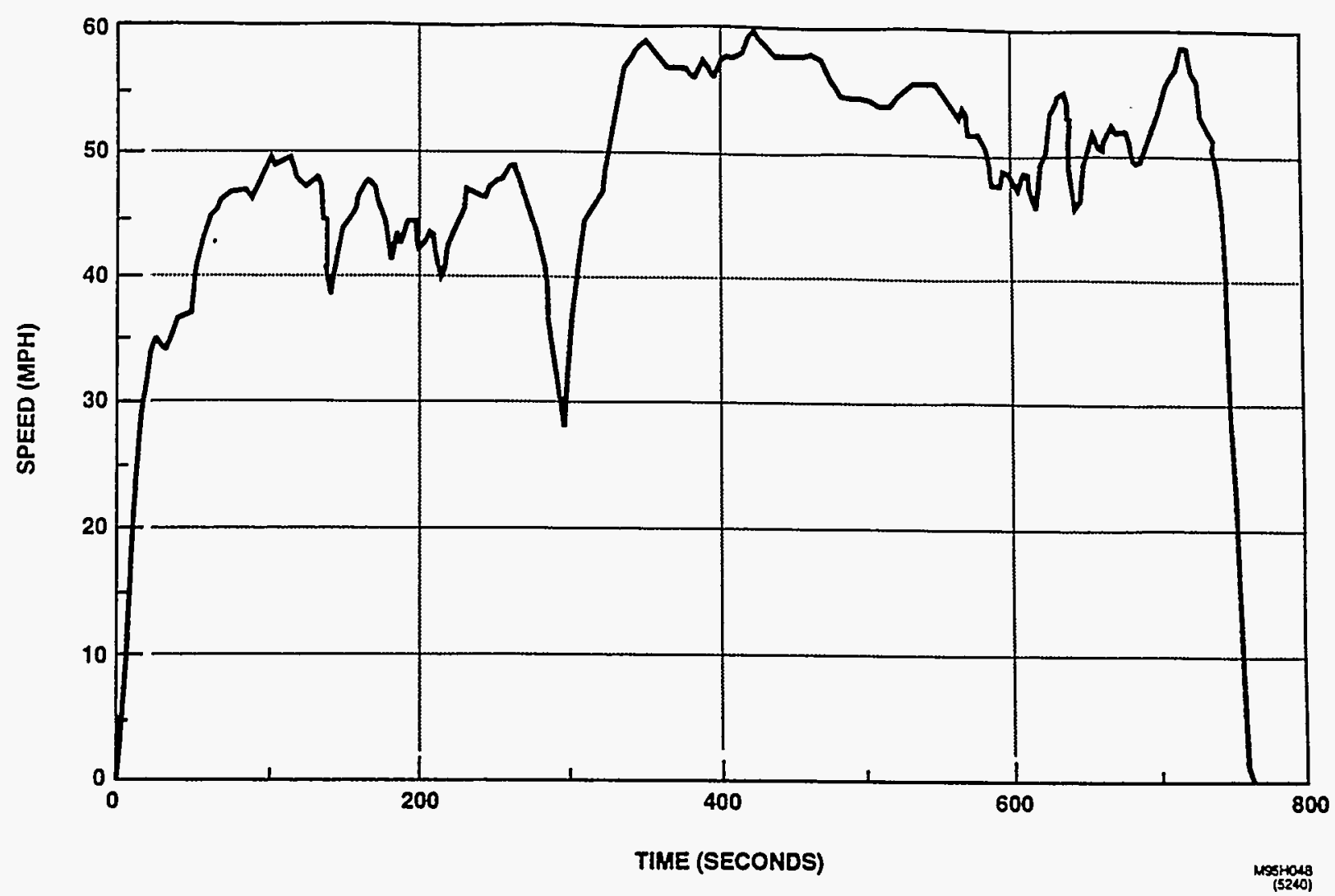

Figure 2-5. HIWAY Velocity Profile

used as input data for the code was created to reflect the vehicle characteristics shown in Table 2-1. The motor file corresponding to a $75 \mathrm{HP}$ motor provided with the simulation package was also modified to reflect the Westinghouse motor as closely as possible.

System power was provided by batteries with an artificial energy content such that any acceleration or speed requirement could be achieved if the motor, transmission, and inverter controller were sufficient for the task. This was done by increasing the charge content of the batteries to 500 Ah and decreasing the output impedance of the battery modules such that the DC power bus will maintain a voltage of 300 VDC. This was done first to determine the vehicle requirements. Later the correct components were modified to determine component performance requirements to achieve the necessary vehicle performance.

\subsubsection{Analytic Modeling}

The power requirements for the system arise from the torque generated on the wheels of the vehicle and the angular velocity of the motor shaft. The torque may be calculated from the force which the wheels must generate against the highway to overcome the areal resistance and 
to achieve the dynamic vehicle performance. Equation 2-1 provides the force balancing equation (the rolling resistance force has not been included in this calculation).

$$
\text { Eq 2-1 Fw }=\text { FArea }+m^{\star} a
$$

where Fw is the force provided by the wheels, FArea represents the wind resistance force, $m$ is the vehicle mass, and $a$ is the dynamic acceleration of the vehicle.

The areal force is given by equation $2-2$.

\section{Eq 2-2 FArea $=K^{*} p^{*} A^{*} v 2$}

where $K$ is a constant, $p$ is the density of air, $A$ is the frontal area and $v$ is the speed of the vehicle.

Since the speed for any time had been defined by the SIMPLEV acceleration cycle, the acceleration was derived from this known speed. As a result, the net force supplied by the wheels was obtained for each speed. The torque supplied to the wheels is then determined by multiplying the wheel force by the radius of the wheel. From this torque and the known transaxle ratio, the torque supplied by the motor is determined (the 85 percent efficiency is taken into account during this calculation).

Once the motor torque is determined, the input power to the motor may be obtained as shown in equation $2-3$.

\section{Eq 2-3 $P=\bullet$}

where $P$ is instantaneous power to the motor, is the torque supplied by the motor, and is the angular speed of the motor.

\subsubsection{CHYHV Modeling}

At the same time that SIMPLEV, Version 3.1, modeling was being conducted, PEI instituted a program to upgrade the simulation code which was in existence at PEI. This program had been used for modeling the Chrysler TeVan and other hybrid vehicles and results from the simulation modeling had been verified by vehicle tests. The upgraded code was labelled, CHYHV, standing for the CHrYsler Hybrid Vehicle simulation code.

One immediate modification of the CHYHV code was to allow the simulation performance to be achieved with an input file defining the vehicle speed versus time (identical to the SIMPLEV cycle definition).

Two simulation runs were performed upon completion of the code modification. The first of these runs directed the vehicle to achieve $60 \mathrm{MPH}$ in the least amount of time possible. The peak power requirement determined from this run was $115 \mathrm{~kW}$. It was noted that the vehicle accelera- 
tion during this simulation was 7.33 feet/sec2 and that the peak power transfer was achieved during the latter stages of the acceleration phase. The second simulation run was performed using the same velocity cycle used in the SIMPLEV run. The result for this simulation run was a peak power transfer of $118 \mathrm{~kW}$. These results compared favorably with those which had been obtained using SIMPLEV.

An analytical exercise was performed next using the SIMPLEV code in which an artificial acceleration cycle (called Accel1) was constructed. This acceleration cycle simulated that which would be expected if a two-speed transmission had been employed. The maximum acceleration was defined to occur within the early phase of the acceleration cycle and a second lower acceleration was sustained until the vehicle reached the $60 \mathrm{MPH}$ speed.

\subsubsection{Simulation Comparisons}

In order to assess the validity of simulation modeling results, a test case was performed using SIMPLEV, CHYHV, and the analytical modeling tool. The test case involved the determination of the peak power and the steady state power requirements for the Baker Grade using the vehicle data provided in Table 2-1. Results for these simulation comparisons are shown in Appendix $E$, Table E-1. Inspection of this data shows that the agreement of results for all three methods is quite good.

\subsection{Baseline Performance}

Once the validity of the simulation modeling had been verified, the simulation of the DPHV system was analyzed using both the CHYHV and analytical model. The CHYHV code modifications included the ability to model the FCS performance using a look-up table for power, efficiency, current and stack voltage provided by AlliedSignal from test data on their 5-cell stacks. Results for each of the cycles described in Section 2.1 were obtained from these system simulations and are discussed below.

\subsubsection{Acceleration Performance}

The calculations were performed for each of the acceleration cycles shown in Figure 2-1. The results for the AccelL and the Accel2 acceleration profiles are shown in Appendix E, Table E-2. There are no regenerative braking effects occurring during this cycle. The acceleration curve for the Accell cycle duplicates that which one would expect to occur for the Westinghouse motor performance in an acceleration phase. The consistency of results between the analytical calculation and those from the CHYHV simulation gives further confidence in the results which have been obtained.

In order to achieve the desired performance of the DPHV vehicle under less than optimal conditions, the higher peak power result determined from the Accel2 profile (rounded to the nearest decade) has been selected as the limiting peak power requirement for the system. Thus the system peak power requirement has been determined to be $100 \mathrm{~kW}$. 


\subsubsection{Baker Grade Performance}

The analysis for the Baker Grade cycle proceeded in the same manner as for the acceleration cycles. CHYHV was used to determine the vehicle peak and average power requirements. The cycle for determining the Baker Grade response requires approximately 34 seconds to achieve the speed of $55 \mathrm{MPH}$ when on a seven percent grade. Results are shown in Appendix E, Table E-3.

The steady state power result validates the decision to specify the FCS power requirement at $40 \mathrm{~kW}$. The LLU surge power only needs to be supplied during the acceleration phase of the cycle.

\subsubsection{FUDS, LA92 Performance}

The FUDS and the LA92 Driving Cycle simulations were performed with the CHYHV simulation code using the same vehicle configurations as the acceleration and Baker Grade cycles. Results of these simulations are shown in Appendix E, Table E-4.

After the system power requirements for the FUDS and LA92 cycles had been determined, the CHYHV simulation was performed with the FCS used as the steady state power source and the LLU used to provide surge power. This data will be discussed in Section 2.4.5.

\subsubsection{HIWAY Performance}

The HIWAY Cycle was performed with the CHYHV simulation code using the same vehicle configurations as the acceleration, Baker Grade, FUDS, and LA92 cycles. Results are shown in Appendix E, Table E-5.

\subsubsection{Combined City/HIWAY Performance}

Both FUDS and HIWAY cycles were simulated with the FCS providing steady state power and the LLU providing surge power requirements. These simulations were performed for the cases involving regenerative braking on and off. Results of these simulations are shown in Table 2-2. These results were obtained using the CHYHV simulation code.

Table 2-2. City/HIWAY Cycle System Response

$\begin{array}{lcccc}\text { Cycle } & \begin{array}{c}\text { Regen } \\ \text { Status }\end{array} & \begin{array}{c}\text { Peak Stack } \\ \text { Power }(\mathbf{k W})\end{array} & \begin{array}{c}\text { Distance } \\ \text { Covered (Mi) }\end{array} & \begin{array}{c}\text { Hydrogen Usage } \\ \text { (Mi/gal gas equivalent) }\end{array} \\ \text { FUDS } & \text { Off } & 13.53 & 9.59 & 55.8 \\ \text { FUDS } & \text { On } & 11.57 & 9.59 & 61.6 \\ \text { HIWAY } & \text { Off } & 11.66 & 10.26 & 91.2 \\ \text { HIWAY } & \text { On } & 11.61 & 10.26 & 94.7\end{array}$


The mileage for the vehicle is determined by the harmonic average of the mileage for the FUDS and HIWAY cycle as shown in equation 2-4. The range for the vehicle is based on the useable quantity of hydrogen contained within the hydrogen storage tanks, 12 pounds. Results for the combined mileage and the total range are shown in Table 2-3.

$$
\text { Eq } 2.4 \quad M=1 /(.55 / M f+.45 / M h)
$$

where Mf represents the FUDS mileage, Mh the HIWAY mileage, and $\mathrm{M}$ the system mileage

Table 2-3. DPHV Combined Mileage and Range Results

\section{Combined Mileage \\ Regen Status}

On

Off
Total Range

(mpg Gasoline Equivalent)

73.1

67.6
(Mi)

348

321

\subsection{Conclusions}

The DPHV system has been modeled using three different simulation techniques for those cycles which determine the system performance requirements. The peak power capability for the system is determined by the acceleration to $60 \mathrm{MPH}$ within 12 seconds. For the LH Sedan this peak power requirement has been set at $100 \mathrm{~kW}$. The steady state maximum power requirement for the system is set by the Baker Grade simulation and has been determined to be $40 \mathrm{~kW}$. This value determines the peak power (net) requirement for the hydrogen-powered FCS. The simulation of the FUDS and HIWAY driving cycles determines the range of the vehicle. This simulation has determined that the system will be capable of achieving a 380 mile range with a 12 pound weight of useable hydrogen when a regenerative braking capability exists. 



\section{SECTION 3}

\section{PEM FUEL CELL SUBSYSTEM}

\subsection{Vehicular PEM Fuel Cells}

\subsubsection{Fuel Cells for Vehicular Power Production}

The electrochemical engine, operating on a Proton Exchange Membrane (PEM) fuel cell stored hydrogen system, has the ability to provide clean and portable power in a safe and reliable manner. Electric vehicles offer a way of meeting zero-emission goals in vehicles powered by either batteries or hydrogen-powered fuel cells. Battery power systems based on current state-ofthe-art technology are expensive, heavy, and allow only limited driving ranges. PEM fuel cells, enhanced by recent developments in membranes, electrodes, and bipolar plates, have exhibited the potential for low cost and for driving ranges comparable to those of current internal Combustion Engine (ICE)-powered vehicles. The PEM fuel cell being developed at AlliedSignal is based on a low material and manufacturing cost approach that targets the automotive market.

\subsubsection{Goals for Vehicular Fuel Cells}

Using commercially available membranes, electrodes, and bipolar plates, PEM fuel cells are typically regarded as producing high power. Existing fuel cell stacks, however, are not commercially viable for automotive transportation applications based on their high cost, heavy weight, and large volume. The PEM fuel cell subsystem concept developed at AlliedSignal constitutes a viable power source for automotive transportation applications on both technical and economic bases.

Table 3-1. PEM FCS Design Goals

\section{Topic}

Cell Voltage ( VDC) at Peak Power

Cell Current (Amperes/cm²) at Peak Power

Specific Power Density (k W/kg)

Volumetric Power Density (kW/l)

Pt Loading ( $\left.\mathrm{mg} / \mathrm{cm}^{2}\right)$

FCS Target Cost (\$/kW)

GMS Target Cost ( $\$ / \mathrm{kW})$

\section{Goal}

0.5

1.0

1.1

1.0

0.25

20

10

Advanced lightweight, high-performance materials are used for key fuel cell stack components - membranes, electrodes, and bipolar plates. These materials are conducive to low-cost, high-speed manufacturing methods. Based on passenger vehicle weight and volume constraints, AlliedSignal has established specific and volumetric power density goals of $1.1 \mathrm{~kW} / \mathrm{kg}$ and $1 \mathrm{~kW} /$ liter, respectively. The development of electrodes with Pt loading of less than $0.25 \mathrm{mg} / \mathrm{cm}^{2} / \mathrm{elec}$ trode is essential to achieving these power density goals at low cost. Target costs for the Subsystem are $\$ 20 / \mathrm{kW}$ for the fuel cell stack and $\$ 10 / \mathrm{kW}$ for the gas management assembly. These 
goals are in accordance with those set forth by the PNGV. Table 3-1 provides a summary view of the PEM FCS design goals.

\subsubsection{Fuel Cell Stack Design to Cost}

AlliedSignal has implemented a Design-To-Cost (DTC) plan for the direct-hydrogen-fueled PEM fuel cell development program to ensure that the system remains economically and technically viable for commercialization. The objective of the plan is to achieve established DTC target cost by treating cost equal in importance to technical and schedule requirements. The DTC approach analyzes what an item or part does relative to what it costs to perform the function. The Functional Analysis System Technique (FAST) is used to visually illustrate the relationship among the different subfunctions to accomplish the overall function. Costs are then allocated to each of these subfunctions and evaluated according to the contribution of each to the accomplishment of the overall function. Design For Manufacturing and Assembly (DFMA) and Integrated Product Development System (IPDS) principles are also applied to control cost. The cost reduction program for the fuel cell subsystem includes: use of existing vehicle parts, evaluation of alternative bipolar plate materials, evaluation of materials and alternative manufacturing processes for the Membrane and Electrode Assembly (MEA) and the canister, and simplification of the GMS.

\subsection{PEM Fuel Cell Conceptual Design}

\subsubsection{Basic Operation of the PEM Fuel Cell}

The basic characteristics of the PEM fuel cell are illustrated in Figure 3-1. Hydrogen gas is oxidized on the anode side to produce $\mathrm{H}+$ ions, which migrate from anode to cathode where liquid water is produced in the reduction of oxygen gas. The overall cell reaction produces electricity and water as its only by-product. Waste heat is produced in the stack as the electrochemical reaction is not 100 percent efficient. Water condensation in the Fuel Cell Stack (FCS) also contributes to the generation of excess heat. With current state-of-the-art technology, adequate operating conditions of the PEM fuel cell for transportation applications were determined to be 2 atmospheres absolute pressure at a temperature of $80^{\circ} \mathrm{C}$. In addition, the electrochemical reaction is enhanced by the humidification of the anode and cathode feed streams. As a result, conditioning of the gases entering the FCS is necessary and includes pressurizing the air stream to approximately 2 atmospheres (atm) and humidifying both the hydrogen and air streams to $85^{\circ} \mathrm{C}$ and $75^{\circ} \mathrm{C}$, respectively.

\subsubsection{Membranes}

Achieving high power densities in the PEM fuel cell requires the membrane to hold the following properties: high proton conductivity, low ohmic resistance, chemical and electrochemical stability, low oxygen and hydrogen permeability, and high mechanical strength. Commercially available membranes were originally developed for use in the chlor-alkali industry, but have since found application as a fuel cell separator because of their ability to conduct protons. Because these membranes were not specifically designed for use in the PEM fuel cell, they have several 


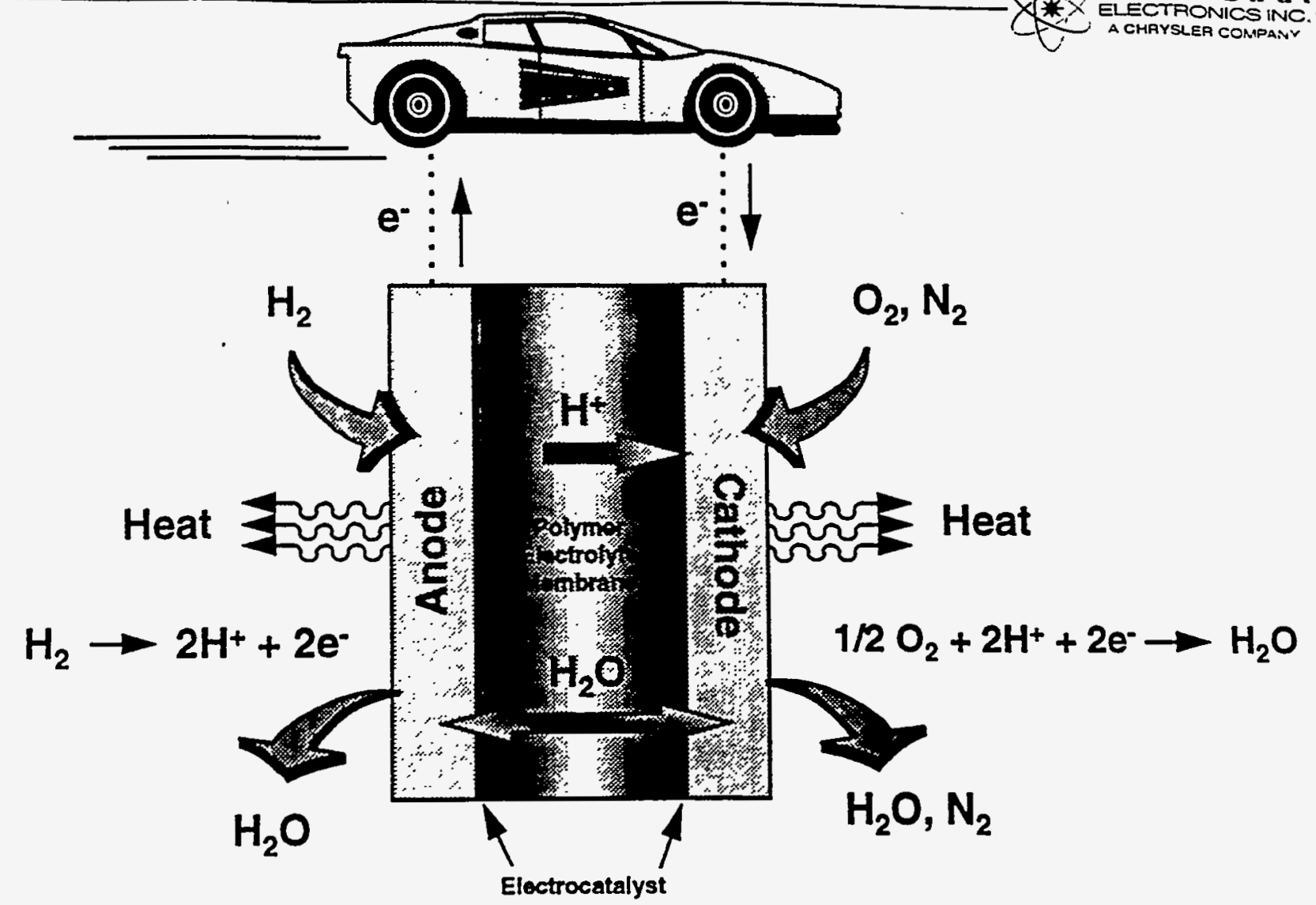

Figure 3-1. Basic Operation of the Vehicular PEM Fuel Cell

shortcomings which limit its potential. The high cost of the membranes, high dependence on water for proton conduction, and the relatively narrow operating temperature range, are just a few of the deficiencies affecting the technical and economic viability of the PEM fuel cell. Efforts at AlliedSignal are focusing on the development of a new generation of membranes specifically geared toward meeting the requirements of automotive applications.

\subsubsection{Electrodes}

Essential to developing low-cost, high power density FCSs is achieving low platinum loadings in the electrodes. Electrodes developed at AlliedSignal have achieved loadings as low as $0.35 \mathrm{mg} / \mathrm{cm} 2 / \mathrm{cell}$, which is comparable to commercially available fuel cell electrodes. Further electrode development is minimizing the number of electrode constituents and improving electrode morphology, while still maintaining satisfactory fuel cell performance. In addition, inexpensive methods for fabricating MEAs are being explored. Working with AlliedSignal Automotive, an inexpensive manufacturing method was developed allowing large, active area MEAs of high quality to be produced in a manufacturing cell environment. 


\subsubsection{Bipolar Plates}

Light weight, low volume, and low cost, as well as easy fabrication through mass production techniques, are important considerations in the development of innovative bipolar plate materials and flow field designs. Graphite has traditionally been the predominant bipolar plate material for PEM fuel cells because of its high conductivity, high strength, and immunity to corrosion. However, it is heavy (due to the required thickness) and expensive, and is not conducive to low-cost, high-speed manufacturing methods. Alternative materials, such as coated metals and conductive polymers, are thinner, lighter, inexpensive, and exhibit the requisite material properties. In addition, their physical structure greatly enhances the simple and inexpensive formation of flow fields. Development of thin, light-weight bipolar plates and compact FCS design packaging has allowed the AlliedSignal FCS to approach the $1.1 \mathrm{~kW} / \mathrm{kg}$ and $1.0 \mathrm{~kW} / \mathrm{liter}$ design goals.

\subsubsection{Fuel Cell Stack Design}

The PEM fuel cell system developed at AlliedSignal employs a modular concept. A set of identical modules connected in series provide the necessary power to the vehicle. Parallel arrangement of modules is also possible; however, the resulting fuel cell system weight, volume, and cost would be higher than if connected in a series arrangement. Voltage requirements of the electric motor govern the operating voltage of the fuel cell system, which is dependent on the total number of cells in the system. The available power for the vehicle is governed by the active area of each cell. As a result of this interaction between voltage and active area, the size and number of modules used depends on the power and voltage requirements of the vehicle. Additional constraints, such as the allowable installation envelope on the vehicle and the cost of each module, also influence the modular design.

Using projected cost targets for the fuel cell components, a study of the trade-offs between fuel cell material costs and stack voltage was conducted. The study focused on the power requirements of the Chrysler LH sedan ( $40 \mathrm{kw}$ usable power for the vehicle). Five 10-kw modules are envisioned for this vehicle; the additional $10 \mathrm{kw}$ are used to power the fuel cell gas management ancillaries and allow for up to $50 \mathrm{mv}$ of degradation per cell in fuel cell performance. The results of the study indicate that a negligible cost difference exists between a fuel cell module designed to a large active area and a low voltage, and that designed to a small active area with a large voltage. In order to package the fuel cell modules in the tunnel of the Chrysler LH sedan, the outer diameter of the stack modules has to be less than $20.5 \mathrm{~cm}$ ( 8 inches). Table $3-2$ shows the design goals for a $50 \mathrm{~kW}$ stack. 
Table 3-2. Mass and Volume Projections for $50 \mathrm{~kW}$ PEM Fuel Cell Stack

$\begin{array}{cccccc}\begin{array}{c}\text { Stack Voltage } \\ \text { (VDC) }\end{array} & \begin{array}{c}\text { Number of } \\ \text { Cells }\end{array} & \begin{array}{c}\text { Active } \\ \text { Area, cm } \mathbf{c m}\end{array} & \begin{array}{c}\text { Module } \\ \text { Weight, } \mathbf{k g}\end{array} & \begin{array}{c}\text { Module } \\ \text { lenght, cm }\end{array} & \begin{array}{c}\text { Module } \\ \text { Diam., cm }\end{array} \\ 200 & 400 & 248 & 7.76 & 21.2 & 22.9 \\ 220 & 440 & 225 & 7.92 & 23.2 & 22.0 \\ 240 & 480 & 207 & 8.10 & 25.2 & 21.2 \\ 260 & 520 & 191 & 8.26 & 27.2 & 20.5 \\ 280 & 560 & 177 & 8.42 & 29.3 & 19.9 \\ 300 & 600 & 165 & 8.58 & 31.2 & 19.3 \\ 320 & 640 & 155 & 8.72 & 33.1 & 18.8\end{array}$

\subsection{Fuel Cell Subsystem Conceptual Design}

The complete PEM fuel cell electrochemical engine incorporates gas management and controller assemblies. Overall fuel cell performance is dependent upon proper conditioning of the reactant gases and strict control of the operating conditions. In addition, adequate processing of the fuel cell product streams is required in order to recover products, unused reactants, and energy of the streams. Rigorous steady-state and dynamic models of the PEM fuel cell subsystem were developed to determine the required components and evaluate alternative configurations and operating points. A trade study of several designs resulted in a subsystem concept which minimizes the overall number of components and optimizes heat and water management at the system level. A flow diagram of the optimal subsystem configuration is shown in Figure 3-2. The subsystem integrates the PEM FCS and Gas Management System (GMS) auxiliaries which include a turbocompressor assembly for pressurization and energy recovery, a closed coolant loop for stack heat removal, and subsystem controls for heat and water management as well as power control. A mock-up of the AlliedSignal Automotive PEM fuel cell power plant concept was fabricated to highlight overall subsystem design requirements (Figure 3-3).

\subsubsection{Turbomachinery}

Rigorous steady-state modeling of the PEM fuel cell subsystem indicates that adequate performance for automotive transportation applications is achieved at approximately 2 atm absolute pressure. A significant fraction of the compression work is supplied through expansion of the exhaust stream from the cathode. A study was conducted on the various types of air compressors that could be used to supply air to the fuel cell stack. Several types of air moving devices were compared in terms of their advantages and disadvantages as applied to the PEM fuel cell. The study concluded that an electric motor-driven, high-speed dynamic compressor with bootstrap expansion turbine running on air bearings would be the smallest and lightest solution. In volume production, this compressor offers the lowest unit cost. The main disadvantage of dynamic compressor concepts is their limited flow range at constant pressure ratios, which severely penalizes fuel cell subsystem efficiencies at the very low power levels. Alternative configurations which would offer a wider operating flow range are also under consideration. 


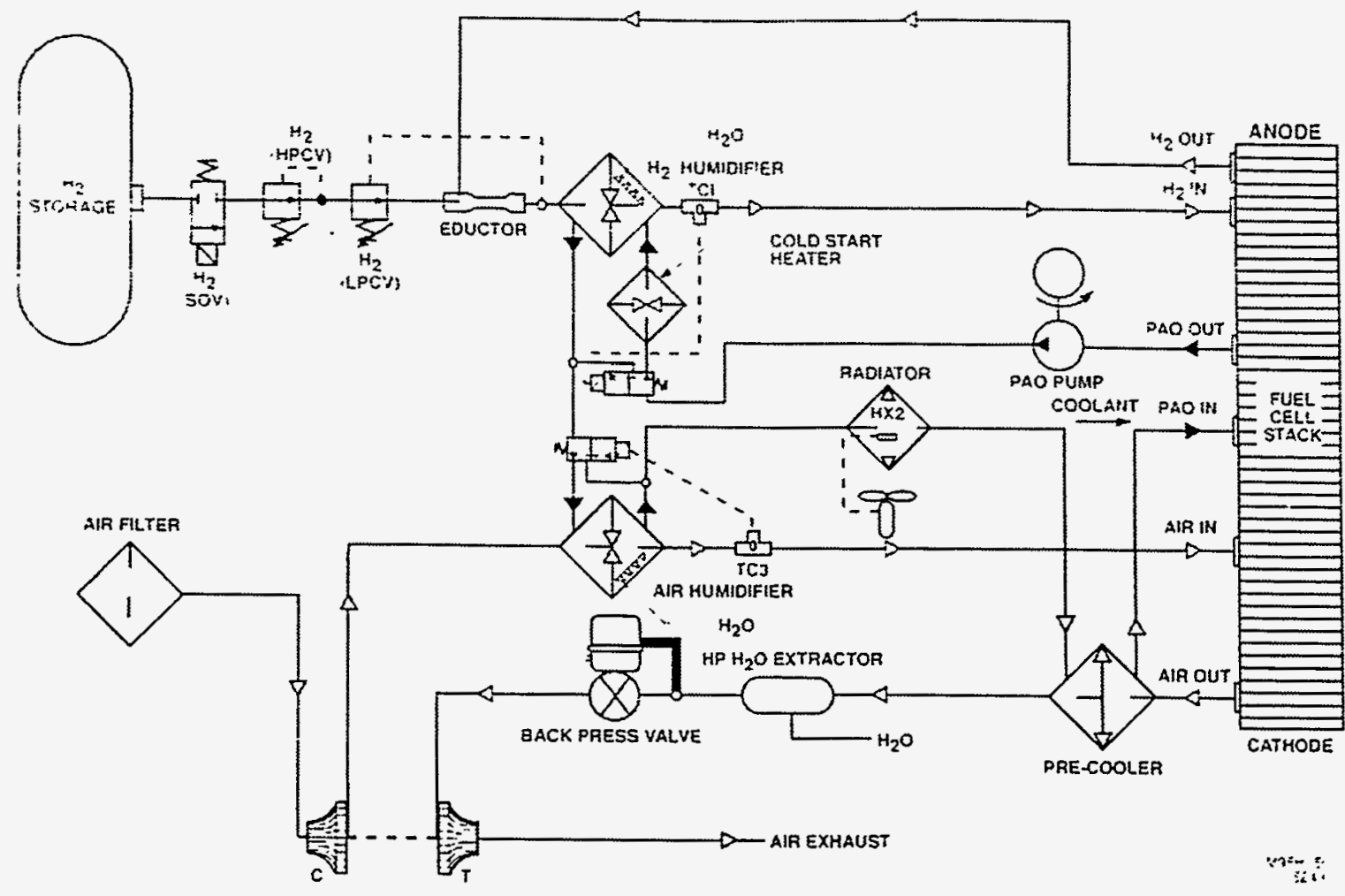

Figure 3-2. Optimal PEM Fuel Cell Subsystem Configuration

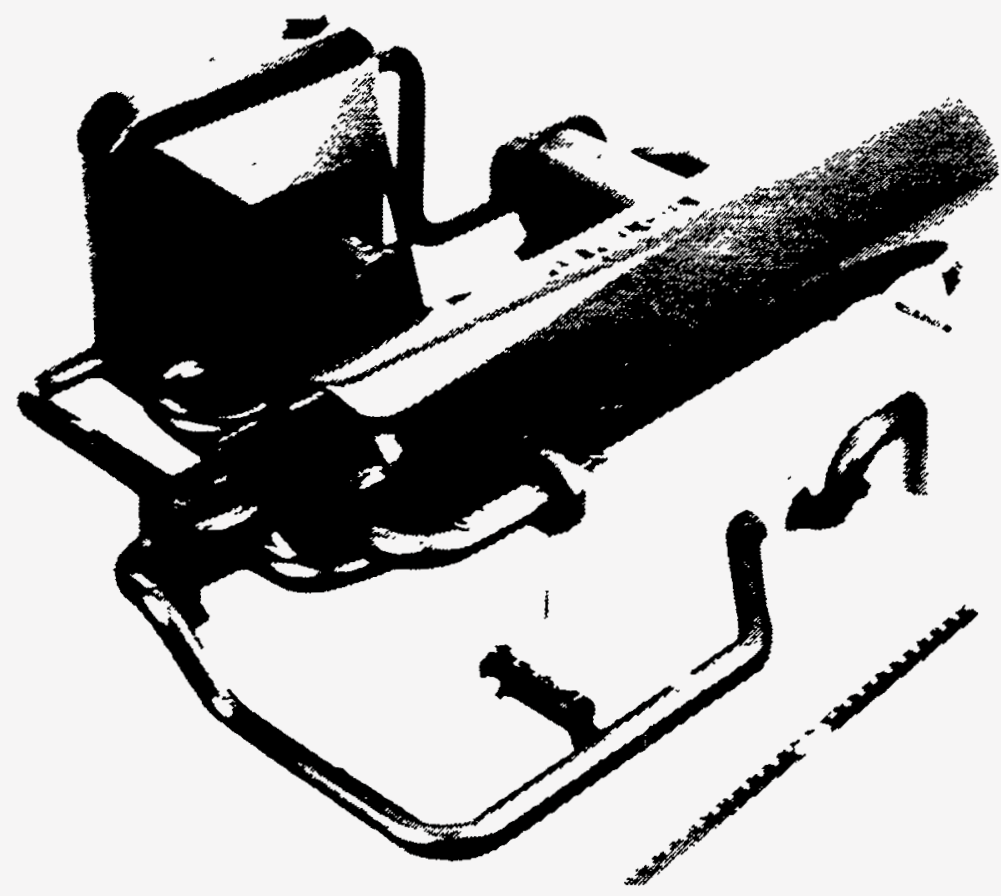

Figure 3-3. AlliedSignal Automotive PEM Fuel Cell Power Plant Concept 


\subsubsection{Heat and Water Management}

Due to thermodynamic inefficiencies, a significant amount of waste heat is generated in the FCS. Heat removal in the fuel cell subsystem is achieved through the closed coolant loop highlighted in Figure 3-4. Requisite coolant properties are: high dielectric strength and specific heat, good thermal conductivity, and low corrosiveness. Coolant exiting the fuel cell stack at $90^{\circ} \mathrm{C}$ initially passes through a hydrogen heater/humidifier, where dry hydrogen is heated to $85^{\circ} \mathrm{C}$ and brought to 100 percent relative humidity using an ultrasonic atomizer. The coolant then passes through the air heater/humidifier, where dry air is saturated to $75^{\circ} \mathrm{C}$. Additional heat removal from the coolant stream is achieved with a radiator. When the FCS is operating at its rated power, all of the coolant passes through the radiator since maximum heat rejection is required to dissipate the heat generated in the FCS. A three-way valve is used to partly bypass the radiator at off-peak power levels. An electric heater is used for cold start-up of the FCS.

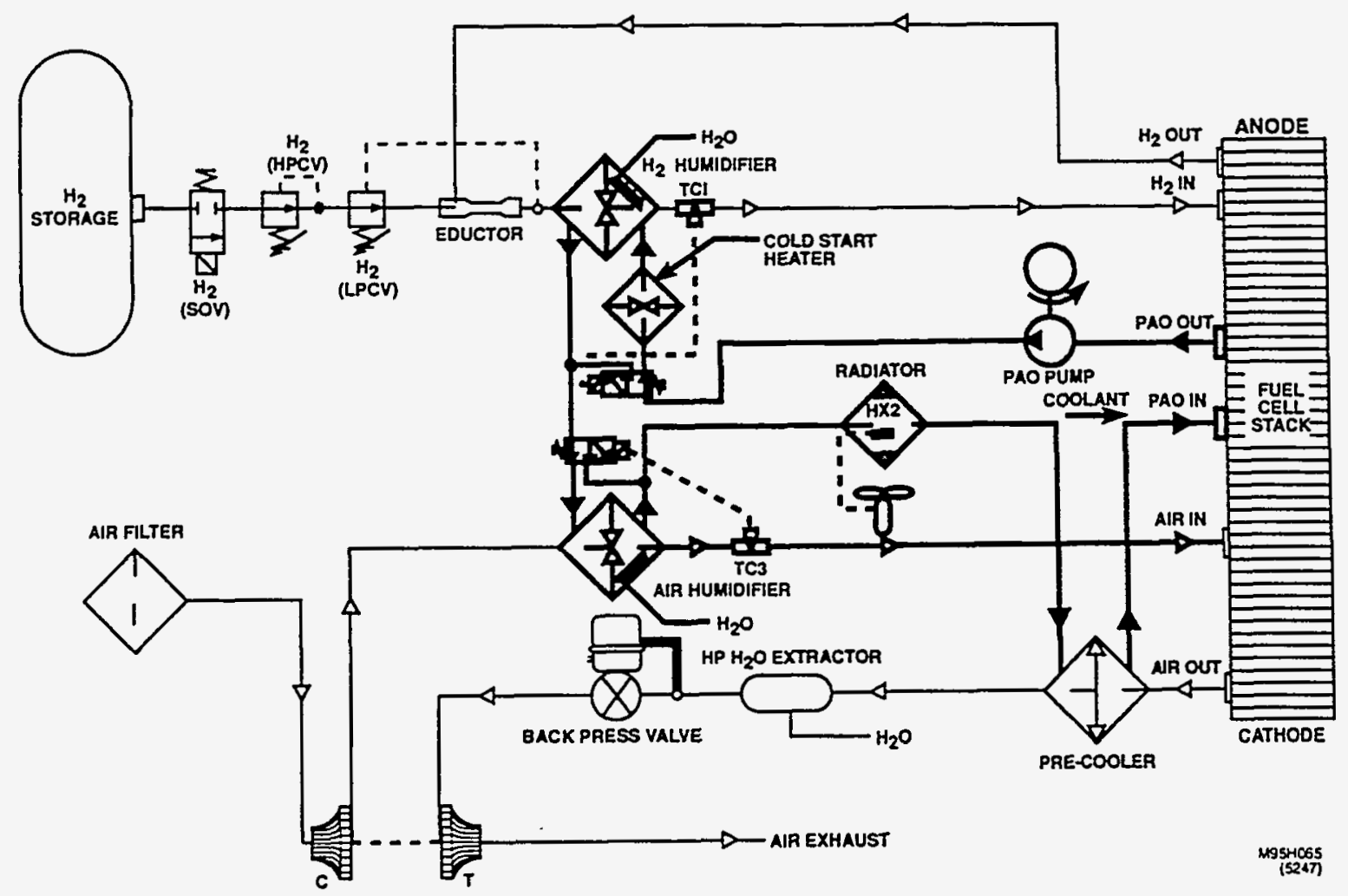

Figure 3-4. PEM Fuel Cell Subsystem Cooling Scheme 
Water condensed in the FCS is used in the humidification of the hydrogen and air streams entering the FCS. Cold turbine exhaust (Figure 3-4) passes through a pre-cooler to condense water from the cathode exhaust gas stream. The water is removed in a high pressure water extractor and used in the humidification process. The super-saturated anode exhaust stream is recirculated back to the hydrogen heater/humidifier inlet using a jet-pump eductor. Achievement of water balance in the fuel cell subsystem depends mostly on the operating pressure and air flow rate.

Efforts are currently focused on reducing both the energy and water requirements of the humidification process. Innovative humidification methods are being considered as viable substitutes for external gas humidification. In addition, technological advances in membrane properties, electrode morphology, and MEA fabrication will allow for lower operating pressures, therefore eliminating the need for a turbocompressor.

\subsection{Performance Characteristics}

Mathematical modeling of the fuel cell subsystem has been performed on several levels. The FCS performance model is an empirical model which uses the Tafel approximation to predict stack performance as a function of pressure, temperature, and gas mole fractions. A FCS design model was developed to predict the size, weight, and cost of the FCS for various geometries, component materials, power levels, and voltages.

At the subsystem level, an ASPEN Plus steady-state model provided preliminary estimates of subsystem performance, which was used in the development of a rigorous Fortran steady-state subsystem model. The Fortran model incorporates rigorous designs of the components shown in Figure 3-2 and uses the FCS performance model as a subroutine. It predicts overall subsystem performance (subsystem efficiency, parasitic power loads, flow rates, pressures, and temperatures of all streams). In addition, a dynamic model was developed to identify subsystem transients and to develop a procedure for start-up sequencing, idling, power load changes, and shutdown.

Water management at the fuel cell subsystem level constitutes a major issue in determining adequate operating conditions. Air stoichiometry and operating pressure need to be properly balanced in order to achieve water balance. Overall water balance in the FCS Subsystem is governed by the amount of water produced in the FCS and the requirements of the hydrogen and air humidifiers. Higher air flowrates and adequate humidification of both hydrogen and air feed streams enhance PEM fuel cell performance. In addition, power requirements for the GMS are minimized at lower operating pressures. However, water requirements for the humidification process increase at lower pressures and higher air flowrates. As a result, achievement of a water balance for the FCS Subsystem sets a lower limit on the operating pressure and an upper limit on the air stoichiometry. Adequate fuel cell performance for automotive applications is achieved at $80^{\circ} \mathrm{C}$ cell temperature and approximately $2 \mathrm{~atm}$ absolute pressure. As a result, air stoichiometries lower than 2.0 are required to achieve water balance (i.e. less than two times the required stoichio- 
metric oxygen rate at a current density of $1 \mathrm{~A} / \mathrm{cm}^{2}$ ). Figure 3-5 shows a representative water balance for the two atmosphere case at varying power levels. As shown in this figure, more water is collected from the stack than that which is required to humidify the inlet gases.

Figure 3-6 compares the polarization curve predicted by the fuel cell performance model with experimental data at $80 \mathrm{C}$ and $2 \mathrm{~atm}$. The experimental data was obtained on a Nafion_112 membrane using AlliedSignal electrodes with a platinum loading of $0.4 \mathrm{mg} \mathrm{Pt/cm} /$ electrode. Further subsystem modeling is based on this polarization data. The rigorous Fortran model was exercised to characterize steady-state subsystem performance at the rated power level and at part-load conditions. Results are based on the performance map of an existing AlliedSignal turbocompressor, chosen for its relatively wide flow range at $2 \mathrm{~atm}$. Flow and pressure control at part-load conditions is achieved by throttling the turbine inlet to regulate air flow (Figure 3-2).

The analysis covered rated power levels ranging between $30 \mathrm{kw}$ and $100 \mathrm{kw}$, at stack voltages of 200-320 VDC. As shown in Figure 3-7, the operating voltage of the FCS has to be lower than 240 VDC at the $50 \mathrm{~kW}$ power level in order to avoid exceeding the $400 \mathrm{VDC}$ level at offpeak power levels. Additional stack sizing constraints indicate that the optimal stack voltage is 240 VDC at the rated power level. Tables 3-3, 3-4, and 3-5 show peak power and off-design performance characteristics of the fuel cell subsystem at gross rated power levels of $30 \mathrm{~kW}, 50$ $\mathrm{kW}$, and $90 \mathrm{~kW}$, respectively. Net power refers to the power generated by the FCS less the parasitic load of the gas management assembly. Subsystem efficiencies listed in these tables are based on the lower heating value of hydrogen fuel.

Figure 3-8 shows FCS and subsystem efficiencies as a function of net power output for a $50 \mathrm{~kW}$ stack ( 5 modules). The fuel cell subsystem delivers $46.7 \mathrm{~kW}$ to the vehicle with a 37.2 percent efficiency ( 40 percent stack efficiency) at the rated power level. As vehicle power requirements diminish, air flow rate through the turbocompressor is lowered by throttling the turbine inlet until surge level is reached. At that point, the bypass valve opens and a constant air flow is maintained through the turbocompressor, which has an adverse effect on overall subsystem efficiency. FCS efficiency increases from 40 percent at peak power to 66 percent at very low power levels. However, due to the limited flow range of the turbocompressor, overall subsystem efficiency peaks at 52 percent ( $20 \mathrm{~kW}$ net power). The corresponding hydrogen usage rate is shown in Figure 3.9 in terms of mass flow rate and in Figure 3-10 in terms of the net electrical output of the spent hydrogen fuel. At the lower power levels, a more significant fraction of hydrogen reacting in the FCS goes toward powering the turbocompressor, which results in higher hydrogen consumption rates per unit of net power delivered to the vehicle. The results highlighted in Figure 310 indicate that power levels below 5-7 percent of the rated power need to be avoided. This could be achieved by producing more power than required by the vehicle at the lower power requirements and using the excess power to recharge the battery. An alternative solution would be to reduce the operating pressure of the FCS at the lower power levels in order to minimize the energy requirements of the turbocompressor. Significant improvements in fuel cell subsystem efficiency could also be achieved through innovative turbocompressor design. Potential gains in efficiency 


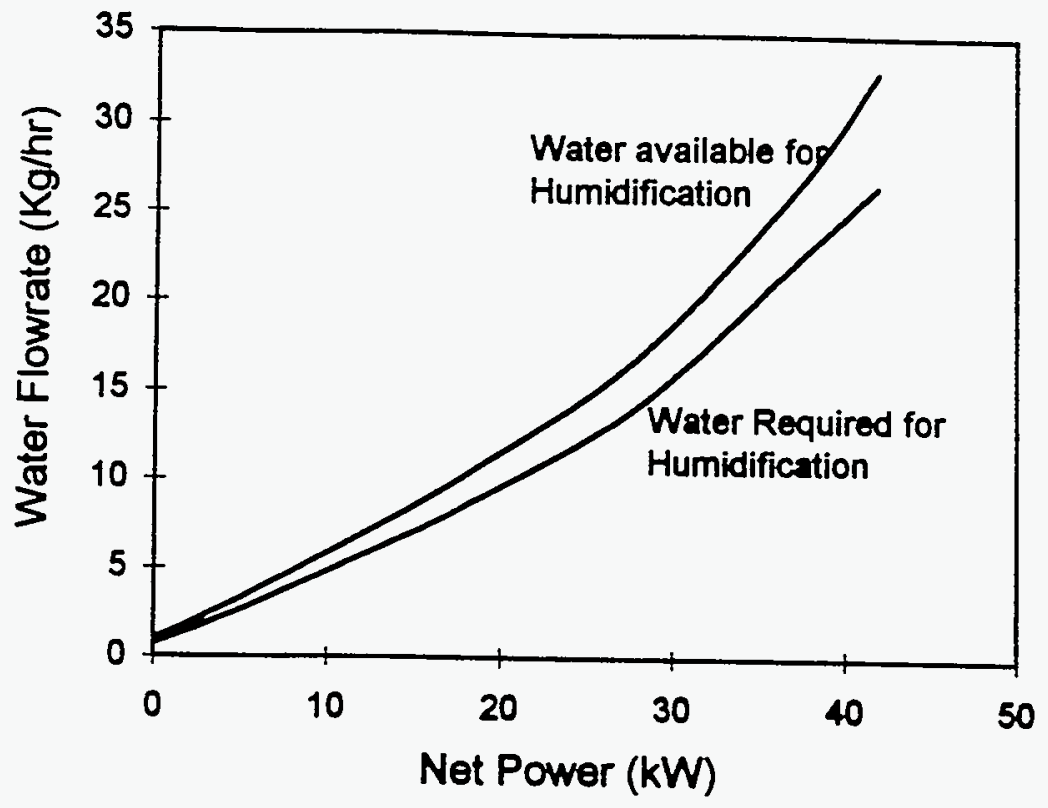

Figure 3-5. Overall Water Balance for the FCS Subsystem at 2 Atmospheres

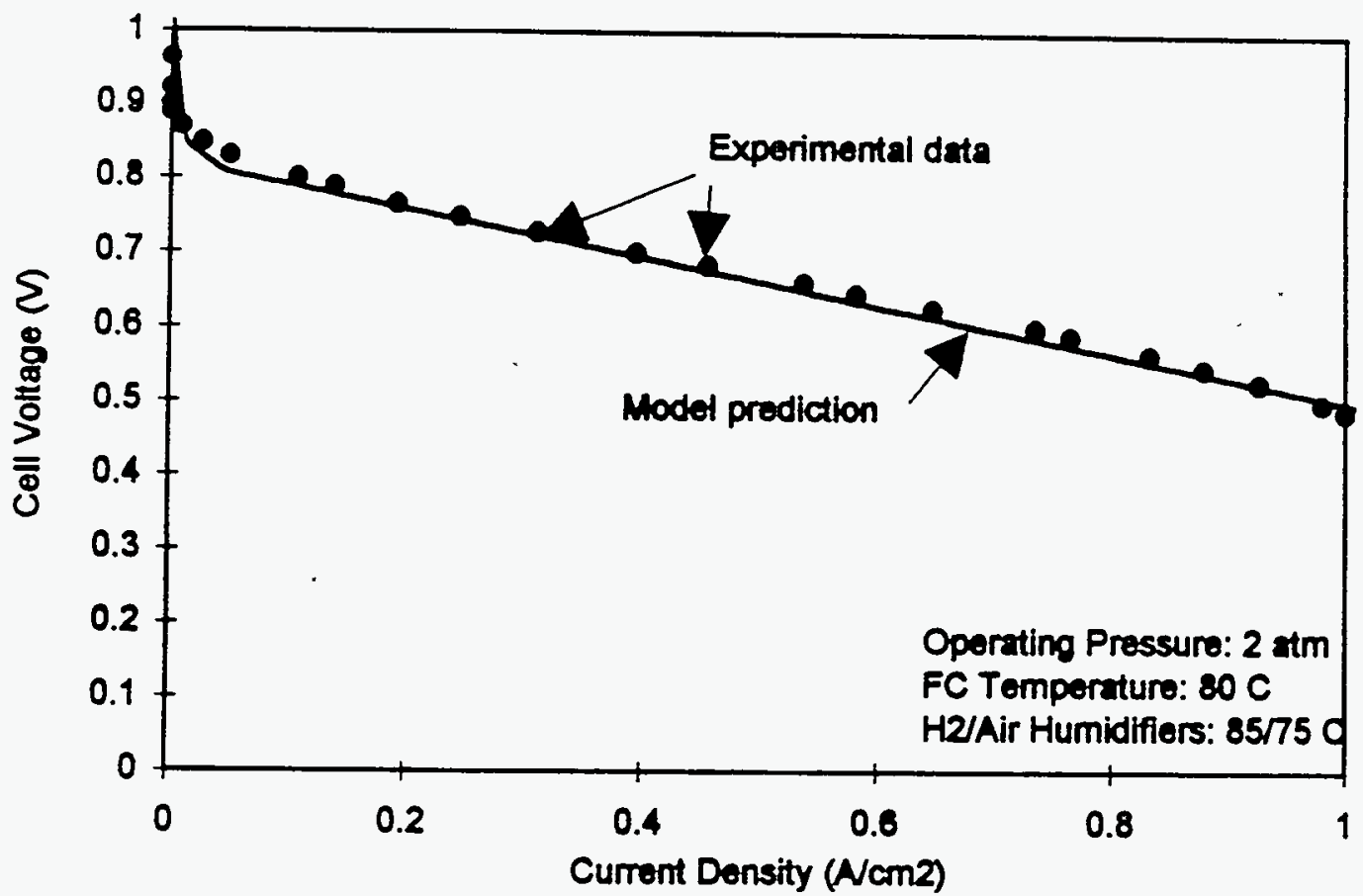

Figure 3-6. Comparison of Model Prediction with Experimental Polarization Curve 


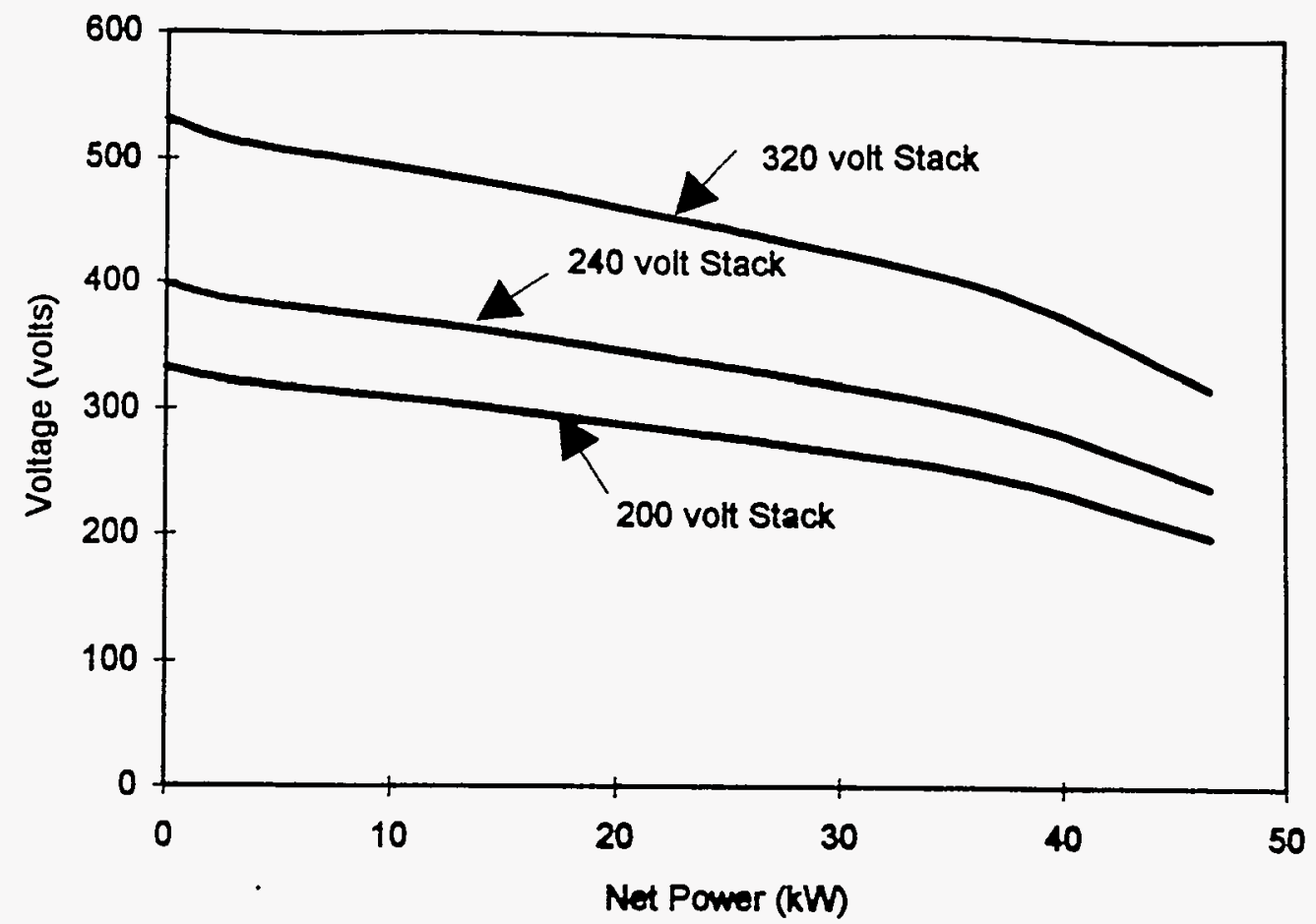

Figure 3-7. Rated Power and Off-Design Stack Voltages for 50 kW Fuel Cell Stack

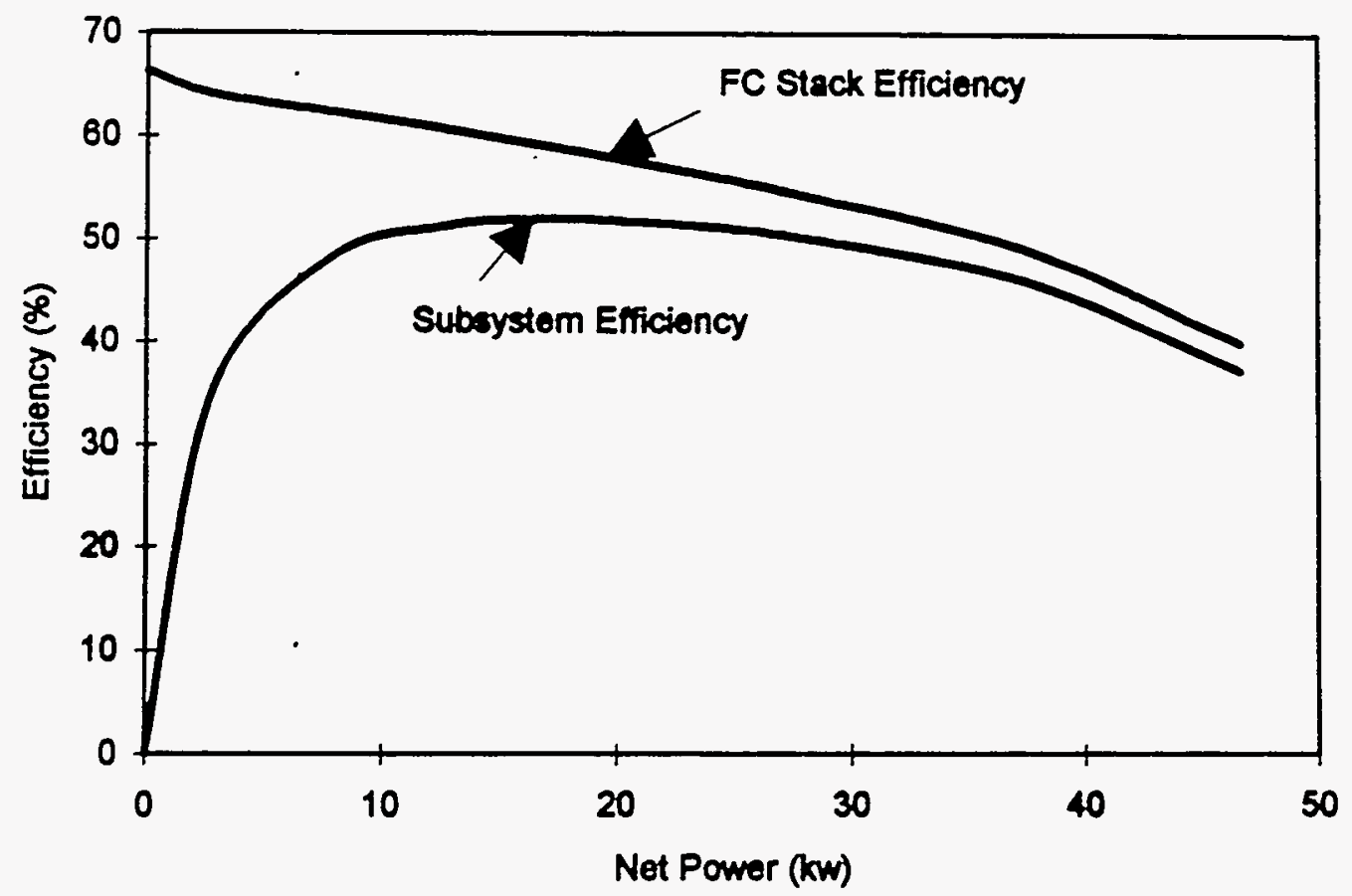

Figure 3-8. Stack and Subsystem Efficiency for $50 \mathrm{~kW}$ FCS 
Table 3-3. Peak Power and Off-Design Performance Data 30 kW PEM FCS

480 Cells, $124 \mathrm{~cm}^{2} /$ Cell, $28.9 \mathrm{~kg}, 17.2 \mathrm{~cm}$ Diameter, $125.8 \mathrm{~cm}$ Length (total)

Gross Power, kW

Net Power, kW

Stack Efficiency, \%

Subsystem Efficiency, \%

Stack Voltage, VDC

Fuel Cell Voltage, VDC

Stack Current, Amperes

Current Density, Amps/cm²

Fuel Cell Temperature, ${ }^{\circ} \mathrm{C}$

Anode/Cathode Pressure, atm.

Hydrogen Usage Rate, $\mathrm{kg} / \mathrm{hour}$

Hydrogen Stoichiometry

Air Flowrate, $\mathrm{kg} /$ hour

Air Stoichiometry

Parasitic Power, kW

Excess System Water, $\mathrm{kg} /$ hour

$\begin{array}{ccc}30.06 & 25.01 & 20.01 \\ 27.90 & 23.48 & 18.60 \\ 39.9 & 47.8 & 52.7 \\ 37.0 & 44.9 & 49.0 \\ 240.0 & 287.6 & 317.3 \\ 0.50 & 0.60 & 0.66 \\ 125.3 & 87.0 & 63.1 \\ 1.01 & 0.70 & 0.51 \\ 80 & 80 & 80 \\ 2 / 2 & 2 / 2 & 2 / 2 \\ 2.27 & 1.57 & 1.14 \\ 1.5 & 1.5 & 1.5 \\ 120.3 & 84.3 & 66.3 \\ 1.5 & 1.5 & 1.7 \\ 2.16 & 1.53 & 1.41 \\ 4.4 & 2.7 & 1.8\end{array}$

15.00
13.60
56.7
51.4
341.0
0.71
44.0
0.35
80
$2 / 2$
0.80
1.5
66.0
2.4
1.40
1.3

10.02
8.62
60.0
51.7
361.2
0.75
27.7
0.22
80
$2 / 2$
0.50
1.5
66.0
3.8
1.40
0.8

5.00

3.60

63.05

45.4

379.3

0.79

13.2

0.11

80

$2 / 2$

0.24

1.5

66.0

8.4

1.40

0.4
2.00

0.60

65.10

19.6

391.8

0.82

5.1

0.04

80

2/2

0.09

1.5

66.0

20.9

1.40

0.2 
Table 3-4. Peak Power and Off-Design Performance Data $50 \mathrm{~kW}$ PEM FCS

480 Cells, $206.5 \mathrm{~cm}^{2} /$ Cell, $40.5 \mathrm{~kg}, 21.2 \mathrm{~cm}$ Diameter, $126.1 \mathrm{~cm}$ Length (total)

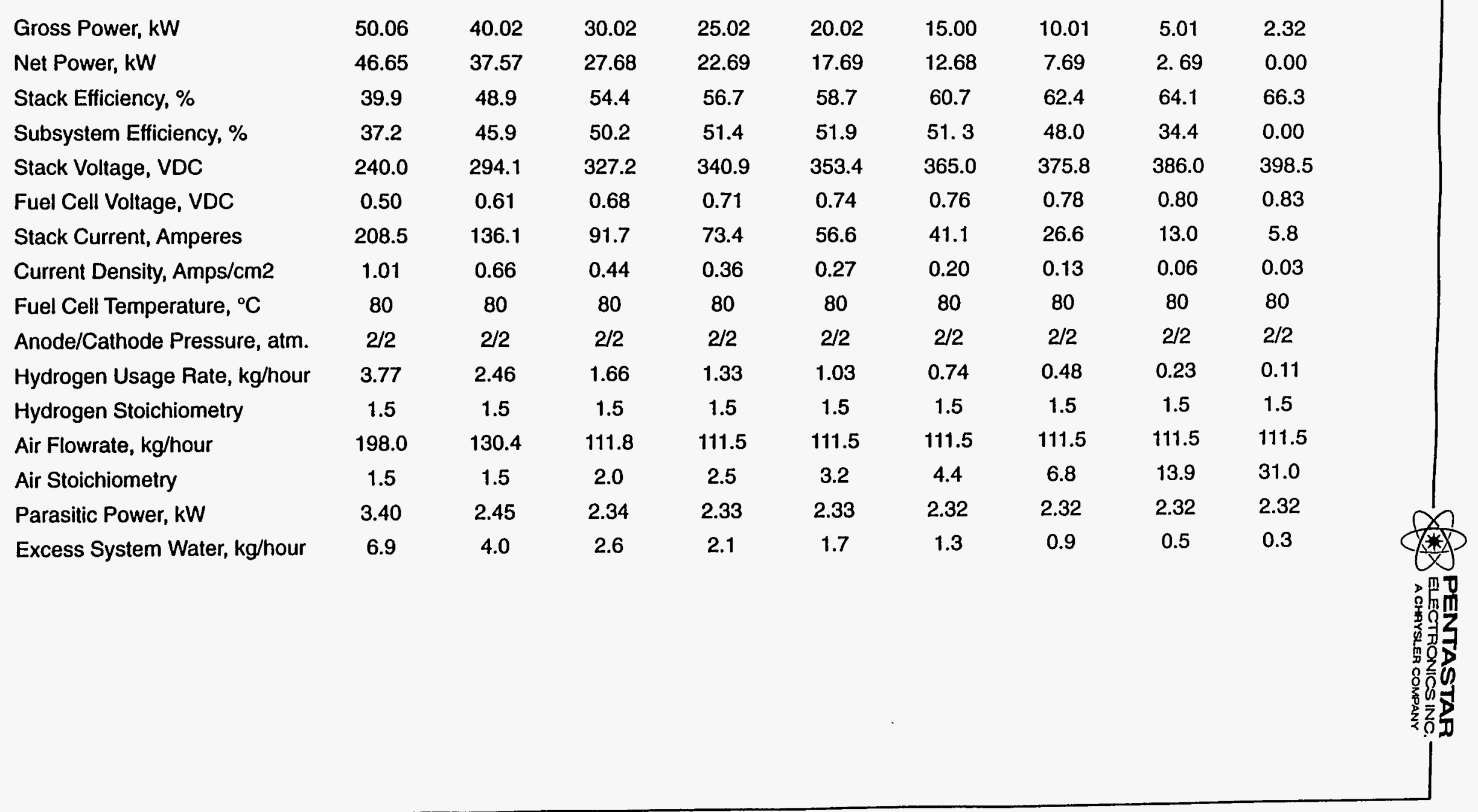


Table 3-5. Peak Power and Off-Design Performance Data $90 \mathrm{~kW}$ PEM FCS

\section{Cells, $371.6 \mathrm{~cm} 2 /$ Cell, $61.3 \mathrm{~kg}, 27.4 \mathrm{~cm}$ Diameter, $126.1 \mathrm{~cm}$ Length (total)}

$\begin{array}{lccccccccc}\text { Gross Power, kW } & 90.09 & 80.06 & 70.04 & 55.02 & 35.05 & 20.06 & 10.01 & 5.01 & 4.20 \\ \text { Net Power, kW } & 83.80 & 75.24 & 65.63 & 50.80 & 30.84 & 15.86 & 5.81 & 0.81 & 0.00 \\ \text { Stack Efficiency, \% } & 39.9 & 45.7 & 49.6 & 54.1 & 58.9 & 62.0 & 64.0 & 65.7 & 66.1 \\ \text { Subsystem Efficiency, \% } & 37.1 & 42.9 & 46.4 & 50.0 & 51.9 & 49.1 & 37.1 & 10.6 & 0.00 \\ \text { Stack Voltage, VDC } & 240.0 & 274.9 & 298.3 & 325.6 & 354.7 & 373.4 & 384.9 & 395.2 & 398.4 \\ \text { Fuel Cell Voltage, VDC } & 0.50 & 0.57 & 0.62 & 0.68 & 0.74 & 0.78 & 0.80 & 0.82 & 0.83 \\ \text { Stack Current, Amperes } & 375.4 & 291.2 & 234.8 & 169.0 & 98.8 & 53.7 & 28.0 & 12.7 & 10.6 \\ \text { Current Density, Amps/cm2 } & 1.01 & 0.78 & 0.63 & 0.45 & 0.27 & 0.14 & 0.07 & 0.03 & 0.02 \\ \text { Fuel Cell Temperature, }{ }^{\circ} \mathrm{C} & 80 & 80 & 80 & 80 & 80 & 80 & 80 & 80 & 80 \\ \text { Anode/Cathode Pressure, atm. } & 2 / 2 & 2 / 2 & 2 / 2 & 2 / 2 & 2 / 2 & 2 / 2 & 2 / 2 & 2 / 2 & 2 / 2 \\ \text { Hydrogen Usage Rate, kg/hour } & 6.79 & 5.27 & 4.25 & 3.06 & 1.79 & 1.30 & 0.97 & 0.47 & 0.19 \\ \text { Hydrogen Stoichiometry } & 1.5 & 1.5 & 1.5 & 1.5 & 1.5 & 1.5 & 1.5 & 1.5 & 1.5 \\ \text { Air Flowrate, kg/hour } & 354.0 & 275.6 & 222.5 & 198.8 & 198.3 & 198.0 & 198.0 & 198.0 & 198.0 \\ \text { Air Stoichiometry } & 1.5 & 1.5 & 1.5 & 1.9 & 3.2 & 6.0 & 12.3 & 25.3 & 30.4 \\ \text { Parasitic Power, kW } & 6.29 & 4.82 & 4.41 & 4.22 & 4.21 & 4.20 & 4.20 & 4.20 & 4.20 \\ \text { Excess System Water, kg/hour } & 10.1 & 7.7 & 6.1 & 4.5 & 2.8 & 1.7 & 0.9 & 0.5 & 0.4\end{array}$




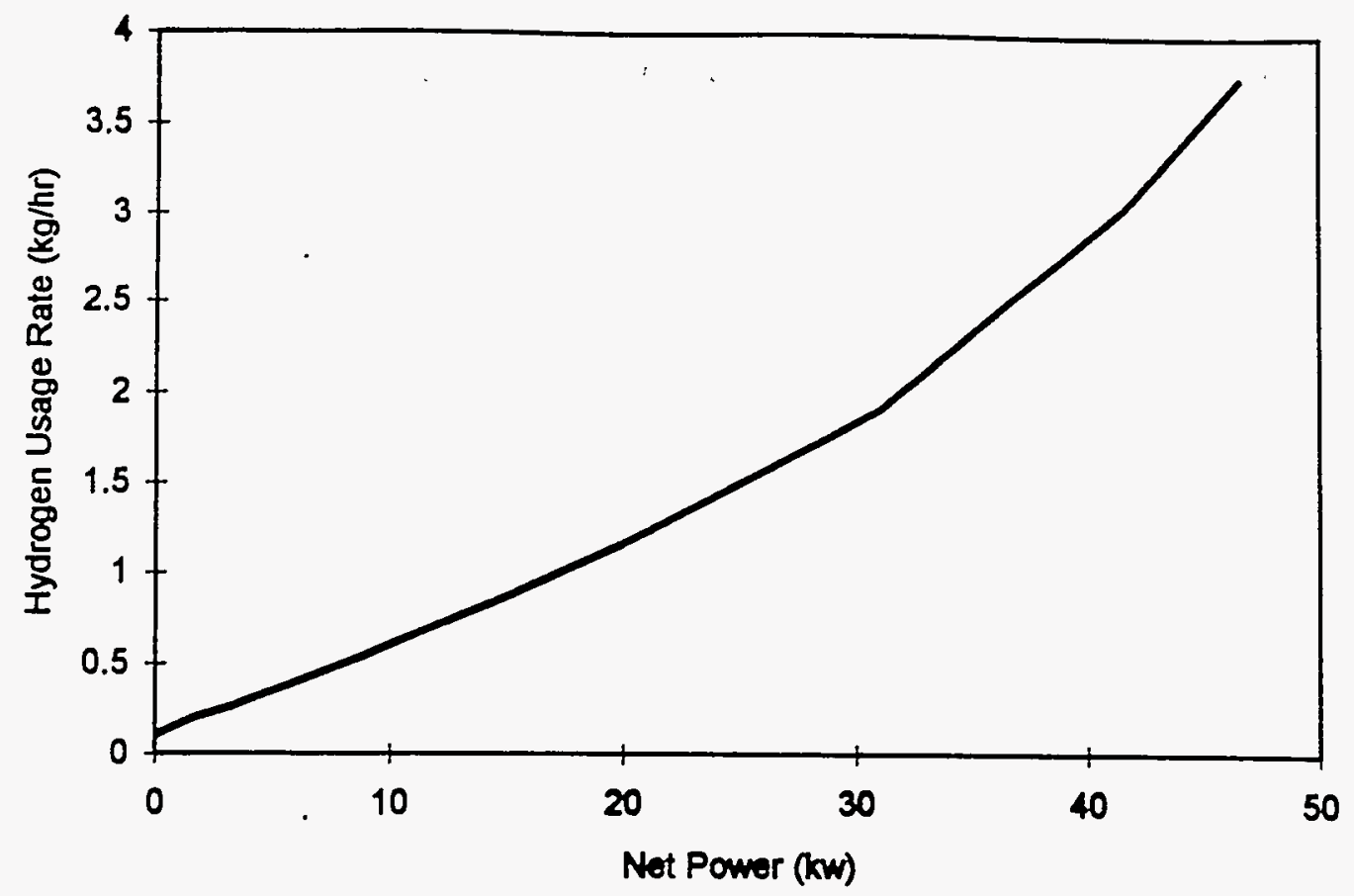

Figure 3-9. Hydrogen Usage Rate (50 kW Stack)

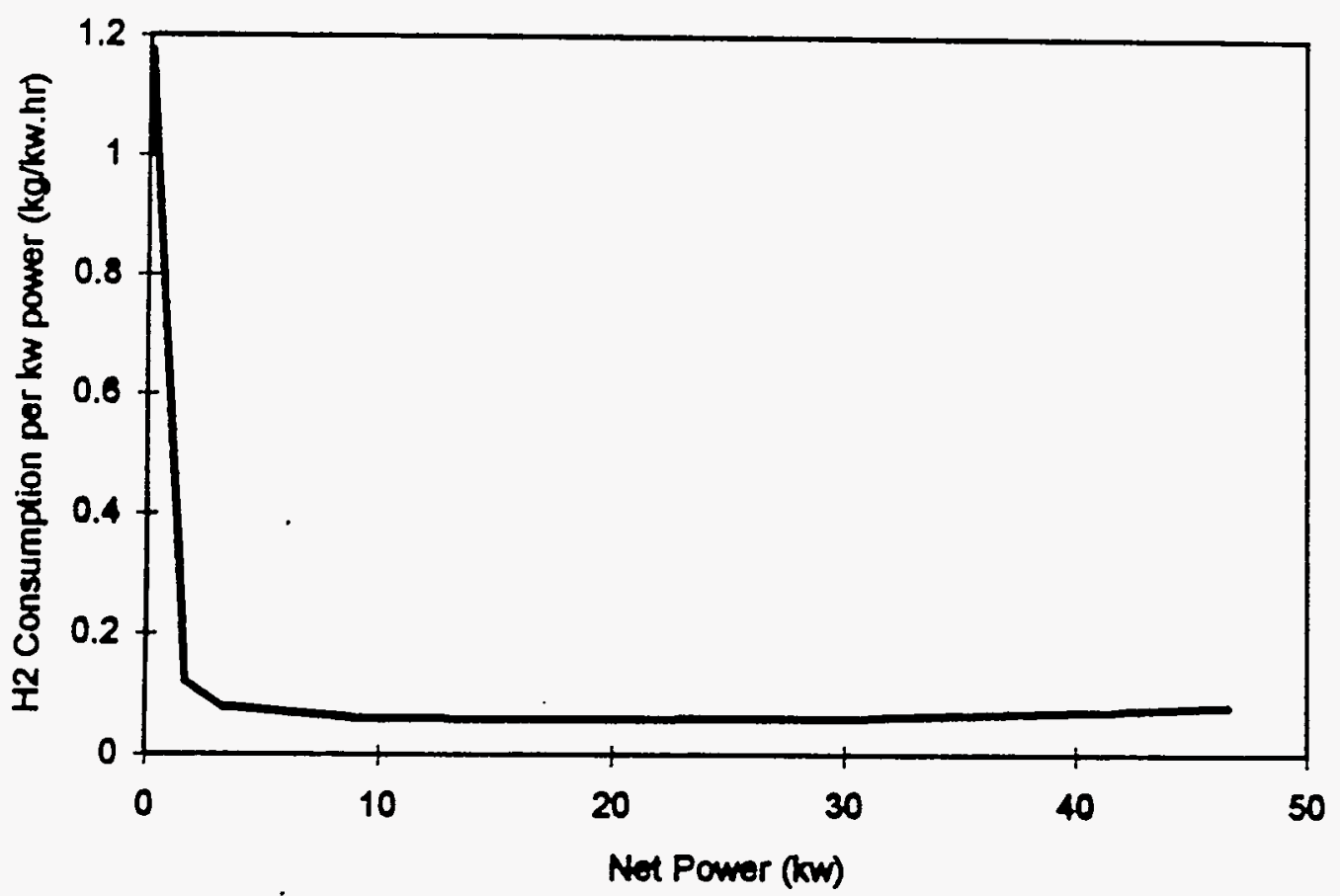

Figure 3-10. Hydrogen Consumption per Unit Power (50 kW Fuel Cell Stack) 
are highlighted in Figure 3-11, which compares subsystem efficiency using existing turbomachinery with that assuming ideal turbocompressor performance (i.e. infinitely wide flow range).

Preliminary analysis of the dynamic behavior of the fuel cell subsystem identified fuel cell temperature as the main transient. As a result, the modeling effort focused on evaluating various temperature control schemes, assuming instantaneous variations in pressures and flow rates. An adequate Proportional-Integral (PI) control algorithm was developed to maintain the temperature of the fuel cell during power load changes. Figure 3-12 shows the effect of a disturbance caused by a load change from $20 \mathrm{~kW}$ to $50 \mathrm{~kW}$, for a $50 \mathrm{~kW}$ stack. As the power required by the vehicle increases, gas flow rates are adjusted instantaneously, along with the coolant flow rate, to accommodate the increase in power and heat output of the stack. The fuel cell temperature increases to approximately $87^{\circ} \mathrm{C}$, but is rapidly restored to $80^{\circ} \mathrm{C}$.

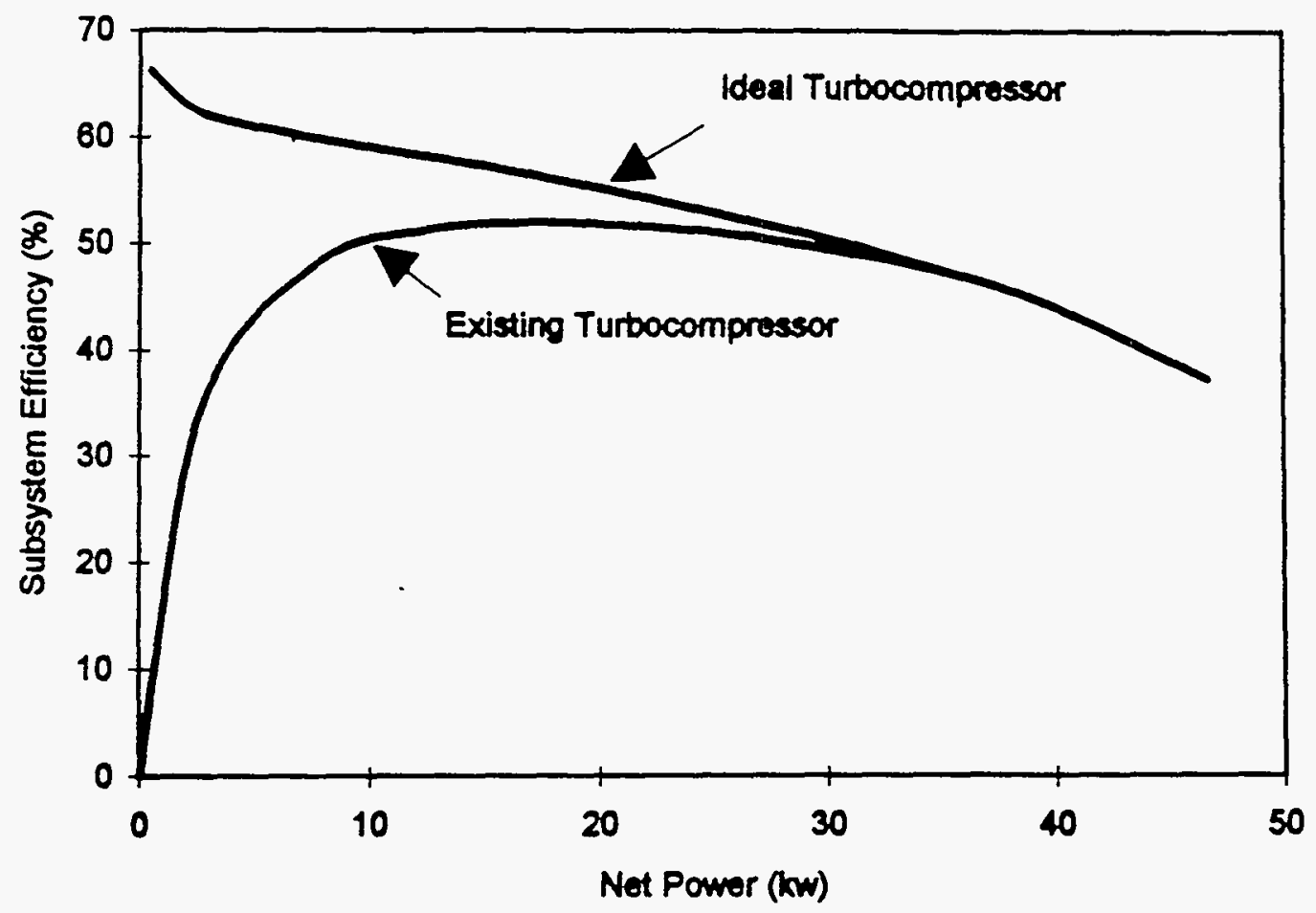

Figure 3-11. Effect of Turbocompressor Design on Subsystem Efficiency 

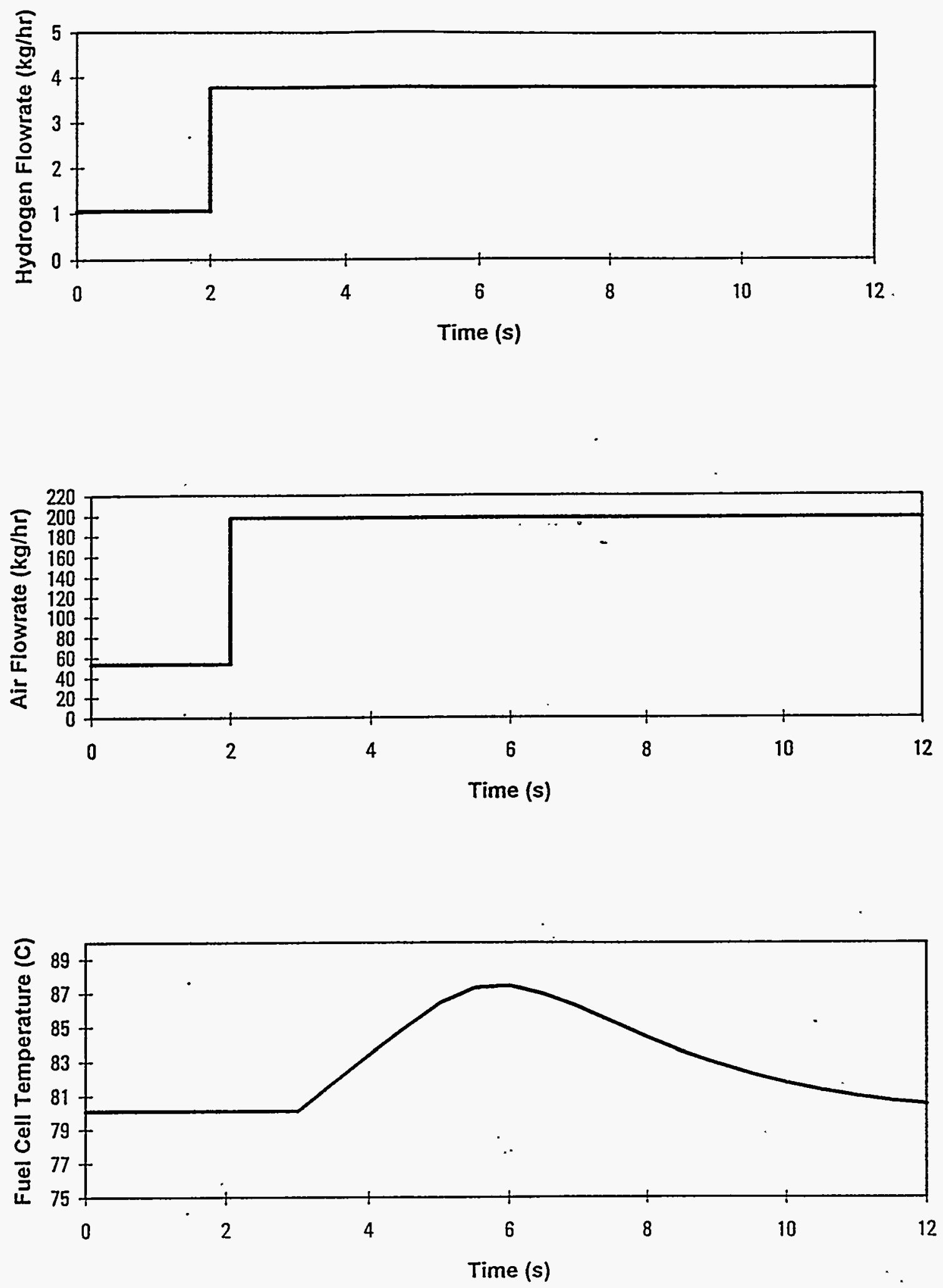

Figure 3-12. Fuel Cell Subsystem Transient Response 20-50 kW Load Change (50 kW Stack) 


\subsection{Gas Management Subsystem Description}

The GMS in development at AlliedSignal is based on results from the steady-state and dynamic modeling of the FCS subsystem. The GMS supplies the FCS with hydrogen fuel and air at the correct temperature, pressure, and humidity to deliver optimum power from the fuel cell. It also contains the controls required to operate the GMS and to provide FCS and GMS status to the DPHV system power controller. A schematic of the GMS is shown in Figure 3-13 and in Appendix C, Figure C-1.

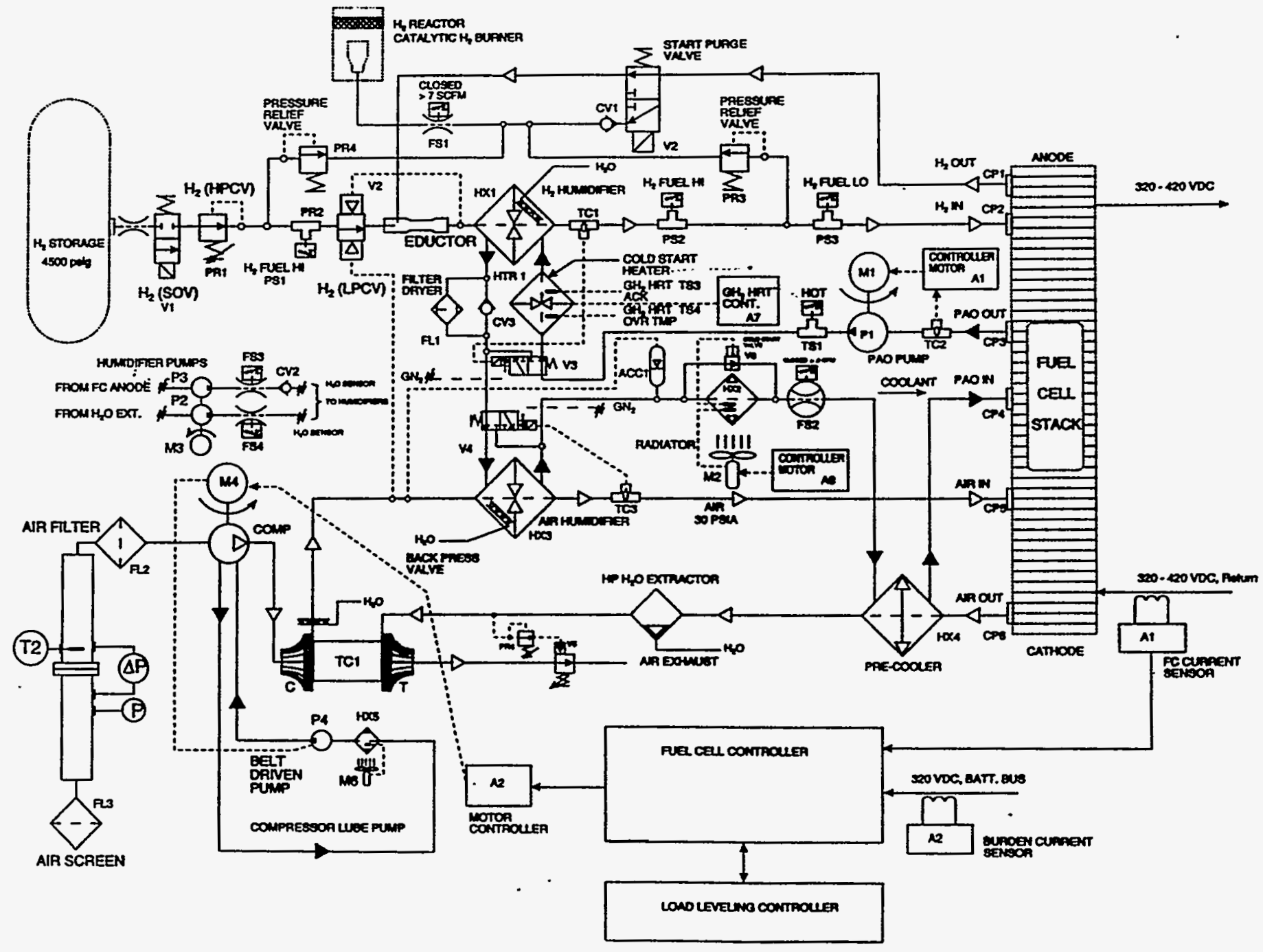

Figure 3-13. Optimal.PEM FCS Configuration 


\subsubsection{Operating Modes}

The GMS contains the controls and logic required to interact with the LLU subsystem to control the fuel cell in the following modes.

- Pressure - Pressure control is achieved by using mechanical control valves. These valves regulate the 300-340 atm (4500-5000 psia) hydrogen to $2 \mathrm{~atm}$ ( $30 \mathrm{psia}$ ) in two stages. The pressure is determined by the valve settings and sensed using a set of $\mathrm{Hi}$ Lo pressure switches. These switches are set at the maximum and minimum operating pressure tolerances.

- Temperature - Both the hydrogen and air feed streams are preheated to the required temperatures $\left(85^{\circ} \mathrm{C}\right.$ and $75^{\circ} \mathrm{C}$, respectively) by the polyalphaolefin (PAO) coolant loop. The temperature control of the PAO at the FCS outlet is set at a nominal value of $90^{\circ} \mathrm{C}$.

- Humidity - A 100 percent relative humidity is desired for the hydrogen and air entering the FCS. Ultrasonic transducers/humidifiers are used to humidify the gas streams.

- Hydrogen Leak Detection - Detection of hydrogen leakage is performed by shutting off the hydrogen supply and measuring the pressure decay. This may be used as a Built-In Test (BIT) test during actual operation, or as a Power On/Off Self-Test (POST) test.

\subsubsection{Hydrogen Component and System Descriptions}

The hydrogen control system consists of the following components:

- Hydrogen Pressure Control Valves - The hydrogen Hi Pressure Solenoid Valve (SOV) is an electrically controlled, pilot operated, slow opening, fast closing solenoid valve. The hydrogen Hi Pressure Control Valve (HPCV) is an industrial pressure regulating valve. It regulates hydrogen input pressures between 300 and 340 atm. (45005000 psia) down to 14-18 atm (200-250 psia) output pressures. When an electrical signal is received, the solenoid valve opens, and the regulator begins operations controlling the pressure to the hydrogen Low Pressure Regulating Valve (LPRV) at the nominal 14-18 atm (200-225 psia) level. The LPRV is a dome-loaded control valve that regulates hydrogen flow to the FCS at a nominal 2 atm ( 30 psia). The actual pressure at the inlet of the FCS is determined by the compressor outlet pressure.

- Hydrogen Start Purge Valve (SPV) - This valve is a three-way valve located in the hydrogen recirculation loop. This valve vents the fuel cell anode to atmosphere through a catalytic reactor, in order to remove any gases $\left(\mathrm{N}_{2}, \mathrm{O}_{2}\right)$ that diffuse through the MEA to the anode side during shutdown. This valve opens only during start-up.

- Pressure Switches - Two normally closed, hermetically-sealed pressure switches are used to verify that hydrogen pressure is maintained within the operating limits. The 
hydrogen Hi Pressure Switch opens when the hydrogen exceeds the maximum allowable pressure and verifies that the HPCV is functioning properly. The Low Pressure Switch (LPS) opens when hydrogen pressure drops below the minimum allowable pressure. The LPS, in conjunction with a timer circuit in the GMS controller, verifies that hydrogen consumption is normal and that no hydrogen leakage through the lines is present.

- Hydrogen Heat Exchanger/Humidifier (HX1) - This heat exchanger/humidifier transfers heat from the PAO coolant loop to the hydrogen feed stream and supplies the water required for humidification in order to maintain an $85^{\circ} \mathrm{C} \mathrm{FCS}$ inlet temperature at 100 percent relative humidity.

- Hydrogen Humidifier Tube Pump (HTP) (P3) (Peristaltic Pump) - The HTP pumps water from the FCS to HX1. The tube pump has no shaft sealing, an indefinite run dry capability, and is self-priming. It feeds water directly to the ultrasonic humidifier.

- Hydrogen Recirculation Subsystem - The eductor system is necessary to distribute the hydrogen evenly throughout the FCS. The eductor (venturi jet pump), powered by high-pressure hydrogen, recirculates the unreacted hydrogen from the FCS to the hydrogen humidification system.

\subsubsection{Air Component and System Descriptions}

- Turbocompressor Subsystem (TCS) - The TCS under development at AlliedSignal consists of a motor-driven air compressor in series with a turbocharger, because currently available dynamic turbocompressors do not offer a wide flow range at the required pressure. The subsystem consists of the following components:

- Motor-Driven Air Compressor (COMP) - The air compressor is a Roots compressor powered by a standard AC electric motor. The air compressor motor speed is controlled via a 0-10 VDC signal. The motor controller is powered by the 320 VDC power bus. The motor speed is controlled by varying the voltage and frequency of the power provided to the motor in accordance with the input control signal.

- Turbocharger (TC1) - The turbocharger is an air-bearing turbocharger that extracts energy from the cathode exhaust stream and uses it to compress the COMP outlet pressure to $2 \mathrm{~atm}$. Water is injected into the outlet of TC1 to pre-humidify the air stream.

- Heat Exchanger/Humidifier (HX3) - This heat exchanger/humidifier transfers heat from the PAO coolant loop to the air feed stream and supplies the water required for humidification in order to maintain a $75^{\circ} \mathrm{C} \mathrm{FCS}$ inlet temperature at 100 percent relative humidity. 
- Air Humidifier Tube Pump (P2) - The tube pump transfers water from the FCS to the HX3 subsystem.

- Precooler Heat Exchanger (HX4) - The vitiated air discharged from the FCS is cooled by the PAO coolant loop to condense water contained in the air stream within this heat exchanger.

- Water Extractor - The vitiated air exhaust from $\mathrm{HX} 4$ is spun by the guide vanes in the water separator. This causes the water vapor to separate from the air stream and flow into the receiver for the humidification subsystem.

\subsubsection{FCS Subsystem Coolant Loop}

A centrifugal PAO pump forces the coolant through the FCS at a rate determined by the thermostat at the FCS outlet. The nominal pump output is $2 \mathrm{~atm}$. absolute, which matches the gas pressures in the stack. The coolant pump motor speed is controlled via a 0-10 VDC signal derived from the coolant temperature and fuel cell control input. The motor controller is powered by the 320 VDC power bus. The PAO coolant $\left(90^{\circ} \mathrm{C}\right)$ exiting the FCS flows through the heat exchanger/ humidifiers to preheat the hydrogen and air feed streams to $85^{\circ} \mathrm{C}$ and $75^{\circ} \mathrm{C}$, respectively. A radiator further cools the $P A O$ to $70^{\circ} \mathrm{C}$. The radiator fan is thermostatically controlled and contains an internal valve to bypass the radiator when necessary.

\subsubsection{FCS Electrical Isolation}

In order to achieve and maintain optimal subsystem performance, it is vital to ensure proper electrical isolation in the PEM FCS subsystem. Current losses in the gas flow lines can be avoided by insulating electrically gas lines and fittings, and grounding the GMS. In addition, high dielectric strength materials for the fuel cell canister need to be used to present current leakage through physical mounts. Shunt currents in the cooling loop are minimized by use of the high dielectric strength coolant, PAO.

\subsubsection{FCS Subsystem Operation}

- Startup Sequencing - In a normal startup sequence $\left(22^{\circ} \mathrm{C}\right.$ ambient temperature), the events are sequenced by the GMS controller. Initially, the humidifier tube pumps start and supply water to the ultrasonic atomizers. The Power Off recirculation fan starts and supplies air to the air side of the FCS.

The hydrogen pressure control valves open and fuel is fed to the anode. The hydrogen entering the fuel cell provides the energy for the eductor to recycle unreacted fuel. Experimental studies have shown that energy 20-25 percent of the rated power can be achieved at ambient conditions $\left(22^{\circ} \mathrm{C}\right.$ FCS, 1 atm. pressure). A fraction of that power is used to drive the Roots compressor, which exhibits very rapid startup. Additional power is diverted to the electric coolant heater located at the outlet of the stack. The 
hot coolant is then used to bring the heater/humidifiers and the FCS up to the required temperatures. The electric heater is turned off when approximately 40 percent of the rated power is achieved. The total time required to achieve the optimal operating conditions $\left(80^{\circ} \mathrm{C}\right.$ at $2 \mathrm{~atm}$.) is estimated to be under 30 seconds.

In cases where the ambient temperature is below freezing (cold startup), the cold start electric hieater uses energy from the LLU $(\approx 4 \mathrm{~kW})$ to melt the ice in the FCS subsystem and preheat the coolant loop. Seven to twelve minutes are required to bring the subsystem up to its operating temperature. Design efforts are under way to reduce this startup time.

- Power Control - The current output of the stack is continuously monitored through a feedforward signal by the GMS controller. When - controller senses a steady-state demand for power, it adjusts the speed of the cor ressor to provide the required air flow rate, and the hydrogen valves adjust accordingly. As hydrogen demand increases, the eductor increases the $\mathrm{H}_{2}$ recirculation rate as more $\mathrm{H}_{2}$ is supplied.

- Idling/Deceleration - When the Hall-effect current sensor detects an idle current demand, the compressor is ramped up to provide the load necessary to maintain fuel cell voltage. This also prepares the FCS for rapid power demand for acceleration, if necessary.

- Shutdown - The HPCV closes and cuts off hydrogen flow to the FCS. The compressor is at idle and depletes the remaining hydrogen from the stack. The cooling system is then shut down and the Power Off recirculation fan intermittently turns on as commanded by the Power Off oxygen sensor to react the residual hydrogen and to maintain proper conditioning of the FCS.

- Operating Limits - Optimal performance of the FCS subsystem for automotive applications is achieved at $2 \mathrm{~atm} ., 80^{\circ} \mathrm{C} \mathrm{FCS}$ temperature, and $85 / 75^{\circ} \mathrm{C}$ humidification temperatures for hydrogen and air, respectively. Maintenance of these operating conditions within tight tolerances ensures consistent subsystem performance. Operating pressures in excess of $2.5 \mathrm{~atm}$. result in improved fuel cell performance. However, overall subsystem performance degrades due to increasing compression requirements. Low operating pressures, on the other hand, require additional water for the humidification process. As a result, water balance at the subsystem level is not achieved at pressures lower than 1.5-1.8 atm. unless air is fed to the FCS at very low stoichiometries (1-15), which in turn leads to diminished FCS performance.

The effect of fuel cell temperature on overall performance is minimal in the $70-90^{\circ} \mathrm{C}$ range. Dynamic modeling of the FCS subsystem has shown that an adequate temperature control algorithm would maintain the temperature of the stack within this range, even in case of significant disturbances such as abrupt power load changes. The state of the water entering the FCS with the feed gases has a significant effect on fuel cell 
performance. Liquid water at the anode/cathode entry points can lead to flooding of the electrodes. As a result, the temperatures of both humidifiers need to be maintained at their optimal values. Experimental studies suggest that a maximum deviation of 2 $3^{\circ} \mathrm{C}$ can be tolerated in the humidifiers.

\subsubsection{FCS Control}

A diagram of the FCS subsystem controller is shown in Appendix C, Figure C-2. The controller communicates fuel cell status with the vehicle power controller via discrete and analog signals to the LLU controller (LLC). The FCS subsystem controller is divided into three sections.

- Control Logic

Sequences Start-Up

Controls Purge

Sequences Shut-Down

Inhibits System if Critical Faults Exist

- Fault Detect and Annunciator

Monitors Critical Temperatures, Pressures, and Flows

Transmits Critical Faults to Control Logic Section

Communicates System Status with the LLC via Discrete Signals

- Servo Control

Monitors Fuel Cell Burden Electrical Current

Transmits Burden Overcurrent to Fault Detect Section

Controls Air Flow in Proportions to Fuel Cell Outlet Temperature

Generates an Analog Signal Representing Hydrogen Fuel Quantity On-Board

The schematic for the Fuel Cell Controller shown in Figure C-2 in Appendix C provides a representation of the logic and not a final design. The Fuel Cell Controller logic is described below.

\subsubsection{FCS Control Logic}

- Subsystem Startup Logic - The controller receives a FUEL CELL ON discrete signal from the LLC. The start sequence is controlled by a Start Timer. The Start Timer enables the purge circuit to purge the fuel cell of spectator gases on the anode side, and inhibits faults such as low coolant flow, low humidification water, and low pressure until these parameters stabilize. The Start Timer is valid for 10 seconds. At the end of the start sequence, the fuel cell is capable of delivering $10 \mathrm{~kW}$ of power. Power delivered 
depends on the demand by the LLC. Full power is available when the coolant temperature is stabilized at the set point of $85^{\circ} \mathrm{C}$ on the outlet of the FCS.

The time the fuel cell requires to heat the coolant is dependent on the load placed on the fuel cell by the LLC. The more load placed on the fuel cell, the more self-heating is induced, and the faster the fuel cell PAO coolant temperature will reach the required set point.

Two provisional inputs are provided to the LLC for off-design operation. The AIR FC FEED FWD allows the LLC to force a greater stoichiometric airflow through the fuel cell. This ratio is normally controlled by the electrical current feedback signal from the output current transducer.

The COOLANT FC FEED FWD allows the LLC to increase the PAO flow regardless of fuel cell PAO outlet temperature. The COOLANT FC FEED FWD typically works in conjunction with the PUMP OVRD signal. These signals have been designed into the system for the sub-zero cold start system that is currently being modeled. Both the AIR FC FEED FWD and the COOLANT FC FEED FWD are provisional inputs, and may not be used unless required by the dynamic system model.

- Subsystem Control - After the initial system startup sequence, the FCS subsystem controller monitors the fuel cell current output. The hydrogen fuel is controlled by mechanical pressure regulators, with hydrogen being recirculated using an ejector pump. The fuel cell controller only needs to monitor hydrogen fuel pressure to verify proper operation. Coolant temperature is controlled by a thermostat on the inlet side of the fuel cell. This thermostat controls the cooling airflow across the radiator, with a valve that bypasses the radiator for cold start. The fuel cell controller monitors the PAO coolant temperature on the outlet side of the fuel cell, and increases the flow to maintain the correct outlet temperature. Correct coolant inlet temperature is critical for the operation of the pre-cooler, which is the source of the humidification water. Correct outlet temperature is critical to the operation of the fuel cell and air and hydrogen humidifiers.

- Subsystem Shutdown - The preferred shutdown sequence is to place the INTEGRITY TEST, 12 Volt discrete signal high. This keeps the fuel cell running, but causes the hydrogen shut-off solenoid valve to close. The $\mathrm{H}_{2}$ PRESS LO and MASTER CAUTION discretes are then sensed. These indicate that the hydrogen fuel is being consumed, creating a low pressure condition on the anode side. This low pressure condition indicates that the fuel cell is not leaking internally. This condition should result in approximately five seconds from the INTEGRITY TEST discrete being activated. At the end of this test, the FUEL CELL ON discrete may then be placed LO, shutting down the system. 


\subsubsection{FCS Subsystem Inhibit and Fault Isolation}

There are five errors that will result in the closing of the Hydrogen Shut-Off Solenoid Valve (SOV), shutting down the fuel cell. The errors latch a relay and require a reset signal to re-enable the system.

\section{Unrecoverable Errors}

- Humid Water (NOT)

- No humidification water flow from the air humidifier pump

- No humidification water flow from the hydrogen humidifier pump

- $\mathrm{H}_{2}$ Press $\mathrm{Hi}$

- High hydrogen pressure before main hydrogen pressure regulator

- High hydrogen pressure at the inlet to the fuel cell

- H.O.T. (High Oil Temperature)

- PAO coolant exiting the fuel cell is above acceptable limits. Fuel Cell overheating

- Ovr Temp (Cold Start Heater)

- The PAO coolant heater temperature is above acceptable limits

- Fc Burden Ovr Current

- Excess electrical current draw by some component in the fuel cell auxiliary subsystem

\section{Note: PAO COOLANT FLOW (NOT)}

PAO coolant flow below low flow limit. This error may be used as an unrecoverable error in a later fuel cell controller design.

The errors shown above require a reset command before restarting which automatically shut down the fuel cell. These errors are expected to be generated by an equipment failure rather than a transient (out-of-tolerance) condition.

\section{Recoverable Errors}

- $\mathrm{H}_{2}$ Press Lo

- Induced by the INTEGRITY TEST

- Low pressure regulator malfunction

- Low hydrogen fuel quantity 
- SOV Fail

- Hydrogen shut-off SOV did not actuate when commanded, sending a feedback signal to the fuel cell controller

- Purge Fail

- Purge flow not present when commanded, sending a purge flow signal to the fuel cell controller

- Htr Fail

- Humidification PAO coolant heater has not reached the desired set point

These error may reflect a transient out-of-tolerance condition reflecting a system error. The LLC has the option of shutting down fuel cell operations if these errors occur. 


\section{SECTION 4 \\ HYDROGEN STORAGE SUBSYSTEM REQUIREMENTS}

\subsection{Hydrogen Storage on Board Vehicles}

\subsubsection{Hydrogen As An Automotive Fuel}

A low-cost, compact means of storing hydrogen is needed for successful commercialization of the Direct Hydrogen-Powered PEM fuel Cell Stack Hybrid Vehicle (DPHV) electro-chemical engine for electric vehicles. Hydrogen is appealing as an automotive fuel because the only byproduct of a low-temperature reaction is water, with no pollutants or greenhouse gases. Hydrogen can either be stored on board a vehicle in its pure form, or produced by reforming a hydrocarbon such as methanol. For the present program, a direct-hydrogen-fueled mandate was part of AlliedSignal's contract in developing a fuel delivery system for the vehicle.

\subsubsection{Goals For Hydrogen Storage On Vehicles}

The main goal for hydrogen storage on board a vehicle is to achieve a driving range of 380 miles with an EPA fuel economy of $80 \mathrm{MPG}$ (see Section 1.1.2). The deliverable amount of hydrogen fuel has been estimated at $12.5 \mathrm{lbs}$. The cost target for the hydrogen storage system is $\$ 300$, which is in accordance with the goal set forth by the Partnership for a New Generation of Vehicles (PNGV).

\subsubsection{Methods For Storing Hydrogen On Vehicles}

Four hydrogen storage methods have been studied as part of the storage system design process. These methods are described below:

- Pressurized Gas Storage - Gaseous hydrogen is the most simple and direct approach, but requires high storage pressures to achieve a reasonable packaging volume. This technology is based on the deployment of compressed natural gas for light duty vehicle use. For automotive applications, lightweight composite fiber wrapped pressure vessels with metallic or plastic liners represent a potential solution in a technically and economically viable storage system. Storage in vehicle systems is presently limited to 3000 psia. However, storage systems with pressures of up to 10,000 psia have been achieved in aerospace applications.

- Cryogenic Liquid Hydrogen Storage - This technology is based on the existing distribution and dispensing of hydrogen and other cryogenic fluids. Liquid hydrogen at cryogenic temperatures provides a much higher packaging density than gaseous storage. However, a significant energy penalty is associated with the liquefaction process.

Liquid hydrogen storage involves the use of a vacuum jacketed super-insulated storage vessel commonly known as a dewar. Many established U.S. suppliers fabricate 
stationary dewars and support equipment for large and small quantity cryogenic applications. A few suppliers produce liquid methane dewars for automotive applications.

- Carbon Molecular Sieve - The objective of the carbon molecular sieve is to increase the storage capacity of compressed gas hydrogen by the addition of activated carbon to the pressure vessel. The carbon material is based on that developed for methane purification pressure swing absorbers. The use of activated carbon to augment pressurized methane storage has been considered recently. A similar approach has been suggested for hydrogen storage. It has been demonstrated that the physical absorption of pressurized hydrogen gas on activated carbon will increase a pressure vessel's storage capacity within a particular temperature and pressure range.

- Metal Hydride Storage - This concept is based on the chemical reaction of hydrogen with a metal alloy to form a hydride. Metal hydride storage can be accomplished at low pressures ( 2 to $7 \mathrm{~atm}$ ) and at room temperature. However, the low hydrogen capacity of existing metal hydrides ( 1 to 1.5 percent by weight) results in heavy storage systems. The heavy weight required to store a sufficient quantity of hydrogen might, therefore, prove to be prohibitive for automotive applications. This, in addition to their excessive cost and the need for considerable heat transfer, renders the use of existing metal hydride technologies unattractive for automotive applications.

- Summary of Storage Method Selection - Pressurized gas storage has been selected as the best near term choice for development for the DPHV program. Advantages include significantly developed and demonstrated technology, simplicity, low weight, simple refueling and no boil-off losses. Liquid storage will also continue to be investigated since it provides the potential of reduced cost, volume and weight as compared to compressed gas. However, significant technical and safety issues must be resolved for this technology to be deployable to the general public. Continued research and development of Carbon Molecular Sieve (CMS) technology is ongoing as a cost sharing effort. At present, however, the CMS materials offer no advantages over compressed gas storage. As for metal hydride storage systems, their weight and cost are prohibitive for automotive applications.

\subsubsection{Specifications For Hydrogen Storage}

No codes or specifications particular to automotive hydrogen fuel systems presently exist. Specifications from the Compressed Natural Gas Vehicles (CNGV) environment were used as guidelines in the formation of the hydrogen system requirements. Such CNGV specifications include: NGV-1, NGV-2, (published by the American Gas Association [AGA]), NHTSA FMVSS 301. Fuel System Integrity (for liquid fueled automobiles), NHTSA 303 Fuel System Integrity (for gaseous fueled automobiles), NHTSA 304 Vehicle Pressure Vessels (produced by the National Highway Traffic Safety Administration) and NFPA-52, CNG vehicular Fuel Systems (produced by the National Fire Protection Association). A complete hydrogen-specific system and component product specification for performance, design, qualification, and production quality is being 
assembled as part of the design and development effort. Existing codes for compressed flammable gases for industrial settings are available and are applicable to the hydrogen infrastructure facilities. Some of the applicable codes and standards for on and off board storage are given in Appendix F, Figure F-1.

\subsection{Gaseous Hydrogen Storage System Concept}

The gaseous hydrogen storage system is being modeled on existing CNGV storage system configurations, such as that used on the CNG powered Dodge Ram Van. Key system performance goals are summarized in Table 4-1.

\section{Table 4-1. Gaseous Hydrogen Storage System Design Goals}

$\begin{array}{ll}\text { Hydrogen Storage Capacity } & 12.5 \mathrm{lbs} \\ \text { Total Syst em Weight } & 217 \mathrm{lbs} \\ \text { Total System Cost } & \$ 300 \\ \text { Total Volume } & <9 \mathrm{ft} 3 \\ \text { Mile Life } & 100,000 \text { Miles } \\ \text { Operation } & \text { Tr ansparent } \\ \text { Refueling Time } & 5 \text { Minutes } \\ \text { Safety } & \text { Equivalent to Gasoline }\end{array}$

Installation studies performed by Chrysler Liberty and Technical Affairs determined the maximum external storage volume to be 12 cubic feet. This was determined by iterating the size and number of typical pressurized cylinder shapes within the existing vehicle design architecture. The 12 cubic foot installation was then iterated with storage pressure assuming carbon fiber overwrapped vessels and ambient temperature storage. A storage pressure of 5000 psia is required to achieve the technical requirements of $12.5 \mathrm{lbs} \mathrm{\textrm {H } ^ { 2 }}$ with an external volume of $12 \mathrm{ft}^{3}$ (9 $\mathrm{ft}^{3}$ internal storage volume).

\subsubsection{System Schematic - Gaseous Hydrogen}

The present gaseous storage system schematic is shown in Figure 4-1. A combination of three storage tanks was found to provide the optimum installation within the vehicle. The baseline design consists of all-composite pressure vessels with carbon fiber overwrap. CNG vessels are commercially available in this configuration (i.e. 3000 psia). Tests conducted with hydrogen using these vessels have shown encouraging results. The increased pressure required for hydrogen storage and the cost of the carbon fiber material present the main technical challenges.

Each tank is shown with manual valve and pressure relief devices. The manual valves are typically provided for tank service considerations. The flow fuse operates in a similar fashion to an electrical fuse. That is, in the event of a downstream leak and flow increases beyond a predetermined level, the flow fuse will stop the flow completely. A single manual valve is provided in series with the flow fuse to provide a shut-off means in case of a minute leak, too small to actuate the flow fuse. 


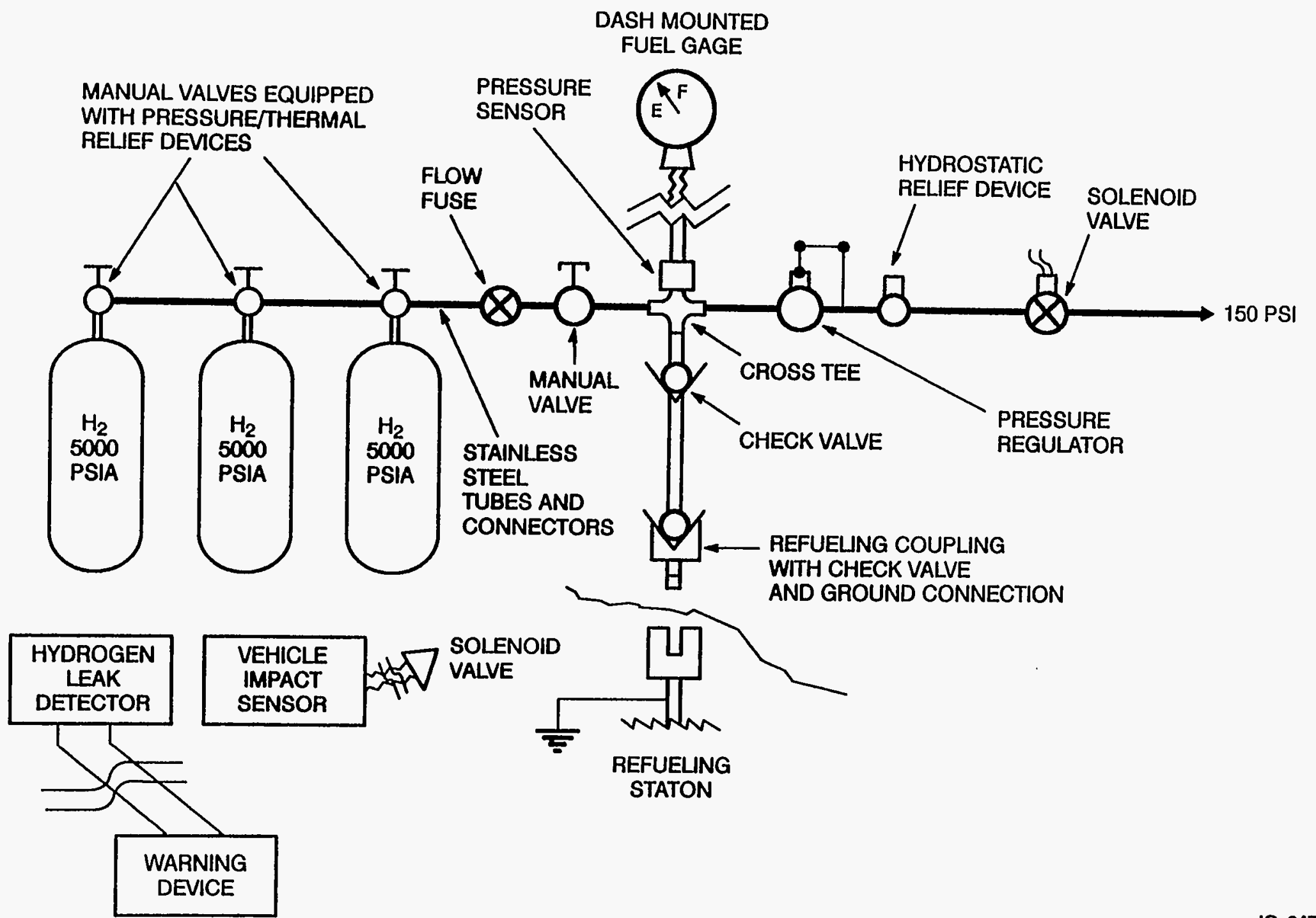

IG-24749

Figure 4-1. Gaseous Hydrogen Storage System Schematic 
A refueling coupling which resembles, in appearance and operation, a gasoline nozzle is being investigated. A refueling coupling must incorporate a ground in order to provide electrical grounding for the vehicle during refueling operations. NGV-1 is being used as a guideline in the design of the refueling coupling. The Refuel Proximity Switch shown in the schematic prevents the vehicle from accidentally being driven while the refueling hose is connected. The Quantity Sender senses tank pressure and temperature, and provides a signal to a dash-mounted "fuel level" indicator gage. Both these functions will be integrated with the Fuel Cell System Controller. A normally closed/fail closed electric shut-off valve actuates the hydrogen flow to the pressure regulator. A flow limiter, or restriction, may be needed to attenuate the sudden pressure spike resulting from the opening of the shut-off valve. The pressure regulator reduces the vessel pressure to a working pressure of 150 psia. The shut-off valve could alternatively be placed down stream of the pressure regulator to reduce the average load on the valve and eliminate pressure spiking the regulator. However, leakage from the regulator could also result in a pressure spike down stream. Further analysis is required to optimize the placement of the valve.

\subsubsection{Storage Vessel Size Estimate}

A storage pressure of 5000 psia is required for ambient temperature storage, as shown in Figure 4-2. The design point demonstrates a density of approximately $1.4 \mathrm{lb}$ per $\mathrm{ft} 3$, which corresponds to a volume of $9 \mathrm{ft}^{3}$ for $12.5 \mathrm{lbs}$ of storage. This translates into an external pressure vessel volume of approximately $12 \mathrm{ft} 3$.

\subsubsection{Installation Concepts}

A single pressure vessel would be most desirable in terms of minimizing both cost and complexity. An installation concept of a large tank combined with a much smaller cylinder is shown in Appendix F, Figure F-2. However, this configuration negates all usable trunk space. As a result, the viability of single tank assembly is limited to trucks or large station wagons, where volume is not a significant issue. Numerous layouts for mid-size passenger vehicles have been generated by Chrysler engineering.

Figure F-3 in Appendix F shows a concept with nine pressure vessels, which utilizes available volume adequately but greatly increases complexity and cost. Alternative layouts considered in this study are shown in Appendix F, Figures F-4 and F-5. However, the optimal configuration for storage of the required volume of hydrogen is shown in Figure 4-3. This system is being modeled in the trunk of the Chrysler LH Sedan and consists of three identical pressure vessels, each 15 inches $O D$ and 39.4 inches long.

With some minor modifications, such as moving the rear seat cushion forward three inches (same position as the standard LH model), and repositioning of the spare tire, $16.5 \mathrm{ft} 3$ of trunk space is available along with $9.0 \mathrm{ft} 3$ of hydrogen storage. 
TEMPERATURE, $\mathrm{K}$

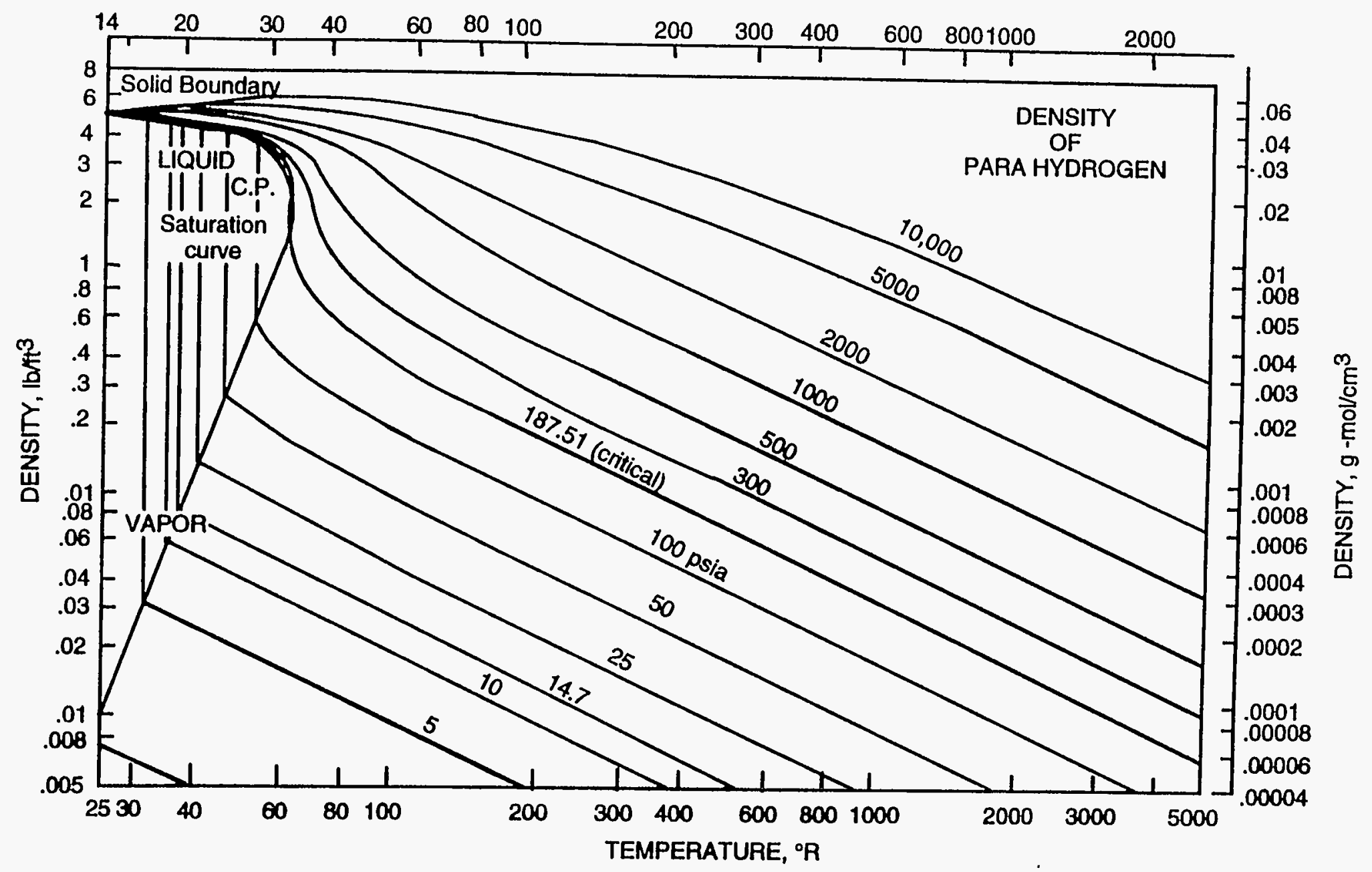

M-03747

Figure 4-2. Hydrogen Density as a Function of Pressure and Temperature 


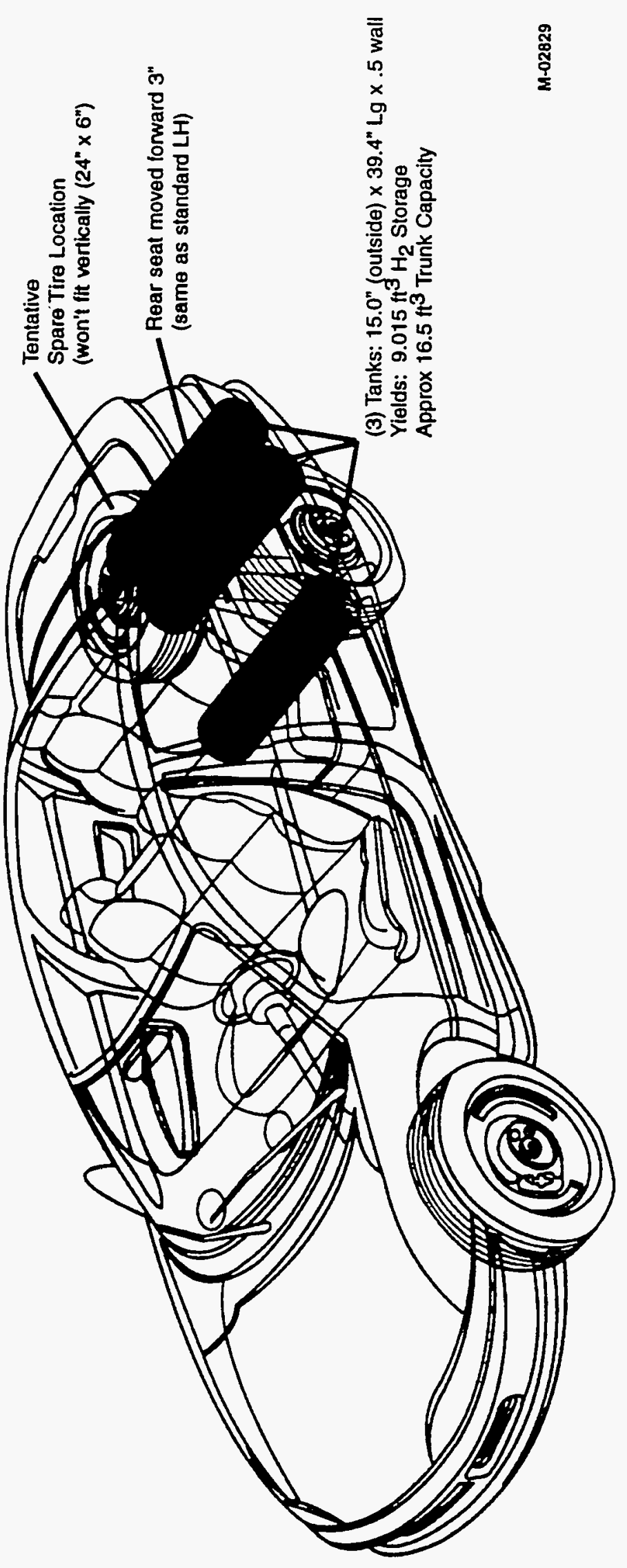

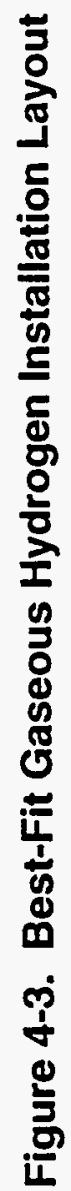




\subsubsection{Gaseous Hydrogen Safety Issues}

Sudden pressure release and fire constitute the primary safety considerations for gaseous hydrogen storage systems. Hydrogen's very low ignition energy and broad range of flammability in air make it susceptible to easy ignition. Hence, leakage will have to be kept to a minimum. Minimal connection interfaces are included in the system design to lessen the potential for leakage. In addition, flexible gas lines minimize leaks during crash impacts by allowing for displacement of components. The feasibility of several on board hydrogen sensing technologies is being evaluated. Gas release after crash impacts should be demonstrated to be consistent with NHTSA FMVSS 301 and 303 at the vehicle test level in future development phases. The ability to shut-off the hydrogen supply in case of an emergency will be incorporated into the FCS subsystem controller logic. This can be integrated in to the vehicle operation logic and activated by any number of conditions such as crash impact, leak detection, operator command, refueling, as well as any fuel cell operational failure. Also, in the case of a system leak, hydrogen shut-off will be accomplished by the flow fuse. An electronic leak detector will be mounted in the vicinity of the hydrogen storage subsystem. This device will warn the driver in the event of a hydrogen leak. Safe containment of the mechanical pressure energy will be demonstrated to be consistent with the bullet impact testing of NGV-2. Since auto-ignition of sudden hydrogen releases is possible, a demonstration test to characterize this event is planned for the first phases of development testing. Means to mitigate risks associated with this type of event will be developed and demonstrated as soon as practical. Since durability of composite CNG vessels has proven to be acceptable, equivalent or better failure rates will be targeted for the hydrogen storage system by providing the same safety factors and structural integrity.

Several fiberglass wrapped compressed natural gas pressure vessel failures have been studied and the lessons incorporated into the design of the hydrogen storage system. Specific installation conditions to be avoided have been identified in the failure analyses. In addition, the baseline hydrogen vessels, which are carbon fiber overwrapped, are less susceptible to the failure mechanism associated with the subject fiberglass CNG vessels.

\subsubsection{Refueling Thermodynamics}

As a result of the continuing effort to make the system indistinguishable to the user from a conventional gasoline automobile, a five minute refueling time goal has been established. When a pressure vessel is filled, compression energy is dissipated as heat. Due to its negative JouleThompson Effect coefficient, the temperature of hydrogen gas rises across a throttle valve. Computational analyses of the thermodynamics of the refueling process indicate that for the adiabatic condition, the temperature of hydrogen gas in the vehicular storage system rises about $270^{\circ} \mathrm{F}$ to $400^{\circ} \mathrm{F}$ when cascade filled from a worst case $130^{\circ} \mathrm{F}$ ambient temperature stationary 6000 psia vessel (Figure 4-4).

The results of an analysis which includes heat transfer to the vessels and environment show that the heat transfer is too slow to markedly reduce gas temperature until well after the refueling process is complete. A five minute simulated refueling with heat transfer is shown in 
$\bar{n}$
0
8
8
0

$\frac{a}{i j}$

1

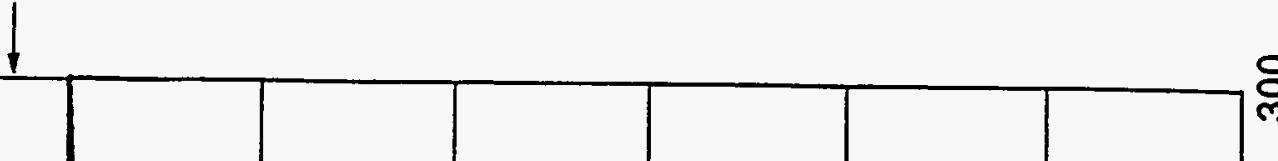

용
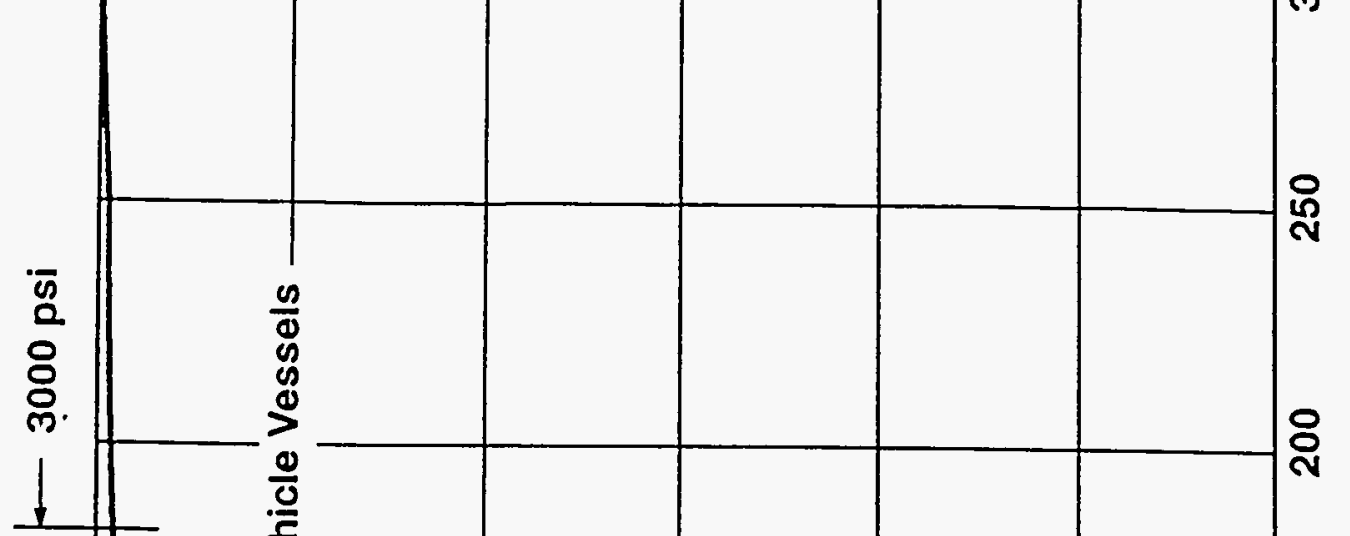

(

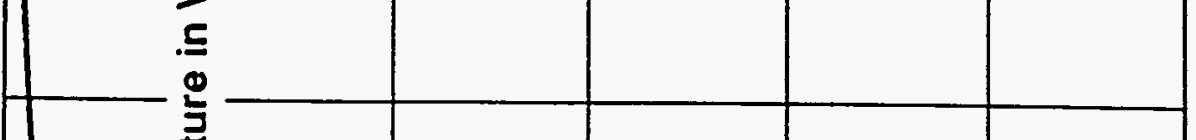

용

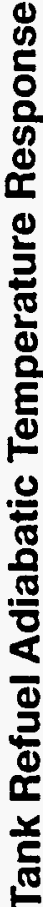

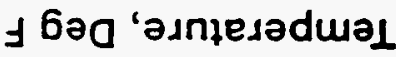

8

우

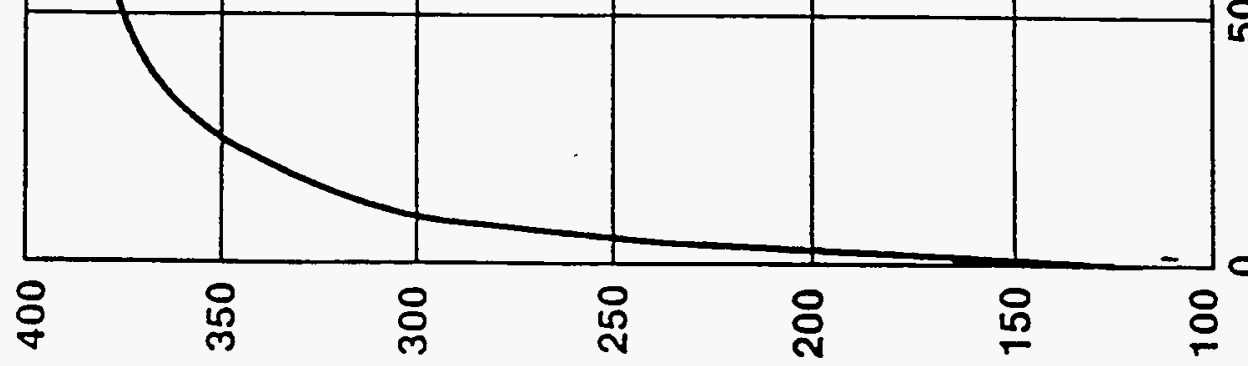

함 
Figure 4-5. The temperature spike which results during the refueling operation could result in a 30 percent reduction in storage capacity for a single refueling. Multiple refuelings, such as filling the vessels to 70 percent of mass capacity, allowing them to cool, then performing a top-off fill would eliminate the temperature spike problem. Very slow filling of the vessels overnight would also eliminate a temperature spike problem. However, a single five minute refueling procedure is the goal of this program. Minimization of the effect of the temperature spike is important in order to avoid increased volume and cost for the system. One potential solution is to expand the stored hydrogen through a turbine in place of a throttle as it enters the storage vessel, which would result in a temperature drop due to the work removed.

However, as shown in Figure 4-6, compressor inefficiencies negate the beneficial effect. The prospect of adding a heat sink media to the inside of the vessels is prohibitive since the quantity of heat generated is very large. About $100 \mathrm{lb}$ of aluminum would have to be added to the pressure vessels to reduce the temperature of the gas by $100 \mathrm{~F}$. Several hundred pounds would have to be added to have any marked beneficial effect.

A technically viable solution to the refueling heat problem is to supply refrigerated hydrogen gas for refueling. Computational analysis has revealed that a hydrogen supply gas temperature of $-100^{\circ} \mathrm{F}$ will eliminate the temperature spike. The energy of compression will raise the temperature of the $-100^{\circ} \mathrm{F}$ gas to an average ambient temperature of $70^{\circ} \mathrm{F}$ as it is compressed in the vessel. Figure 4-7 shows that for various initial fill conditions, a supply temperature of $-100^{\circ} \mathrm{F}$ results in ambient temperature within the bottle with no danger of over-pressurization.

While technically viable, the cost of refrigerating a gaseous hydrogen supply to $-100^{\circ} \mathrm{F}$ is prohibitive. However, a liquid hydrogen supply system, such as that shown in Figure 4-8C, could provide hydrogen at reduced temperature with little cost impact to the system or fuel. A refrigeration system would not be required since the liquid hydrogen's extreme cold temperature could be utilized. This is most likely the best long-term solution to the fast fill problem since it has been projected that large scale delivery of hydrogen will have to be in liquid form to be economical.

For a gaseous hydrogen supply system the most cost effective method to achieve a complete fill in five minutes is to over-pressurize the vessels. The pressure will diminish to the rated operating pressure when the vessels cool down to ambient temperature. This scheme is currently used for CNG-powered vehicles. CNG refueling dispensers are temperature compensated such that a complete fill is assured up to an ambient temperature of $72^{\circ} \mathrm{F}$. An overpressurization of as much as 25 percent is done to accomplish the complete fill. A similar approach could be taken for the hydrogen storage vessels. However, a greater over pressurization would be required for hydrogen due to its negative Joule-Thompson coefficient and its unfavorable compressibility factor characteristics. It has been computed that a 7000 psia fill at $72^{\circ} \mathrm{F}$ would be required to ensure a complete fill for 5000 psia ambient temperature storage, thus requiring a 40 percent overpressure. 


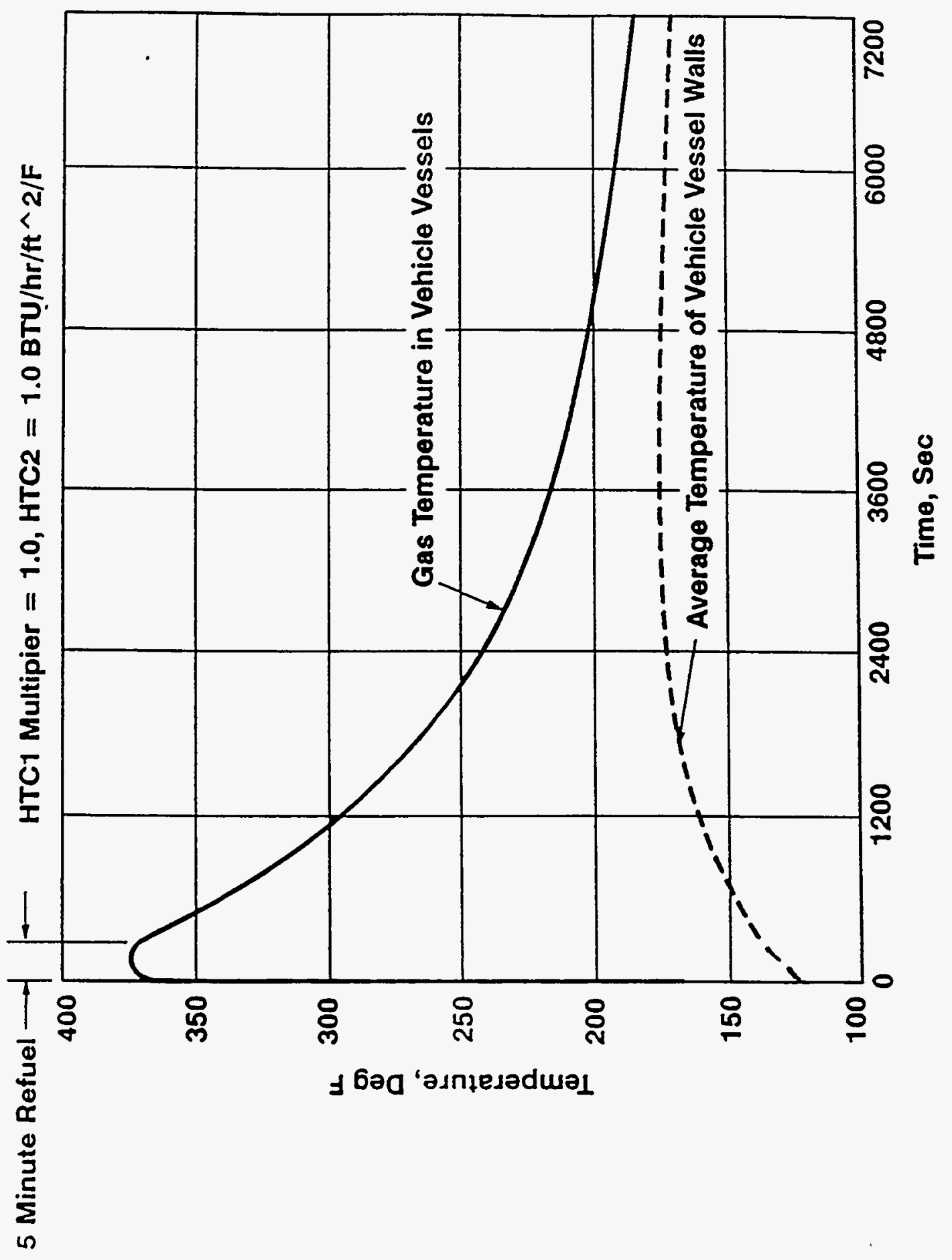

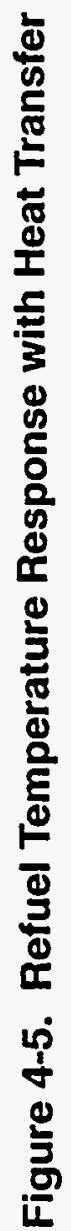




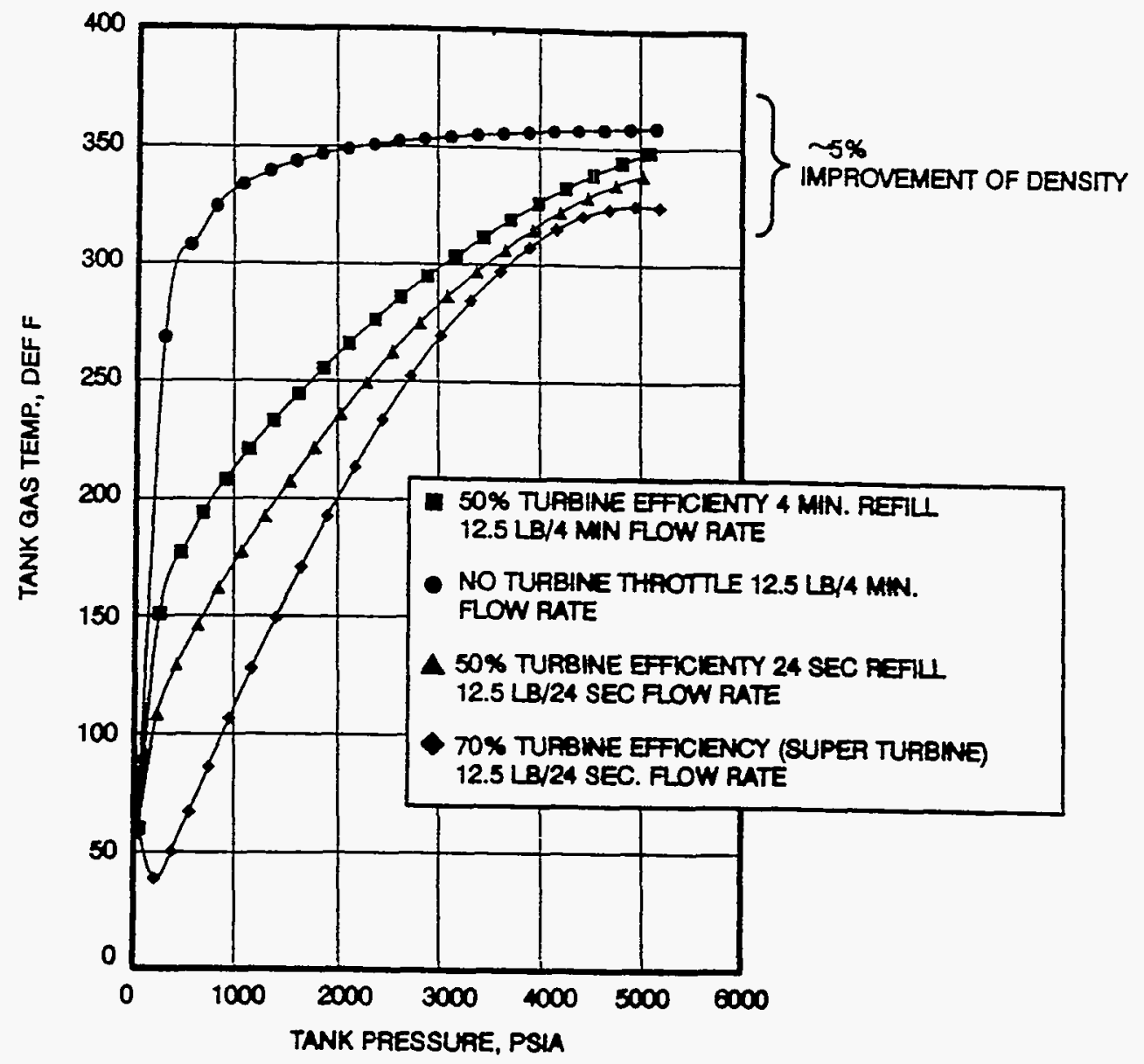

Figure 4-6. Hydrogen Tank Refueling Temperature Rise

10-24115-1

As part of the development research on the Hydrogen Storage Subsystem, an EDO LiteRider, Model $45 \mathrm{~L}$, cylinder was subjected to a hydrogen fast fill ( $5000 \mathrm{psia}$ ) and discharge test. The purpose of the test was threefold:

- To determine the overpressure required to achieve a 5000 psia fill

- To determine overpressure relief thermal temperature requirements

- To investigate the vessel material compatibility with hydrogen.

Temperature data was recorded from thermocouples placed inside the bottle. The hydrogen was supplied by five 6000 psia hydrogen storage cylinders connected by $3 / 8^{\prime \prime}$ stainless steel tubing. The cylinder was filled to approximately 5150 psia within 30 seconds. The cylinder was then left at pressure for approximately four hours. Finally the hydrogen was rapidly discharged. The vessel was then cut into sections for analysis. 


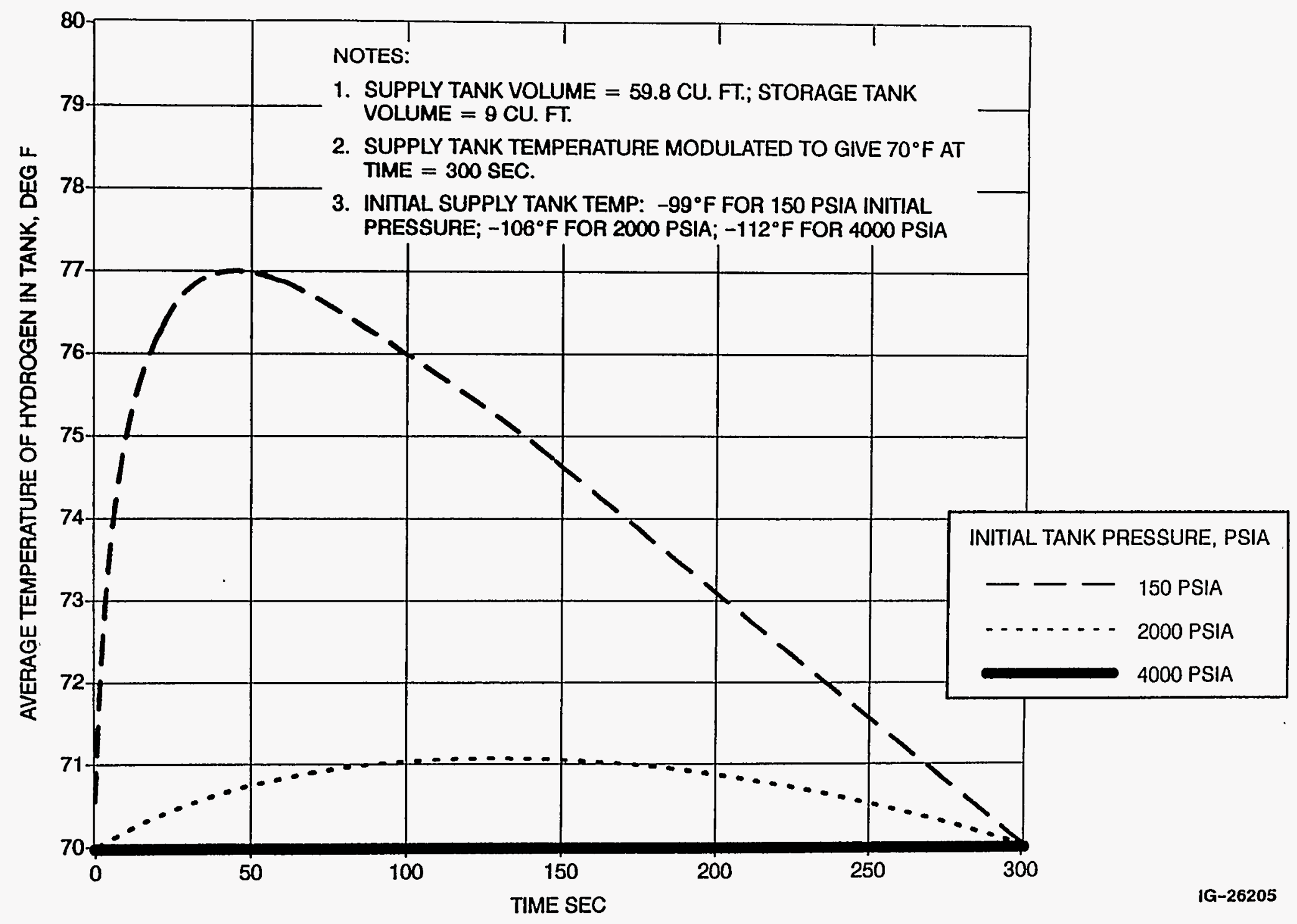

Figure 4-7. Refueling Tank Temperature Rise without Turbine 
The results of the test procedure are especially encouraging. The test indicates that an overpressure of 800 psia (5800 psia total) is required to achieve a settled pressure of 5000 psia. This pressure is much less than the overpressure which was analytically determined. Actual heat transfer from the entering hydrogen to the vessel is far better than that which was calculated. Samples of the liner material from the test vessel and from an untested vessel were taken to AlliedSignal for analysis. Laboratory analysis indicates that no changes were detected in the liner material due to the hydrogen pressurization, soak, and rapid depressurization cycle.

\subsubsection{High Pressure Refueling Schemes}

Three potential refueling schemes are shown in Figure 4-8. The first utilizes a 60 cubic foot 8000 psia reservoir which feeds gas through a throttle and a heat exchanger to produce the $100^{\circ} \mathrm{F}$ hydrogen to the tank at 5000 psia. The second scheme is similar to the first except that a cascade of two reservoirs is used to reduce total compression costs. The 4000 psia reservoir fills the tank partly, followed by the 8000 psia reservoir. The third system employs a liquid stationary reservoir which pumps liquid hydrogen to a vaporizer in order to refrigerate the hydrogen to $100^{\circ} \mathrm{F}$. An economic analysis of the alternative schemes is necessary to determine the optimal configuration.
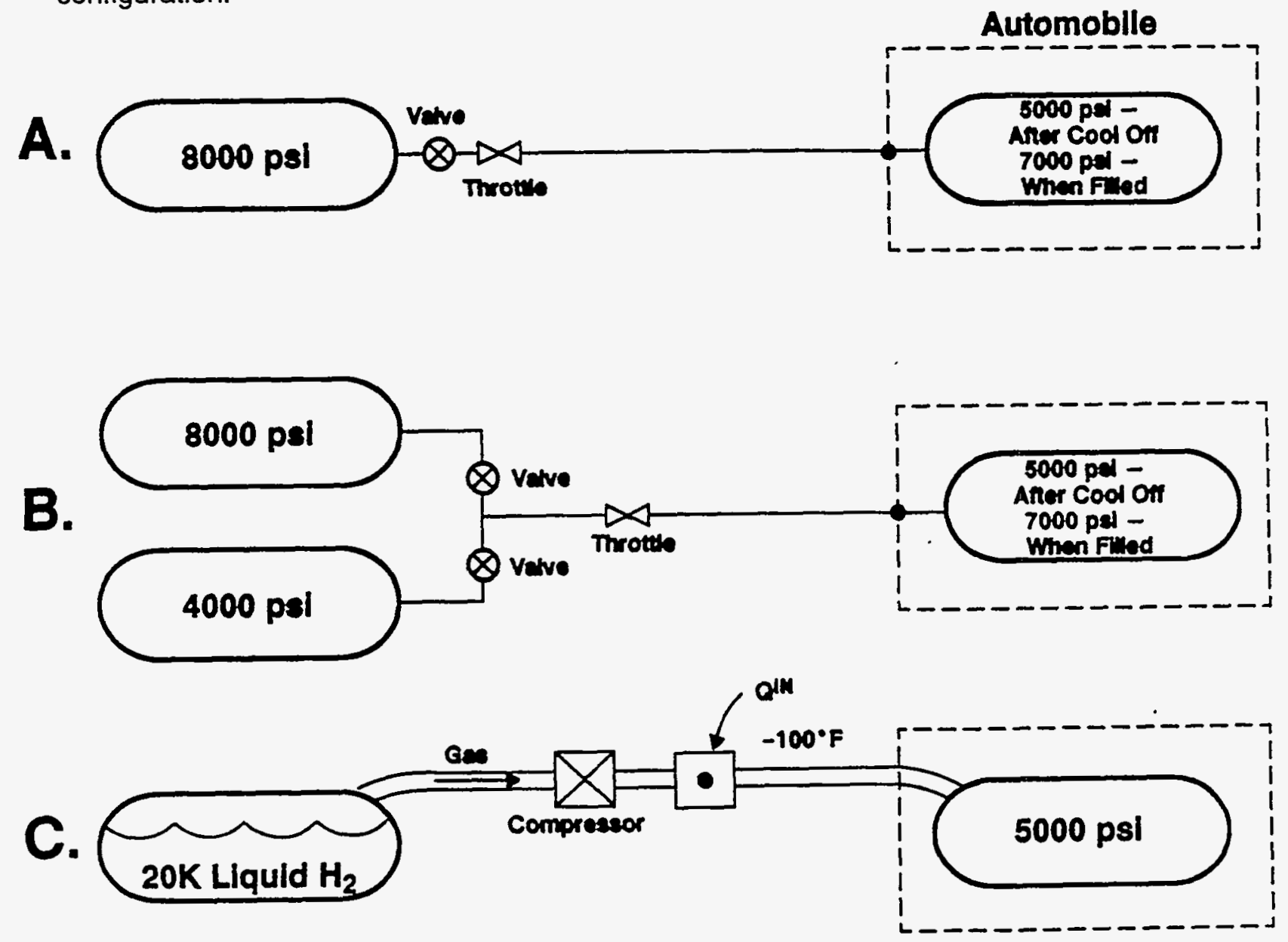

IG-24350-1

Figure 4-8. Potential Refueling Schemes for Pressurized Gas Storage Systems 


\subsubsection{Barriers To Commercialization}

The primary barrier to the large-scale commercialization of this technology is cost. The pressure, weight, and volume requirements for effective hydrogen storage restrict vessel materials to the strongest and lightest pressure vessel overwrap fibers. The carbon fiber utilized in the pressure vessels is the primary cost driver in the hydrogen storage system. Current carbon fiber world production capacity would have to double in order to support production of 100,000 vehicles per year. Evaluation of the potential cost reductions achievable through economies of scale for carbon fibers is necessary.

The thermal issues involved in the refueling process pose some additional technical challenges. Compression heating during refueling results in a significant increase in gas temperature in the vessel, thus reducing storage efficiency. Providing an overpressure to the storage system is necessary to achieve a complete refuel within five minutes. The cost impact of a thermally-managed sub-ambient hydrogen supply needs to be investigated.

Safe operation of pressurized hydrogen storage systems must also be demonstrated. Issues of flammability due to leakage and sudden release of pressure must be dealt with in the detailed design of the system and demonstrated prior to commercial deployment and customer acceptance.

\subsection{Liquid Hydrogen Storage System Concept}

Liquid hydrogen storage on the vehicle has been identified as an alternative approach to pressurized gas storage, with potential advantages in both cost and volume. However, challenges posed by operational and renewable-source infrastructure considerations must be taken into account in evaluating the viability of this system. Key system performance goals are summarized in Table 4-2.

Table 4-2. Liquid Hydrogen Storage System Design Goals

Hydrogen Storage Capacity
Total Subsystem Weight
Total Subsystem Cost
Total Volume
Mile Life
Operation
Refueling Time
Safety

$12.5 \mathrm{lbs}$
$100 \mathrm{lbs}$
$\$ 300$
$<6 \mathrm{ft} 3$
100,000 Miles
Transpare nt
5 Minutes
Equivalent to Gasoline

\subsubsection{System Schematic - Liquid Hydrogen}

A schematic of a liquid hydrogen storage system is given in Appendix F, Figure F-6. The storage dewar is connected to the fuel cell via a manual service valve, a pressure relief valve, and 
a pressure regulator. A pressure switch is connected to a tank heater which may be required to boil off hydrogen gas for maximum-rate consumption.

\subsubsection{Liquid Hydrogen Safety Issues}

The refueling of a liquid hydrogen dewar can potentially be severely hazardous. In addition to frostbite, liquid hydrogen $\left(20^{\circ} \mathrm{K}\right)$ can cause nitrogen and oxygen in the air to liquefy if not properly insulated and isolated. Liquid oxygen is extremely hazardous when in contact with various substances. In addition, the risk of oxygen entering a liquid hydrogen storage system is very serious.

\subsubsection{Refueling of a Liquid System}

Refueling a dewar is more complicated and time consuming than a pressurized gas vessel. An empty dewar will boil off significant amounts of hydrogen as it is being cooled to the temperature of liquid hydrogen. Measuring the hydrogen retained by the dewar is also difficult, particularly in the high-pressure system where the liquid/gaseous boundary can become indeterminate. Significant engineering efforts to automate the refueling process are required in order for liquid hydrogen systems to attain commercial viability.

A schematic of the proposed liquid refueling system is shown in Figure 4-9. Liquid is pumped by pressure in the reservoir or the pump, as required. A vent return line sends gas from the automobile tank back to the reservoir.

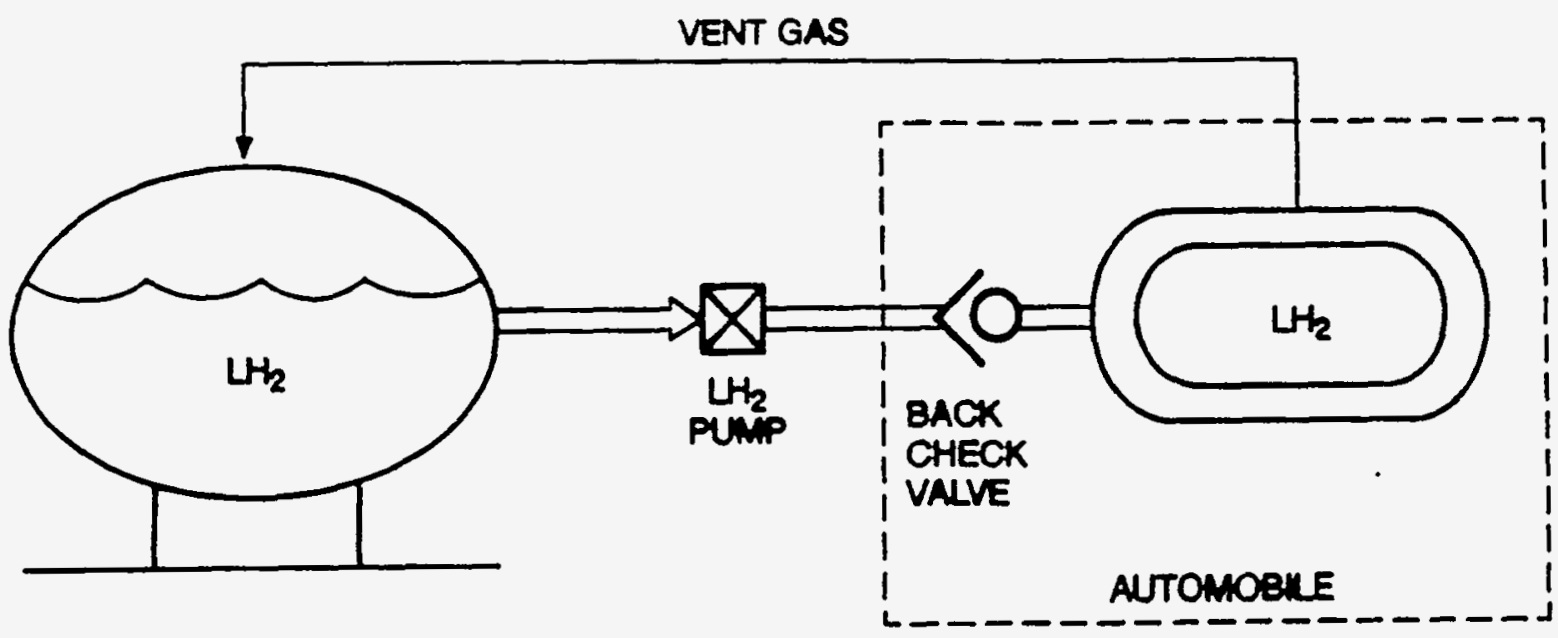

Figure 4-9. Proposed Liquid Refueling Scheme 


\subsubsection{Barriers To Commercialization}

A number of technical challenges currently impede the wide-spread commercialization of liquid hydrogen storage systems. As heat leaks into the dewar, hydrogen gas must be vented after a "lock-down" time has elapsed to avoid bursting of the vessel; vaporization of liquid hydrogen can generate pressures as high as 20,000 psia if fully restrained to ambient temperature. Boil-off of liquid hydrogen raises several operational issues. Boil-off gas must not be directly vented due to the associated flammability hazard; this is particularly true in parking structures. The boil-off gas could be reacted in a small fuel cell, a catalytic reactor, or a combustor. Such a device has not yet been designed and demonstrated for this application.

The boil-off rates also affect the economics of liquid hydrogen storage systems. With current technology, boil-off rates of about two percent per day are achievable. This translates into a hydrogen loss of $0.25 \mathrm{lbs}$ per day for a storage of $12.5 \mathrm{lbs}$. Therefore, if the vehicle were totally idle, the dewar would begin to vent after one day and would be empty in 50 days. An adequate solution to the boil-off problem would be to increase the lock down time by increasing the vent pressure of the dewar. Computational Analyses have shown that by using a vent pressure of 2000 psia, the lock down time could be increased to 80 days.

However, this would require a dewar with a substantially reinforced internal tank in order to withstand the additional pressure, thus increasing cost and complexity. Cryogenic refueling hazards and complexity also pose some serious barriers to commercialization of the on-board liquid hydrogen storage system.

\subsection{Dewar Size Estimates}

The volume required to store $12.5 \mathrm{lbs}$ of hydrogen in liquid form is less than $3 \mathrm{ft}^{3}$. Based on currently available designs, this translates into an external dewar volume of about $6 \mathrm{ft}$, as shown in Appendix F, Figure F-7 (most of the additional $3 \mathrm{ft}^{3}$ required is for a vacuum void insulation jacket). Hence, a significant reduction in storage volume can be achieved with liquid hydrogen storage. A schematic of the installation for a liquid hydrogen system is shown in Figure 4-10.

Liquid dewars are operated at relatively low pressures (typically less than $150 \mathrm{psia}$ ). As a result, a significant cost reduction can be achieved compared to pressurized gas storage, since no high strength reinforcing materials are required for a dewar. They are typically constructed of stainless steel sheet and welded together. 



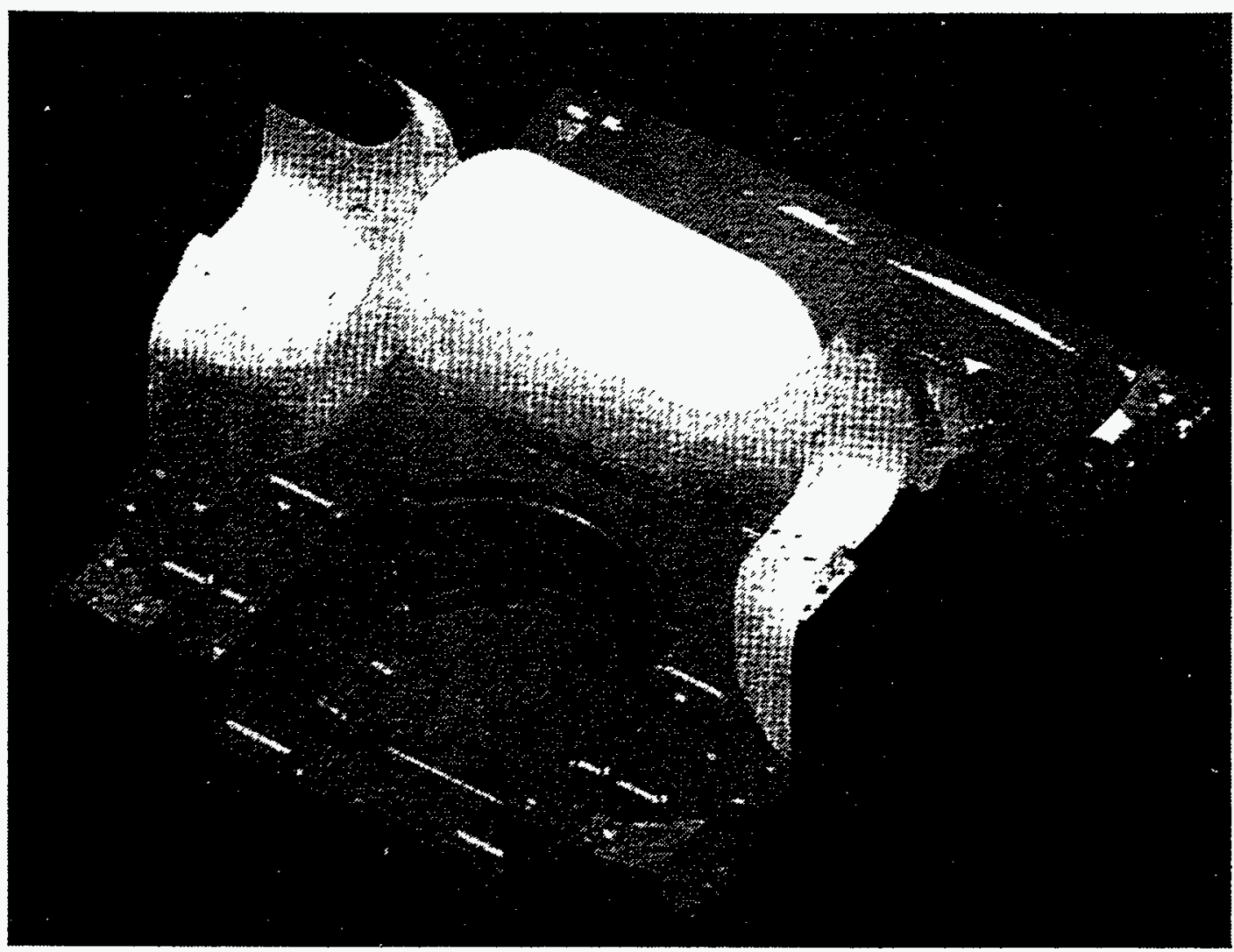

Figure 4-10. Liquid Hydrogen Installation Layout (1-Tank) 


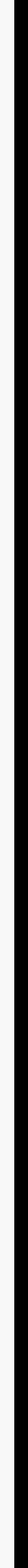




\section{SECTION 5 \\ LOAD LEVELING UNIT SUBSYSTEM}

The Fuel Cell Stack (FCS) provides the DC Power Bus with a continuous energy source for normal operations, while the Load Leveling Unit (LLU) provides energy to supplement the FCS when transient power demands are requested. A trade study to select the LLU that is best suited for the Direct Hydrogen Fueled Proton Exchange Membrane Fuel Cell System for a Hybrid Vehicle (DPHV) system has been performed. The three technologies that were considered as candidates included the use of batteries, flywheels, and capacitors to provide the energy for transient conditions. After consideration of cost, availability, weight, and other factors, the battery technology was selected for the DPHV system.

Once the LLU power source was selected, the requirements for the electronics necessary to interface the LLU with the FCS, power bus and motor controller were defined. The requirements, circuit selection, and operation are discussed in the following paragraphs.

\subsection{Load Leveling Unit Concept}

The most cost effective way to realize the high efficiency and low emissions of a direct hydrogen-fueled fuel cell-powered vehicle and still retain the performance characteristics inherent in today's Internal Combustion Engine (ICE) is through the use of an auxiliary power source. This technique allows the fuel cell to provide power efficiently to the electric motor for most vehicle drive situations, while the auxiliary power source provides power to augment the fuel cell during peak vehicle load situations such as acceleration. Following these peak load periods, the auxiliary source is recharged from the fuel cell using excess power not required for the motor. As an added bonus, the auxiliary power source is available as "bootstrap" power for the fuel cell start-up.

Figure 5-1 illustrates the major components required for the operation of the LLU, the Load Leveling Controller (LLC), the chopper/regulator, and the battery pack. The key element in the successful and efficient operation of the LLU is the LLC. Although the FCS subsystem performs in a closed loop fashion for optimal efficiency for any given load, the LLC imposes that load via the chopper/regulator based on the vehicle power or battery recharge needs at any given moment. The LLC uses inputs from the power bus (current and voltage), battery State of Charge (SOC) and FCS status as the bases for its control algorithm outputs to the chopper/regulator. The controller's main control output is a duty cycle control signal to the chopper/regulator, which forces more or less average current onto the vehicle primary power bus and thus places a larger or smaller electrical load on the FCS.

The battery pack is the "leveler" part of the LLU. It stores electrical energy provided by the FCS during non-peak power modes, by the motor during regenerative braking or from an external power source when the vehicle is non-operational. The battery gives up its energy under the following conditions: 


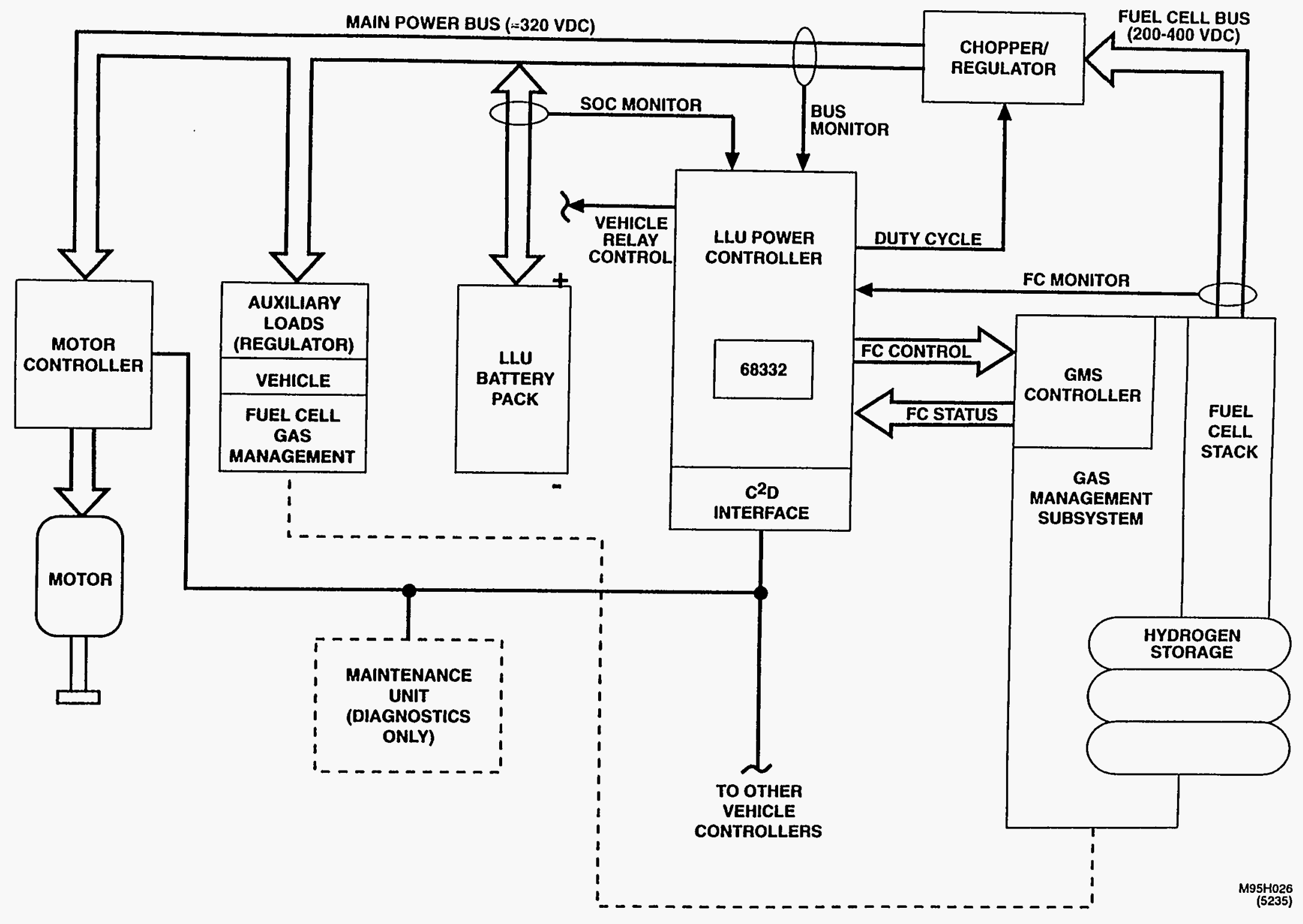

Figure 5-1. LLU Component Configuration 
- When FCS power is unavailable during start-up and power is required for auxiliary vehicle and FCS components.

- When the FCS is unable to provide the necessary power for required vehicle performance during peak power cycles such as rapid acceleration.

The system architecture with the batteries located directly on the motor controller power bus was chosen due to the lower impedance ( $60 \mathrm{mohm}$ in a 320 VDC stack) and relatively constant voltage characteristics of the battery packs which are available as compared to those characteristics of the FCS subsystem. Because the battery pack repeatedly is charged and discharged during a drive cycle, impedance is critical to the vehicle's operating efficiency. Energy losses for these charge/discharge cycles are thus minimized with the battery directly on the motor controller power bus.

The FCS, with a voltage variation from 200 to 400 VDC over its load range and with a nominal impedance of 125 mohm, operates more efficiently as an average power device with its output regulated by the chopper/regulator.

\subsection{LLU Subsystem Description}

Because LLU operation is determined by vehicle modes of operation, an overview of LLU operation is best illustrated by a typical drive cycle. Figure 5-2 illustrates the various modes the LLU will undergo and the relationship of FCS and the LLU battery power outputs during these modes. The optimization of system performance by the LLC for each mode is critical to achievement of the overall desired efficiency (and thus vehicle range).

\subsubsection{Overall System Overview}

The 9 modes of system operation are shown in Table 5-1 and are described in the following pages. Each of these descriptions include the system status and a brief summary discussion of the mode.

- System Dormant Mode (Mode 1)

Status:

- FCS Power: OFF, unless supporting battery recharge

- FCS Ancillaries: OFF, unless supporting battery recharge

- Regeneration: None

- Vehicle Velocity: N/A, vehicle stopped

- Vehicle Ancillaries: Off 


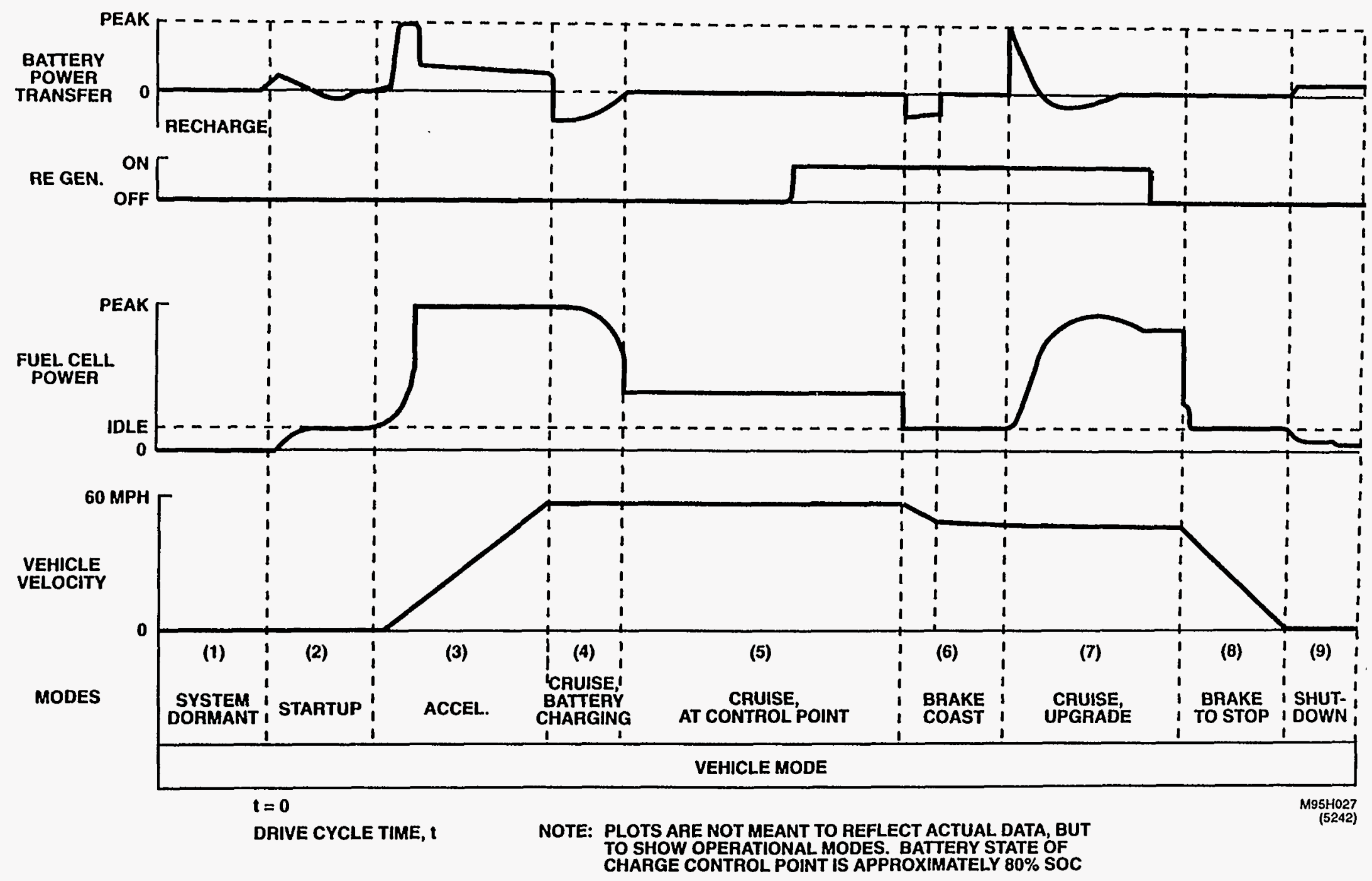

Figure 5-2. Vehicle Operational Effects on LLU Operation 
Table 5-1. DPHV Mode Description

\begin{tabular}{cll}
$\begin{array}{c}\text { Mode } \\
\text { Number }\end{array}$ & \multicolumn{1}{c}{ Title } & FCS Power \\
1 & System Dormant & Off \\
2 & System Start-up & On \\
3 & System Acceleration & Full Power \\
4 & Cruise & $\begin{array}{l}\text { Full Power then } \\
\text { Cruise Power }\end{array}$ \\
5 & Cruise & On \\
6 & Brake, Coast & Idle \\
7 & Cruise, Up grade & Increased Power \\
8 & Braking & \\
9 & System Shutdown & Idle \\
\end{tabular}

\begin{abstract}
LLU Batteries
Charging if source available

Provides power to FCS and vehicle

Provides power to motor as required

Recharge from accelerate, then no power output
\end{abstract}

No power output required

Recharge if required, receive regen brake energy

Provide power during FCS ramp up, then recharge, then idle.

Recharge from motor

Idle (assume regen braking has been manually turned off)

During this mode, the primary concerns are that the FCS subsystem is in a safe shutdown, and that the LLU battery pack be left in a SOC range so that the vehicle will be ready for the next drive cycle. Preparation for system shutdown is carried out in mode 9.

\section{- System Start-up (Mode 2)}

Status:

- FCS Power: On, but not yet delivered to motor

- FCS Ancillaries: On

- LLU Batteries: Providing energy to FCS and vehicle accessories

- Regeneration: N/A

- Vehicle Velocity: N/A, vehicle stopped

- Vehicle Ancillaries: On, if required.

During this mode, the FCS subsystem is beginning coolant flow, air flow, and the stack is warming up, using energy from the battery pack to run the FCS anciliary subsystems. Additionally, the battery pack may also be required to provide energy to the vehicle ancillaries such as the dome light or dashboard indicators. Built-In-Test (BIT) status will be provided to the operator during start-up.

The duration of this mode will be dependent on how much time is required before the FCS is able to provide usable power. Thirty seconds is considered the maximum ac- 
ceptable time from initiation of start-up until the FCS is ready to provide power. If further testing of the FCS indicates start-up times longer than this, the battery pack, will be required to provide the additional energy thereby increasing the Ah capacity requirement of the LLU.

\section{- Acceleration (Mode 3)}

Status:

- FCS Power: Full power (worst case)

- FCS Ancillaries: On

- LLU Batteries: Providing "make-up" power to achieve desired acceleration

- Regeneration: N/A

- Vehicle Velocity: Moderate acceleration but requiring more power than the fuel cell can provide.

- Vehicle Ancillaries: On, as required.

During this mode, the FCS may be required to provide the maximum power available, with the battery pack augmenting this power to give the desired acceleration. The LLU dictates this mix of power based on battery SOC and FCS status. The worst case for this mode is the 0 to $60 \mathrm{MPH}$ acceleration in 12 seconds, which was used to determine maximum system power (and thus maximum energy requirements from the battery pack). The LLU battery pack is sized at $2.7 \mathrm{kWh}, 60 \mathrm{~kW}$ peak power so that the acceleration is achieved in 12 seconds as required and the battery drops only to a SOC shown below.

$$
\mathrm{SOC}=95 \%-(60 \mathrm{~kW} * 12 / 3600) \cdot 100 \%=88 \%
$$

\section{$2.7 \mathrm{kWh}$}

assuming a 95 percent SOC at the beginning of the acceleration cycle.

Other variations on this mode are:

- The acceleration rate is lower than the maximum, in which case the FCS requires little or no energy from the LLU batteries

- The FCS is still in its start-up cycle and is not ready to provide full power when acceleration is initiated, and the batteries must provide most or all of the energy for acceleration and cruise until the FCS comes on line 


\section{- Cruise, Battery Charging (Mode 4)}

Status:

- FCS Power: Cruise Power plus Battery Charging Power - decreasing as battery returns to control point

- FCS Ancillaries: On

- LLU Batteries: Accepting charge from FCS to return to control point state of charge

- Regeneration: N/A

- Vehicle Velocity: Constant

- Vehicle Ancillaries: On, as required

In this mode, the FCS provides the necessary power to the drive train to maintain speed. It also provides power to recharge LLU to replace energy consumed during Mode 3. The amount of recharge is determined by the LLC control algorithm which maintains the LLU state of charge at a specified level. The further the LLU is from this control point the more aggressive the charge. As the LLU returns to normal energy level, the power from the FCS approaches the cruise power level.

\section{- Cruise (Mode 5)}

Status:

- FCS Power: On at Cruise Power Level

- FCS Ancillaries: On

- LLU Batteries: Recharging, if required, but not providing power

- Regeneration: N/A

- Vehicle Velocity: Constant

- Vehicle Ancillaries: On, as required.

In this mode, the FCS provides the necessary power to the DC power bus. The FCS ancillaries are optimized for efficiency for that point on the fuel cell performance curve. The worst case for this mode is the Baker Grade drive cycle. Simulation models have determined a sustained requirement for almost $40 \mathrm{~kW}$ output from the FCS for this case. This information was used to size the FCS. The average power required for the cruise mode for normal highway conditions is expected to be in the $10-20 \mathrm{~kW}$ range. 
- Brake, Coast (Mode 6)

- FCS Power: On, idle mode

- FCS Ancillaries: On, minimal power draw

- LLU.Batteries: Accepting Regenerative Braking Power (SOC increasing above control point)

- Regeneration: On (if enabled) delivering energy to the battery proportional to the deceleration rate.

- Vehicle Velocity: Decreasing

- Vehicle Ancillaries: On, as required

This mode represents vehicle braking followed by a no power coast. While the brake is depressed, a proportional amount of energy is recovered and directed to the battery for recharging. If the LLU was previously at the SOC control point, the SOC would increase above this point. When traction power was again needed, the LLC would allow this excess energy to be consumed prior to requesting additional power from the FCS. If the LLU remains below the control point after braking, normal operation resumes immediately upon application of traction power.

\section{- Cruise on Grade (Mode 7)}

Status:

- FCS Power: On at elevated power level

- FCS Ancillaries: On at elevated power level

- LLU: Provide supplemental power while FCS ramps up. Recharge after FCS assumes full power requirement

- Regeneration: N/A

- Vehicle Velocity: Constant

- Vehicle Ancillaries: On, as required.

This mode is representative of reapplication of traction power after a short term idle situation such as coast or while waiting at a stop. Initially the LLU provides supplemental power until the FCS ramps to the required power level. The FCS then provides traction power plus recharging power to return the LLU to the control point. 
If the grade exceeds 8 percent, then the FCS will be incapable of supplying all the required power so the LLU will continue to provide supplemental power as required similar to Mode 3.

\section{- Brake to Stop (Mode 8)}

Status:

- FCS Power: On in idle mode

- FCS Ancillaries: On at minimal power

- LLU Batteries: Recharging, if required

- Regeneration: Disabled (for this example)

- Vehicle Velocity: Decreasing by mechanical braking and road/zero losses

- Vehicle Ancillaries: On as required

This mode represents a braking action without regenerative braking. Here traction power is zero and all braking energy is dissipated as heat with no recovery. If the LLU has been providing supplemental power during Mode 7, the FCS would provide recharging energy during this mode.

\section{- System Shutdown (Mode 9)}

Status:

- FCS Power: Preparing to Power Down

- LLU Batteries: Recharging, if required

- Regeneration: None

- Vehicle Velocity: Stopped

- Vehicle Ancillaries: On until shutdown complete.

During this mode, the GMS is performing an orderly shutdown of its FCS. Dependent on the results of further safety studies (particularly for the case of leaving a parked vehicle with the FCS running at a low idle), the system may stay on long enough to bring the LLU battery pack to full SOC and possibly to perform an equalization charge. The LLC will "supervise" this orderly shutdown and will store the last SOC measurement before it is also shut down. Safety concerns may prevent continued operation of 
the fuel cell after the ignition is turned off. In this case it may be necessary to recondition the LLU during periods of opportunity while driving the vehicle.

\subsubsection{Battery Pack Assembly}

The DPHV program will require a battery pack to supplement the energy being supplied by the PEM FCS. PEI has performed a series of computer modeling exercises, as discussed in Section 2.0, to determine the required battery pack capacity. The results of this modeling effort indicate LLU battery pack requirements as shown in Table 5-2.

\section{Table 5-2. LLU Battery Requirements}

\section{Requirement}

Nominal Battery Pack Voltage

Minimum Operational Battery Voltage

Peak Battery Power (6-10 Seconds)

Maximum Battery Energy

\section{Value}

320 VDC

$240 \mathrm{VDC}$

$60 \mathrm{~kW}$

$2.7 \mathrm{kWh}$

Additional desired characteristics include:

- Good recharge performance of less than 60 minutes from a 50 percent $S O C$

- High specific energy; greater than $30 \mathrm{Wh} / \mathrm{kg}$

- High volumetric energy; greater than $80 \mathrm{Wh} /$ liter

- Good peak power; greater than $0.2 \mathrm{~kW} / \mathrm{kg}$

- Availability by the third quarter of 1995

Existing batteries available for electric and/or hybrid vehicles typically target some but not all of the Table 5-2 requirements. Batteries with high peak power will not have adequate energy, those with sufficient energy will be excessively heavy, those with good recharge capabilities degrade from excessively deep discharge cycling. The "Perfect" battery is currently not available but several companies are working toward solutions to meet the hybrid electric vehicle needs.

PEl has performed a study of numerous battery technologies including the following: LeadAcid, Nickel-Cadmium, Nickel Metal Hydride, Nickel-Iron, and Lithium Monosulfide. Although some of these technologies show promise in meeting the needs of Hybrid Vehicles their maturity of design, cost, or other limiting constraints make their use in current vehicle development prohibitive. The selection process focused not only on the battery's ability to provide pack performance to meet the requirements detailed in Table 5-2 but also on the volume, weight, and packaging flexibility. Additionally the availability of batteries for near term applications has made certain battery types and manufacturers more appealing than others. 
The battery pack, implementation, battery selection, and conclusions are discussed below:

- Battery Implementation

The battery pack selected will supply 320 VDC to the vehicle power bus to meet the requirements of the motor selected for this program (see Section 1.0). Most of the battery manufacturers surveyed supply their products in 2 VDC individual cells which, in most cases, are packaged into a 12 VDC module. Figure 5-3 shows the typical configuration for the battery pack and the instrumentation necessary for battery pack monitoring.

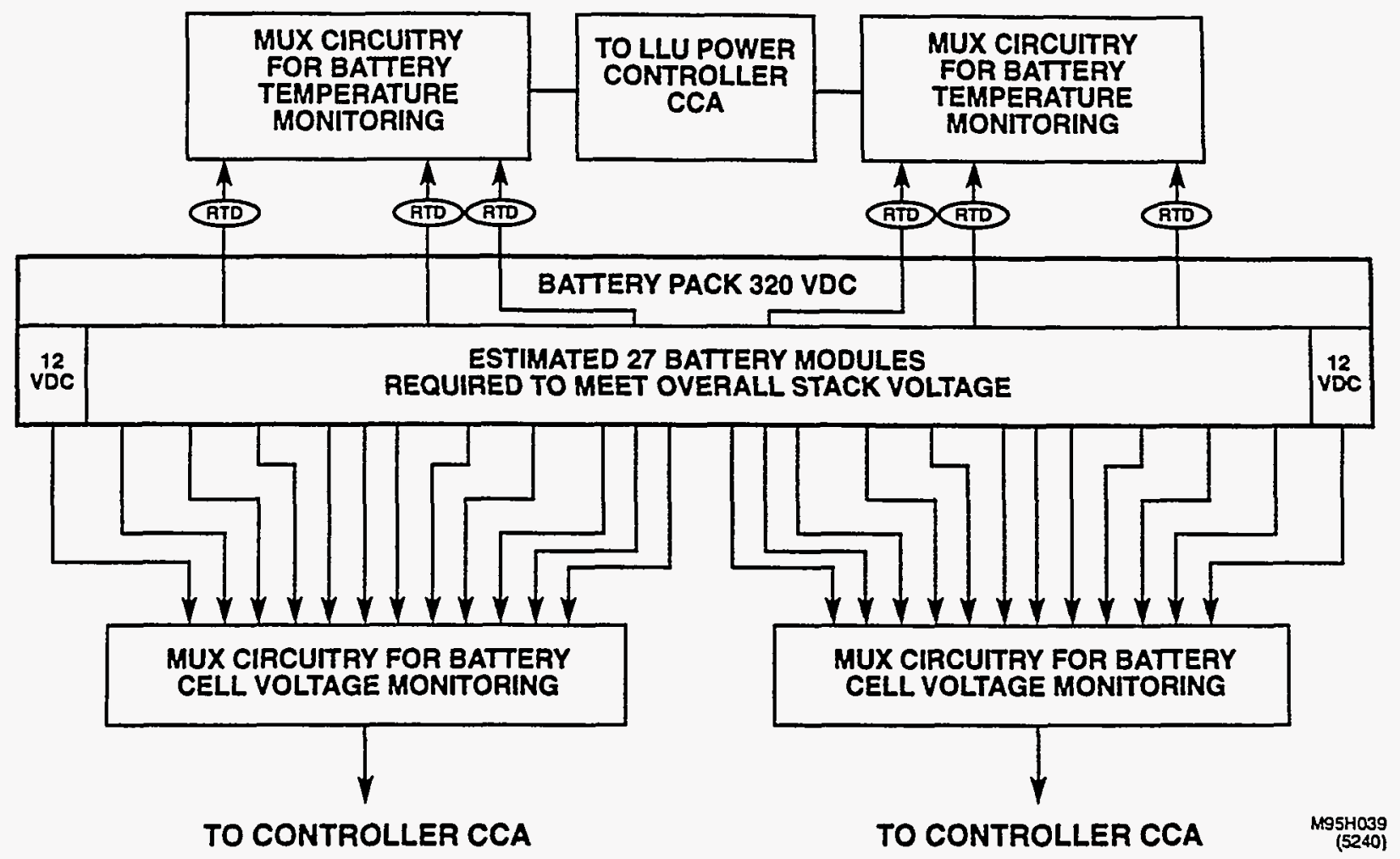

Figure 5-3. DPHV Battery Configuration for Cell and Stack Monitoring

The battery pack will be monitored at intermediate points within the pack using a simple voltage measurement scheme to determine each cell's condition and to identify any performance degradation within the pack. Temperature monitoring will be implemented within the pack using a thermistor bead configuration as shown in Figure 5-4. Additionally, the overall battery pack will be periodically returned to 100 percent SOC to avoid degradation of individual cells. This equalization cycle serves to prolong the life of the pack in the hybrid vehicle environment of repeated charge/discharge cycles. 
THERMISTOR BEAD

FENWAL 192-502LET-A01

5 KOHM $2 \%$

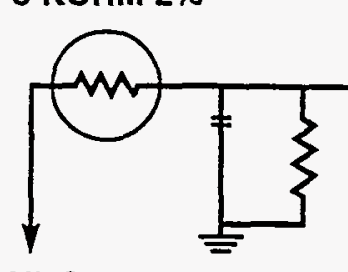

5 VDC

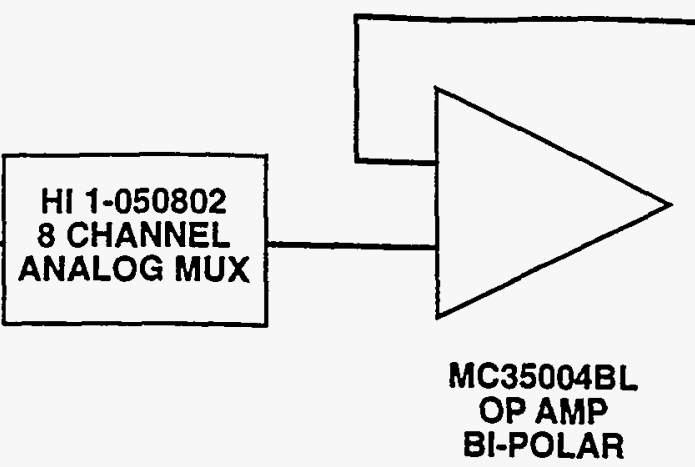

BI-POLAR

Figure 5-4. Typical Battery Temperature Sensing Circuitry

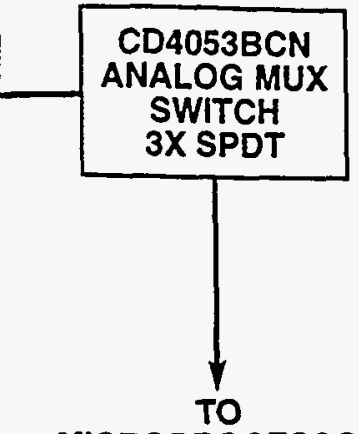

MICROPROCESSOR

- Battery Selection

PEl's investigation has led to a focus on the Lead-Acid type batteries. Over the past few years, innovations in Lead-Acid batteries have improved energy density, power, and cycle life. Integral to these innovations has been the development of composite materials for use in the battery plate designs. In several instances companies are using a composite lead wire to form a mesh to make up the battery grid system with individual layers separated by an insulating material. Among the companies leading in these technological innovations are Electrosource and Bolder Technology.

The Bolder Technology design incorporates a spiral wound approach, Figure 5-5, and their resulting batteries are showing a high peak power output in the range of 0.8 to 1.0 $\mathrm{kW} / \mathrm{kg}$. At present they have developed a 1.2 Ah cell with an individual cell voltage of 2.0 VDC. Bolder currently has capability to supply a battery "string" consisting of four individual battery mini-stacks to provide $320 \mathrm{VDC}$ at $4.8 \mathrm{Ah}$. Bolder is also working toward a 10 Ah pack design which better suits the needs of DPHV. However, this effort is currently not a high priority and requires additional research funds to promote an accelerated design effort. As Table 5-3 shows, the Bolder Battery compares very favorably to the other choices because of the high peak power capability. Additionally, the Bolder Battery is stated to be a sealed device which makes the mounting options more flexible. Availability, however, may be a problem for the current DPHV program. Bolder has indicated a mid-1995 availability for a prototype battery pack. The total output of $4.8 \mathrm{Ah}$ would not be adequate for PEl to test all aspects of the vehicle drive cycles but could be used for approximately 50 percent of the testing to provide data concerning the feasibility of using this technology in its later development stages. 


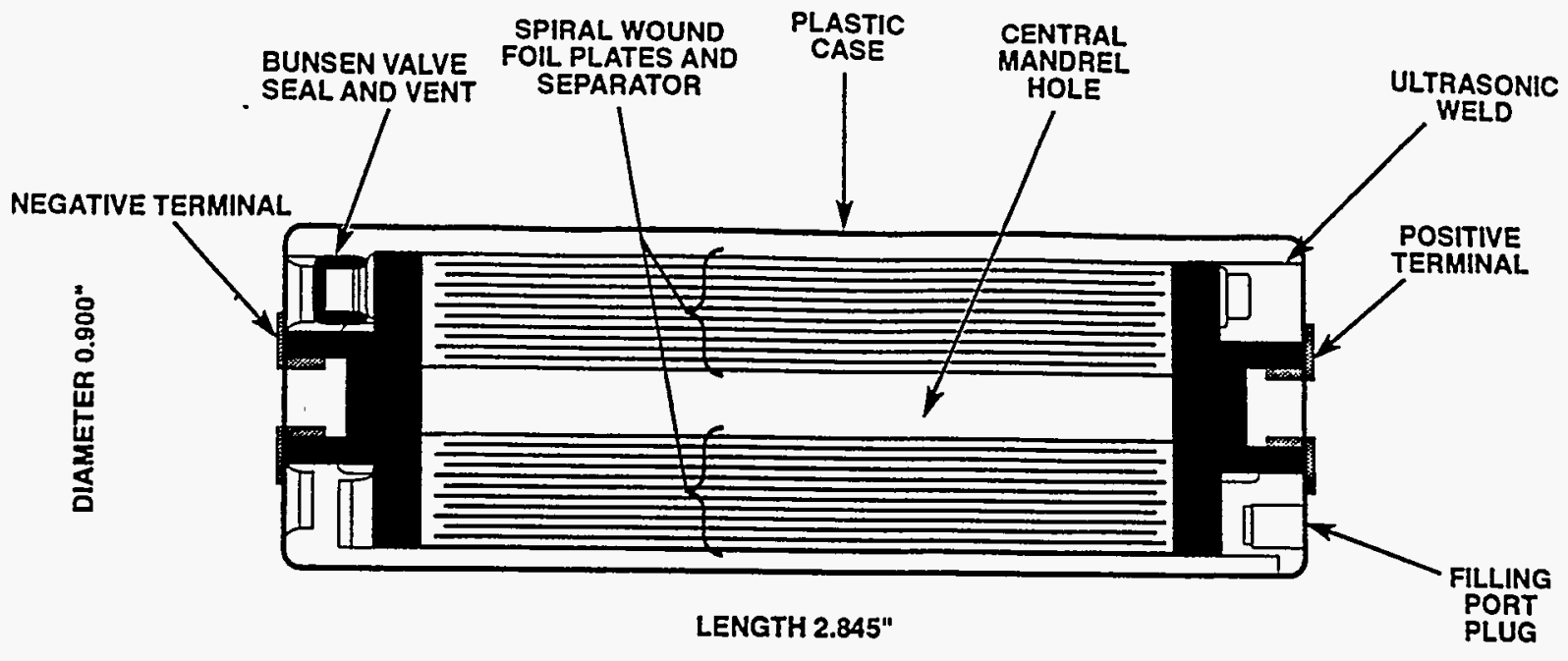

M95H047

Figure 5-5. Bolder Spiral-Wound Battery Technology

Table 5-3. Battery Technology Comparison Trade-Off Matrix

Electric Chemistry
Source
Specific Energy (W-hr/kg)
Volumetric Energy (W-ht
Peak Power (kW/kg)
Self-Discharge Loss
Price/Output ( $\$ / k W$-hr)
Reliability/Life Cycles
Impedance (Ohms)
Mounting Orientation
Overcharge Capability
Individual Cell Voltage
Weakness
Strength

Technology Maturity (10= mature)

Nickel Cadmium
SAFT STM5-200
55
104
.175
2000
$>900$

Plates must be vertical

Low gassing at High SOC

1.2 volts

Very expensive

Environmentally insuitable

10

\section{Lead Acid}

Electrosource Horizon $12 \mathrm{~N} 85$ is baseline

41

83.9

.240

$.003 \%$ per day $27^{\circ} \mathrm{C}$

150

TBD

$<.0015$ per 12 Volt Module

Plates must be horizontal sealed

Thermal and gassing and life considerations

2.0 volts

No hybrid batteries being developed currently

High energy, rapid recharge, sealed low impedence

8
Lead Acid

Boulder Technology

$\sim 30$

$-85$

$.8-1.0$

$<.3 \%$ per day

TBD

TBD

.0016 per 1.2 A-hr Cell

Flexible since cells are

Good up to 1 Coulomb

2.0 volts

Not currently available

High power density, rapid recharge, sealed, flexible mounting

2 
The Electrosource "Horizon" battery incorporates the composite lead wire technology which is woven into grids which are then interconnected by wire to form a bipolar unit (see Figure 5-6). One grid is pasted as a positive and the other as a negative with the paste being a proprietary material which does not require hydro-setting. Electrosource currently is producing a valve regulated lead-acid battery specifically tailored for pure electric vehicle applications where higher specific energy is a critical requirement. Electrosource currently has in production their "N" series of batteries (12N95 and 12N85) with the $12 \mathrm{~N} 95$ being the battery designed for Chrysler for the TEVan programs. The $12 \mathrm{~N} 85$ is a second generation design using the same technology but with improvements in the case and connectors to reduce the overall size and weight of the battery pack.

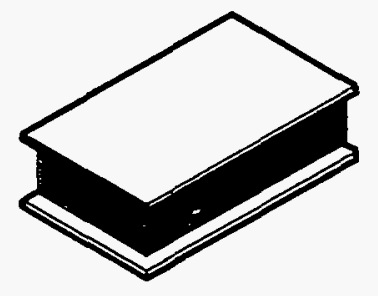

HORIZON HORIZONTAL PLATE ORIENTATION

- ELIMINATES SHEDDING OF ACTIVE MATERIAL FROM GRIDS

- ELIMINATES INTRA-PLATE ACID

STRATIFICATION

- IMPROVES HEAT DISTRIBUTION

- IMPROVES OXYGEN RECOMBINATION

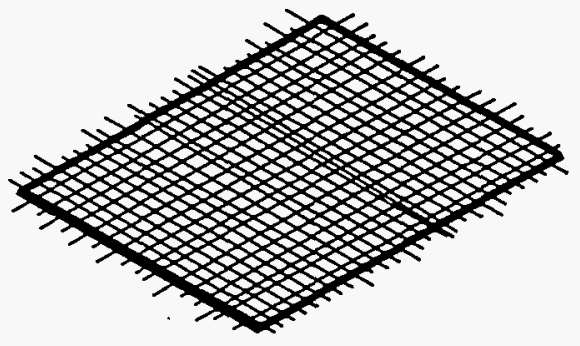

HIGH TENSILE STRENGTH MATERIAL STABILIZES PLATE DIMENSIONS ELIMINATING GRID GROWTH

- ALLOWS USE OF PURE LEAD OF LOW TIN CONCENTRATION ALLOYS TO MINIMIZE CHARGE GASSING AND POSITIVE PLATE CORROSION

- GLASS-FILAMENT CORE ELIMINATES NEED FOR ANTIMONY,CALCIUM OR OTHER ALLOYS TO INCREASE GRID STRENGTH

- CO-EXTRUSION OF LEAD WIRES PRODUCES EXTREMELY FINE GRAIN STRUCTURE HIGHLY RESISTANT TO GRID CORROSION

\section{Figure 5-6. Electrosource "Horizon" Battery Features}

Electrosource is also addressing the unique needs of Hybrid vehicles by developing their new " $U$ " series of batteries. The " $U$ " series is being developed to produce better peak power performance with reduced size and capacity. Electrosource is currently in a position to immediately supply their $12 \mathrm{~N} 85$ model batteries for use during the DPHV development phase with intentions of having the " $U$ " series available for the integration phase.

As currently configured, the Electrosource 12 N85 will meet the power requirements identified for DPHV but will exceed capacity in terms of battery energy (20.4 kWh supplied versus $2.7 \mathrm{kWh}$ required). This battery will also exceed the desired weight but this should not be a problem in the initial developmental phase. 
The best that industry has to offer is still not the "Perfect" battery for the DPHV application. During this phase of the program, certain trade-offs will have to be made. The most critical of these trade-offs will be the ratio of energy to weight/volume. The weight of a battery stack which is currently available, with sufficient capacity to meet system requirements, will be detrimental to overall performance if implemented into the vehicle. This issue will be addressed as the program continues.

\section{- Conclusions}

PEI has determined that the Electrosource "Horizon" battery will be the battery of choice during the development phase. It will be a program goal to test a battery pack from Bolder later in the program. Additionally PEI will continue to investigate the available technologies as new battery designs mature and approach a point of manufacturing viability.

\subsubsection{Chopper/Regulator Assembly}

Requirements for the Chopper/Regulator subsystem are shown in Table 5-4. The implementation of the design to satisfy these requirements are discussed below.

Table 5-4. Chopper/Regulator Requirements

Requirement
Maximum Output Power
Minimum Output Power
Output Voltage
Input Voltage
Non-isolated
Current Regulator

Value

$40 \mathrm{~kW}$

$0 \mathrm{~kW}$

240 to 320 VDC

200 to 400 VDC

Current Regulator

- Circuit Selection

The LLU chopper/regulator is required to supply a voltage to the bus that can be either higher or lower than the FCS output. This prevents the use of either a basic step-down or a step-up regulator only. By combining the two basic regulator circuits, a step-up/ step-down configuration can be created that employs only one simple inductor. The combined configuration is shown in Figure 5-7.

\section{- Current Mode Control}

The system design requires that the output current of the chopper/regulator be controlled. Current mode control methods used in typical power supplies are well suited for this application. A current request is determined by the LLC and a control voltage proportional to the required current is sent to the chopper/regulator. A simplified current control circuit is shown in Figure 5-8. When the switching device is commanded 


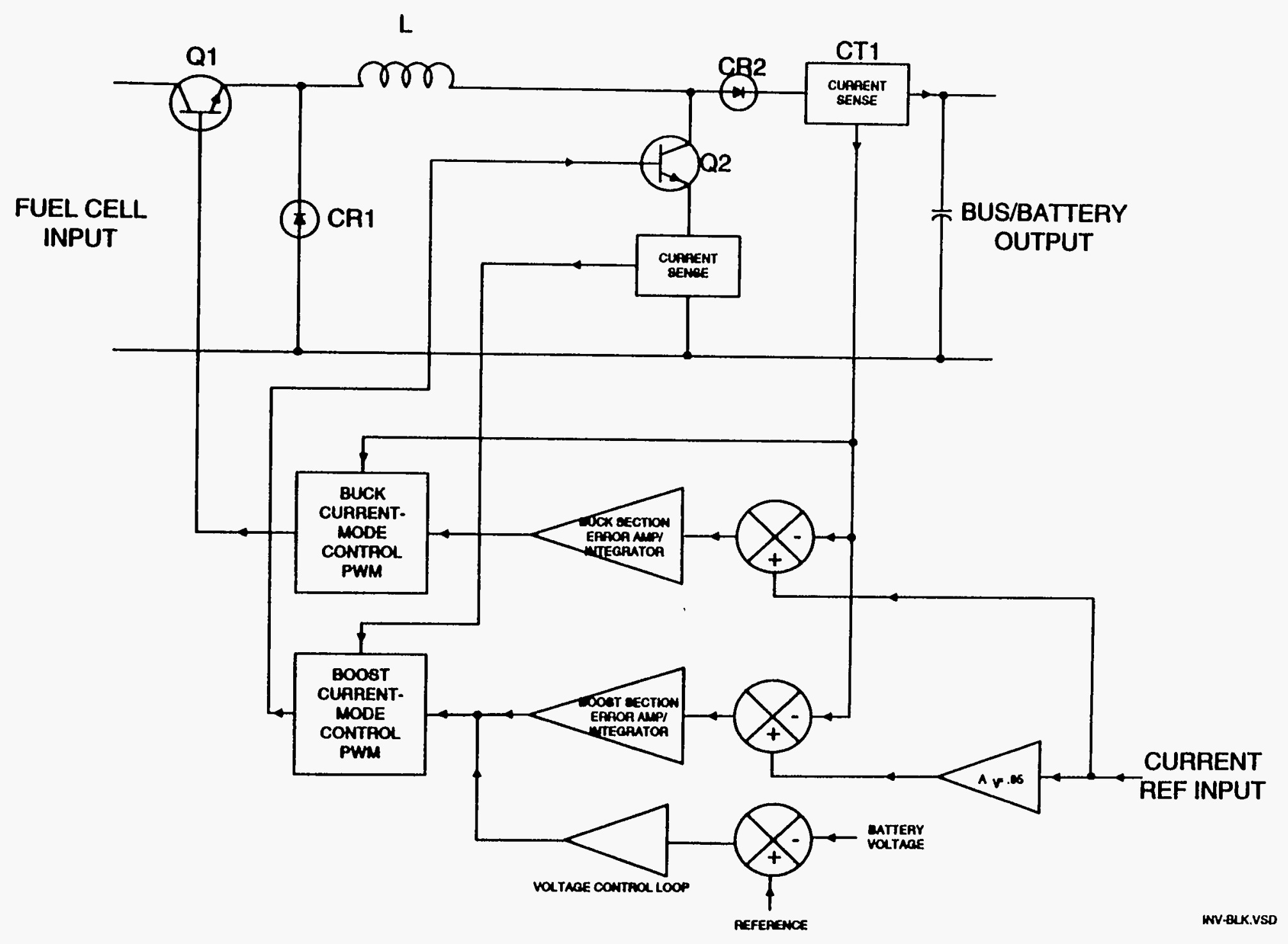

Figure 5-7. Chopper/Regulator Configuration 


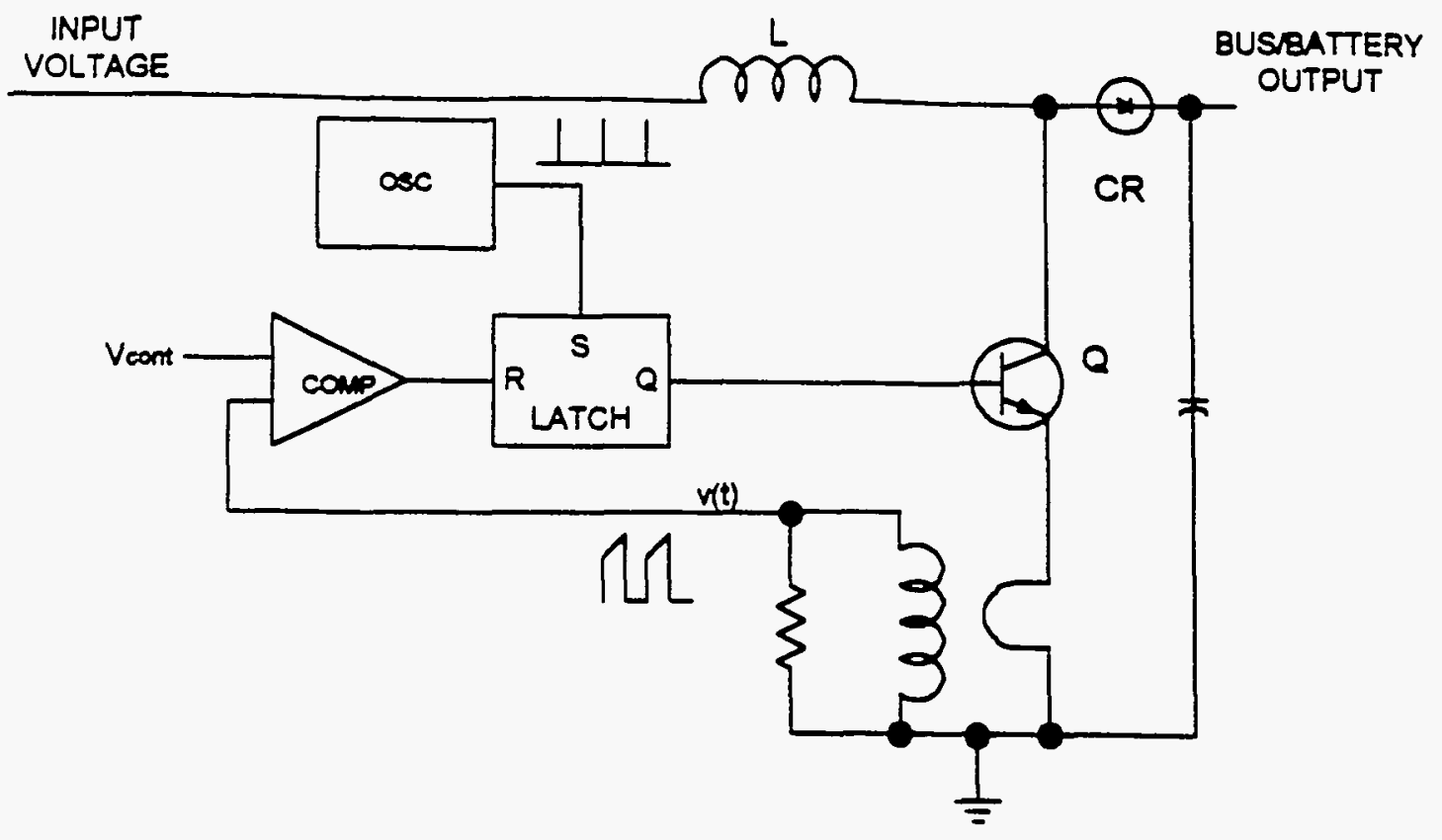

Figure 5-8. Current Control Circuit

"ON" by the oscillator, the upward ramping inductor current is monitored with a current transformer and converted to a voltage, $v(t)$, that is a scaled replica of the inductor current.

When this voltage reaches the control voltage , Vcont, the switching device is turned "OFF". The switching device remains "OFF" until the next oscillator pulse triggers the circuit "ON". Therefore, the control loop regulates the peak current through the switch and through the inductor. The peak current is averaged and compared to the request from the controller, and a resulting error signal is generated to provide the degree of accuracy required by the system.

Some advantages of the current mode control are:

- Excellent open-loop D.C. and dynamic line regulation result because current sources inherently reject input voltage changes.

- Automatic pulse-by-pulse current limiting.

- The inductor pole and 2 nd order characteristics are eliminated, resulting in a simplified control loop. Extremely high closed loop gain-bandwidth can be safely used. 
- No conditional loop stability problems exist when the effective battery capacitance changes.

- Boost Operation

If the output voltage to provide the requested current is greater than the fuel cell voltage, the circuit is automatically configured as a boost (step-up) regulator by circuits internal to the chopper/regulator. Specifically this is accomplished by turning the switching device Q1 "ON" for the entire time. This mode allows the output voltage to be adjusted to any value that is greater than the input. The simplified circuit for this mode is shown in Figure 5-9.

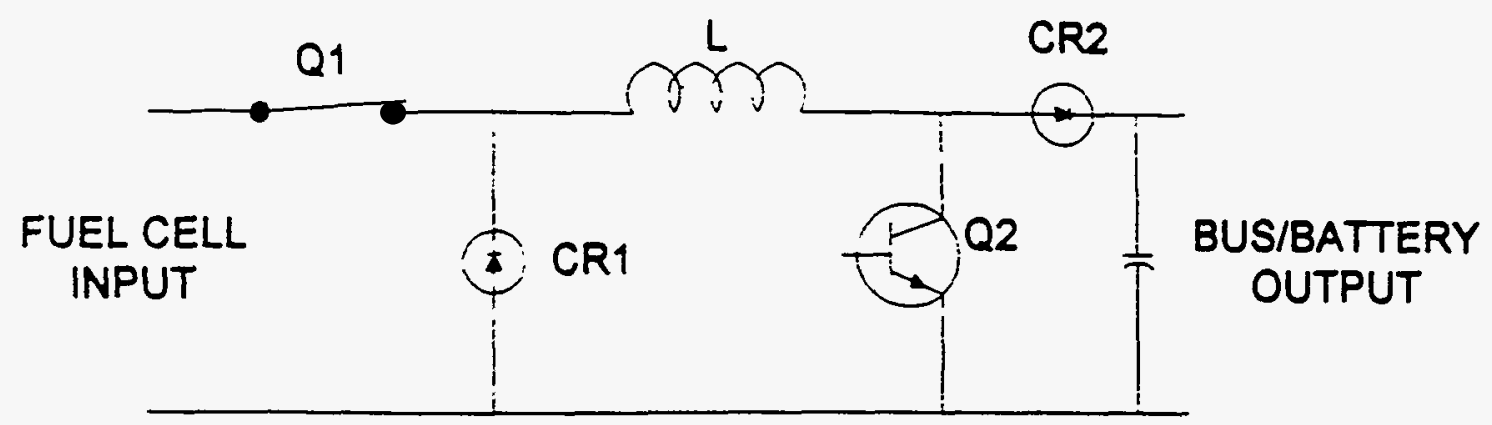

Figure 5-9. Simplified Boost Current Circuit

The circuit operation can be described as follows. When Q2 is in the "ON" state, the current in the inductor $L$ ramps from zero current to a value:

Eq 5-1)

$\|=($ Vin $\times$ ton $) / L$

where ton is the time $Q 2$ is turned "ON".

After Q2 has been on for ton seconds, Q2 is turned "OFF" and the magnetic field in the inductor will start to collapse generating a reverse voltage that forward biases diode CR2. For this design, the system operates in a discontinuous mode where the inductor current is allowed to completely decay to zero each cycle. All energy that was stored in the inductor is then transferred to the output. The output voltage becomes:

Eq 5-2)

$$
\text { Vout }=\operatorname{Vin}(\text { ton } / \text { toff })+\operatorname{Vin}
$$

Equation 5-2 shows that the output is always greater than Vin and is controlled by the ratio of the ton to toff. 


\section{- Buck Operation (Step-Down)}

If the required output voltage is less than the fuel cell voltage, the circuit is configured as a buck (step-down) regulator by inhibiting switching device Q2 "ON" for the entire time. This configuration allows the output voltage to be adjusted to any value that is less than the input. The simplified circuit for this mode is shown in Figure 5-10.

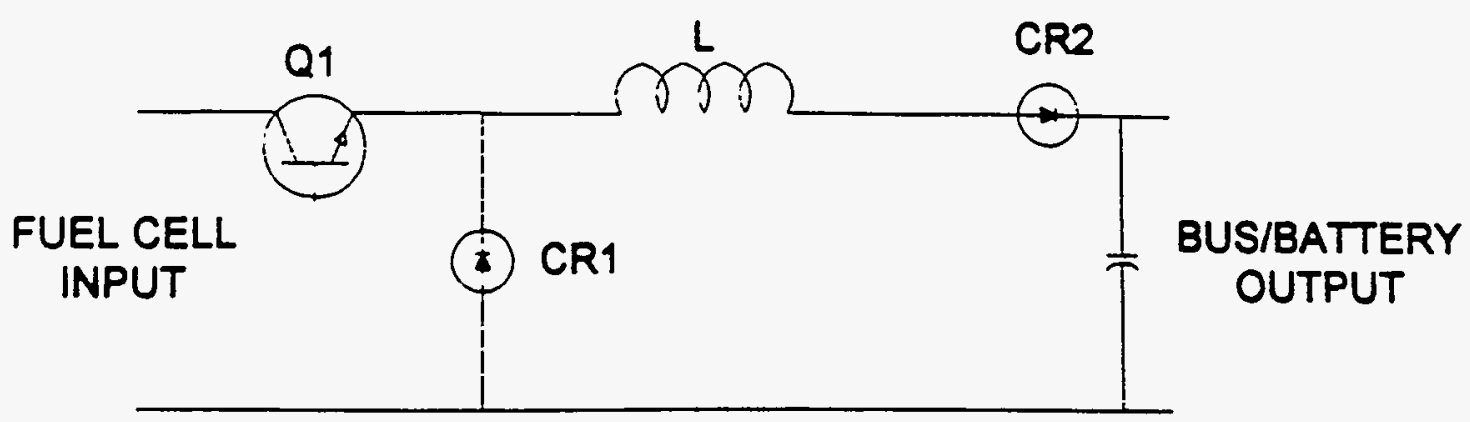

Figure 5-10. Simplified Buck Current Circuit

The circuit operation can be described as follows. Switching device Q1 provides a variable duty cycle square wave to an output filter. The filter averages the waveform and produces a DC output. When Q1 is in the "ON" state, the current in the inductor $L$ increases to a value:

Eq 5-3)

$$
I I=((\text { Vin }- \text { Vout }) \times \text { ton }) / L
$$

where ton is the time Q1 is turned "ON".

After Q1 has been on for ton seconds, Q1 is turned "OFF" and the magnetic field in the inductor will start to collapse generating a reverse voltage that forward biases diode CR1. The peak current will decay at a rate of Vout/L. Since the inductor is sized to not completely discharge during the cycle, the circuit operates in a continuous mode. Energy that was stored in the inductor is then transferred to the output. The output voltage becomes:

Eq 5-4)

$$
\text { Vout }=\text { Vin } \times \text { ton } /(\text { ton }+ \text { toff })
$$

This equation shows that the output is always less than Vin and is controlled by the ratio of the ton to the switching period. 
- Operational Tradeoff Discussion

Transformer isolated topologies were rejected as candidates. The application does not require input-to-output isolation, and the addition of typical transformers would decrease the efficiency by two to three percent. For a $40 \mathrm{~kW}$ throughput power, this would result in an additional 800 to 1200 watts to be dissipated by the thermal management system. Three non-isolated topologies were compared to determine the optimum choice for this application. The three methods were:

1) Non-isolated flyback type - This type is capable of both step-up and step-down operation as required by the application, but develops negative output voltages. To use this circuit would require that the fuel cell return be connected to the positive terminal of the battery.

Major advantages - simple control circuit; inherently power limited.

Major disadvantages - right half plane zero, difficult to compensate for all required operating conditions; negative output voltage.

2) Combined step-up/step-down, single controller - The basic circuit connections are shown in Figure 5-8. However, it is possible to use a single controller to simultaneously modulate both switching devices.

Major advantage - simple single control circuit; Since a switching device is in series with Vout, current limiting can easily be implemented.

Major disadvantages - Two switching devices operating simultaneously doubles switching losses. While this is not a problem for low input voltages ( $<50 \mathrm{VDC})$, it becomes a major power loss for this application since the input voltage is 200 to 400 VDC.

3) Combined step-up/step-down, dual controllers - The basic circuit is shown in Figure 5-7. Two separate controllers are use, one for the buck section and one for the boost.

Major advantage - Since a switching device is in series with Vout, current limiting can easily be implemented. Unlike the configuration discussed in 2) above, only one power switch is modulated at any one time. Switching losses (a serious problem for high input voltages) are limited to one device.

Major disadvantages - Requires two separate control circuits. Requires additional low level circuits to determine when to configure as a buck or a boost circuit.

The combined step-up/step-down topology discussed in 3) above has been chosen for implementation. The disadvantage discussed for this method does increase the control electron- 
ics. However, the cost of these small signal devices is insignificant compared to the reduction in switching losses. The higher losses would reduce the reliability of the power devices, and also result in increased heatsink and thermal management costs. Design considerations for the chopper/regulator are discussed in Appendix A.

\subsubsection{Power Controller}

The LLC will be a microprocessor based system used to monitor and control the energy system of the DPHV project. Requirements for the LLC are described in the following pages.

The LLC will have the following capabilities:

a) Regulate chopper power via an analog output

b) Maintain battery environment

c) Maintain communication with controllers on the Chrysler Collision Detection (CCD) bus

d) Optimize GMS control as defined and matured during the test phase

e) Control and report on the prognostic and diagnostic activity for the Energy Control System

f) Process computations of critical data relating to control algorithms

g) Monitor the chopper/regulator status via a discrete input

\section{- LLC Implementation}

The PEI controller approach is based upon utilizing a previous processor design with some modifications for the DPHV project. This design includes a Motorola MC68332 micro-controller, a 32-bit integrated micro-controller which combines high-performance data manipulation capabilities with powerful peripheral subsystems. The MC68332 features fully static, high-speed complementary metal-oxide semiconductor (CMOS) technology. Based upon the 68020 CPU32 instruction set, the MC68332 provides enhanced system performance and utilizes the extensive software base for the Motorola family of processors (see Figure 5-11 for the MC68332 block diagram).

The MC68332 contains intelligent peripheral modules such as the Time Processor Unit (TPU), which provides 16 microcoded channels for performing time related activities ranging from simple input capture to complex motor control. High-speed serial communications are provided by the Queued Serial Module (QSM) with synchronous and asynchronous protocols available. Two kilobytes of fully static standby Random Access Memory (RAM) allow fast two-cycle access for system and data stacks and vari- 


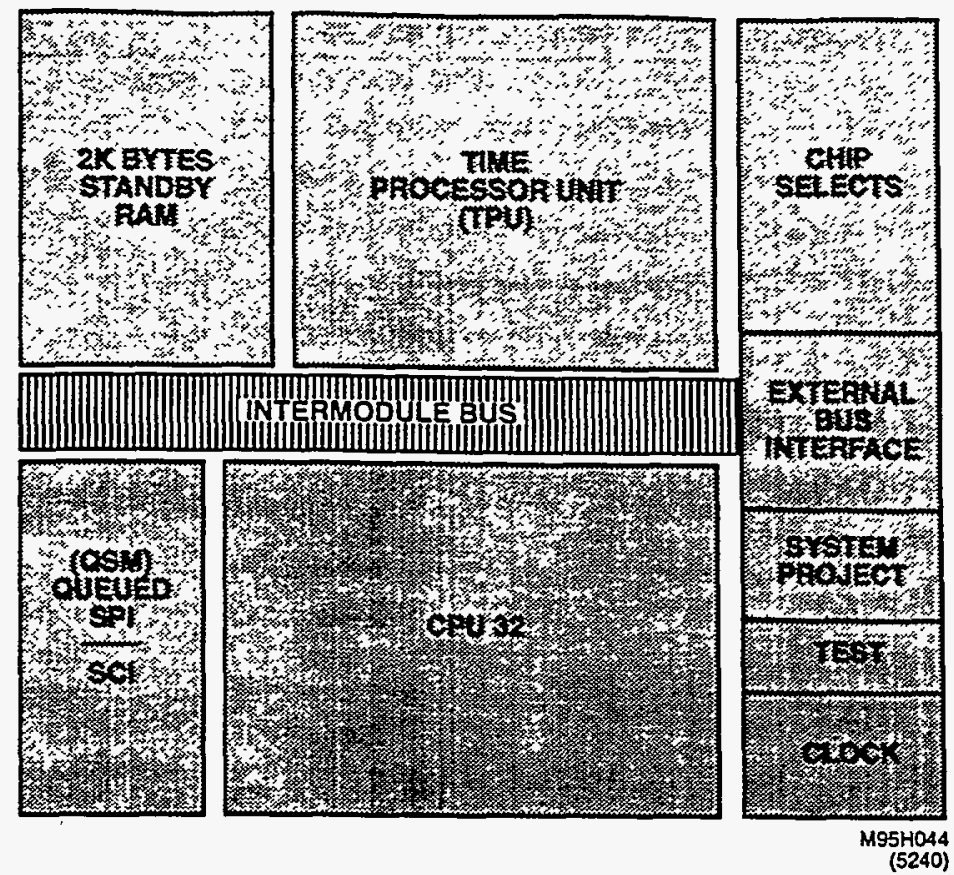

Figure 5-11. MC68332 Block Diagram

able storage with provision for battery backup. Twelve chip selects enhance system integration for fast external memory or peripheral access. These modules are connected on-chip via the Inter-Module Bus (IMB).

The LLC will provide the integrated monitoring and control of the energy system for the DPHV project. See the tables in Appendix B for the Input/Output definition details. Data is gathered from analog and discrete measurements. The LLC will use this data to control a wide range of battery-related functions such as heating and cooling. The LLC will monitor and regulate the power delivered to motor bus from the FCS. Power regulation will be accomplished by supplying an analog input to the chopper/regulator and by supplying an analog signal to the GMS feed forward input. This regulation is based upon battery conditions ( $\mathrm{SOC}$ and temperature), current, and anticipated motor bus requirements with the operational goal being to provide smooth peak power surges in the most efficient manner possible.

Another goal is to recoup, conserve, and optimize energy usage to obtain the 380 mile range goal and to insure long battery life.

The following are some processing items and relationships that must be considered to achieve our overall system goals.

a) Open Circuit Pack Voltage vs State of Charge

b) Pack Voltage vs Rate of Discharge 
c) Cell Capacity vs Cell Temperature

d) Specific Energy vs Specific Power Performance

e) Cell Impedance vs State of Charge

f) Stand Loss Characteristics

g) Optimized Charging Algorithm for the Selected Batteries

h) Optimized Methods of State of Charge Determination

i) Optimization of Fuel Cell power request

j) Optimized Methods of anticipating power needs

k) Controlling the fuel cell feed forward airilow

It is anticipated that significant fuel stack testing will be required before the control algorithms are fully optimized.

The LLC will be designed to provide the following functionality:

1. Determine the Battery SOC based on a number of critical parameters such as Battery Amp Hour Capacity, the current total number of Amp Hours discharged from the battery, and Amp Hours provided by regeneration or the FCS subsystem.

2. Measure total pack voltage.

3. Measure individual module voltage.

4. Measure battery charge and discharge currents.

5. Supervise all charging activities based on a unique algorithm for the specific battery used.

6. Determine battery capacity.

7. Determine battery impedance.

8. Maintain the battery thermal environment during charging if required.

9. Maintain the battery environment within prescribed limits.

10. Supervise a ventilation system to control the accumulation of battery gases if required. 
11. Maintain communications with the Motor Controller and other off-board monitoring devices (i.e. Maintenance Unit [MU] or Data Acquisition System [DAS]).

12. Maintain and regulate requested power from the GMS via the chopper/regulator and feed forward signal. The requested power will be based upon SOC of the battery pack. This will be a linear algorithm since the power requested is interpolated linearly between two SOC endpoints.

13. Provide runtime error detection and reporting. This shall be accomplished using an error prioritization method. The system would be shutdown upon detecting a fatal error.

14. Provide Diagnostics of the LLC.

Software has been written and verified on a prototype system to maintain the battery environment, communicate with other controllers, and process computations of some critical data. The balance of software will be written to complete the functionality discussed above. This software will utilize a mixture of $C$ and 68332 Assembly as appropriate and the RXTC Operating System (OS).

\subsection{DTC Considerations for LLU}

From the onset of the DPHV program, the realization of a vehicle which is cost competitive with existing ICE-powered vehicles has been considered critical to program success. Each major component of the system is being selected or designed with attention to the following factors:

1) Present performance and cost

2) Eventual production cost

3) Obstacles to be overcome or technology which must be advanced prior to the commercial production of a viable system.

The LLU items being considered for DTC purposes include:

1) LLU Power Controller CCA: This includes the Circuit Card Assembly (CCA) on which the microprocessor, memory and signal conditioner, and serial bus interface circuity reside.

2) Battery Pack: This includes the batteries, the tray or enclosure, any venting or forced air accessories, and temperature or voltage transducers.

3) Chopper/Regulator: Includes the CCA and any chassis mounted components related to performance of this circuit. 
4) Packaging and Interconnects: Includes housing, cables, relays, heat sinks, and special cooling components, if required.

DTC considerations for each of these items are discussed below.

- LLU Power Controller

The cost improvements for production will come primarily from the consolidation of functions into fewer components through hybridization or incorporation of functions into Application Specific Integrated Circuits (ASICs). Also as the development program progresses and control of the system is optimized, it may be possible to reduce the circuitry implemented in the development LLC and thus reduce the cost.

- Battery Pack

Major technology and producibility improvements are needed in this area to meet the overall DTC cost goals for the system. Present battery systems for electric vehicles are designed for high specific energy so that range can be maximized. Requirements for this and other hybrid vehicle systems force battery developers toward high peak power, reasonable energy density, and light weight. Although there is a market in the portable power tool industry for this type of battery, the vehicle market is new for this area of development. The battery industry, however, is accelerating development and when the market matures, there should be significant cost reductions. Other items within the battery pack such as transducers, packaging, and cooling accessories are fairly mature technologies and will not see much cost improvement.

- Chopper/Regulator

The major cost drivers for this circuitry are the high current carrying components such as the chopper transistors, diodes, and the inductor. These must be high current and high voltage devices. There is still some room for maturity in the Isolated Gate Bipolar Transistor (IGBT) technology, the selected switching devices for the development phase and a chance for breakthroughs in fabrication techniques for these devices is possible. Otherwise, one would expect only the reductions due to the broader market and higher production quantities brought about by the proliferation of these devices to the automotive market. Presently they are primarily used in stationary power switching stations in industrial applications.

- Packaging and Interconnects

There are no known technology-driven items in this category which will benefit cost as component technology matures. The key to optimization of cost is to apply a strict DTC program to the design of the LLU enclosure and interconnects at the onset of the program and to keep production cost as a major factor in design decisions. 
- DTC Status

Previous DTC estimates lumped the chopper/regulator and the LLC together and the packaging and interconnect elements were not broken out separately. In the future, these will be tracked as separate items as shown in Appendix D. The area of chief interest for the LLU is the battery pack. Technology advancements in the high power/ lightweight battery area is required before the needed drastic cost reductions can be obtained. Ultracapacitors are a possible replacement for the battery pack if the technology advancement/cost reduction progress is more rapid in this area. Both technologies will be tracked carefully through the course of the DPHV program for any advancements which may help the DTC effort. 


\section{SECTION 6 \\ POWER TRAIN REQUIREMENTS}

The power train for the DPHV will consist of a three-phase AC motor with its associated motor controller. This motor is spray oil-cooled. Vector control techniques are used for precise torque generation and exact matching of field to motor capability. The motor controller is powered by a nominal DC voltage of 324 VDC with an operational voltage range from 120 to 400 VDC.

The output torque from this motor is coupled to the wheels via a fixed speed reduction gear subsystem with a gear ratio of 9.34 . Table 6-1 shows the design parameters for this motor.

Table 6-1. Westinghouse 3-Phase AC Induction Motor Design Characteristics

Full Load Parameter

Rated Voltage (Leg-to-Leg)

Rated Voltage (Leg-to-Neutral)

Slip

RPM

Power Factor

Rated Torque

Breakdown Torque

Rated Current

Efficiency

HP at 11000 RPM
Value

160.0

92.38

$1.5 \%$

8220

$89 \%$

123

310

245

$90.6 \%$ (Minimum)

56.0

\subsection{Motor Operating Characteristics}

Table 6-2 shows the full operating characteristics for the Westinghouse motor (NS308 $M A C$ ). The data shows the motor efficiency at various speed and load points (not all data points are shown in this table). At each RPM point, several electric motor output torques and powers are measured. The power into the motor and motor controller (labelled as Battery HP) is also measured. The efficiency of the motor and controller is then calculated from the ratio of the shaft HP to the Battery HP.

Table 6-2. Westinghouse Motor Operating Characteristics

$\begin{array}{rrccc}\text { RPM } & \text { In-lb } & \text { Shaft HP } & \text { Battery HP } & \text { Efficiency (\%) } \\ 1026 & 3.1 & 0 & 0.4 & 14.0 \\ 1034 & 470.2 & 7.7 & 9.9 & 78.1 \\ 1048 & 973.1 & 16.2 & 20.4 & 79.2 \\ 1058 & 1491.3 & 25.0 & 32.5 & 77.0 \\ 1066 & 1970.5 & 33.3 & 44.7 & 74.5 \\ 2043 & 78.7 & 2.5 & 3.2 & 78.8 \\ 2051 & 471.8 & 15.4 & 17.8 & 86.2\end{array}$


Table 6-2. Westinghouse Motor Operating Characteristics (Continued)

$\begin{array}{lrrrc}\text { RPM } & \text { In-lb } & \text { Shaft HP } & \text { Battery HP } & \text { Efficiency (\%) } \\ 2062 & 1234.9 & 40.4 & 46.5 & 86.9 \\ 2075 & 1766.2 & 58.1 & 68.2 & 85.2 \\ 2080 & 1876.7 & 65.3 & 77.3 & 84.4 \\ 3039 & 104.4 & 5.0 & 6.1 & 93.2 \\ 3048 & 713.6 & 34.5 & 38.2 & 90.3 \\ 3057 & 970.8 & 47.1 & 52.0 & 90.5 \\ 3067 & 1502.7 & 73.2 & 81.6 & 89.6 \\ 3076 & 1977.3 & 96.5 & 109.5 & 88.2 \\ 4026 & 25.7 & 1.6 & 2.2 & 73.3 \\ 4031 & 428.0 & 27.4 & 30.3 & 90.5 \\ 4046 & 928.1 & 59.6 & 64.6 & 92.3 \\ 4057 & 1567.7 & 100.9 & 112.4 & 89.8 \\ 4061 & 1703.0 & 109.8 & 124.1 & 88.5 \\ 5037 & 45.4 & 3.6 & 4.6 & 78.3 \\ 5055 & 103.1 & 8.3 & 9.8 & 84.7 \\ 5061 & 880.9 & 70.8 & 77.3 & 91.5 \\ 5068 & 1243.1 & 100.0 & 113.8 & 87.9 \\ 6024 & 86.1 & 8.2 & 9.8 & 84.1 \\ 6030 & 324.4 & 31.0 & 34.4 & 90.3 \\ 6045 & 740.8 & 71.1 & 78.8 & 90.2 \\ 6053 & 8963.3 & 92.6 & 105.6 & 87.6 \\ 7060 & 8.5 & 1.0 & 1.7 & 55.0 \\ 7064 & 40.3 & 4.5 & 5.7 & 78.8 \\ 7070 & 276.7 & 31.1 & 33.9 & 91.5 \\ 7079 & 403.7 & 45.4 & 49.6 & 91.5 \\ 7088 & 617.6 & 69.5 & 78.0 & 89.1 \\ 7096 & 836.3 & 94.2 & 112.0 & 84.1 \\ 8056 & 23.8 & 3.0 & 4.2 & 72.3 \\ 8062 & 72.2 & 9.2 & 11.0 & 84.2 \\ 8068 & 237.0 & 30.3 & 32.5 & 83.3 \\ 8081 & 432.5 & 55.5 & 61.9 & 89.6 \\ 8089 & 591.2 & 75.0 & 87.5 & 86.7 \\ 8091 & 662.7 & 85.1 & 103.2 & 82.5 \\ 9037 & 24.7 & 3.5 & 4.7 & 75.2 \\ 9042 & 69.3 & 9.9 & 11.6 & 86.4 \\ 9048 & 211.4 & 30.4 & 33.1 & 91.8 \\ 9060 & 385.2 & 55.4 & 61.6 & 89.9 \\ 9069 & 515.1 & 74.1 & 88.3 & 83.9 \\ 10083 & 16.8 & 2.7 & 5.2 & 51.2 \\ 10092 & 78.2 & 12.5 & 13.6 & 92.3 \\ 10098 & 265.1 & 42.5 & 46.3 & 91.9 \\ 10104 & 377.6 & 60.6 & 69.9 & 86.7\end{array}$




\section{SECTION 7 \\ AUXILIARY SUBSYSTEM REQUIREMENTS}

Three major subsystems comprise the auxiliary vehicle subsystem. These subsystems are the heating/cooling, regenerative braking and the electrical power, steering subsystems.

\subsection{Heating/Cooling Subsystem Design}

The goal for the design of the heating/cooling subsystem is to develop a heat pump system which will both heat and cool the interior of the vehicle.

System components include two refrigerant coils, one inside the HVAC subsystem and one in the motor compartment, an electric motor-driven compressor operating on $320 \mathrm{VDC}$, a combination expansion valve and receiver/drier which allows for bi-directional refrigerant flow (a new invention from Liberty and Technical Affairs), a four-way valve which controls the direction of refrigerant flow to put the system in the heating or cooling mode and a $134 \mathrm{~A}$ refrigerant. The refrigerant, $134 \mathrm{~A}$, essentially is pure 1,1,1,2-tetrafluoroethane, commonly known as HFC-134A. This HVAC subsystem is designed to have power requirements between 3 and $5 \mathrm{~kW}$. Figure 7-1 shows the HVAC heat pump refrigerant circuit diagram for this design.

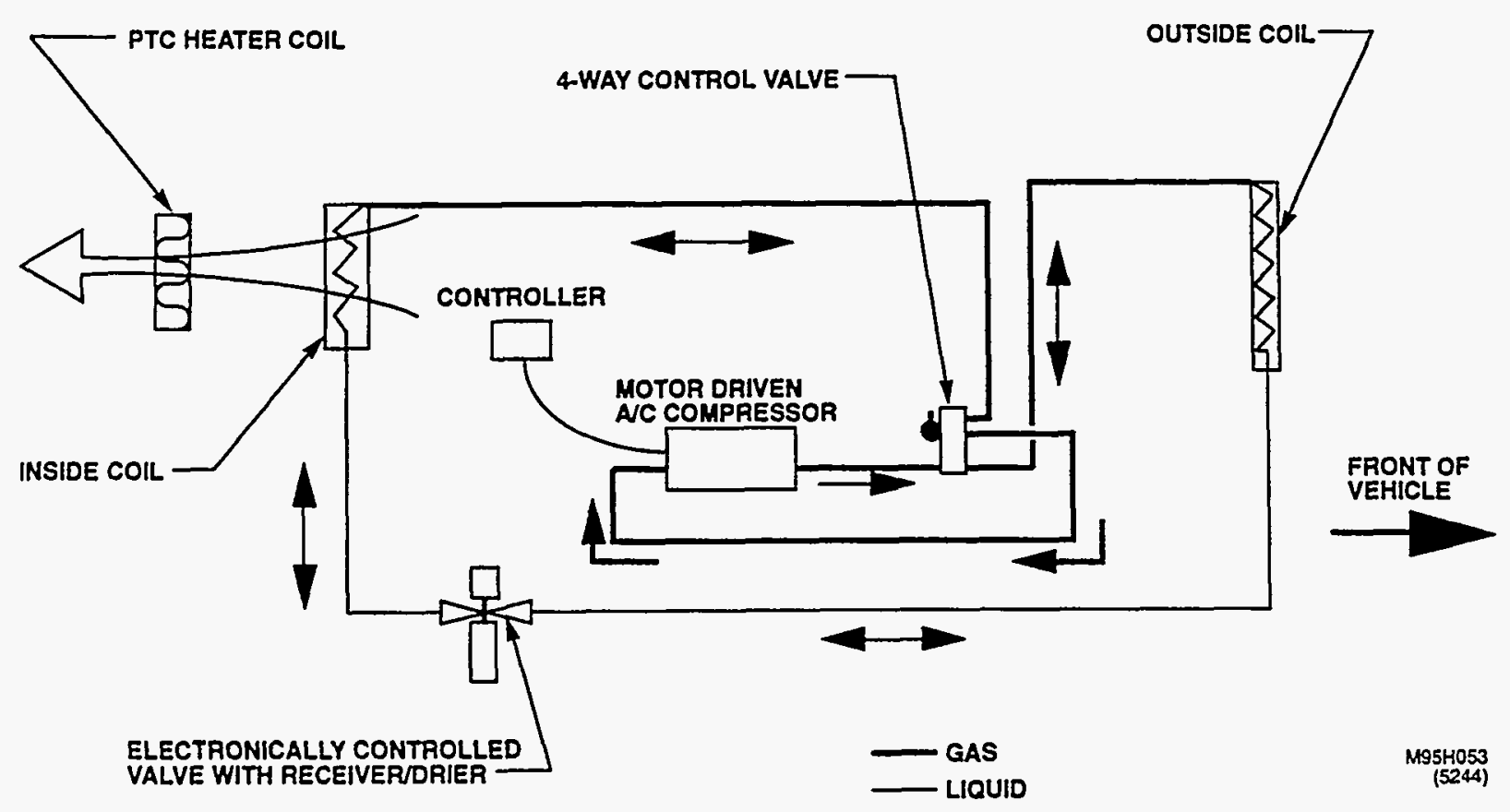

Figure 7-1. HVAC Refrigerant Circuit Diagram 
The benefits of the HVAC design are to satisfy the customer's heating and cooling expectations while minimizing system energy usage. The heat pump system may be used in conjunction with PTC ceramic heaters to meet the federal defroster performance standard, MVSS-103.

The heat pump system has demonstrated heating capability at $5^{\circ} \mathrm{F}$ with a coefficient of performance of 1.5 (less than 2.0 is desirable) at the Valeo test laboratory.

\subsubsection{Auxiliary Subsystem Power Allocation}

Table 7-1 shows the auxiliary subsystem power and weight allocations.

Table 7-1. HVAC Subsystem Allocations

$\begin{array}{lccc}\text { Component } & \text { Max imum Power (kW) } & \text { Supply Voltage (VDC) } & \text { Mass (kg) } \\ \text { Compressor } & 2.0 & 320 & 2.5 \\ \text { Condensor } & \text { N/A } & 2.4 & \\ \text { Evaporator } & (5.23 \text { Capacity) } & 1.8 & \\ \text { Heater HEX/Collector } & (10.5 \text { Capacity) } & 5.0 & \\ \text { Coolant Fan } & 2.0 & 2.0 & 1.8 \\ \text { Heater Blower Fan } & 0.25 & 320 & 0.5 \\ \text { Expansion Valve } & \text { N/A } & 320 & 1.0 \\ \text { Actuators (2) } & 0.05 & 320 & \\ \text { Ducts/Fasteners } & \text { N/A } & 10.0 & \\ \text { Seals } & \text { N/A } & 1.5 & \\ \text { Hoses/Fittings } & \text { N/A } & 2.4 & 0.2 \\ \text { Controller } & 0.01 & 320 & 31.1 \\ \text { Total } & 4.36 & & \end{array}$

\subsection{Regenerative Braking Subsystem}

The regenerative braking subsystem is designed and developed by AlliedSignal Automotive. The purpose for this subsystem is to maximize energy recovery during vehicle deceleration. The design incorporates antilock braking and traction control functions into the base braking system. This design provides a seamless transition between regenerative and friction braking. The subsystem design provides a brake-by-wire feature with dual system pedal actuated hydraulic brakes for fail-safe operation in case of electrical failure. Figure 7-2 shows the overall subsystem configuration.

Electrical specifications for the regenerative braking subsystem include operation on a 12 VDC voltage input, a periodic peak power draw of $0.42 \mathrm{~kW}$, and an average power draw of $70 \mathrm{~W}$.

\subsection{Electrical Power Steering (EPS) Subsystem}

The EPS subsystem is designed and developed by TRW. This subsystem operates on 320 VDC with maximum power requirements less than $1 \mathrm{~kW}$ in stall conditions. The design is a natural solution for electric vehicle power steering applications. 


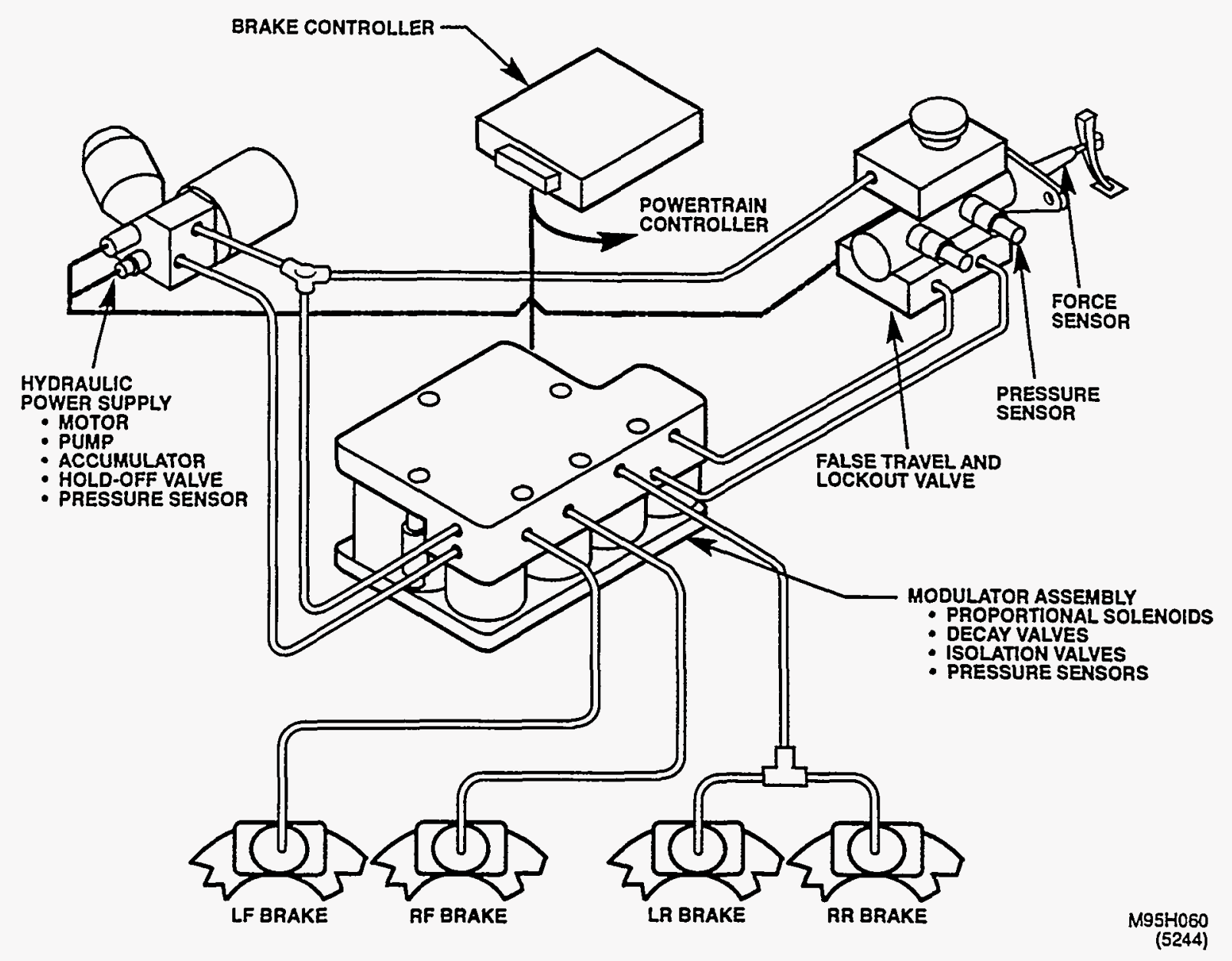

Figure 7-2. Regenerative Braking Subsystem Configuration

The EPS is shown in Figure 7-3. This subsystem has been designed, developed, manufactured, and tested as a complete system. The subsystem provides an energy efficient operation which only uses power when steering is required. Fuel savings up to $0.6 \mathrm{mpg}$ have been achieved on Internal Combustion Engine (ICE) vehicles. Steering subsystem operations have been shown to provide superior dynamic response since the EPS is highly programmable in response to torque, speed, and steer rate.

The design provides better optimization of assist, yaw stability, center feel, and returnability. Interaction of this subsystem with other chassis functions is possible.

Steering assist is available when the motor is not running with a possible $2200 \mathrm{lbs}$ of rack force available. On-board diagnostics are available with better fault detection than conventional systems. 


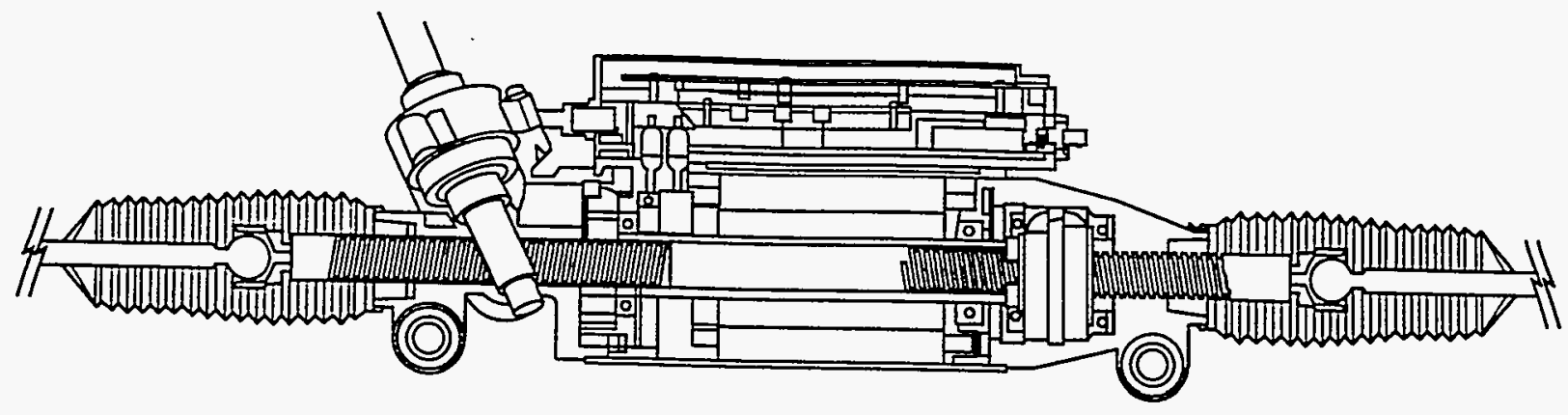

M.95HO32
$(5241)$

Figure 7-3. Electric Power Steering Subsystem 


\section{SECTION 8 \\ ACRONYM LIST AND DEFINITIONS}

Table 8-1 contains a list of acronyms and abbreviations used in this document. Column two of the table contains the definition of the acronym or abbreviation.

\section{Table 8-1. List of Acronyms}

\begin{tabular}{|c|c|}
\hline Acronym & Definition \\
\hline$A C$ & Alternating Current \\
\hline Ah & Ampere-Hour \\
\hline ASIC & Application Specific Integrated Circuit \\
\hline atm & At mosphere \\
\hline BIT & Built-ln Test \\
\hline $\mathrm{CCA}$ & Circuit Card Assembly \\
\hline CCD & Chrysler Collision Detection \\
\hline CHYHV & CHrYsler Hybrid Vehicle \\
\hline CMOS & Complementary Metal-Oxide Semiconductor \\
\hline CNG & Compressed Natural Gas \\
\hline CNGV & Compressed Natural Gas Vehicles \\
\hline $\mathrm{cm}$ & Centimeter \\
\hline CMS & Carbon Molecular Sieve \\
\hline DAS & Data Acquisition System \\
\hline$d B$ & Decibel \\
\hline DFMA & Design for manufacturing and assembly \\
\hline DPHV & Direct-Hydrogen-Fueled Proton Exchange Membrane Fuel Cell System for a Hybrid Vehicle \\
\hline DTC & Design-to-Cost \\
\hline EPA & Environmental Protection Agency \\
\hline EPS & Electrical Power Steering \\
\hline FCS & Fuel Cell Stack \\
\hline FUDS & Federal Urban Driving Schedule \\
\hline GMS & Gas Management Subsystem \\
\hline HP & Horsepower \\
\hline HPCV & Hi Pressure Control Valve \\
\hline HSS & Hydrogen Storage Subsystem \\
\hline HTP & Humidifier Tube Pump \\
\hline HVAC & Heating/Ventilation/Air Conditioning \\
\hline $\mathrm{Hz}$ & Hertz (Cycles/Second) \\
\hline ICE & Internal Combustion Engine \\
\hline IGBT & Isolated Gate Bipolar Transistor \\
\hline IMB & Inter-Module Bus \\
\hline $1 / 0$ & Input/Output \\
\hline IPDS & Integrated Product Development System \\
\hline $\mathrm{kg}$ & Kilogram \\
\hline
\end{tabular}




\section{Table 8-1. List of Acronyms (Continued)}

\section{Acronym}

\section{Definition}

$\begin{array}{ll}\text { kW } & \text { Kilowatts } \\ \text { kWh } & \text { Kilowatt-Hour } \\ \text { I } & \text { Liter } \\ \text { Ibs } & \text { Pounds } \\ \text { LLC } & \text { Load Leveling Unit Controller } \\ \text { LLU } & \text { Load Leveling Unit } \\ \text { LPRV } & \text { Low Pressure Regulating Valve } \\ \text { LPS } & \text { Low Pressure Switch } \\ \text { MEA } & \text { Membrane Electrode Assembly } \\ \text { mg } & \text { Milligram } \\ \text { Mi } & \text { Miles } \\ \text { mohm } & \text { Milliohm } \\ \text { mpg } & \text { Miles per Gallon } \\ \text { MPH } & \text { M iles per Hour } \\ \text { MU } & \text { Maintenance Unit } \\ \text { mV } & \text { Millivolt } \\ \text { OS } & \text { Operating System } \\ \text { PAO } & \text { polyalphaolefin } \\ \text { PEM } & \text { Proton Exchange Membrane } \\ \text { PI } & \text { Proportional-Integral } \\ \text { PNGV } & \text { Partnership for a New Generation of Vehicles } \\ \text { POST } & \text { Power On/Off Self-Test } \\ \text { Psia } & \text { Pounds per Square Inch Absolute } \\ \text { PWM } & \text { Pulse Width Modulator } \\ \text { QSM } & \text { Queued Serial Module } \\ \text { RPM } & \text { Revolutions per Minute } \\ \text { SOC } & \text { State of Charge } \\ \text { SOV } & \text { Solenoid Valve } \\ \text { SPV } & \text { Start Purge Valve } \\ \text { TPU } & \text { Time Processor Unit } \\ \text { VDC } & \text { Volts (Direct Current) } \\ \text { Wh } & \text { Watt-Hour } \\ & \end{array}$




\section{APPENDIX A \\ CHOPPER/REGULATOR DESIGN}

\section{Design Considerations}

The chopper/regulator inverter provides an output current that is proportional to the CURRENT REFERENCE INPUT signal from the LLC circuitry. The inverter gain is $30 \mathrm{Amps}$ NDC for all combinations of battery voltages and output loads. A block diagram for the complete chopper/ regulator is shown in Figure 5-7 and a schematic of the control circuit is shown in this Appendix. A discussion of the operation is presented below. Part identification reflects the schematic drawing located herein.

The output current from the chopper/regulator is continuously monitored by the current transformer, CT1. The output of CT1 is integrated to provide a DC signal proportional to the average current delivered to the load. The same device used to average (or integrate) the current signal functions as an error amplifier. The devices used for averaging (integrating) are U11 (U12). The resultant output signal from the error amplifier/integrator is a voltage which is proportional to the difference between the actual output current and the desired current requested by the LLC. This output signal is used to vary the pulse width of the signal to the chopper and hence regulates the current to the desired level.

Separate error amplifier/integrators are used for the buck and boost configurations, but both use CT1 to monitor the actual output current. The switch from buck to boost or vice versa is automatic. If the input voltage is less than that required to provide the required current, the buck control Pulse Width Modulator (PWM) causes Q1 to activate. The boost control PWM begins to step the input voltage to the required level to provide the necessary output current. Conversely, if the input voltage is higher than that required to provide the necessary output current, the buck PWM modulates the input voltage and the boost PWM never activates Q2.

A smooth transition for input voltages at the threshold modes is assured by reducing the current request signal applied to the boost error amplifier by 5 percent. This transition functions in much the same way as hysteresis operations with voltage comparators.

The reduction of output current by 5 percent for the boost mode has no effect on the overall system performance since the invertor is a gain block in the overall control system formed by the SOC monitoring circuit and the LLC. In addition to monitoring output load current, CT1 is also used to control the buck current mode PWM since the output is a scaled replica of the current switched by $Q 1$. For the boost mode, a separate current transformer directly monitoring the current in Q2 is required for current mode control.

A voltage control loop is also used for protection should the battery and/or load be disconnected during operation. The details for this circuit are shown on sheet 6 of the schematics. The voltage loop is designed to regulate the output voltage (regardless of the current request) to 360 
VDC. For normal operations, the output voltage is less than 360 VDC. Thus the voltage loop is saturated and is transparent to circuit operation. If, however, the battery/load is disconnected, the boost regulator would try to increase the output voltage as high as possible in attempt to provide the requested current and damage could occur. Sufficient output capacitance is provided to limit the amplitude of the output voltage transients until the voltage loop can automatically begin to operate and provide fail-safe conditions. A separate overvoltage comparator is used to turn the inverter off if the output exceeds 375 VDC as a redundant fail-safe mechanism. The comparator does not latch off and allows the unit to resume operation when the output voltage is reduced to values at or below 360 VDC.

A small signal model was developed for both the normal mode and for the voltage control mode for stability analysis. The low frequency, open-loop gain for the normal mode is $100 \mathrm{~dB}$ and the bandwidth is $2 \mathrm{~Hz}$. The rate of closure is $6 \mathrm{~dB} /$ octave, resulting in stable operation. The voltage loop also closes at $6 \mathrm{~dB} /$ octave, however the bandwidth is $100 \mathrm{~Hz}$ to provide fast response time when activation is required. A model of the Electrosource Horizon Battery was used as an output load for the AC model.

An internal housekeeping supply is used to provide operational voltages for the control circuits. Three outputs are provided: +15 VDC, -15 VDC and an isolated +15 VDC bias voltage for the high voltage drivers. The topology for the supply is a current mode flyback design. A complete schematic for the design is shown on sheet 5 . The supply is powered from either the battery or the FCS. This allows the unit to continue operations during various fault modes which might occur. 


\begin{tabular}{l|l|l|l|}
\hline 8 & 7 & 6 & 5 \\
\hline
\end{tabular}

NOTES:

1. APPLICABLE STANDARO/SPECIFICATIONS:

A. DOD-STD-00100D(AR)

2. FOR ASSEMBLY DRAWING SEE

3. UNLESS OTHERWISE SPECIFIEO: RESISTANCE VALUES ARE IN OHMS CAPACITANCE VALUES ARE IN MICROFARADS

4. LEGEND:

$(1) \longleftarrow$ LOCATOR NUM,BER

$\frac{1}{2} \longleftarrow$ SHEET NUMBER

5. PARTIAL REFERENCE DESIGNATORS ARE SHOWN, FOR COMPLETE DESIGNATION PREFIX WITH UNIT NUMBER OR SUBASSEMBLY DESIGNATION

\begin{tabular}{|c|c|c|c|}
\hline \multicolumn{5}{|c|}{$\begin{array}{c}\text { HIGHEST } \\
\text { REFERENCE } \\
\text { DESIGNATION }\end{array}$} \\
\hline R57 & C29 & L1 & 02 \\
\hline T1 & U17 & CR28 & P1 \\
\hline E3 & & & \\
\hline \multicolumn{4}{|c|}{$\begin{array}{c}\text { REFERENCE } \\
\text { DESIGNATIONS } \\
\text { NOT USED }\end{array}$} \\
\hline & & & \\
\hline & & & \\
\hline & & & \\
\hline
\end{tabular}




\begin{tabular}{|l|l|l|l|}
\hline 8 & 7 & 6 & 5 \\
\hline
\end{tabular}




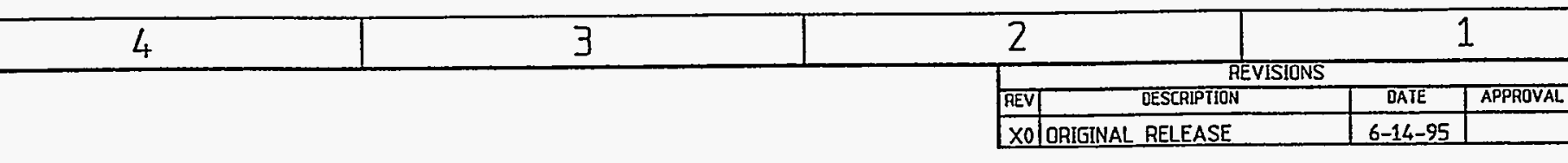




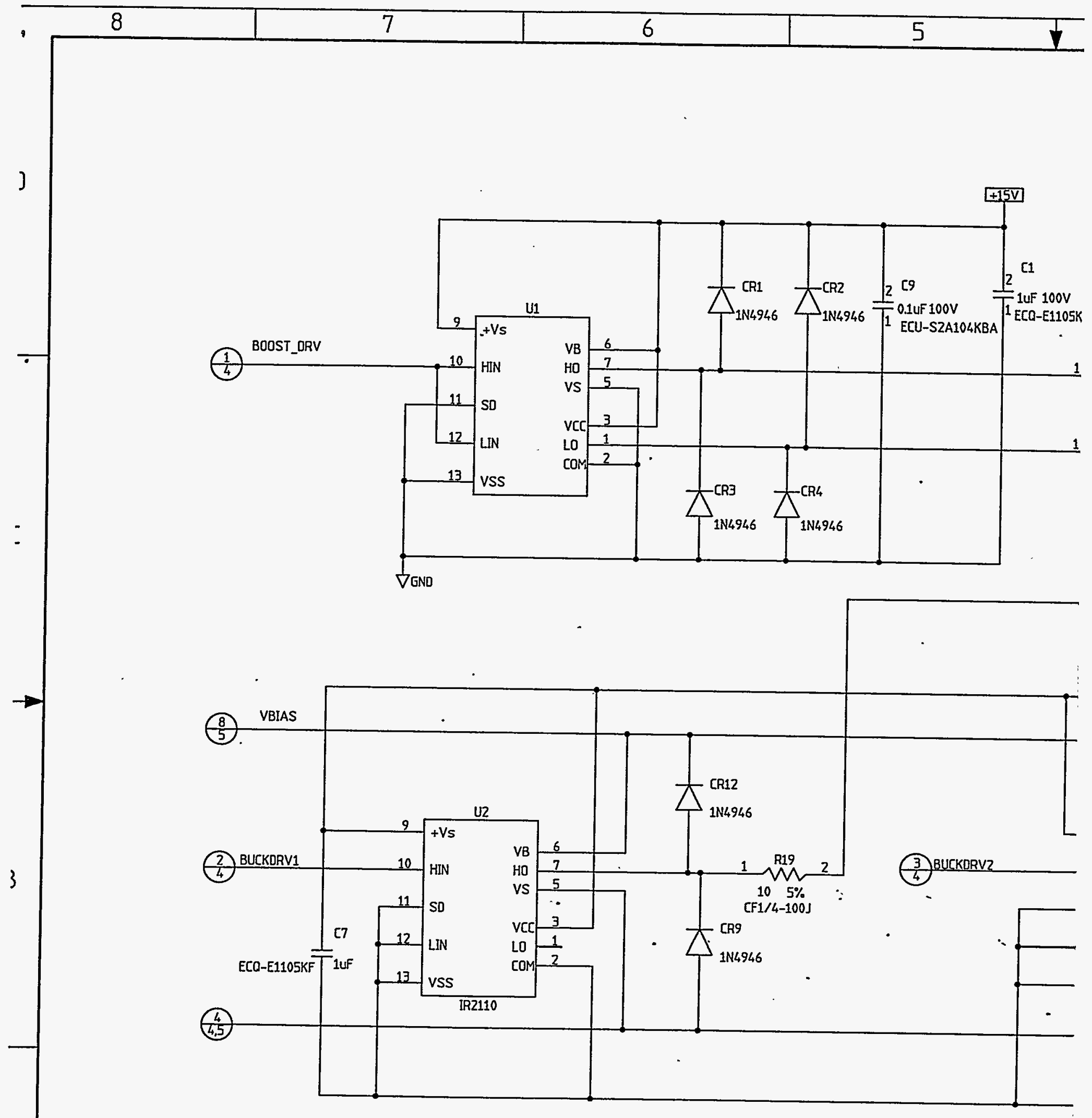





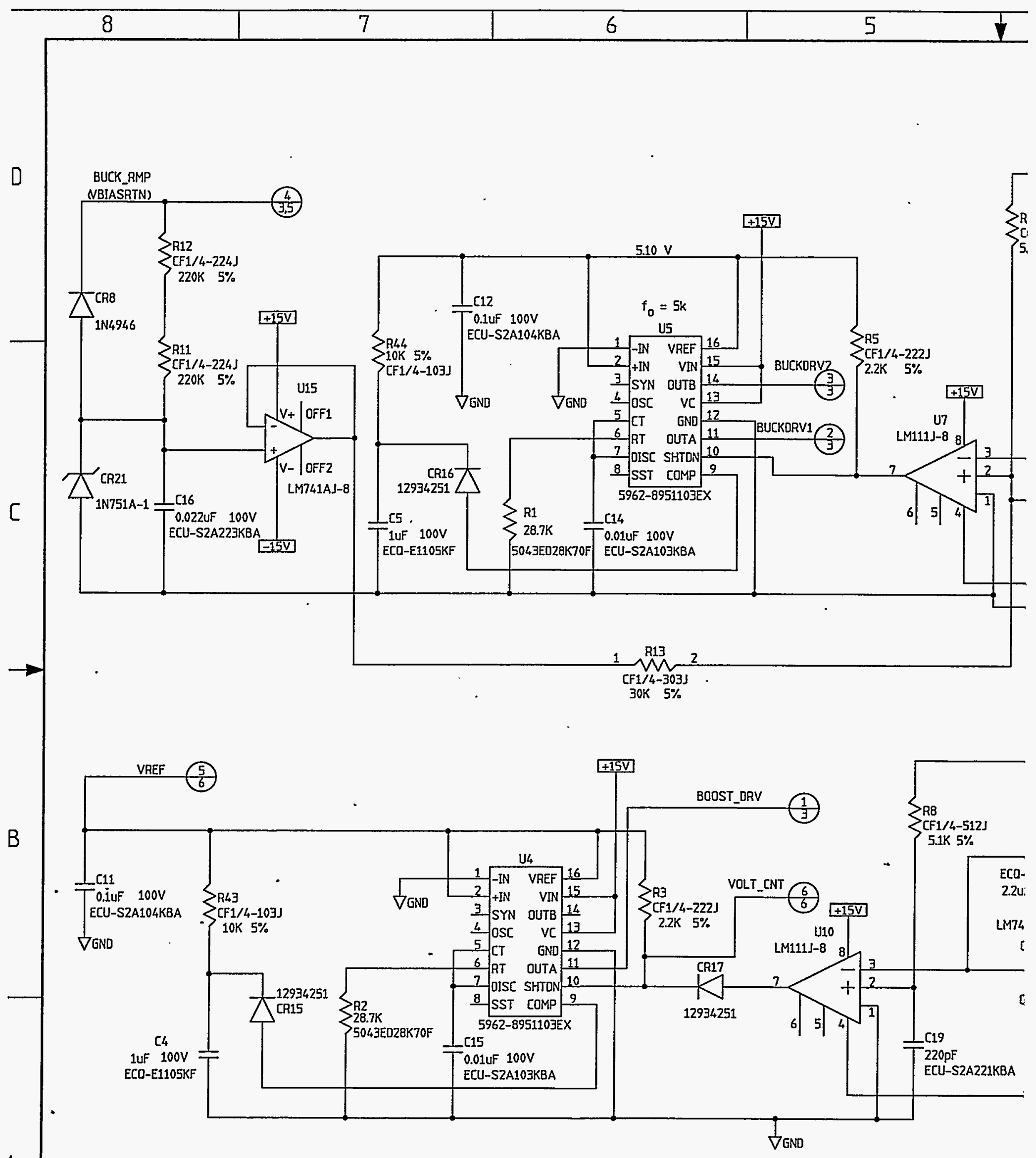

4 


\section{8}

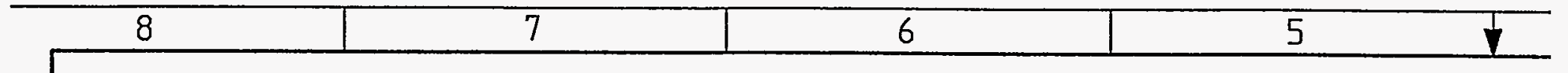

HOUSE KEEPING P1-20

FILTER CAPACITOR WTB4OPR9J548

VBAT 6

BATTERY VOLTAGE BATTERY VOLTAGE

BATTERY VOLTAGE

$P 1-6$

$P 1-7$

$\mathrm{P} 1-26$

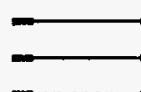

$\underbrace{C R 6}_{1 N 4946}$
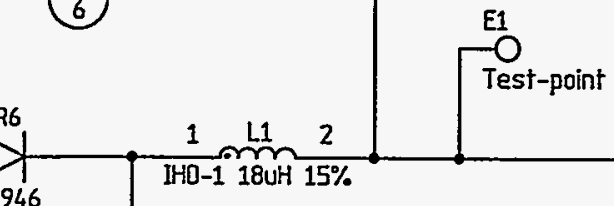

FUEL CELL INPUT

FUEL CELL INPUT

FUEL CELL INPUT

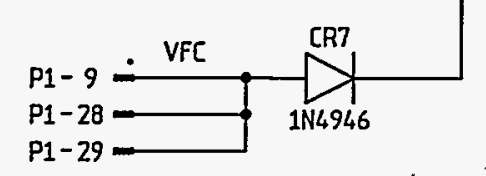
IHO-1 18UH $15 \%$

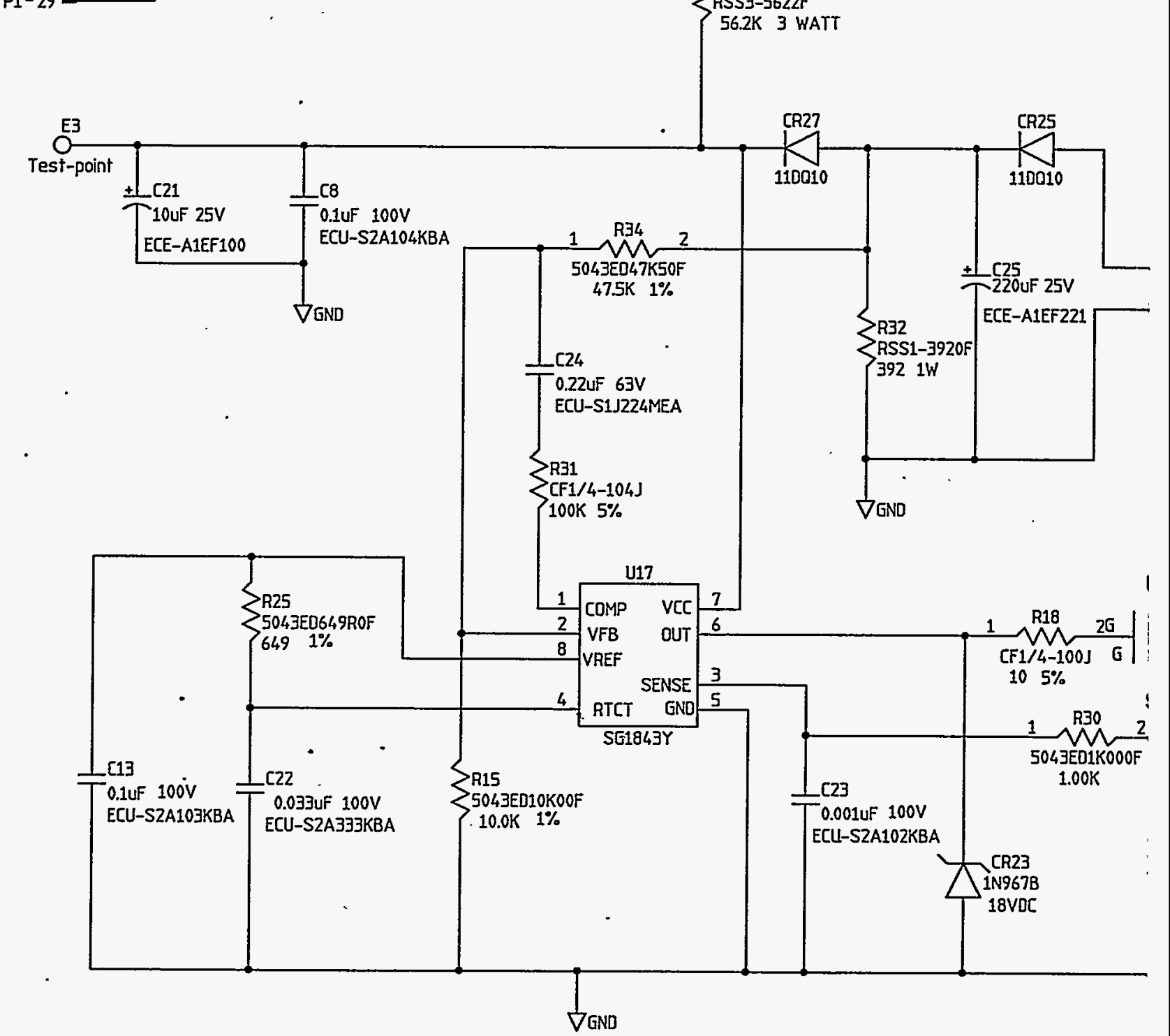



VOLTAGE CONTROL LOOP

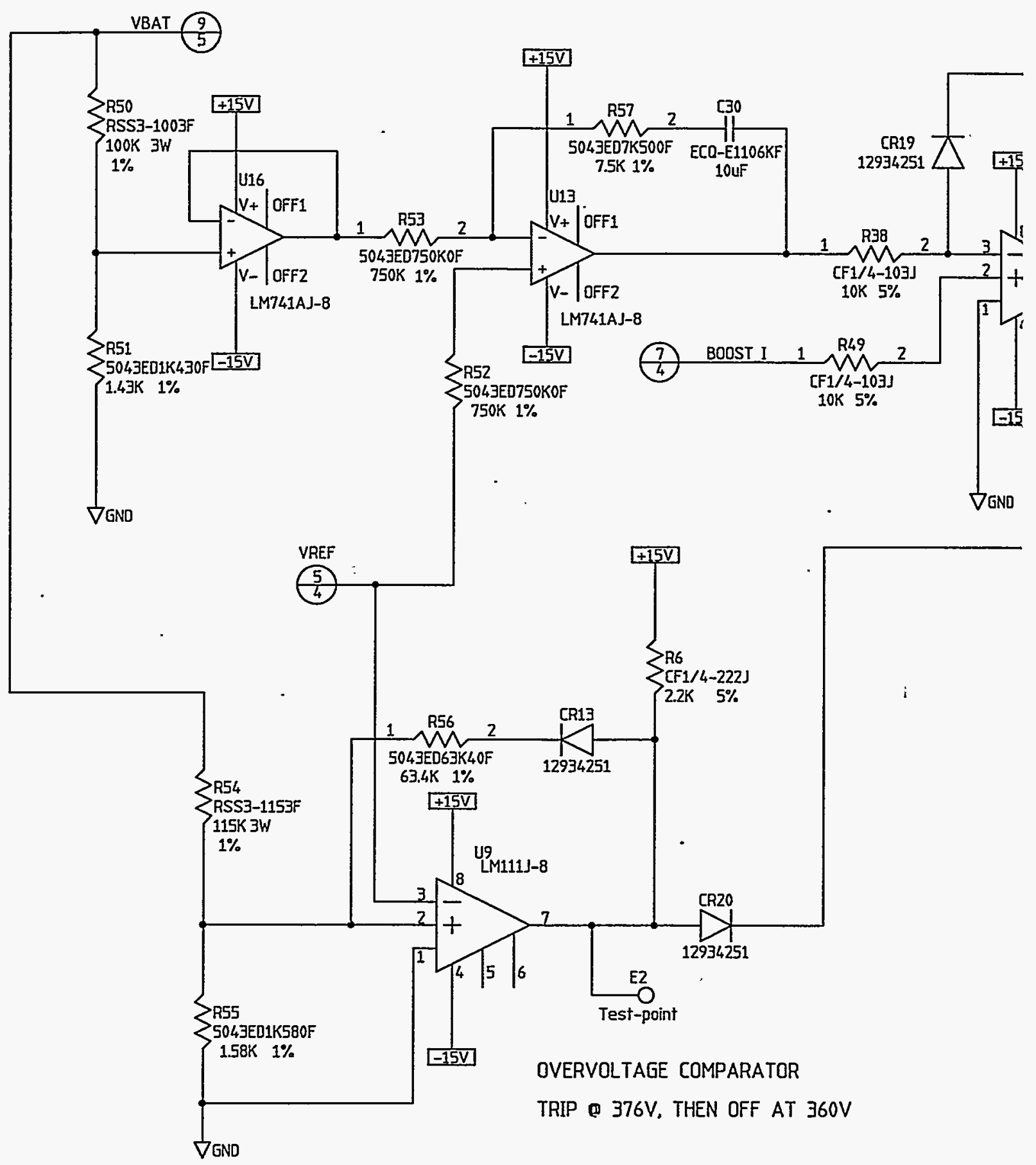

$A$ 


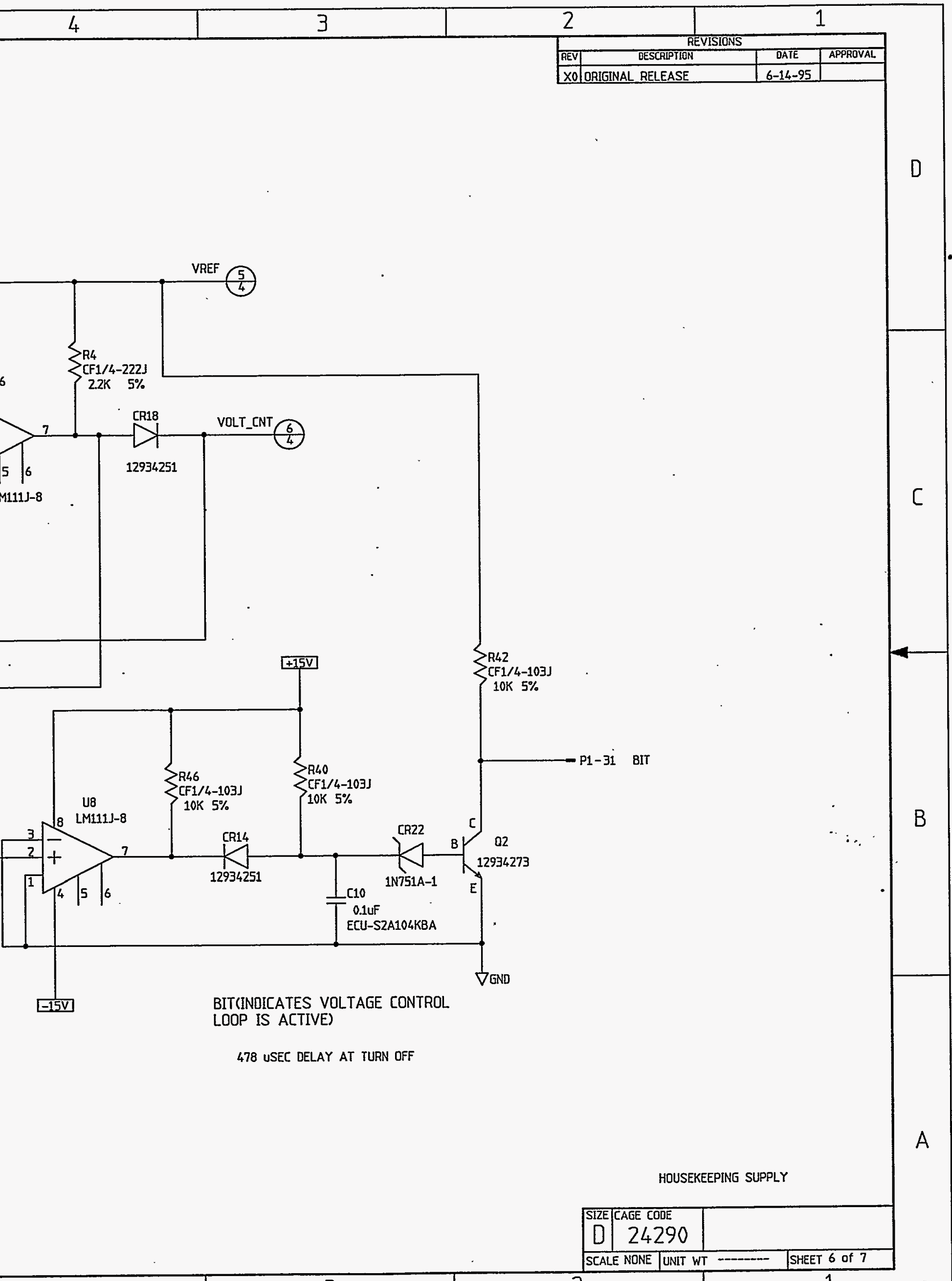




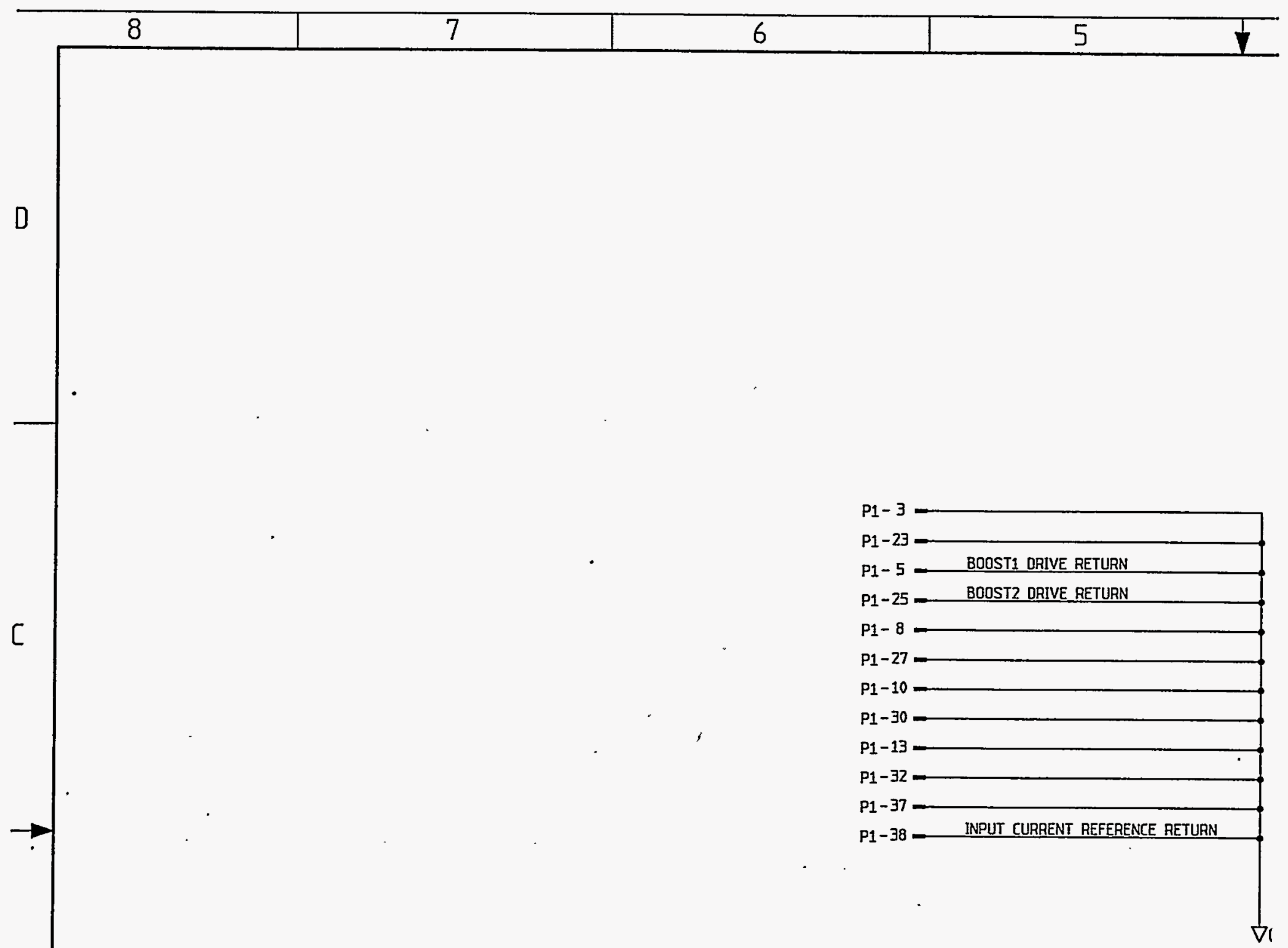

B

NOTE: PIN NUMBERS 19, 39, 40 ARE SPARES. 


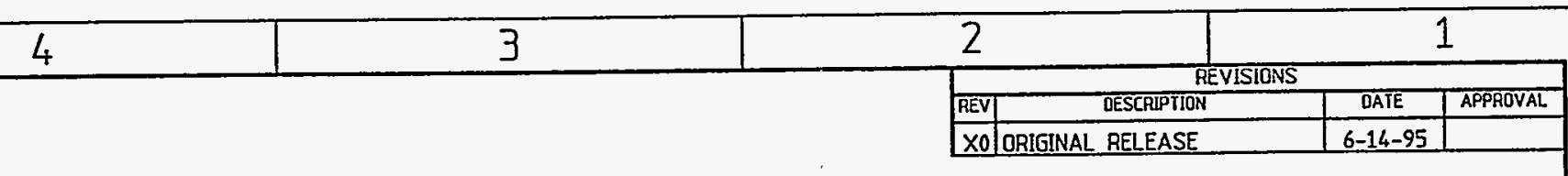




\section{APPENDIX B CONTROLLER DESIGN}

The following tables define the Input/Output $(1 / O)$ interfaces to the Load Leveling Unit Controller (LLC) as they currently exist. The new DAC output address is not presently defined and will be required for completion of the LLC software

Table B-1. TPU $1 / O$

\begin{tabular}{cll} 
Channel Number & \multicolumn{1}{c}{ Function } & \multicolumn{1}{c}{$\begin{array}{c}\text { Description } \\
0\end{array}$} \\
1 & DIO - Output & Maintenance Required Light \\
2 & PWM - Output & SOC Meter \\
3 & PWM - Output & Fan Speed Control \\
4 & DIO - Output & FCS Self-Test \\
5 & FQM - Input & Fan \#1 RPM \\
6 & FQM - Input & Fan \# 2 RPM \\
7 & DIO - Output & FCS ON/OFF \\
8 & DIO - Output & Charge Lamp \\
9 & Not Used & N/A \\
10 & DIO - Output & Heater ON \\
11 & D IO - Input & Ignition Switch ACCESSORY \\
12 & DIO - Input & Ignition Switch ON \\
13 & DIO - Input & Ignition Switch START \\
14 & DIO - Output & Watchdog Timer RESET1 \\
15 & Not Used & N/A \\
Notes: & Not Used & N/A \\
Recommended that this output be moved to PE3. &
\end{tabular}

Table B-2. Discrete Outputs, Non-CPU Resident (Address $10002 \mathrm{H}$ and any Even Address from $10000 \mathrm{H}$ to 107FFH)

Bit Number

0

1

2

3

4

5

6

7

8

9

10
Description

Module Select 0

Module Sel ect 1

Module Select 2

Module Select 3

Module Select 4

Module Select 5

Battery Voltage Select

Battery Voltage Read

Module Voltage Read Low

Module Voltage Read High

Battery Current Sensor Range High 
Table B-2. Discrete Outputs, Non-CPU Resident (Address $10002 \mathrm{H}$ and any Even Address from $10000 \mathrm{H}$ to $107 \mathrm{FFH}$ ) (Continued)

Bit Number

11

12

13
Description

LLC Power ON (Relay Latch)

Spare

Spare

Table B-3. CPU-Based Discrete $1 / O$, Interrupts, and Serial Communications

Pin Name

PQS6

$\mathrm{RXD}$

TXD

PF1

IRQ4

IRQ5

IRQ7

MOSI

MISO

\section{Description}

DI, Pol arity of Battery Current

Serial Data Input

Serial Data Output

Interrupt, DI, Programmable, CCD Idle Detect

$16 \mathrm{C} 30$ Serial Port $B$ Interrupt Line

16C30 Serial Port A Interrupt Line

External Watchdog Timer Interrupt (NMI)

Queued Serial Data Output

Queued Serial Data Input

Table B-4. Serial Analog Data Channels

Channel Number

0

1

2

3

4

5

6

7

8

9

10

\section{Description}

Multiplexed Module Voltages

Battery Pack Voltage

Battery Temperature Sensor \#1

Battery Temperature Sensor \#2

Battery Temperature Sensor \#3

Battery Temperature Sensor \#4

Battery Temperature Sensor \#5

Battery Temperature Sensor \#6

Not Used

Battery Current

Not Used 


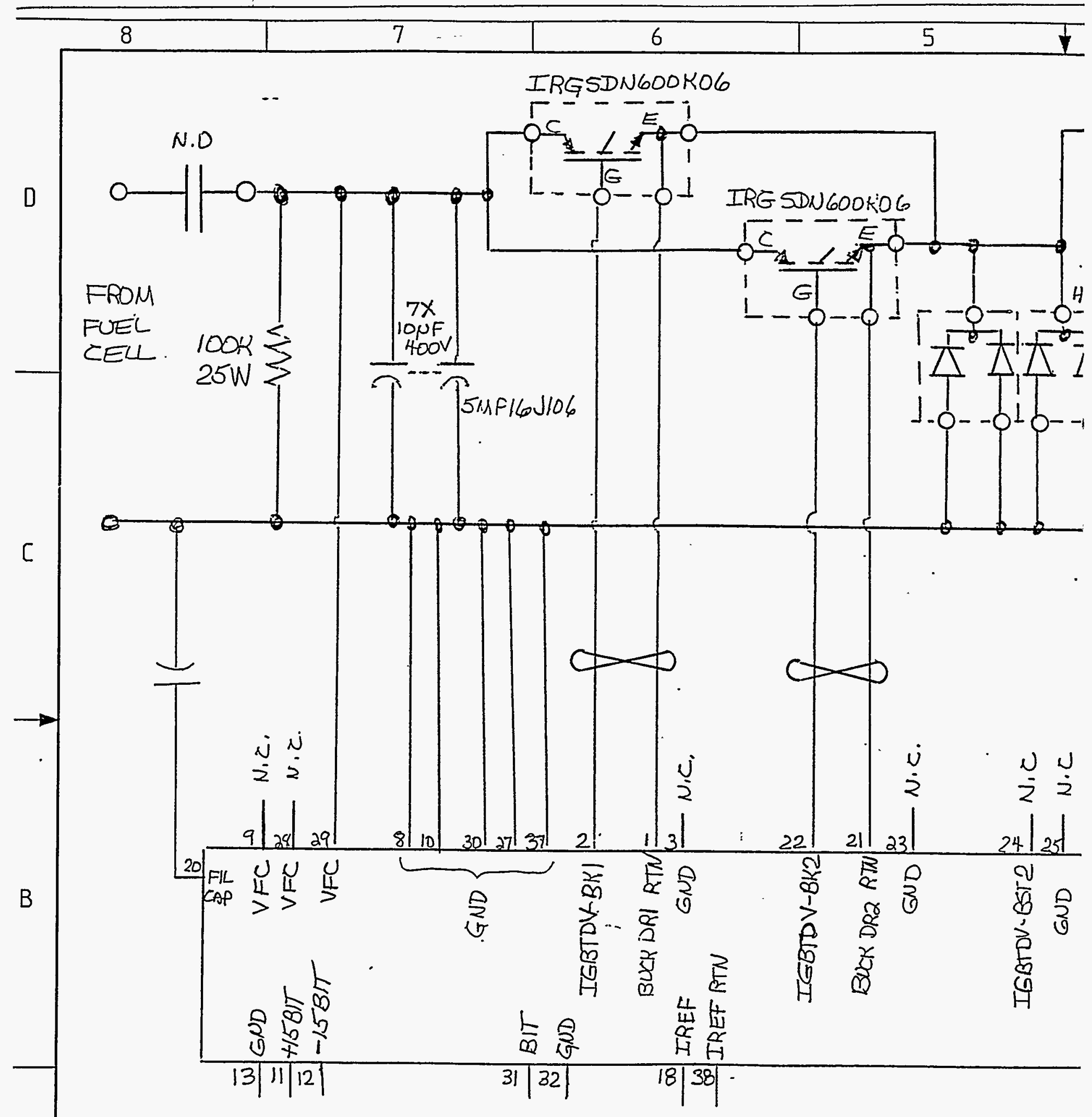




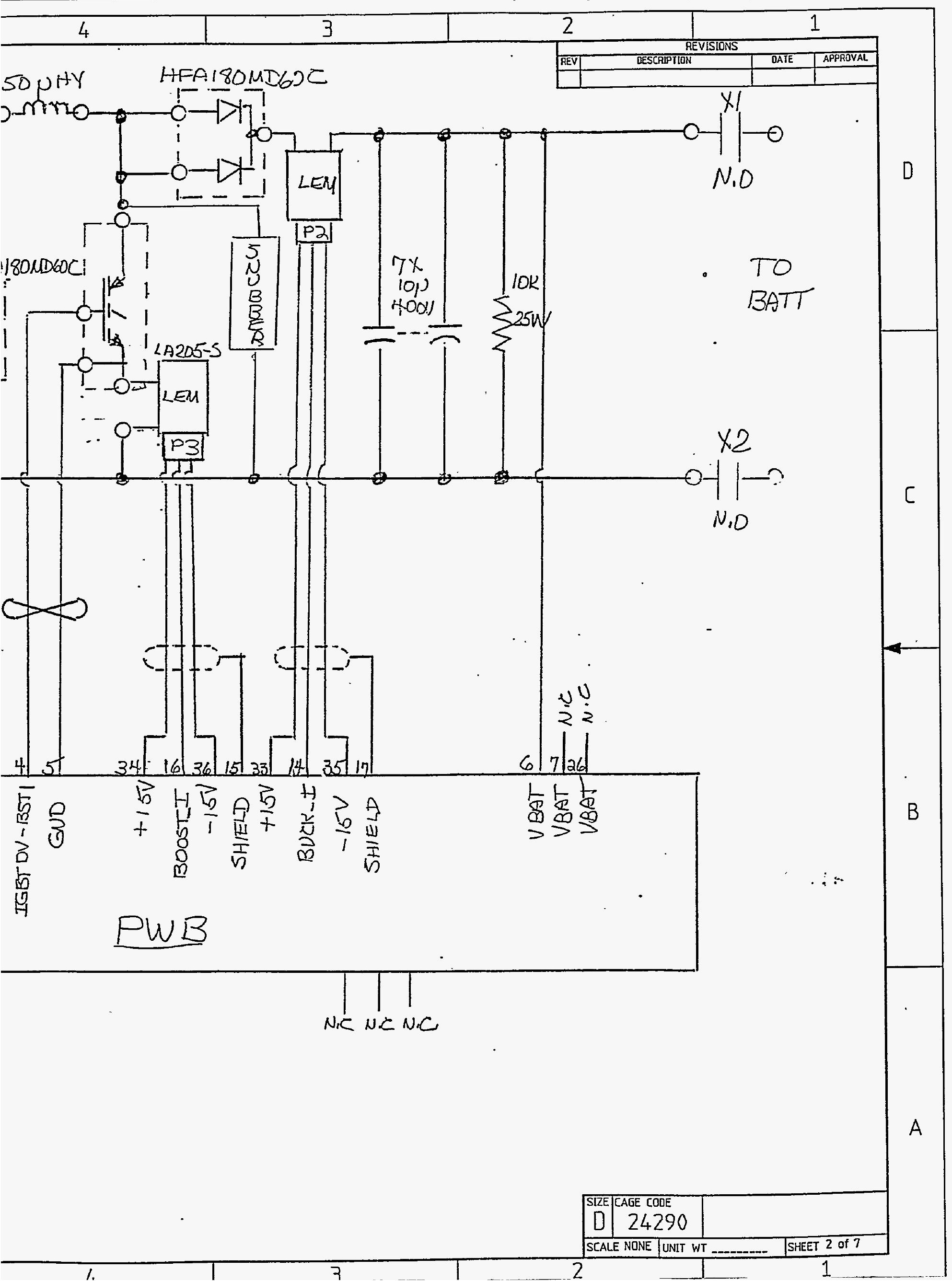


GAS MANAGEMENT CONTROLLER 


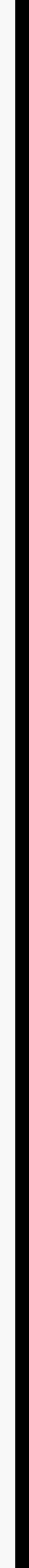




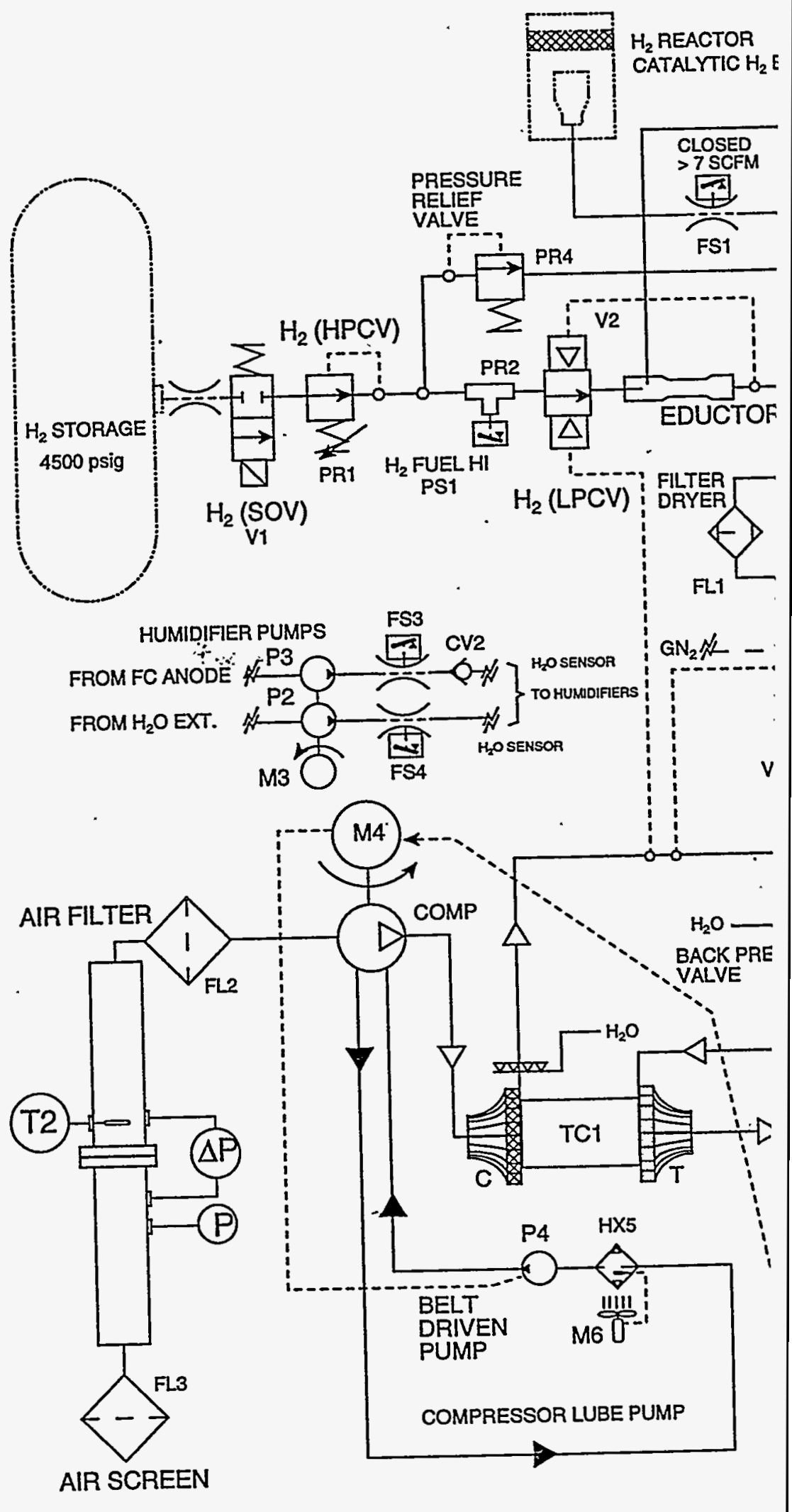


APPENDIX D

\section{LLU DESIGN TO COST SUMMARY}

2-1-95 5-3-95 SMALL QTY. SMALL QTY. PROD. EST GOAL

LLU ELECTRONICS

$$
\text { LLC }
$$

CHOPPER/REGULATOR

PACKAGING/INTERCONNECTION

BATTERY PACK

LLU TOTAL

-PACKAGING ESTIMATES WERE INCLUDED AS A PART OF LLC.

$\begin{array}{rrrr}\$ 2,500 & \$ 1,350 & \$ 500 & \$ 150 \\ \$ 2,500 & \$ 1,850 & \$ 675 & \$ 150 \\ \$ 12,000 & \$ 900 & \$ 250 & \\ \$ 17,000 & \$ 11,000 & \$ 4,500 & \$ 500 \\ & \$ 15,100 & \$ 5,925 & \$ 800\end{array}$




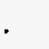




\section{APPENDIX E \\ SIMULATION MODELING DATA}

This appendix provides the results which have been obtained from the DPHV simulations for each of the cycles described in section 2.1 of this document.

\section{E.1 Baker Grade Simulations}

Table E-1 shows the results of the simulation results for the Baker Grade. Steady state power is defined as the power required to maintain the vehicle speed at the $55 \mathrm{MPH}$ limit after that speed has been obtained.

Table E-1. Simulation Code Result Comparison

$\begin{array}{lcc}\text { Code } & \text { Peak Power (kW) } & \text { Steady State Power (kW) } \\ \text { SIMPLEV } & 57.69 & 39.31 \\ \text { CHYHV } & 57.63 & 38.53 \\ \text { Analytical } & 55.05 & 36.29\end{array}$

The results shown in the table indicate that there was good agreement between these simulation methods. The analytical solution did not include the rolling resistance force which is included in both the SIMPLEV and the CHYHV modeling codes. Regenerative braking also is not considered in these simulation results since no deceleration occurs in the Baker Grade cycle.

\section{E.2 Acceleration Performance}

The results for the AccelL and the Accel2 acceleration profiles are shown in Table E-2. There are no regenerative braking effects occurring during this cycle. The consistency of results between the analytical calculation and those from the CHYHV simulation gives further confidence in the results which have been obtained. All powers in this table are in $\mathrm{kW}$.

$\begin{array}{rrc}\text { Table E-2. Comparison of CHYHV and Analytical Peak Power Results } \\ \text { Cycle } & \text { CHYHV } & \text { Analytical } \\ \text { Accel2 } & 101.6 & 103.3 \\ \text { AccelL } & 76.3 & 68.3\end{array}$

The acceleration curve for the Accell cycle duplicates that which one would expect to occur for the Westinghouse motor performance in an acceleration phase. The results confirmed the finding that less power was required for the acceleration occurring in the early stages of the cycle than for the profile such as Accel 2 in which a constant acceleration is maintained throughout the cycle. 


\section{E.3 Baker Grade Performance}

The analysis for the Baker Grade cycle proceeded in the same manner as for the acceleration cycles. CHYHV was used to determine the vehicle peak and average power requirements. Table E-3 shows the comparison of the data obtained from CHYHV with that using analytical means.

\begin{tabular}{lcc}
\multicolumn{2}{c}{ Table E-3. Analytical versus } & CHYHV Baker Grade Data \\
Parameter Measured & CHYHV & Analytical \\
Peak Power $(\mathrm{kW})$ & 57.63 & 55.05 \\
Steady State Power $(\mathrm{kW})$ & 39.31 & 36.29
\end{tabular}

\section{E.4 FUDS/LA92 Cycle Performance Results}

The FUDS and the LA92 Driving Cycle simulations were performed with the CHYHV simulation code using the same vehicle configurations as the acceleration and Baker Grade cycles. Results are shown in Table E-4. All system energies are representative of one cycle of operation.

Table E-4. DPHV System Response for FUDS/LA92 Cycles

$\begin{array}{lccc}\text { Cycle } & \text { Peak Power (kW) } & \text { Average Power (kW) } & \text { System Energy (kWh) } \\ \text { FUDS } & 40.22 & 4.72 & 1.750 \\ \text { LA92 } & 56.13 & 7.22 & 2.673\end{array}$

\section{E.5 HIWAY Cycle Performance Results}

The HIWAY Driving Cycle simulation was performed with the CHYHV simulation code using the same vehicle configurations as the acceleration and Baker Grade cycles. All system energies are representative of one cycle of operation. The system requirements were obtained with regenerative braking disabled. Thus the results shown in Table E-5 are conservative.

Table E-5. DPHV System Response for HIWAY Cycles

$\begin{array}{cccc}\text { Cycle } & \text { Peak Power (kW) } & \text { Average Power (kW) } & \text { System Energy (kWh) } \\ \text { HIWAY } & 32.68 & 9.62 & 4.420\end{array}$




\section{APPENDIX F \\ HYDROGEN STORAGE DESIGNS}

This appendix contains the applicable codes and standards for hydrogen storage along with several configurations for the DPHV system with various storage designs.

Codes and Regulation

NFPA 50A - Gaseous H2 at Consumer Sites

ASME (VIII) - Pressure Vessels

AGAVAGA - Various

ANSI - Various

USDOT - 3AL

ISO - Various

CTC/Transport Canada

ANSI/AGA NGV 1 - Refueling Devices

ANSI/AGA NGV 2 - NGV Containers

DOT/NHTSA Motor Vehicle Safety Standards

NFPA 52 - CNG Vehicular Fuel Storage

CAN1 b149 - NGV Containers and Refueling

CSA B51 (2) NGV Vehicle Cylinders

Local Authority

Self Regulation

$\begin{array}{cccc}\begin{array}{c}\text { Site } \\ \text { Setups }\end{array} & \begin{array}{c}\text { Mobil } \\ \text { Systems }\end{array} & \text { Cylinders } & \begin{array}{c}\text { Refueling } \\ \text { Devices } \\ \text { Stations }\end{array} \\ \mathrm{X} & \mathrm{X} & \mathrm{X} & \mathrm{X} \\ \mathrm{X} & \mathrm{X} & \mathrm{X} & \mathrm{X} \\ \mathrm{X} & \mathrm{X} & \mathrm{X} & \mathrm{X} \\ \mathrm{X} & \mathrm{X} & & \\ & \mathrm{X} & \mathrm{X} & \mathrm{X} \\ \mathrm{X} & \mathrm{X} & \mathrm{X} & \\ & \mathrm{X} & & \end{array}$

G

G $\quad G$

G $\quad G$

G $\quad G$

G $\quad G \quad G$

G $\quad$ G

$x \quad x$

$x \quad x$

G

$X$

$x$

G

G

$x$

$x$

Figure F-1. Applicable Codes and Standards for Off- and On-Board Storage 



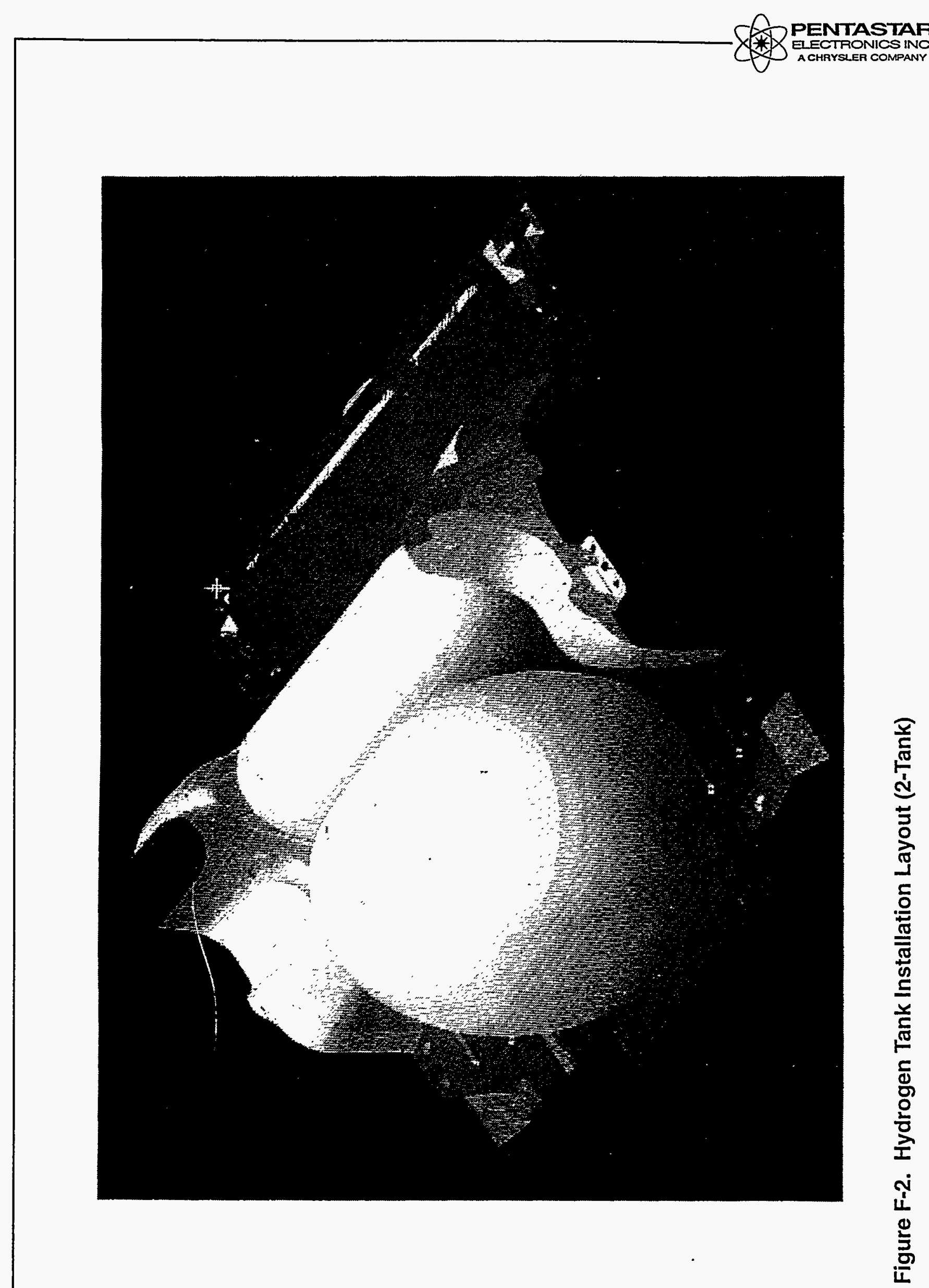





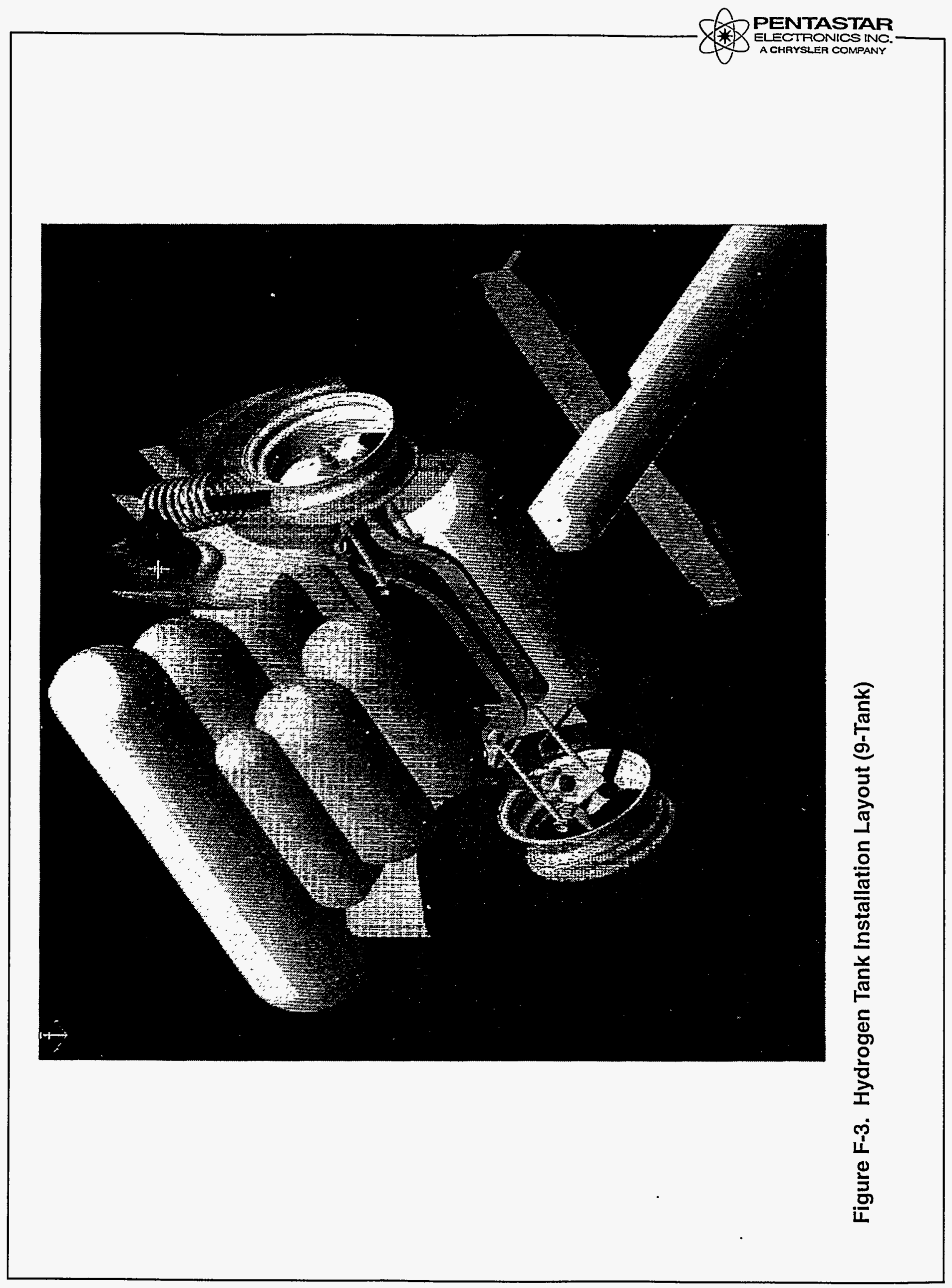





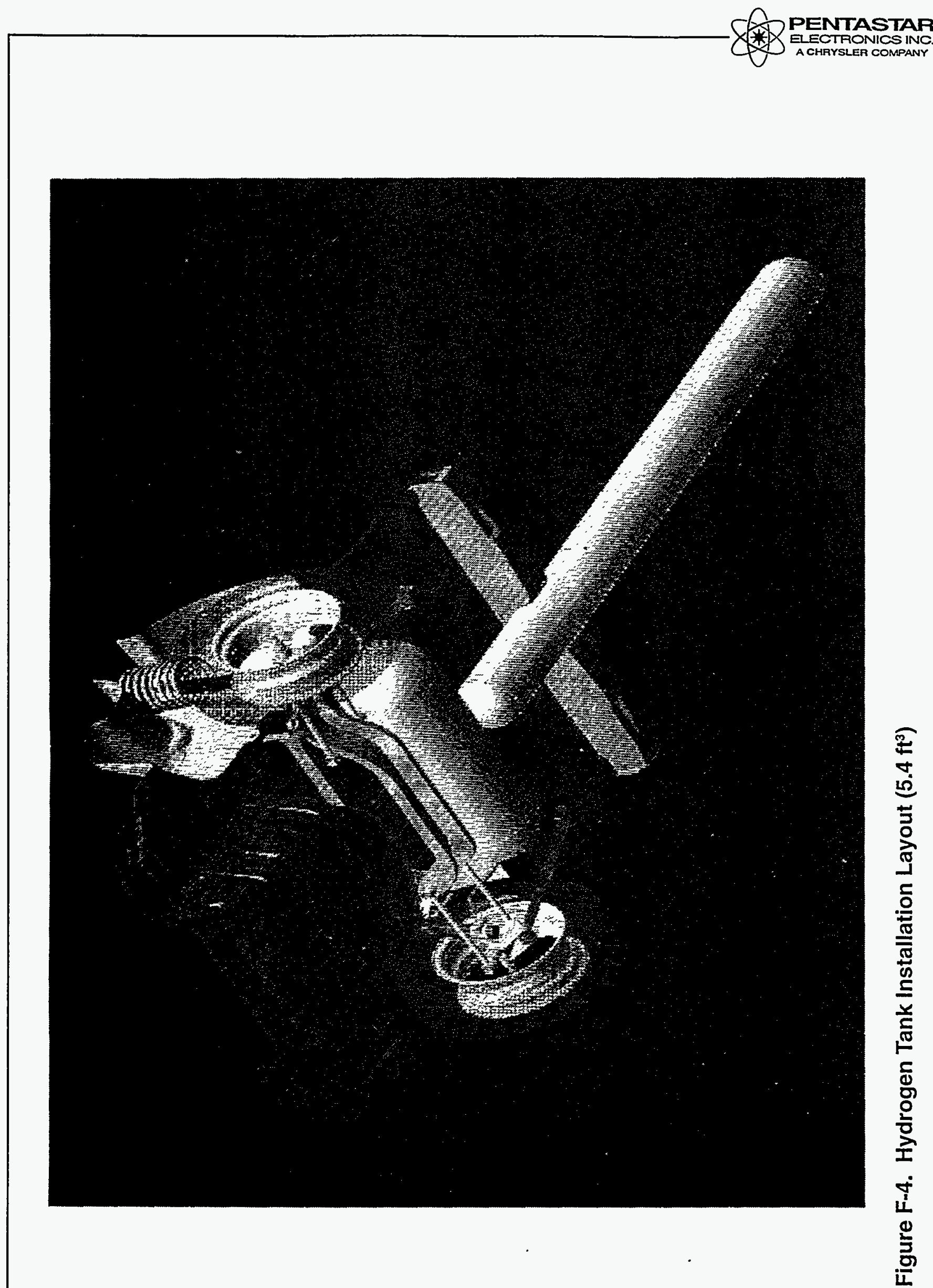





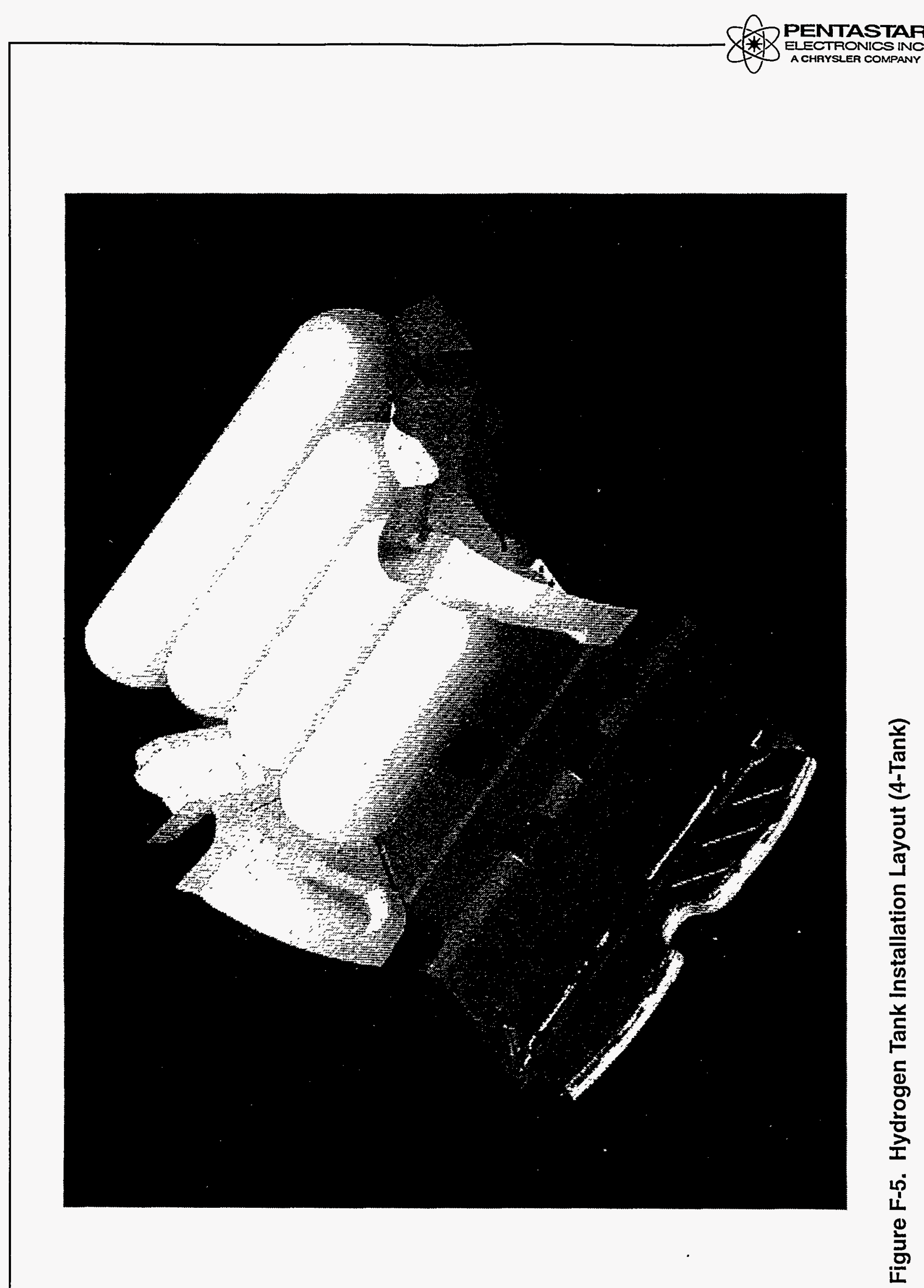




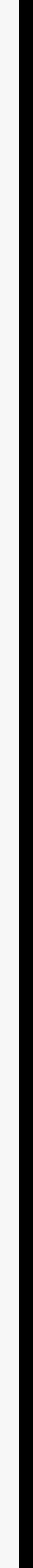




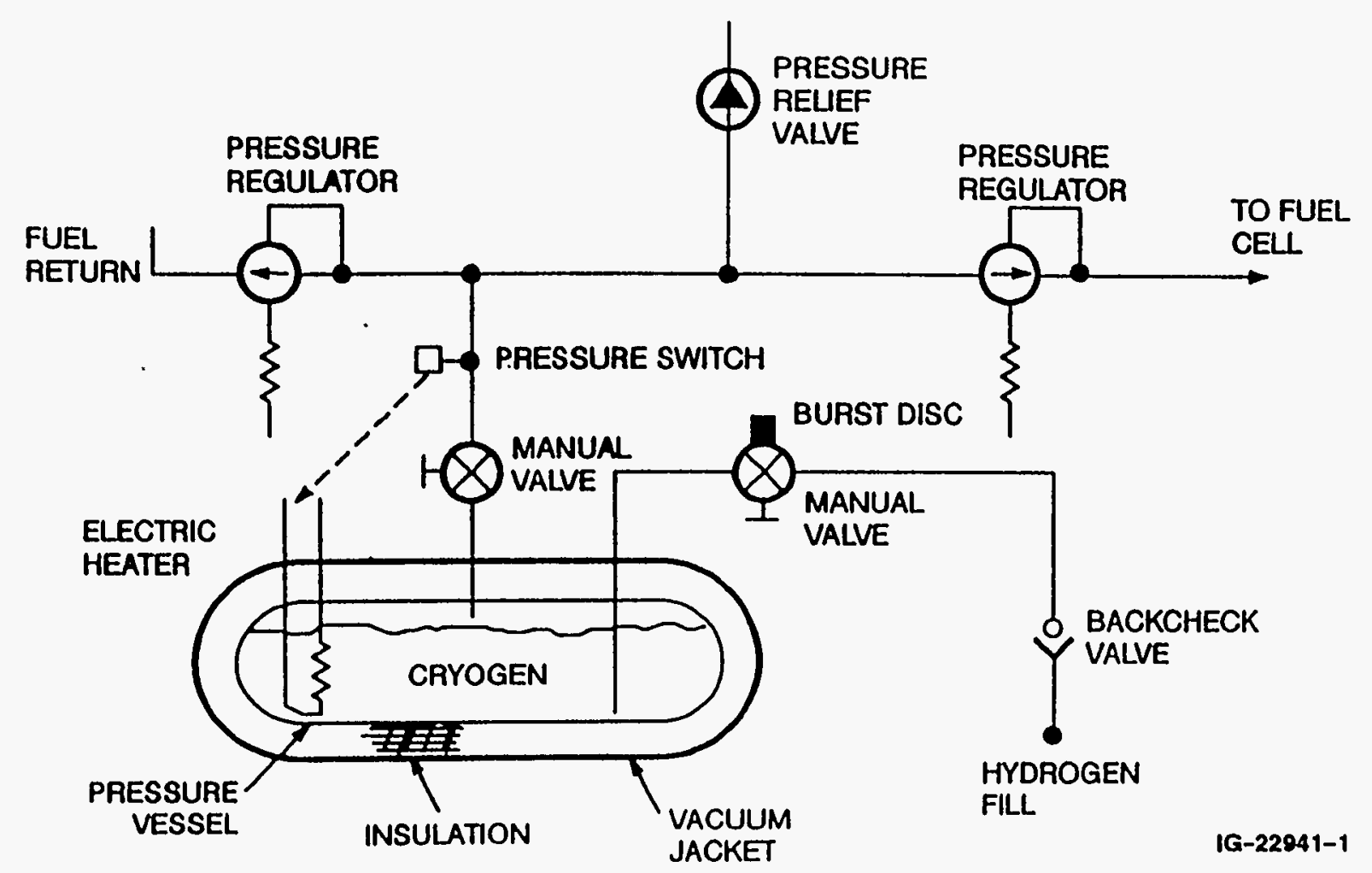

Figure F-6. Liquid Hydrogen Storage System Schematic 


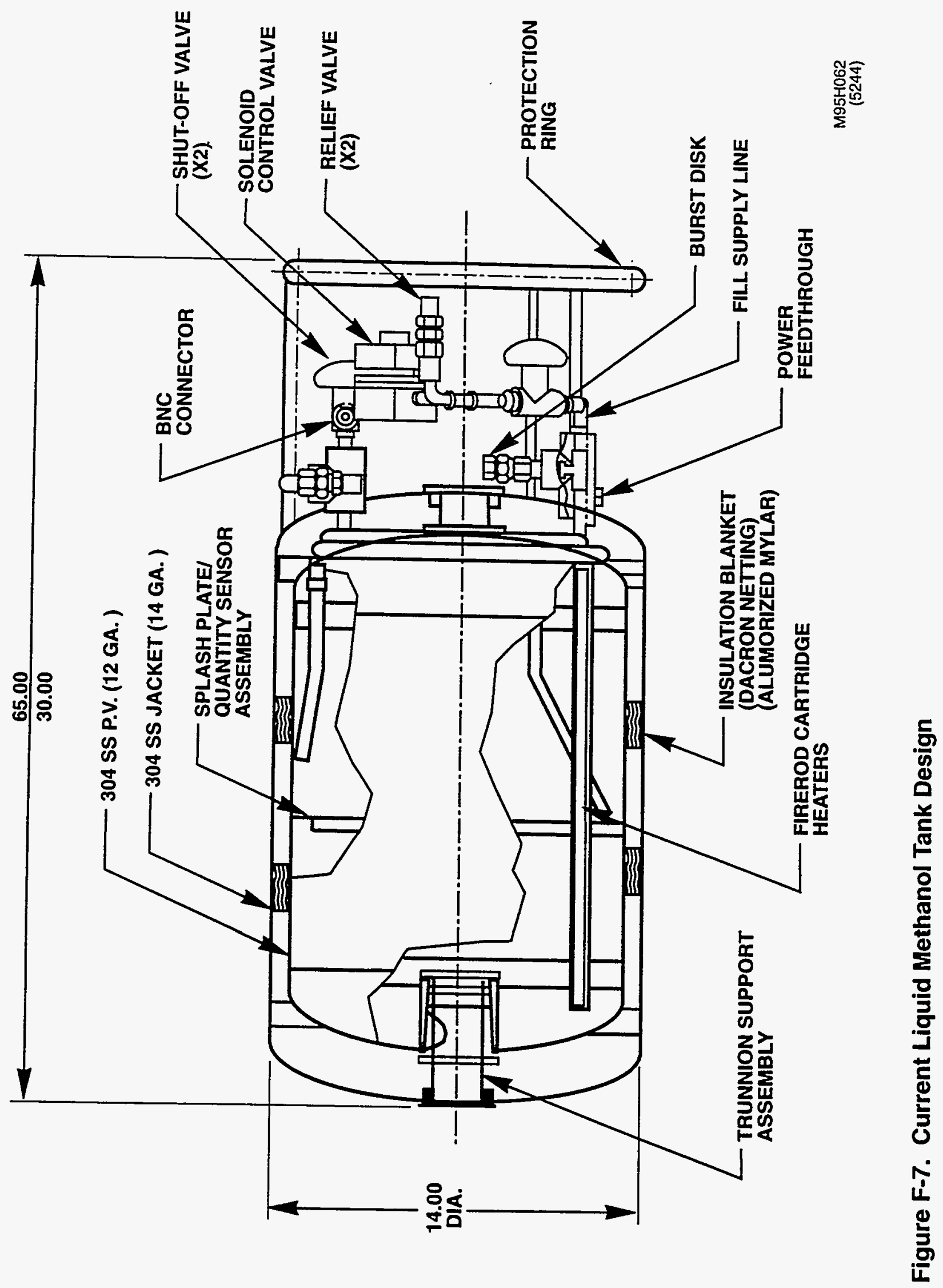

